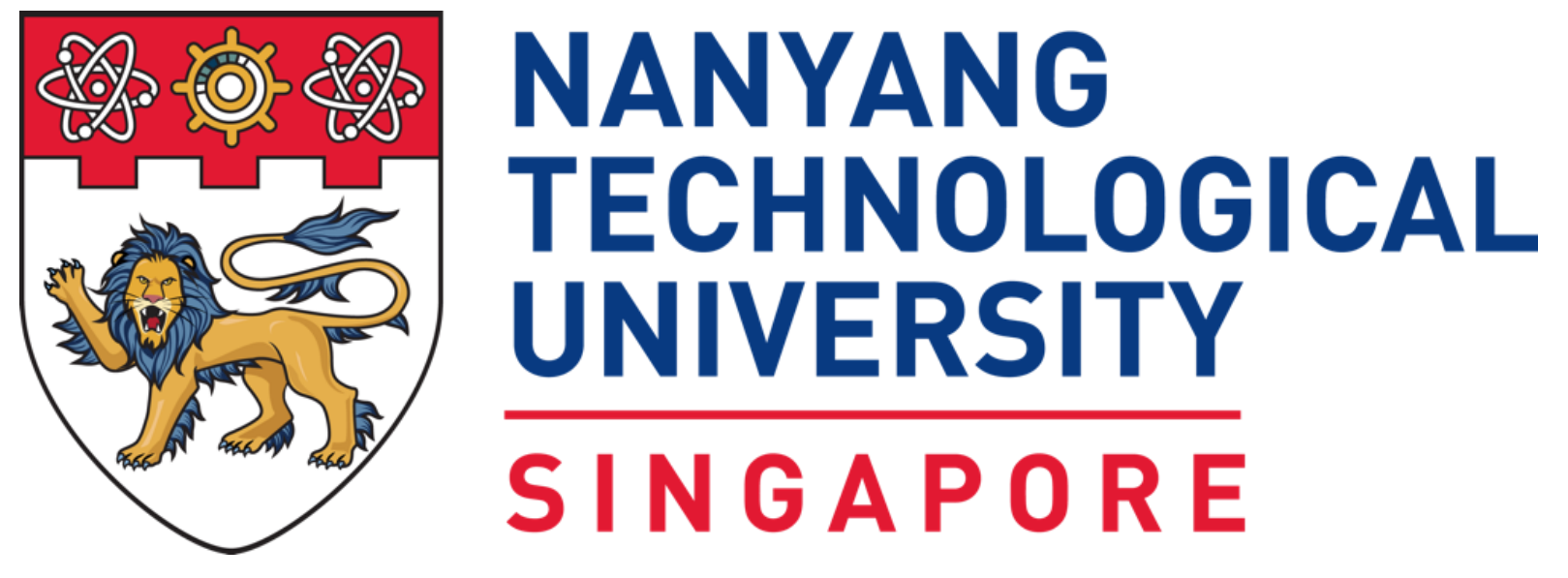

\title{
BACTERIAL SYNTHESIS OF NANOCATALYST AND BIOFILM- TEMPLATED NANOCATALYTIC SYSTEM FOR WATER PURIFICATION
}

NG CHUN KIAT

INTERDISCIPLINARY GRADUATE SCHOOL 


\section{BACTERIAL SYNTHESIS OF NANOCATALYST AND BIOFILM- TEMPLATED NANOCATALYTIC SYSTEM FOR WATER PURIFICATION}

\section{NG CHUN KIAT \\ INTERDISCIPLINARY GRADUATE SCHOOL}

A thesis submitted to the Nanyang Technological University in fulfilment of the requirement for the degree of Doctor of Philosophy 


\section{ACKNOWLEDGEMENT}

I would like to express my heartfelt thanks to my supervisor, Assistant Professor Cao Bin, for his guidance throughout my research. As a chemistry student, I came in to work in Singapore Centre for Environmental Life Science Engineering (SCELSE) with little theoretical and experimental knowledge in the field of environmental engineering and biotechnology. Bin meticulously taught me the basic know-hows in this field which gave me a head-start towards being an independent researcher in SCELSE. Without his help and inspiration, much of my time would be spent on banging my head on the table instead of executing well-planned experiments with a clear objective and aim in mind. His profound knowledge and experience in the area of environmental life-science engineering has provided me immense guidance during my scientific journey. Bin embodies the ideology of interdisciplinary research and deeply influences my perspective towards scientific research. His work ethics, diligence and curiosity for new knowledge is an inspiration to me. It is my great privilege and honour to be able to learn from such a splendid supervisor and researcher to explore new concepts and hypothesis over the last 5 years, including the times during my undergraduate summer research, my undergraduate Final-YearProject (FYP), and subsequently my PhD research project.

I would like to thank my co-supervisor, Professor Sanjay Swarup, for his guidance on metabolomics studies, and his constructive feedback on my research progress. Sanjay made several critical recommendations on the experimental methodologies to be used in my research and raised alternative aims and research routes that can potentially contribute to my research objectives. I would also like to extend my 
gratitude to my mentor, Assistance Professor Yang Liang, for his guidance on my project and his aptitude to tolerate my silly questions regarding microbiology.

I am also very grateful to be able to work with some of the best researchers in their respective fields and having them as my collaborators. They include Dr. Ji Liang Hui from Temasek Life Sciences Laboratory (Singapore), Prof Tang Chuyang from The University of Hong Kong, Prof Song Hao from Tianjin University (China), Prof Staffan Kjelleberg from SCELSE, Prof Lu Lanyuan from Nanyang Technological University (Singapore) and Prof Wang Rong from Singapore Membrane Technology Centre.

A special thanks to members of Environmental Microbial Biotechnology \& Bioengineering (EMBB) research group (also fondly known as Bin's research group) - Krish, Yichao, Yuanzhao, Yingdan, Anee, Yidan, Sudha, Daphne and Amit. I would also like to thank other fellow SCELSE colleagues for their immense support in my research.

I would like to take this opportunity to acknowledge my friends and family members, especially my parents, for their unwavering support in my pursuit for academic excellence. I would be forced to take another career path due to financial difficulties if my father chose to retire when he was retrenched, instead of finding a new job, in his 50 s.

Finally, I would like to acknowledge the financial support from National Research Foundation and Ministry of Education Singapore under its Research Centre of Excellence Program, and Interdisciplinary Graduate School Premium Scholarship for the year 2013-2017. 
ACKNOWLEDGEMENT

TABLE OF CONTENTS III

LIST OF FIGURES VIII

LIST OF TABLES XIII

LIST OF ABBREVIATIONS XIV

LIST OF PUBLICATIONS XVIII

$\begin{array}{ll}\text { ABSTRACT } & X X\end{array}$

CHAPTER 1: INTRODUCTION 1

1.1. Background 1

1.2. Research gaps and challenges 2

1.3. Objectives 3

1.4. Scope 4

CHAPTER 2: LITERATURE REVIEW 6

2.1. Background on bacterial synthesis of nanomaterials 6

2.2. Biofilms and biofilm-based bioprocesses 19

$\begin{array}{lr}\text { 2.2.1. Biofilm matrix } & 19\end{array}$

2.2.2. Biofilm Formation and Development 22

2.2.3. Biofilm Regulation and Signalling 25

2.2.4. Biofilm Heterogeneity and Chemical Gradients 27

2.2.5. Redox Activities of EPS 30

2.3. Immobilisation of nanoparticles in biofilm matrix 35

$\begin{array}{llllll}\text { CHAPTER 3: INFLUENCE OF OUTER MEMBRANE C-TYPE } 39 & 39\end{array}$ CYTOCHROMES ON PARTICLE SIZE AND ACTIVITY OF EXTRACELLULAR NANOPARTICLES PRODUCED BY SHEWANELLA ONEIDENSIS

3.1. Introduction 39

3.2. Material and Methods 41

3.2.1. Bacterial Strains and Growth Conditions 41

3.2.2. Extracellular Synthesis of Nanoparticles 42

3.2.3. Field Emission Scanning Electron Microscopy and Energy- 42

Dispersive $X$-Ray Spectroscopy 
3.2.4. Transmission Electron Microscopy

3.2.5. Size Distribution 43

3.2.6. Antibacterial Activity of Biogenic AgNPs 43

3.2.6.1. Minimal Inhibitory Concentration (MIC) Test 43

3.2.6.2. Bactericidal Assay 44

3.2.7. Inductively Coupled Plasma Mass Spectrometry 44

3.2.8. Catalytic Activity of Biogenic Ag, S NPS

3.3. Results and Discussion $\quad 45$

3.3.1. Biogenic AgNPs and $\mathrm{Ag}_{2} S$ NPs 45

3.3.2. Particle Size 46

3.3.3. Antibacterial Activity of AgNPs 48

3.3.4. Catalytic activity of $\mathrm{Ag}_{2} \mathrm{~S} N \mathrm{NS} \quad 50$

3.4. Conclusions 53

CHAPTER 4: REDUCTIVE FORMATION OF PALLADIUM 56 NANOPARTICLES BY SHEWANELLA ONEIDENSIS: ROLE OF OUTER MEMBRANE CYTOCHROMES AND HYDROGENASES

4.1. Introduction 56

4.2. Materials and Methods 58

4.2.1. Bacterial Strains and Growth Conditions 58

4.2.2. $P d(I I)$ reduction by resting cells $\quad 59$

4.2.3. Quantification of $P d(I I) \quad 59$

4.2.4. Flavin quantification using fluorescence 60

4.2.5. Transmission electron microscopy (TEM) 60

4.3. Results and Discussion 61

4.3.1. Pd(II) reduction by resting cells follows first-order Monod 61 model

4.3.2. Outer membrane c-type cytochromes MtrC/OmcA do not play 63 an essential role in $\mathrm{Pd}(\mathrm{II})$ reduction

4.3.3. [NiFe]-hydrogenase HyaB facilitates $P d(I I)$ reduction 66

4.3.4. Proposed mechanisms of hydrogenase-facilitated Pd(II) 68 reduction 
5.1. Introduction

5.2. Materials and methods

5.2.1. Bacterial strains and growth conditions 74

5.2.2. Construction of c-di-GMP mutants 76

5.2.3. Growth of S. oneidensis biofilms and Pd(II) reduction 77

5.2.4. Biofilm viscosity 78

5.2.5. Epifluorescence microscopy

5.2.6. Field emission scanning electron microscopy and energy- 79 dispersive $X$-ray spectroscopy

5.2.7. X-ray diffraction 79

5.2.8. Biofilm-associated Pd nanoparticles 79

5.2.9. Size distribution and zeta-potential measurements 80

5.2.10. Transmission electron microscopy 80

5.2.11. Catalytic activity of the biofilms 81

5.2.12. Proteomics analysis 81

5.2.12.1. Preparation of cellular proteins 81

5.2.12.2. iTRAQ labelling 82

5.2.12.3. $L C-M S / M S$ and data analysis 84

5.2.13. Static Biofilm assay and Motility assay 84

5.2.14. C-di-GMP extraction and quantification 85

5.2.15. Iron reduction and quantification 86

5.2.16. Western blotting 86

5.2.17. Biofilm extraction and quantification 87

5.2.18. RNA extraction, sequencing and analysis 87

5.3. Results and Discussion $\quad 89$

5.3.1. Biofilms reduce $P d(I I)$ and accumulate $P d(0)$ nanoparticles $\quad 89$ under aerobic conditions

5.3.2. Biofilms with in situ generated $P d(0)$ nanocrystals have 95 nanocatalytic activity 
5.3.3. Pd(II) inhibits cellular respiration and energy metabolism: risk 98 of biofilm detachment

5.3.4. Genetic engineering of intracellular c-di-GMP for robust 105 nanocatalytic biofilm

5.3.5. c-di-GMP quantification in MR-1 WT vs c-di-GMP mutant

5.3.6. Transcriptomic analysis: Influence of increasing c-di-GMP on 106 Mtr pathway in MR-1

5.3.7. Transcriptomic analysis: Influence of increasing c-di-GMP on Motility in MR-1.

5.3.8. Influence of increasing c-di-GMP on biofilm formation and detachment in MR-1.

5.4. Conclusions

120

CHAPTER 6: SYNTHESIS OF ROBUST BIOFILM-TEMPLATED HETEROATOM-DOPED CARBON-PALLADIUM NANOCOMPOSITE CATALYST FOR HEXAVALENT CHROMIUM REDUCTION

6.1. Introduction

6.2. Material and Methods

6.2.1. Chemicals, Bacterial strains and growth conditions

6.2.2. Growth of $S$. oneidensis biofilms and $\mathrm{Pd}(\mathrm{II})$ reduction

6.2.3. Field emission scanning electron microscopy and energydispersive $X$-ray spectroscopy

6.2.4. Controlled pyrolysis of biofilm-nanopalladium catalyst

6.2.5. $X$-ray diffraction

6.2.6. Chromium reduction of the catalytic systems

6.3. Results and Discussion

6.3.1. Formation of abiotic biofilm-templated heteroatom ( $N$ and $P$ )doped carbon-palladium nanocomposite via controlled pyrolysis

6.3.2. $\mathrm{Cr}(\mathrm{VI})$ reduction and catalyst recycling

6.3.3. Environmental applications 
7.2.1. Integration of biofilm-based nanocatalyst with membrane 140 technology

7.2.2. Biofilm-based nanocatalyst for energy-related applications 


\section{LIST OF FIGURES}

Figure 2.1. Illustration of the metal-reducing (MTR) pathway in

S. oneidensis. The MTR pathway consists of a number of electron carrier proteins including CymA, MtrA, MtrC, and OmcA. The electrons obtained from bacterial metabolism are transferred across the periplasmic space to the outer membrane, where MtrC and OmcA can use the electrons to reduce metal(loid)s. Reproduced from ( $\mathrm{Ng}$ et al 2015) with permission from "John Wiley and Sons"

Figure 2.2. Model of Shewanella oneidensis MR-1 [NiFe]hydrogenase-mediated $\mathrm{Tc}(\mathrm{VII}) \mathrm{O}_{4}{ }^{-}$reduction. [NiFe]hydrogenase, situated in the periplasm, catalyse the reduction of $\mathrm{Tc}(\mathrm{VII})$ by coupling the oxidation of $\mathrm{H}_{2}$ into $\mathrm{H}^{+}$. Reproduced from (Shi, Belchik et al. 2011) with permission from "American Society for Microbiology".

Figure 2.3. The EPS matrix at different dimensions. a) Model of a surface-attached biofilm. b) Major components in the EPS matrix, such as polysaccharides, proteins and extracellular DNA. c) Possible interaction that contribute to the overall structure integrity of the EPS matrix. d) Molecular modelling simulation of the interaction between alginate (right) and lipase (left) of Pseudomonas aeruginosa in aqueous solution. Reproduced from (Flemming and Wingender 2010) with permission from "Nature Publishing Group"

Figure 2.4. Main stages of biofilm development cycle - initial attachment, microcolony formation, biofilm maturation, and biofilm dispersal.

Figure 2.5. Structure and physiological function of c-di-GMP. Reproduced from (Hengge 2009) with permission from "Nature Reviews Microbiology".

Figure 2.6. Spatial and temporal magnetic resonance map of

$\mathrm{Cr}$ (III) concentration from batch-mode reduction of $\mathrm{Cr}(\mathrm{VI})$ using biofilm-Pd catalyst. Concentration of $\mathrm{Cr}$ (III) decrease due to precipitation of solid $\mathrm{Cr}(\mathrm{OH})_{3}$ and building up of gas bubbles 


\begin{tabular}{|c|c|}
\hline $\begin{array}{l}\text { (black regions within the reactor). Reproduced from } \\
\text { (Beauregard, Yong et al. 2010) with permission from "John } \\
\text { Wiley and Sons". }\end{array}$ & \\
\hline $\begin{array}{l}\text { Figure 2.7. Proposed mechanism for the EAB-mediated } \\
\text { synthesis of } \mathrm{Ag} @ \mathrm{TiO}_{2} \text { nanocomposites. Reproduced from } \\
\text { (Khan, Ansari et al. 2013) with permission from "The Royal } \\
\text { Society of Chemistry". }\end{array}$ & 37 \\
\hline $\begin{array}{l}\text { Figure 3.1. TEM images of the extracellular AgNPs }(\mathrm{A} \text { and } \mathrm{B}) \text {, } \\
\mathrm{Ag}_{2} \mathrm{~S} \text { NPs }(\mathrm{C} \text { and } \mathrm{D}) \text { produced by different } S \text {. oneidensis } \\
\text { strains: WT }(\mathrm{A} \text { and } \mathrm{C}), \Delta(m+r C-o m c A)(\mathrm{B} \text { and } \mathrm{D}) \text {, and the } \\
\text { average }(n=3) \text { hydrodynamic diameters of the biogenic NPs } \\
\text { (E). }\end{array}$ & 47 \\
\hline $\begin{array}{l}\text { Figure 3.2. } \mathrm{IC}_{50} \text { values }(n=8) \text { of the biogenic AgNPs produced } \\
\text { by WT and } \Delta(m \operatorname{tr} C \text {-omc } A) \text { (bars), and the dissolution of } \\
\mathrm{Ag}^{+}(n=3 \text {; circles). }\end{array}$ & 49 \\
\hline $\begin{array}{l}\text { Figure 3.3. Kinetic curves of the accumulation of } \mathrm{MV} \cdot+\text { in } \\
\text { solutions containing } \mathrm{Na}_{2} \mathrm{~S} \text { in the absence of } \mathrm{Ag}_{2} \mathrm{~S} \mathrm{NPs} \text {, and in } \\
\text { the presence of cell-associated or non-cell-associated } \mathrm{Ag}_{2} \mathrm{~S} \\
\text { NPs produced by S. oneidensis MR-1 WT. }\end{array}$ & 51 \\
\hline $\begin{array}{l}\text { Figure 3.4. Kinetic curves of the accumulation of MV-+ in } \\
\text { solutions containing } \mathrm{Na}_{2} \mathrm{~S} \text { in the presence of non-cell- } \\
\text { associated } \mathrm{Ag}_{2} \mathrm{~S} N \mathrm{NPs} \text { produced by } \mathrm{S} \text {. oneidensis MR-1 WT } \\
\text { and } \Delta(m \operatorname{tr} C-\mathrm{omc} A) \text {. }\end{array}$ & 53 \\
\hline $\begin{array}{l}\text { Figure 4.1. The rate of } \mathrm{Pd}(\mathrm{II}) \text { reduction by } \mathrm{S} \text {. oneidensis with } \\
\text { formate as an electron donor measured as a function of initial } \\
\mathrm{Pd}(\mathrm{II}) \text { concentration at } 30^{\circ} \mathrm{C} \text {. The solid line represents the } \\
\text { best fit. The rate of } \mathrm{Pd} \text { reduction can be well described by a } \\
\text { first-order model }-\mathrm{d}[\mathrm{Pd}(\mathrm{II})] / \mathrm{d} t=\mathrm{k} 1 \times[\mathrm{Pd}(\mathrm{II})] \text { where the } \\
\text { parameter } \mathrm{k}_{1} \text { was determined to be } 164.3 \mathrm{~h}^{-1} \text { per cell in the } \\
\text { reduction of } \mathrm{Pd}(\mathrm{II}) \text { within the concentration range of } 0-4 \mathrm{mM} \text {. }\end{array}$ & 62 \\
\hline
\end{tabular}


Figure 4.2. (A) Dispersion of $\operatorname{Pd}(0)$ nanoparticles (black) in a suspension of cells (green). Cells were stained with DAPI. For enhanced clarity, the image was pseudo-colored. (B) TEM image showing the association of $\operatorname{Pd}(0)$ nanoparticles with $S$. oneidensis MR-1.

Figure 4.3. Specific rates of $\mathrm{Pd}(\mathrm{II})$ reduction (determined for the first $3 \mathrm{~h}$ ) by $S$. oneidensis MR-1 WT and OMC mutants with $20 \mathrm{mM}$ lactate or formate as electron donors in $30 \mathrm{mM}$ HEPES buffer $(\mathrm{pH} 7.0)$ under no-growth conditions. Data represent the mean and standard deviation $(n=3)$.

Figure 4.4. Specific rates of $\mathrm{Pd}(\mathrm{II})$ reduction by $\mathrm{S}$. oneidensis MR-1 WT and hydrogenase mutants with $20 \mathrm{mM}$ formate as electron donors in 30 mM HEPES buffer $(\mathrm{pH}$ 7.0) under nogrowth conditions. Specific reduction rate was determined for the first $3 \mathrm{~h}$ of $\mathrm{Pd}(\mathrm{II})$ reduction.

Figure 4.5. Model of hydrogenase-facilitated $\mathrm{Pd}(\mathrm{II})$ reduction by $S$. oneidensis with formate as electron donors.

Figure 5.1. A) Graph showing dissolved oxygen (DO) concentration from various distance from the bottom of the biofilm. B) Schematic diagram showing the reduction of $\mathrm{Pd}(\mathrm{II})$ ions to $\operatorname{Pd}(0)$ nanoparticles within the biofilm under bulk oxic condition.

Figure 5.2. Immobilisation of Pd in S. oneidensis MR-1 biofilms. Each data point represents the average of three replicates. Insets show the growth of $S$. oneidensis biofilms (pink color) in the first 3 days.

Figure 5.3. (A) FE-SEM image and a representative EDX spectrum of the biofilm-Pd association; (B) XRD pattern of the biofilm-Pd association: peaks at around $40^{\circ}, 46^{\circ}, 68^{\circ}, 82^{\circ}$, and $86^{\circ}$ correspond to the (111), (200), (220), (311), and (222) planes of an fcc lattice, respectively.

Figure 5.4. (A) Dispersion of $\mathrm{Pd}(0)$ nanoparticles (black) in suspension of cells (green) from the biofilms visualised by overlay of bright-field and fluorescence imaging. Cells were 


\begin{tabular}{|c|c|}
\hline $\begin{array}{l}\text { stained with DAPI. For better image clarity, the image has } \\
\text { been pseudo-colored. (B) TEM image showing the association } \\
\text { of } \mathrm{Pd}(0) \text { nanoparticles with bacterial cells at the single-cell } \\
\text { scale. (C) Size distribution and zeta potential and }(\mathrm{D}) \text { a } \\
\text { representative TEM micrograph of the non-cell-associated } \\
\mathrm{Pd}(0) \text { nanoparticles in the biofilm-Pd(0) association. }\end{array}$ & \\
\hline $\begin{array}{l}\text { Figure 5.5. TCE dechlorination rate by nanocatalytic biofilms } \\
\text { and its various fractions, namely matrix-associated } \mathrm{Pd}(0) \mathrm{NPs} \\
\text { and cell-associated } \mathrm{Pd}(0) \mathrm{NPs} \text { are shown in the graph. } \mathrm{Pd}(0) \text { - } \\
\text { free abiotic and biotic control were also conducted. }\end{array}$ & 96 \\
\hline $\begin{array}{l}\text { Figure 5.6. A representative temporal profile of the dissolved } \\
\text { oxygen concentration in the outlet of a biofilm reactor with } S \text {. } \\
\text { oneidensis biofilms growing it. }\end{array}$ & 98 \\
\hline $\begin{array}{l}\text { Figure 5.7. Rate of } \mathrm{Fe}(\mathrm{III}) \text { reduction by } S \text {. oneidensis MR-1 } \\
\text { WT and c-di-GMP mutant. }\end{array}$ & 107 \\
\hline $\begin{array}{l}\text { Figure 5.8. Western Blot: Quantification of outer-membrane c- } \\
\text { type cytochrome MtrC and OmcA in S. oneidensis MR-1 WT } \\
\text { and c-di-GMP, with mutant lacking MtrC (e.g. } \Delta m t r C \text { ) and } \\
\text { OmcA (e.g. } \triangle \text { omcA) as negative control. }\end{array}$ & 108 \\
\hline $\begin{array}{l}\text { Figure 5.9. Swimming Motility Assay: Comparison of colony } \\
\text { diameter between S. oneidensis MR-1 WT and c-di-GMP } \\
\text { mutant. }\end{array}$ & 114 \\
\hline $\begin{array}{l}\text { Figure 5.10. Viscosity measurement of } S \text {. oneidensis MR-1 } \\
\text { WT and c-di-GMP mutant biofilm. }\end{array}$ & 116 \\
\hline $\begin{array}{l}\text { Figure 5.11. OD } 600 \text { measurement (left y-axis) and static biofilm } \\
\text { assay (right y-axis), showing the relative amount of planktonic } \\
\text { cells and biofilm of } S \text {. oneidensis MR- } 1 \text { WT and c-di-GMP } \\
\text { mutant respectively. }\end{array}$ & 117 \\
\hline $\begin{array}{l}\text { Figure 5.12. Flow cell biofilm: CLSM 3D images and } \\
\text { orthogonal views of } S \text {. oneidensis MR-1 WT (A and C) and C- } \\
\text { di-GMP mutant (B and D) respectively, showing biofilm } \\
\text { formation after } 72 \text { hours of growth under hydrodynamic } \\
\text { conditions. The white bar represents } 100 \mu \mathrm{m} \text {. }\end{array}$ & 118 \\
\hline
\end{tabular}


Figure 5.13. Percentage of $\mathrm{Cr}(\mathrm{VI})$ removed by various biofilm samples, namely biofilm control (no Pd) of wt and c-di-GMP mutant and nanocatalytic biofilm wt and c-di-GMP mutant in the first and fifth reaction with catalyst recycling. All experiments are done in triplicates.

Figure 6.1. Schematic diagram of $(A)$ functionalising biofilm with Pd NPs, resulting in nanocatalytic biofilm and (B) possible interactions between Pd NPs and EPS components.

Figure 6.2. SEM image of (A) carbon felt, (B) biofilmnanopalladium catalyst on carbon felt, (C) pyrolysed biofilmtemplated carbon-palladium nanocomposite on carbon felt. White bar represents $1 \mu \mathrm{m}$. Images are taken with the same magnification (x 5000). SEM-EDX image of (D) an area of interest of the biofilm-templated C-Pd nanocomposite, and EDX-profile of the area of interest of (E) palladium, $(F)$ phosphorus and $(\mathrm{G})$ nitrogen

Figure 6.3. $\mathrm{Cr}(\mathrm{VI})$ reduction of $\mathrm{C}-\mathrm{Pd}$ nanocomposite, nanocatalytic biofilm (c-di-GMP strain), no-Pd biofilm control (c-di-GMP) and pyrolyzed biofilm control (no Pd) samples on the $1 \mathrm{st}$ and 5 th catalytic reaction. Initial concentration of 0.1 $\mathrm{mM} \mathrm{Cr}(\mathrm{VI})$ was introduced into the system, and formic acid (1\%) was used as electron donor. All $\mathrm{Cr}(\mathrm{VI})$ reduction experiment are conducted in triplicates.

Figure 7.1. Schematic diagram of the couping of biofilmtemplated C-Pd nanocomposite catalyst with microporous PES hollow fiber membrane system. 


\begin{tabular}{|l|c|}
\hline $\begin{array}{l}\text { Table 2.1. Summary of recent studies on bacterial } \\
\text { synthesis of gold, silver and palladium NPs. }\end{array}$ & 8 \\
\hline $\begin{array}{l}\text { Table 2.2. Dissolved oxygen (DO) sensors used in } \\
\text { biofilm studies }\end{array}$ & 29 \\
\hline $\begin{array}{l}\text { Table 2.3. Recent studies on redox activity of } \\
\text { biofilm }\end{array}$ & 31 \\
\hline Table 4.1. S. oneidensis strains used in this study & 58 \\
\hline Table 5.1. S. oneidensis strains used in this study. & 75 \\
\hline $\begin{array}{l}\text { Table 5.2. The catalytic activity of the nanocatalytic } \\
\text { biofilm and its two fractions of biofilms-associated } \\
\text { Pd(0) nanoparticles are compared in the table. }\end{array}$ & 97 \\
\hline $\begin{array}{l}\text { Table 5.3. Selected down-regulated proteins } \\
\text { involved in energy metabolism. }\end{array}$ & 100 \\
\hline $\begin{array}{l}\text { Table 5.4. Transcriptomic data of MTR-pathway- } \\
\text { related gene expression in S. oneidensis MR-1 WT } \\
\text { and c-di-GMP mutant. }\end{array}$ & 104 \\
\hline $\begin{array}{l}\text { Table 5.5. Transcriptomic data of motility-related } \\
\text { gene expression in S. oneidensis MR-1 WT and c- } \\
\text { di-GMP mutant. }\end{array}$ & 109 \\
\hline $\begin{array}{l}\text { Table 5.6. Rate of cell detachment rate from flow } \\
\text { cell biofilm of S. oneidensis MR-1 WT and c-di-GMP } \\
\text { mutant. }\end{array}$ & 140 \\
\hline $\begin{array}{l}\text { Table 7.1. Comparison of genetic manipulation and } \\
\text { physical alteration approach on performance of } \\
\text { nanocatalytic biofilm. }\end{array}$ & \\
\hline
\end{tabular}




\section{LIST OF ABBREVIATIONS}

\begin{tabular}{|c|c|}
\hline$\times g$ & g-force in centrifuge \\
\hline${ }^{\circ} \mathrm{C}$ & Degree Celsius \\
\hline$\mu \mathrm{g}$ & Microgram \\
\hline$\mu \mathrm{L}$ & Microlitre \\
\hline$\mu \mathrm{M}$ & Micromolar concentration \\
\hline$\mu \mathrm{m}$ & Micrometre \\
\hline$\mu$ moles & Micromoles \\
\hline $2 \mathrm{D}$ & Two dimension \\
\hline $3 \mathrm{D}$ & Three dimension \\
\hline AC & Activated carbon \\
\hline $\mathrm{Ag}$ & Silver \\
\hline $\mathrm{C}$ & Carbon \\
\hline c-di-GMP & Bis-( $\left(3^{\prime}-5^{\prime}\right)$-cyclic dimeric guanosine monophosphate \\
\hline CFU & Colony forming unit \\
\hline CLSM & Confocal laser scanning microscopy \\
\hline COM & Center of mass \\
\hline $\mathrm{Cr}$ & Chromium \\
\hline CTC & 5-cyano-2,3-di-4-tolyl-tetrazolium chloride \\
\hline $\mathrm{Cu}$ & Copper \\
\hline DAPI & 4'-6-diamidino-2-phenylindole \\
\hline DGCs & Diguanylate cyclases \\
\hline DMRB & Dissimilatory metal-reducing bacteria \\
\hline $\mathrm{DO}$ & Dissolved oxygen \\
\hline E. coli & Escherichia coli \\
\hline e.g. & Example \\
\hline E1 & Estrone \\
\hline E2 & $17 \beta$-estradiol \\
\hline
\end{tabular}




\begin{tabular}{|c|c|}
\hline E3 & Estriol \\
\hline EAB & Electrically-active biofilm \\
\hline EDCs & Endocrine disrupting chemicals \\
\hline eDNA & Extracellular Deoxyribonucleic Acid \\
\hline EDX & Energy-Dispersive X-Ray Spectroscopy \\
\hline EE2 & 17a-ethynylestradiol \\
\hline EET & Extracellular electron transport \\
\hline EPS & Extracellular polymeric substances \\
\hline etc & et cetera \\
\hline FDR & False Discovery Rate \\
\hline $\mathrm{Fe}$ & Iron \\
\hline Fe(III)-NTA & Ferric nitrilotriacetate \\
\hline FHL & Formate-hydrogen lyase \\
\hline GFP & Green fluorescent protein \\
\hline h & Hour \\
\hline HEPES & 4-(2-hydroxyethyl)-1-piperazineethanesulfonic acid) \\
\hline HFBA & Heptafluorobutyric acid \\
\hline HPLC & High performance liquid chromatography \\
\hline IC50 & Half maximal inhibitory concentration \\
\hline $\mathrm{kDa}$ & kilo-dalton \\
\hline kV & kilo-volt \\
\hline LB & Lysogeny Broth \\
\hline $\mathrm{MB}$ & Methylene blue \\
\hline MD & Molecular dynamics \\
\hline metal(loid) & Metal and metalloid \\
\hline $\min$ & Minute \\
\hline $\mathrm{mL}$ & Milli-liter \\
\hline MOPS & (3-(N-morpholino)propanesulfonic acid \\
\hline MRI & Magnetic resonance imaging \\
\hline mRNA & Messenger RNA \\
\hline
\end{tabular}




\begin{tabular}{|c|c|}
\hline MS & Mass spectrometry \\
\hline MTR & Metal reducing \\
\hline MV & Methylviologen \\
\hline $\mathrm{N}$ & Nitrogen \\
\hline $\mathrm{NaCl}$ & Sodium chloride \\
\hline nd & no data \\
\hline $\mathrm{Ni}$ & Nickel \\
\hline $\mathrm{nm}$ & Nanometre \\
\hline NPs & Nanoparticles \\
\hline $\mathrm{O}$ & Oxygen \\
\hline OMCs & Outer membrane cytochromes \\
\hline$P$ & Phosphorous \\
\hline P. aeruginosa & Pseudomonas aeruginosa \\
\hline PCB & Polychlorobiphenyls \\
\hline PCR & Polymerase chain reaction \\
\hline $\mathrm{Pd}$ & Palladium \\
\hline PDEs & Phosphodiesterases \\
\hline PES & Polyethersulfone \\
\hline PGA & Poly- $\beta-1,6-G \mid c N A c$ \\
\hline PIPES & Piperazine-N, $\mathrm{N}^{\prime}$-bis(2-ethanesulfonic acid) \\
\hline $\mathrm{pm}$ & Picometre \\
\hline PME & Particle mesh Ewald \\
\hline PMF & Potential of mean force \\
\hline PS & Polysulfone \\
\hline PVDF & Poly(vinylidene fluoride) \\
\hline qPCR & Quantitative polymerase chain reaction \\
\hline RMSD & Root mean squared displacements \\
\hline RNA & Ribonucleic acid \\
\hline roGFP & Redox sensitive green fluorescent protein \\
\hline ROS & Reactive oxygen species \\
\hline
\end{tabular}




\begin{tabular}{|l|l|}
\hline RP & Reverse phase \\
\hline RPKM & $\begin{array}{l}\text { Reads assigned per kilo-base of target per million } \\
\text { mapped read }\end{array}$ \\
\hline rpm & Rounds per minute \\
\hline S. oneidensis & Shewanella oneidensis MR-1 \\
\hline SCX & Strong cation exchange \\
\hline SEM & Scanning Electron Microscopy \\
\hline SMD & Steered molecular dynamics \\
\hline SPC & Single point charge \\
\hline SPR & Surface plasmon resonance \\
\hline Tc & Technetium \\
\hline TCE & Trichloroethylene \\
\hline TCEP & Tris(2-carboxyethyl) phosphine \\
\hline TEAB & Triethylammonium bicarbonate \\
\hline TEM & Transmission Electron Microscopy \\
\hline Ti & Titanium \\
\hline TOF & Time-of-flight \\
\hline U & Uranium \\
\hline UF & Voltrafiltration \\
\hline UV & \\
\hline V/v & Volume \\
\hline vol & \\
\hline
\end{tabular}




\section{LIST OF PUBLICATIONS}

\section{Journal papers}

Ng CK, Bope DC, Nalapraju A, Cheng Y, Lu L, Wang R, Cao B (2017) Concentrating synthetic estrogen 17a-ethinylestradiol using microporous polyethersulfone hollowfiber membranes: Experimental exploration and molecular simulation. J 314: $80-87$.

$\mathrm{Ng} \mathrm{CK}$, Cao B (2015) What exactly are you filtering out? Environ Sci Technol 49 (9): 5259-5260.

Ng CK, Sivakumar K, Liu X, Madhaiyan M, Ji L, Yang L, Tang C, Song H, Kjelleberg $S$, Cao B (2013) Influence of outer membrane c-type cytochromes on particle size and activity of extracellular nanoparticles produced by Shewanella oneidensis. Biotechnol Bioeng 110(7): 1831-1837.

Ng CK, Tan TKC, Song H, Cao B (2013) Reductive Formation of Palladium Nanoparticles by Shewanella oneidensis: Role of Outer Membrane Cytochromes and Hydrogenases. RSC Adv 3(44): 22498-22503.

Liu T, Yu Y, Deng X, Ng CK, Cao B, Wang JY, Rice S, Kjelleberg S, Song H (2015) Enhanced Shewanella biofilm promotes bioelectricity generation. Biotechnol Bioeng 112: 2051-2029.

Luhung I, Wu Y, Ng CK, Miller D, Cao B, Chang V (2015) Protocol improvement for low concentration of DNA-based bioaerosol sampling and analysis. PLoS One 10(11): e0141158.

Zhang Y, Ng CK, Cohen Y, Cao B (2014) Cell growth and protein expression of Shewanella oneidensis in biofilms and hydrogel-entrapped cultures. Mol Biosyst 10(5): 1035-1042.

\section{Book Chapter}

Ng CK, Mohanty A, Cao B (2015) Biofilms in Bio-Nanotechnology, in BioNanoparticles: Biosynthesis and Sustainable Biotechnological Implications (ed O. V. Singh), John Wiley \& Sons, Inc, Hoboken, NJ. doi: 10.1002/9781118677629.ch4 


\section{Conference presentations}

Ng CK, Cao B (2016). Concentrating 17a-Ethinyl Estradiol (EE2) Using PES HollowFibre Membranes: Experimental Exploration and Molecular Modelling. $2016 \mathrm{AIChE}$ Annual Meeting, San Francisco, CA, USA. (Oral Presentation)

Ng CK, Cao B (2016). Engineering Biofilm for Remediation of Environmental Chromium(VI) Contamination. 6th International Conference on Environment Science and Biotechnology, Kyoto, Japan. (Oral Presentation) [Won the Best Oral Presentation award]

Ng CK, Ding Y and Cao B (2014). Understanding and harnessing the power of biofilm matrix: What we have learned from Shewanella biofilms. Biofilm6, Vienna, Austria. (Poster Presentation) 


\begin{abstract}
Microorganisms have the potential to change the oxidation state of metals and these microbial processes have opened up a new window for novel applications including biosynthesis of metal nanomaterials. Planktonic cells based synthesis of metal nanomaterials has been studied previously; however, much of the mechanistic details are still relatively unknown. The application of planktonic cells-based metal nanomaterials synthesis is constrained to batch and fed-batch processes. Moreover, planktonic cells have low tolerance to toxic substrates or products which undermine the synthesis efficiency of metal nanomaterials.
\end{abstract}

Microbial biofilms might offer a solution. Biofilms are structured, surface-associated, microbial communities that are prevalent in most natural environments, engineering systems and clinical settings. One of the most important features of a biofilm is the presence of extracellular polymeric substances (EPS) that form a matrix and encase the cells in the biofilm. Cells in biofilms often form structurally stable communities and show a remarkable resistance against various biocides. Hence, we hypothesize that biofilm may be a good candidate to use for the synthesis of metal nanomaterials.

This project aims to develop a robust and efficient biofilm-based nano-catalytic system which is applicable to water purification and environmental remediation. To understand the mechanism of nanomaterial production by microorganism, we used model organism Shewanella oneidensis MR-1 to synthesize silver, silver sulfide and palladium nanoparticles. We showed that the synthesized metal and metalloid nanoparticles exhibit catalytic activity. Microbial synthesis of silver and silver sulfide is influenced by outer membrane cytochromes, while synthesis of palladium nanoparticles (NPs) is influenced by periplasmic [NiFe]-hydrogenase. In addition, we 
also revealed that in extracellular biosynthesis of NPs, the usually neglected noncell-associated NPs could have high catalytic activity, highlighting the need of novel methods that can efficiently retain extracellular NPs in the biosynthesis processes.

The second part of the project focused on exploring the reductive formation of $\operatorname{Pd}(0)$ nanoparticles in biofilms under ambient conditions, understanding the metabolic responses of the biofilms during the process of palladium nanoparticles synthesis, and developing a robust nanocatalytic biofilm through genetic engineering. We showed that the $S$. oneidensis biofilms can reduce $\mathrm{Pd}(\mathrm{II})$ and accumulate $\mathrm{Pd}(0)$ nanocrystals with a size of $10-20 \mathrm{~nm}$ in the biofilm matrix and in the cell membrane even under bulk aerobic conditions, and that the $S$. oneidensis biofilms with $\operatorname{Pd}(0)$ nanocrystals exhibit nanocatalytic activity. However, we also observed that Pd(II) exposure inhibits cellular respiration and energy metabolism of $S$. oneidensis cells, posing a risk of biofilm detachment.

To improve the robustness of biofilm-based nanocatalyst, we explored two approaches: (1) genetic manipulation via c-di-GMP pathway and (2) physical alteration via controlled pyrolysis. In previous studies, c-di-GMP has been reported to be able to influence the production of EPS and influence biofilm processes such as cell dispersal. In our study, we showed that we can increase the production of EPS and alleviate the biofilm detachment during the biofilm's exposure to Pd(II). The insertion of plasmid pYedQ2 can increase the production of cytoplasmic c-di-GMP, an upstream signalling molecule which influences several key cellular processes, such as cellular motility, extracellular electron transport, iron uptake and biofilm formation in S. oneidensis MR-1. 
Further, we also showed that controlled pyrolysis leads to carbonisation of biofilm and formation of stable, abiotic heteroatom ( $\mathrm{N}$ and $\mathrm{P}$ )-doped carbon-palladium ( $\mathrm{C}$ Pd) nanocomposite catalyst. Moreover, the pyrolysed biofilm-templated C-Pd nanocomposite catalyst show high $\mathrm{Cr}(\mathrm{VI})$ reduction, and maintained high reduction rate even on the 5th catalytic cycle. Although the pyrolysed heteroatom-doped carbon on its own has no $\mathrm{Cr}(\mathrm{VI})$ reduction activity, it seems to enhance the catalytic activity of the Pd nanocrystals in the C-Pd nanocomposite. 


\section{CHAPTER 1: INTRODUCTION}

\subsection{Background}

Microorganisms can change the oxidation state of metals and these microbial processes open up new opportunities for researchers to explore novel applications, for example, the biosynthesis of metal nanomaterials (De Corte, Hennebel et al. 2012, Sintubin, Verstraete et al. 2012). In contrast to conventional chemical and physical methods that often involve the use of toxic chemicals and harsh conditions, microbial synthesis of nanomaterials can be achieved in aqueous phase under gentle and environmentally benign conditions (Lloyd, Byrne et al. 2011). This approach has become an attractive focus in current green nanotechnology research towards sustainable development.

Certain biogenic metal nanomaterials such as palladium, silver, and gold nanoparticles exhibit catalytic activities and the bacteria-nanomaterial associations, known as metalised bacterial cells, can be exploited for environmental remediation (De Windt, Boon et al. 2006, Hennebel, De Gusseme et al. 2009, Forrez, Carballa et al. 2011) and synthesis of fine chemicals (Sobjerg, Gauthier et al. 2009, Heugebaert, De Corte et al. 2012, Bennett, Mikheenko et al. 2013). The metalised cells reported in most, if not all, previous studies were prepared using planktonic cultures. The planktonic cells based approach is restricted to batch and fed-batch bioprocesses which is of lower efficiency compared to continuous reactor operations. Moreover, additional steps are required to recover the metallised planktonic cells which are often time-consuming and energy intensive. Another limitation of using planktonic cells is that they have low tolerance to metal and metalloid ions which might compromise the integrity of the bacteria cells during the biosynthesis of metal nanomaterials. 
Biofilms are microbial communities where the cells are encased and immobilised by a self-fabricated extracellular polymeric substances (EPS) matrix (Flemming and Wingender 2010). Unlike planktonic cells, biofilm cells have much higher tolerance to antimicrobial agents and other toxic chemicals (Flemming 2011). It is also comparatively much simpler to recover the immobilised biofilm cells as compared to the free floating planktonic cells. Biofilm-nanomaterial associations are suitable catalyst for both batch and continuous reactor operations. Hence, the use of biofilms to mediate the synthesis of biogenic nanocatalysts is a promising approach to developing catalytic systems for environmental and chemical applications.

\subsection{Research gaps and challenges}

Biofilms may be as effective as planktonic cells for the synthesis of biogenic nanomaterials, while providing added advantages such as heightened tolerance to toxicity, ease of nanomaterial recovery, and versatility in operational modes. However, various limitations prevent the biofilm-based synthesis of nanomaterials and its subsequent deployment of biofilm-nanomaterials associations for practical applications to be widely carried out.

The mechanisms of nanomaterial synthesis using planktonic and biofilm cells are not well understood. Moreover, the role of EPS matrix in production of nanomaterials within biofilm is largely unexplored. Since the synthesis of metal nanomaterials involves reduction of metal ions, it may be possible that certain cells surface and EPS matrix-associated redox proteins, especially those with extracellular electron transport (EET) capabilities, can contribute to the synthesis of nanomaterials within biofilm (Cao, Shi et al. 2011). It is important to elucidate and understand the mechanistic details of 
the biofilm-based synthesis of nanomaterials for its optimisation and execution in large-scale industrial settings.

The use of biofilm for the synthesis of nanomaterials may affect how cells grow and function. As some metal ions are toxic to planktonic cells (Melber, Keller et al. 2002), certain cells responces (e.g. cell dispersal) may be triggered due to stress when exposed to the metal ions used for nanomaterial synthesis. Furthermore, natural biofilm development involves stages such as biofilm detachment. If not controlled properly, biofilm detachment and cell dispersal can lead to loss of precious nanomaterials.

Biofilm engineering can be deployed to alleviate the bottlenecks that limit the widespread use of biofilm-based bioprocesses, such as synthesis of biogenic nanomaterials. Understanding the underlying mechanisms of nanomaterial synthesis and engineering biofilm to be robust with lower detachment are key challenges associated with biofilm-based synthesis of nanomaterial for practical applications.

\subsection{Objectives}

The overall objective of this research is to explore the use of biofilms for the synthesis of nanocatalysts and the development of biofilm-templated nanocatalytic systems. Specifically, the following three aims are to be achieved:

(i) To explore the role of key bacterial membrane and matrix-associated redox proteins, such as c-type cytochromes and hydrogenases, in biosynthesis of nanocatalysts.

(ii) To engineer biofilms to make it more robust with lower detachment. 
(iii) To remove biomass from nanocatalytic biofilms through controlled pyrolysis to achieve and maintain a higher catalytic activity.

\subsection{Scope}

This thesis contains seven chapters, namely introduction, literature review, four research chapters and conclusion with future recommendations.

In Chapter 1, a brief background on microbial synthesis of nanomaterials and biofilmbased biocatalysis is introduced. This chapter discussees the advantages of biofilmbased synthesis of nanomaterials as compared to planktonic approaches, while listing the limitations of such biofilm-based bioprocesses. This chapter also describes the objective and scope of this study in detail.

Chapter 2 entails the literature review for the entire thesis. This chapter examines the bacterial synthesis of nanomaterial and its application in environmental remediation. This is followed by the introduction of biofilm mode of life, biofilm matrix components and biofilm biology. It also describes the significance of bioremediation as compared to other current technologies in the removal of emerging contaminants from the environment.

Chapter 3 presents the mechanistic study on the role of outer membrane cytochromes and hydrogenases of Shewanella oneidensis MR-1 on the reductive formation of biogenic silver and silver sulfide nanoparticles.

Chapter 4 reports the mechanistic study on the role of outer membrane cytochromes and hydrogenases of $S$. oneidensis MR-1 on the reductive formation of biogenic palladium nanoparticles. 
Chapter 5 presents the in situ bioreductive formation of palladium nanoparticles in the biofilm matrix and engineering of biofilms with nanocatalytic activity (a.k.a nanocatalytic biofilm) via genetic manipulation of bis-(3'-5')-cyclic dimeric guanosine monophosphate (c-di-GMP) level.

Chapter 6 presents the engineering of nanocatalytic biofilm via controlled pyrolysis to form robust biofilm-templated heteroatom-doped carbon-palladium nanocomposite catalyst.

Chapter 7 concludes with the summary of studies covered in this thesis and provides some future recommendations. 


\section{CHAPTER 2: LITERATURE REVIEW}

A portion of this chapter has been published as $\mathrm{Ng}$ CK, Mohanty A and Cao B (2015) Biofilms in Bio-Nanotechnology, in Bio-Nanoparticles: Biosynthesis and Sustainable Biotechnological Implications (ed O. V. Singh), John Wiley \& Sons, Inc, Hoboken, NJ. doi: 10.1002/9781118677629.ch4. Permission has been granted by the licensed content publisher "John Wiley and Sons" to use the published content as a chapter in this thesis.

\subsection{Background on bacterial synthesis of nanomaterials}

There are many instances where nature acts as a guide to human advancement in technology. In the search for a more environmentally benign approach to synthesize nanomaterials, researchers drew inspiration from the way microorganisms interact with metals and metalloids in the natural environment. Microorganisms have the potential to change the oxidation state of metals and metalloids via oxidation and reduction, and these microbial processes (i.e. biomineralisation) have provided access to novel applications including biosynthesis of metal and metalloid nanomaterials (Hennebel, De Gusseme et al. 2009, Durán and Seabra 2012).

Conventional synthesis of metal nanomaterials uses chemical and physical methods that often involve the use of toxic chemicals and harsh conditions (Raveendran, Fu et al. 2003). In contrast, microbial synthesis of metal nanomaterials can be achieved in aqueous phase under gentle and environmentally benign conditions (Hennebel, De Gusseme et al. 2009, Lloyd, Byrne et al. 2011). This approach has become an attractive focus in current research on green nanotechnology research towards sustainable development. 
Many types of microbes can be utilised to catalyse the synthesis of biogenic metal or metalloid nanomaterials (De Corte, Hennebel et al. 2012, Sintubin, Verstraete et al. 2012). Biogenic metal nanomaterials, such as that of gold, silver and palladium, can exhibit catalytic properties which are applicable in fine chemical synthesis and other industrial catalytic processes (Deplanche, Merroun et al. 2012, Corbos, Ellis et al. 2013). Table 2.1 summarises the recent studies on bacterial synthesis of gold, silver and palladium nanomaterials. 
Table 2.1. Summary of recent studies on bacterial synthesis of gold, silver and palladium nanomaterials.

\begin{tabular}{|c|c|c|c|c|c|}
\hline Metal & Bacteria & Size (nm) & Electron Donor(s) & $\begin{array}{c}\text { Application(s) of } \\
\text { synthesized nanomaterial }\end{array}$ & References \\
\hline \multirow[t]{4}{*}{ Gold } & \multirow[t]{2}{*}{$\begin{array}{l}\text { Shewanella } \\
\text { oneidensis }\end{array}$} & $5-20$ & Hydrogen gas, formate & No data (nd) & $\begin{array}{l}\text { (De Corte, Hennebel et } \\
\text { al. 2011) }\end{array}$ \\
\hline & & $5-30$ & Yeast extract & nd & $\begin{array}{l}\text { (Suresh, Pelletier et al. } \\
\text { 2011) }\end{array}$ \\
\hline & $\begin{array}{l}\text { Rhodopseudomonas } \\
\text { capsulata }\end{array}$ & $10-20$ & Pyruvate & nd & (He, Guo et al. 2007) \\
\hline & $\begin{array}{l}\text { Mixed Community } \\
\text { (Anaerobic Sludge) }\end{array}$ & $15-21$ & Acetate & $\begin{array}{l}\text { Catalysis for hydrogen } \\
\text { production }\end{array}$ & (Khan, Lee et al. 2013) \\
\hline
\end{tabular}




\begin{tabular}{|c|c|c|c|c|c|}
\hline & Shewanella algae & $10-20$ & Lactate & nd & $\begin{array}{l}\text { (Konishi, Tsukiyama et } \\
\text { al. 2007) }\end{array}$ \\
\hline & $\begin{array}{l}\text { Geobacillus } \\
\text { stearothermophilus }\end{array}$ & $5-14$ & $\begin{array}{l}\text { Casein, soybean meal, } \\
\text { dextrose }\end{array}$ & nd & $\begin{array}{l}\text { (Mohammed Fayaz, } \\
\text { Girilal et al. 2011) }\end{array}$ \\
\hline \multirow[t]{4}{*}{ Silver } & $\begin{array}{l}\text { Bacillus } \\
\text { licheniformis }\end{array}$ & $40-60$ & Nitrate & nd & $\begin{array}{l}\text { (Kalimuthu, Suresh } \\
\text { Babu et al. 2008) }\end{array}$ \\
\hline & $\begin{array}{l}\text { Geobacillus } \\
\text { stearothermophilus }\end{array}$ & $5-35$ & $\begin{array}{l}\text { Casein, soybean meal, } \\
\text { dextrose }\end{array}$ & nd & $\begin{array}{l}\text { (Mohammed Fayaz, } \\
\text { Girilal et al. 2011) }\end{array}$ \\
\hline & $\begin{array}{l}\text { Lactobacillus } \\
\text { farciminis }\end{array}$ & $14-20$ & \multirow[t]{2}{*}{ Tryptic soy } & Antimicrobial activity & \multirow[t]{2}{*}{$\begin{array}{l}\text { (Sintubin, De Windt et } \\
\text { al. 2009) }\end{array}$} \\
\hline & $\begin{array}{l}\text { Lactobacillus } \\
\text { rhamnosus }\end{array}$ & $13-18$ & & Antimicrobial activity & \\
\hline
\end{tabular}




\begin{tabular}{|c|c|c|c|c|}
\hline $\begin{array}{l}\text { Lactobacillus } \\
\text { plantarum }\end{array}$ & $16-22$ & & Antimicrobial activity & \\
\hline $\begin{array}{l}\text { Lactobacillus } \\
\text { fermentum }\end{array}$ & $5-15$ & Tryptic Soy & Virus disinfection in water & $\begin{array}{l}\text { (De Gusseme, } \\
\text { Hennebel et al. 2011) }\end{array}$ \\
\hline $\begin{array}{l}\text { Shewanella } \\
\text { oneidensis }\end{array}$ & $2-6$ & Yeast extract & Antimicrobial activity & $\begin{array}{l}\text { (Suresh, Pelletier et al. } \\
\text { 2010) }\end{array}$ \\
\hline & $40-42$ & Lactate & Antimicrobial activity & $\begin{array}{l}\text { (Ng, Sivakumar et al. } \\
\text { 2013) }\end{array}$ \\
\hline Bacillus cereus & 5 & Yeast extract & Antimicrobial activity & $\begin{array}{l}\text { (Sunkar and Nachiyar } \\
\text { 2012) }\end{array}$ \\
\hline $\begin{array}{l}\text { Ureibacillus } \\
\text { thermosphaericus }\end{array}$ & $1-100$ & Yeast extract & nd & $\begin{array}{l}\text { (Juibari, Abbasalizadeh } \\
\text { et al. 2011) }\end{array}$ \\
\hline
\end{tabular}




\begin{tabular}{|c|c|c|c|c|}
\hline Corynebacterium & $5-15$ & Beef extract & nd & (Zhang, Li et al. 2005) \\
\hline $\begin{array}{l}\text { Brevibacterium } \\
\text { casei }\end{array}$ & $10-50$ & Beef extract & Anti-coagulative activity & $\begin{array}{l}\text { (Kalishwaralal, Deepak } \\
\text { et al. 2010) }\end{array}$ \\
\hline $\begin{array}{l}\text { Staphylococcus } \\
\text { aureus }\end{array}$ & $160-180$ & Beef extract & Antimicrobial activity & $\begin{array}{l}\text { (Nanda and Saravanan } \\
\text { 2009) }\end{array}$ \\
\hline $\begin{array}{l}\text { Rhodobacter } \\
\text { Sphaeroides }\end{array}$ & $2-16$ & Malate & nd & (Bai, Yang et al. 2011) \\
\hline $\begin{array}{l}\text { Plectonema } \\
\text { boryanum }\end{array}$ & $1-50$ & Nitrate & nd & $\begin{array}{l}\text { (Lengke, Fleet et al. } \\
\text { 2007) }\end{array}$ \\
\hline $\begin{array}{l}\text { Geobacter } \\
\text { sulfurreducens }\end{array}$ & $20-40$ & Acetate & nd & $\begin{array}{l}\text { (Law, Ansari et al. } \\
\text { 2008) }\end{array}$ \\
\hline
\end{tabular}




\begin{tabular}{|c|c|c|c|c|c|}
\hline \multirow[t]{6}{*}{ Palladium } & $\begin{array}{l}\text { Geobacter } \\
\text { sulfurreducens }\end{array}$ & $14-36$ & Hydrogen gas, acetate & nd & $\begin{array}{l}\text { (Yates, Cusick et al. } \\
\text { 2013) }\end{array}$ \\
\hline & $\begin{array}{l}\text { Shewanella } \\
\text { oneidensis }\end{array}$ & $45-55$ & Hydrogen gas, formate & $\begin{array}{l}\text { Reductive degradation of } \\
\text { perchlorate }\end{array}$ & $\begin{array}{l}\text { (De Windt, Boon et al. } \\
\text { 2006) }\end{array}$ \\
\hline & & $10-20$ & Formate & nd & $\begin{array}{l}\text { ( } \mathrm{Ng}, \text { Cai Tan et al. } \\
\text { 2013) }\end{array}$ \\
\hline & $\begin{array}{l}\text { Desulfovibrio } \\
\text { desulfuricans }\end{array}$ & $45-55$ & Hydrogen gas, formate & $\begin{array}{l}\text { Hydrogen generation from } \\
\text { hypophosphite }\end{array}$ & $\begin{array}{l}\text { (Yong, Rowson et al. } \\
\text { 2002) }\end{array}$ \\
\hline & $\begin{array}{l}\text { Clostridium } \\
\text { pasteurianum }\end{array}$ & $8-16$ & Biogenic hydrogen gas & Immobilisation of chromate & $\begin{array}{l}\text { (Chidambaram, } \\
\text { Hennebel et al. 2010) }\end{array}$ \\
\hline & $\begin{array}{l}\text { Pseudomonas } \\
\text { aeruginosa }\end{array}$ & $16-28$ & nd & nd & $\begin{array}{l}\text { (Srivastava and } \\
\text { Constanti 2012) }\end{array}$ \\
\hline
\end{tabular}




\begin{tabular}{|c|c|c|c|c|}
\hline $\begin{array}{l}\text { Rhodobacter } \\
\text { sphaeroides }\end{array}$ & $3-10$ & Hydrogen gas, formate & $\begin{array}{l}\text { Dechlorination of } \\
\text { chlorinated aromatic } \\
\text { compounds }\end{array}$ & $\begin{array}{l}\text { (Redwood, Deplanche } \\
\text { et al. 2008) }\end{array}$ \\
\hline $\begin{array}{l}\text { Clostridium } \\
\text { butyricum }\end{array}$ & $10-50$ & \multirow[t]{6}{*}{ Biogenic hydrogen gas } & \multirow[t]{6}{*}{$\begin{array}{l}\text { Dehalogenation of } \\
\text { diatrizoate }\end{array}$} & \multirow[t]{6}{*}{$\begin{array}{l}\text { (Hennebel, Van Nevel } \\
\text { et al. 2011) }\end{array}$} \\
\hline Citrobacter braakii & $10-30$ & & & \\
\hline $\begin{array}{l}\text { Klebsiella } \\
\text { pneumoniae }\end{array}$ & nd & & & \\
\hline $\begin{array}{l}\text { Enterococcus } \\
\text { faecium }\end{array}$ & nd & & & \\
\hline Escherichia coli & nd & & & \\
\hline $\begin{array}{l}\text { Bacteroides } \\
\text { vulgatus }\end{array}$ & nd & & & \\
\hline
\end{tabular}




\begin{tabular}{|l|l|l|l|l|}
\hline Cupriavidus necator & $10-30$ & Hydrogen gas & Catalysis for Suzuki- & (Gauthier, Søbjerg et \\
\cline { 1 - 3 } & $50-150$ & & Miyaura and Mizoroki-Heck & al. 2010) \\
metallidurans & & & \\
\hline
\end{tabular}


Various bacteria, mostly dissimilatory metal reducing bacteria, have been employed to produce metal(loid) nanomaterials (Lovley 1991). Among them, metal-reducing bacteria from Shewanella and Geobacter genera are of great interest because they have a relatively well-characterized electron transport chain that can transport electrons across cell membranes and is capable of reducing metal(loid)s at the cell exterior, giving a relatively narrow size distribution and minimizing post-production extraction and purification (Shi, Richardson et al. 2009, Sintubin, Verstraete et al. 2012). Strict anaerobic conditions are often required for Geobacter species, while Shewanella can grow well in both aerobic and anaerobic conditions, rendering Shewanella an important bacterium in bio-nanotechnology. S. oneidensis is one oftenused metal-reducing bacterium in biosynthesis of metal(loid) nanomaterials.

Although a wide range of bacteria have been used for the synthesis of metal(loid) nanomaterials, the molecular mechanisms underlying the biosynthesis processes are largely unknown. Based on previous literature, the conclusions we can draw include: (1) both cell-mediated and biologically influenced redox reactions are often involved; (2) dominating mechanisms vary in different bacteria; and (3) primary molecular sites responsible for the biosynthesis in a certain bacterium can be very different for different metal(loid)s.

In the biosynthesis of nanomaterials by bacteria, both cell-mediated and biologically influenced reactions have been reported. In organisms such as $E$. coli and $P$. aeruginosa, the conversion of soluble metal(loid)s to their insoluble nanosized structures is a general detoxicification mechanism where surface proteins, polysaccharides, and periplasmic proteins are often involved and there are no specific biomolecular sites responsible for the biosynthesis of metal(loid) nanomaterials. 
In S. oneidensis, c-type cytochromes, a class of redox proteins, have been shown to play a central role in metal reduction (Fredrickson, Romine et al. 2008). The outer membrane of $S$. oneidensis contains c-type cytochromes including two bestcharacterized outer membrane c-type cytochromes (OMCs) MtrC and OmcA (Shi, Chen et al. 2006). Figure 2.1 shows the illustration of the metal-reducing (MTR) pathway in S. oneidensis. Extensive studies have suggested the important role of OMCs in efficient reduction of various metal(loid)s including $\mathrm{Fe}(\mathrm{III}), \mathrm{Cr}(\mathrm{VI}), \mathrm{Tc}(\mathrm{VII})$, and U(VI) (Marshall, Beliaev et al. 2006, Marshall, Plymale et al. 2008, Belchik, Kennedy et al. 2011). 


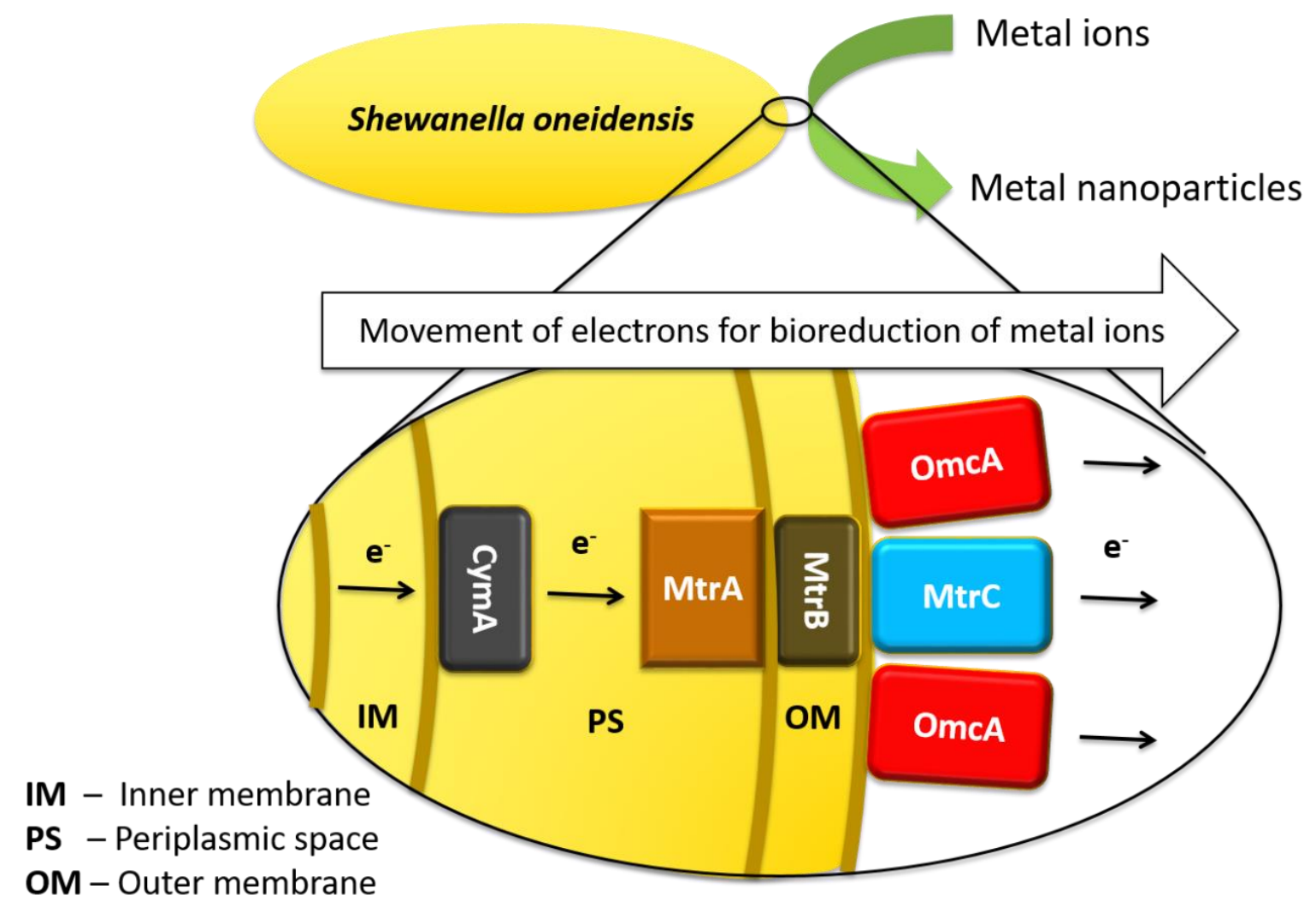

Figure 2.1. Illustration of the metal-reducing (MTR) pathway in S. oneidensis. The MTR pathway consists of a number of electron carrier proteins including CymA, MtrA, MtrC, and OmcA. The electrons obtained from bacterial metabolism are transferred across the periplasmic space to the outer membrane, where $\mathrm{MtrC}$ and OmcA can use the electrons to reduce metal(loid)s. Reproduced from (Ng et al 2015) with permission from "John Wiley and Sons"

In addition to c-type cytochromes, hydrogenases comprise another class of redox proteins that play a central role in microbial reduction of metals in S. oneidensis. Figure 2.2 shows the model of $S$. oneidensis MR-1 [NiFe]-hydrogenase in $\mathrm{Tc}(\mathrm{VII})$ reduction. 


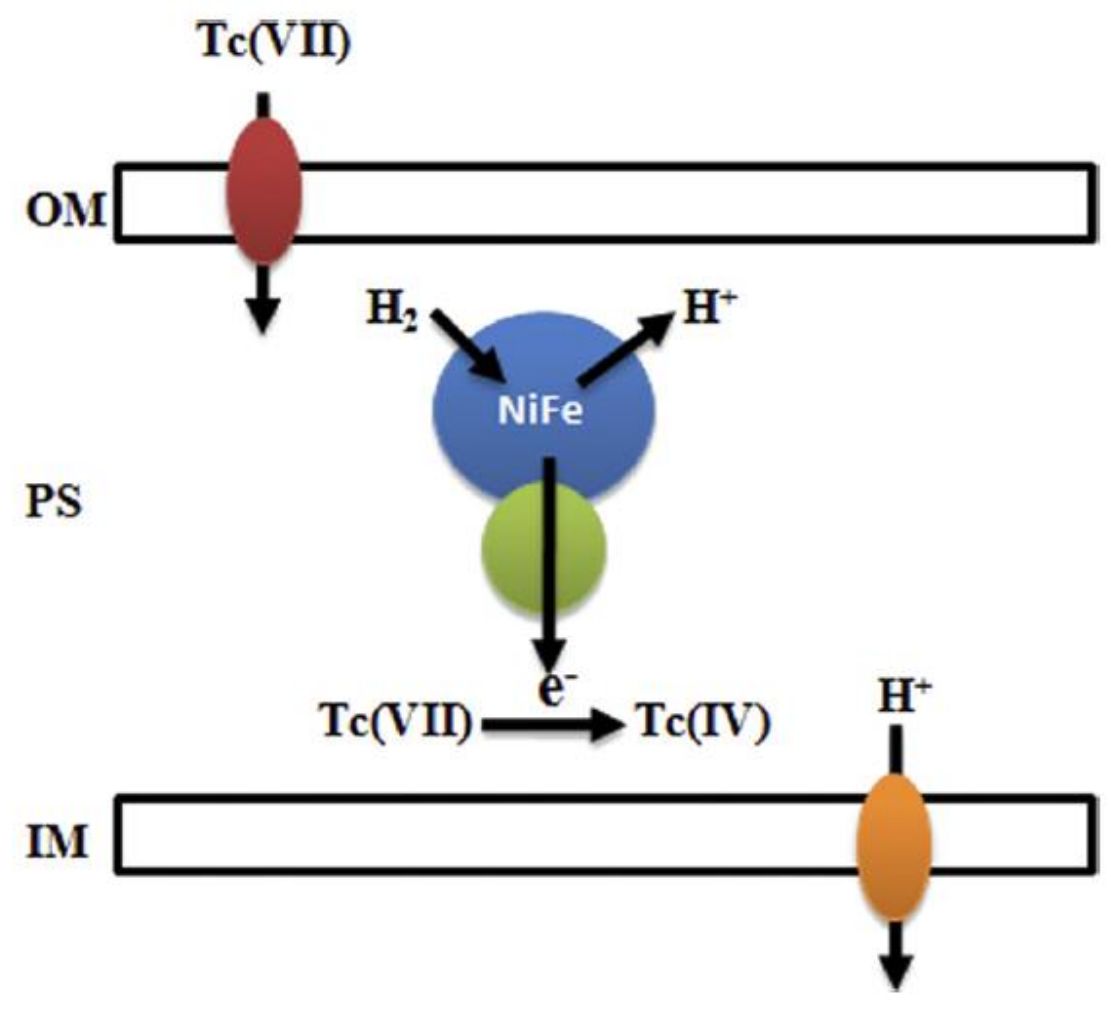

Figure 2.2. Model of $S$. oneidensis $\mathrm{MR}-1$ [NiFe]-hydrogenase-mediated $\mathrm{Tc}(\mathrm{VII}) \mathrm{O}_{4}{ }^{-}$reduction. [NiFe]-hydrogenase, situated in the periplasm, catalyse the reduction of $\mathrm{Tc}(\mathrm{VII})$ by coupling the oxidation of $\mathrm{H}_{2}$ into $\mathrm{H}^{+}$. Reproduced from (Shi, Belchik et al. 2011) with permission from "American Society for Microbiology".

The genome of $S$. oneidensis MR-1 encodes both a [FeFe]-hydrogenase HydAB and a [NiFe]-hydrogenase HyaAB. HydA functions as a hydrogen-forming hydrogenase, while HyaB can function either in formation or oxidation of hydrogen as a bidirectional hydrogenase. Previous studies have shown that the [NiFe]-hydrogenase of MR-1 was involved in $\mathrm{H}_{2}$-driven reduction of $\mathrm{Tc}(\mathrm{VII})$ to $\mathrm{TC}(\mathrm{IV}) / \mathrm{Tc}(\mathrm{V})$ (Marshall, Plymale et al. 2008, Shi, Belchik et al. 2011). However, the contribution of OMCs and hydrogenases to bioreduction of silver and palladium in S. oneidensis has not been well elucidated.

The gap in the detailed understanding of bioreduction mechanism, along with other limitations, hampers the widespread use of bacteria for the synthesis of nanomaterials. 
Currently, most of the biogenic nanomaterials were prepared by planktonic cell cultures. While the planktonic cells-based approach for the synthesis of nanomaterials works well in the laboratory-scale studies (De Corte, Hennebel et al. 2012), this method is only applicable to batch or fed-batch processes and not suitable for highly efficient continuous processes commonly deployed in industrial settings which uses less down-time for maintenance (Gross, Hauer et al. 2007). Moreover, it is energy intensive and time consuming to harvest the metal nanomaterials that are attached onto planktonic cells. Another limitation of planktonic cells is their low tolerance to metal and metalloid ions, which affects the integrity of the cell walls and viability of the planktonic cells, and prevents the use of higher metal ion concentration for faster rate of nanomaterial synthesis.

As such, there is a need to explore a new system for biosynthesis of nanomaterials, where cells can be immobilised for easy recovery of the produced metal nanomaterials and where cells have higher tolerance to toxic metal ions for faster rate of metal nanomaterial synthesis. Cells in biofilm mode seem to be a promising approach to synthesise nanomaterials as biofilm cells are able to retain the functionality of planktonic cells while compensating their limitations.

\subsection{Biofilm and biofilm-based processes}

\subsubsection{Biofilm matrix}

Biofilm mode of life is ubiquitous in most natural and man-made environments. Bacteria switch between the planktonic and biofilm mode of life depending on the environmental stresses such as salinity, availability of nutrient and predation etc. Unlike in planktonic mode where individual cells suspend freely in the liquid medium, a biofilm consist of bacteria communities encased and immobilised by self-produced 
extracellular polymeric substances (EPS) matrix and are found between interfaces, namely solid-liquid interfaces (e.g. river-bed biofilms), solid-air interfaces (e.g. bacteria colonies on agar plate) and liquid-air interfaces (e.g. pellicles) respectively (Branda, Vik et al. 2005). There are also other types of microbial communities such as floc, granule and sludge which are not attached to an interface but shared many characteristics of biofilms.

With increasing knowledge on biofilm, it became apparent that besides their diverse physical appearances, biofilms which constitute various compositions of bacteria species can exhibit strikingly different chemical and biological processes. These biofilm processes include, but not limited to, photosynthesis, denitrification, methanogenesis, bioluminescence, nitrogen fixation, fermentation and metal reduction, all of which are important to biogeochemical cycling and other processes in nature.

One of the most important features of a biofilm is the presence of extracellular polymeric substances (EPS) which form a three dimensional matrix and encase the bacteria within the biofilm. Extensive studies have demonstrated a wide range of advantages of EPS matrix for the biofilm mode of life (Flemming and Wingender 2010, Flemming 2011). The EPS matrix allows bacteria to form structurally stable biofilm communities and show a remarkable tolerance against various toxic compounds and antibacterial agents. Other beneficial characteristics of biofilm include resistance against desiccation, attachment to favourable environment and the obstruction of grazing by predators etc.

The components of EPS in biofilms are very complex and differ from species to species, but generally consist of biomolecules such as carbohydrate, proteins, lipids 
and extracellular DNA (eDNA) (Flemming and Wingender 2010, Flemming 2011).

Figure 2.3 illustrates the schematic diagram of biofilm and biofilm matrix with EPS components.
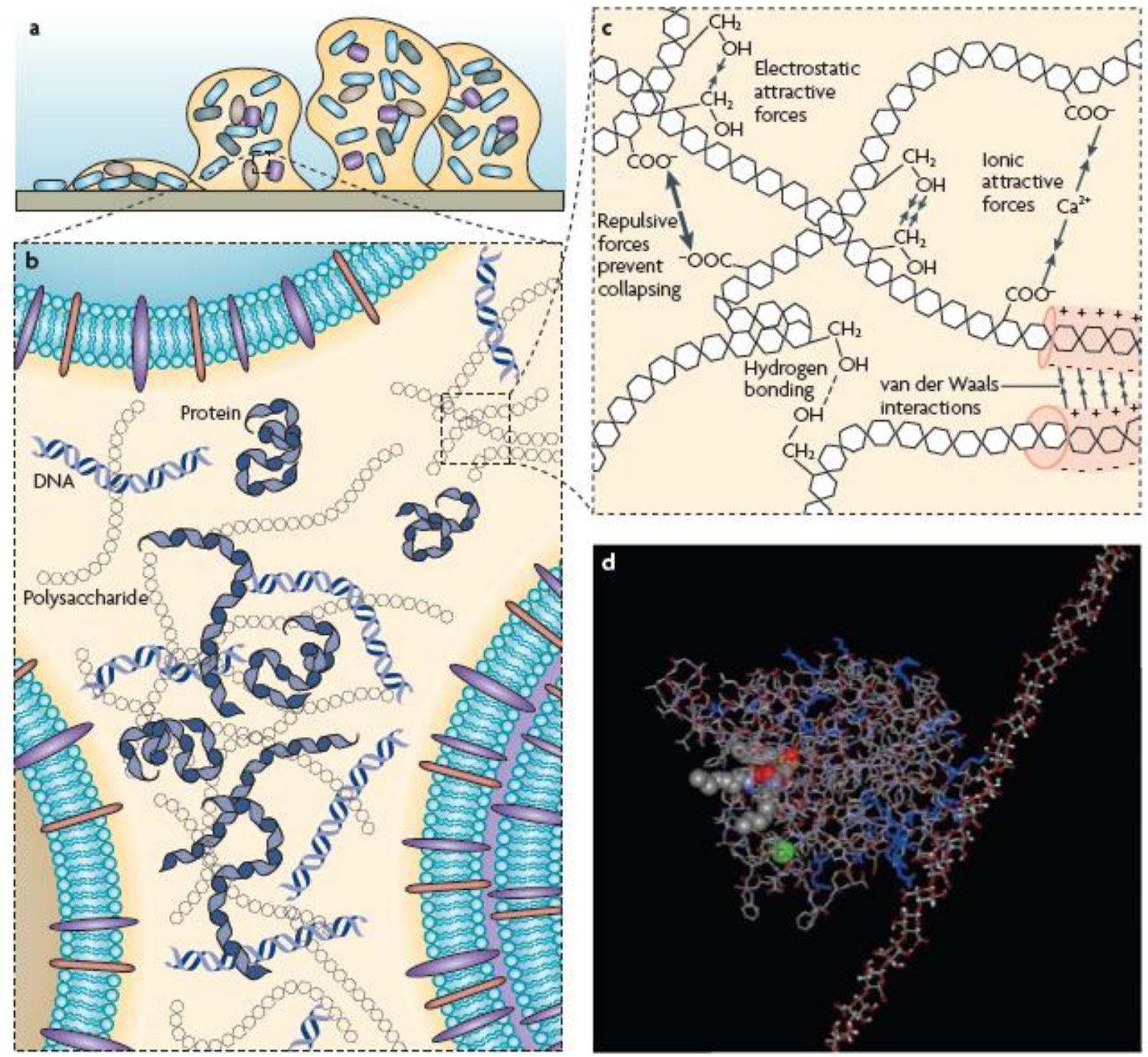

Figure 2.3. The EPS matrix at different dimensions. a) Model of a surface-attached biofilm.

b) Major components in the EPS matrix, such as polysaccharides, proteins and extracellular

DNA. c) Possible interaction that contribute to the overall structure integrity of the EPS

matrix. d) Molecular modelling simulation of the interaction between alginate (right) and lipase (left) of Pseudomonas aeruginosa in aqueous solution. Reproduced from (Flemming and Wingender 2010) with permission from "Nature Publishing Group" 
The complexity of EPS and their spatial and temporal heterogeneity within biofilms poses great difficulty in isolating and analysing them. Several EPS extraction techniques have been reported (Jahn and Nielsen 1995, Wuertz, Spaeth et al. 2001, Liu and Fang 2002, Comte, Guibaud et al. 2006, Adav and Lee 2008), and these shed light on the identity of some EPS components. As of now, several biomolecules which influence biofilm development have been identified. Many strains of Pseudomonas spp. have the capacity to excrete at least three types of extracellular polysaccharides, namely alginate, Pel and Psl, and these are important to the structural stability of the biofilms formed (Kolter and Greenberg 2006, Ryder, Byrd et al. 2007). Poly- $\beta-1,6$ GlcNAc (PGA) and curli are found to affect the development of biofilm by promoting abiotic surface binding, intercellular adhesion and mediate cohesion in EPS matrix of Escherichia coli biofilm (Prigent-Combaret, Prensier et al. 2000, Wang, Preston et al. 2004, Ryu and Beuchat 2005). In Bacillus subtilis biofilms, amyloid fibers were shown to support the structure of the biofilm by promoting cell-cell binding and surface adhesion (Romero, Aguilar et al. 2010). In many species of bacteria such as Rhodobacter sphaeroides and Vibrio cholerae, flagella play an important role not only in motility, but contribute to biofilm stability as well (Pratt and Kolter 1998, Prigent Combaret, Prensier et al. 2000, Watnick, Lauriano et al. 2001, Branda, Vik et al. 2005, Wilkinson, Chacko et al. 2011). In Shewanella spp., a 285 kDa multi-domain protein BpfA has been associated with the function of promoting biofilm formation (Theunissen, De Smet et al. 2010, Cao, Shi et al. 2011).

\subsubsection{Biofilm Formation and Development}

Biofilm development can be described in various stages where cells switch from the free-swimming planktonic mode to the sessile biofilm mode. Figure 2.4 illustrates the 
various stages of biofilm development. The first stage of biofilm development starts with the initial attachment of planktonic cells onto a substratum, usually in an environment that is favourable for cell growth (Halan, Buehler et al. 2012). The attached cells then produce EPS which holds the cells firmly to the substratum. Besides EPS, outer cell membrane appendages such as flagellum and pili form structural anchorage and contribute to cell attachment onto substratum (Flemming and Wingender 2010, Flemming 2011). Intermolecular forces such as hydrophobic interactions, hydrogen bondings, electrostatic interactions and Van der Waals forces within EPS help to promote cell adhesion onto substratum.

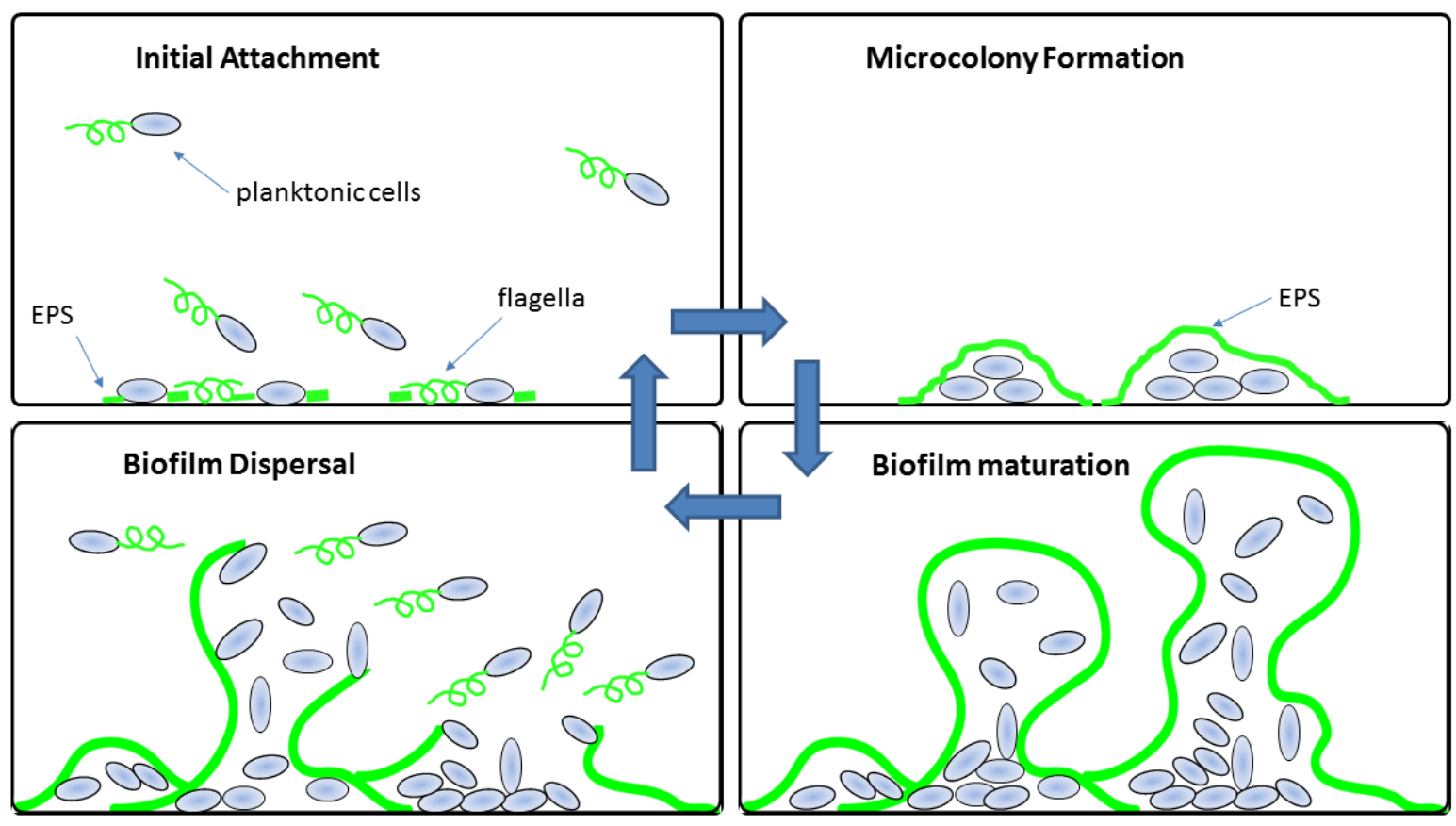

Figure 2.4. Main stages of biofilm development cycle - initial attachment, microcolony formation, biofilm maturation, and biofilm dispersal.

The second stage of biofilm development begins with cell multiplication and increase secretion of EPS to form microcolonies on the substratum. The EPS serves as a scaffold and provide structural support and stability to the microcolonies. Moreover, 
the EPS matrix functions as external barrier and provides resistance against toxic substances, antibacterial agents and predation from grazers (Flemming 2011).

In the third stage of biofilm development, the microcolonies grow in size and form 'mushroom-shaped' towering structures with high surface to volume ratio to better facilitate mass transfer of substrates and waste products into and out of the biofilm matrix (Bishop, Zhang et al. 1995, O'Toole and Kolter 1998). Microenvironments exist heterogeneously in the mature biofilm due to diffusion limitation. For example, oxygen level is high near the surface of the biofilm, but drastically declines in regions deep within the biofilm that houses respiring cells (Zhang, $\mathrm{Ng}$ et al. 2014). The EPS can also serve as food source for the cells during periods of low nutrient level, and prevents desiccation due to its water retention capability (Flemming and Wingender 2010, Flemming 2011).

In the fourth stage of biofilm development, mature biofilm starts to disperse with environmental cues such as low nutrient level, oxygen depletion, low level of nitric oxide and changes in temperature and availability of iron (McDougald, Rice et al. 2012). At this stage, cells regain motility and escape from the EPS matrix in search for another conducive environment for growth and colonisation, and thus, the biofilm development cycle repeats over and over again (Landini, Antoniani et al. 2010).

Biofilm development is a complicated process and it requires delicate regulation systems to coordinate at each developmental stage. It is essential for regulatory systems such as intracellular signalling (e.g. cyclic-di-GMP) and intercellular signalling (e.g. quorum sensing) to work in tandem for successful execution of and smooth transition between various stages of biofilm development (Landini, Antoniani et al. 2010). 


\subsubsection{Biofilm Regulation and Signalling}

Bacterial cells were long thought to be 'individualistic', where the decision-making processes are solely influenced by the organism itself. However, in 1979, Nealson and Hastings observed bioluminescence in Vibrio fischeri, and that such phenomenon occurred only when there is high cell density. This is currently considered the model system for quorum sensing in most gram-negative bacterium. Quorum sensing is an intercellular signalling process where bacteria detect and alter behaviour based on the extracellular concentration of secreted signal molecules. The concentration of the signal molecules, also known as autoinducers, is typically proportional to the cell density and a minimum level or threshold autoinducer concentration must be reached before a specific behaviour, caused by autoinducer-dependent gene expression, can take place.

Quorum sensing has been associated to many microbial processes, including but not limited to bioluminescence, biofilm development, virulence, and siderophore production. Techniques which alters autoinducers to influence biofilm formation have been relatively well explored, but are mainly focused on inhibiting biofilm maturation and generally limited to applications in pharmaceuticals and anti-biofouling (Prouty, Schwesinger et al. 2002, Hammer and Bassler 2003, Hentzer and Givskov 2003, Salta, Wharton et al. 2010). Such techniques can be broadly classified in two categories: autoinducer degradation and autoinducer receptor inhibition. Recent application in anti-biofouling based on autoinducer degradation describes the use of an enzymeimmobilised nanofiltration membrane to mitigate biofouling based on quorum quenching, where the immobilised enzyme, acyclase, previously established to degrade autoinducer acyl-homoserine lactone ( $\mathrm{AHL}$ ) effectively, suppresses the 
production of EPS, and hence prevents biofilm maturation (Kim, Choi et al. 2011). On the other hand, for application in pharmaceuticals via autoinducer receptor inhibition, a recent study examined the effectiveness of various synthetic quorum sensing inhibitors and found that meta-bromo-thiolactone not only prevents virulence factor expression and biofilm formation but also protects Caenorhabditis elegans and human A549 lung epithelial cells from quorum-sensing-mediated killing by Pseudomonas aeruginosa (O’Loughlin, Miller et al. 2013).

Besides intercellular signalling, intracellular signalling is also an important component in biofilm formation and development. Bis-(3'-5')-cyclic dimeric guanosine monophosphate (c-di-GMP), an important intracellular signalling molecule, acts as a global regulator which influences the switching between the planktonic and biofilm mode in bacteria cells. Figure 2.5 shows the structure and physiological function of cdi-GMP. C-di-GMP is synthesized by diguanylate cyclases (DGCs) and is broken down by phosphodiesterases (PDEs). DGC activity is influenced by GGDEF domain, while PDE activity is influenced by EAL domains. C-di-GMP is known to stimulate the synthesis of adhesins and other EPS matrix components, while inhibiting various forms of motility (Jenal and Malone 2006, Wolfe and Visick 2008, Hengge 2009). There are numerous studies on the manipulation of c-di-GMP to influence biofilm development, and this is done mainly through the genetic manipulation by inserting genes coding either the GGDEF or EAL domain to increase or decrease the level of c-di-GMP respectively (Simm, Morr et al. 2004, Gjermansen, Ragas et al. 2006, Kuchma, Brothers et al. 2007, Rakshe, Leff et al. 2011). 


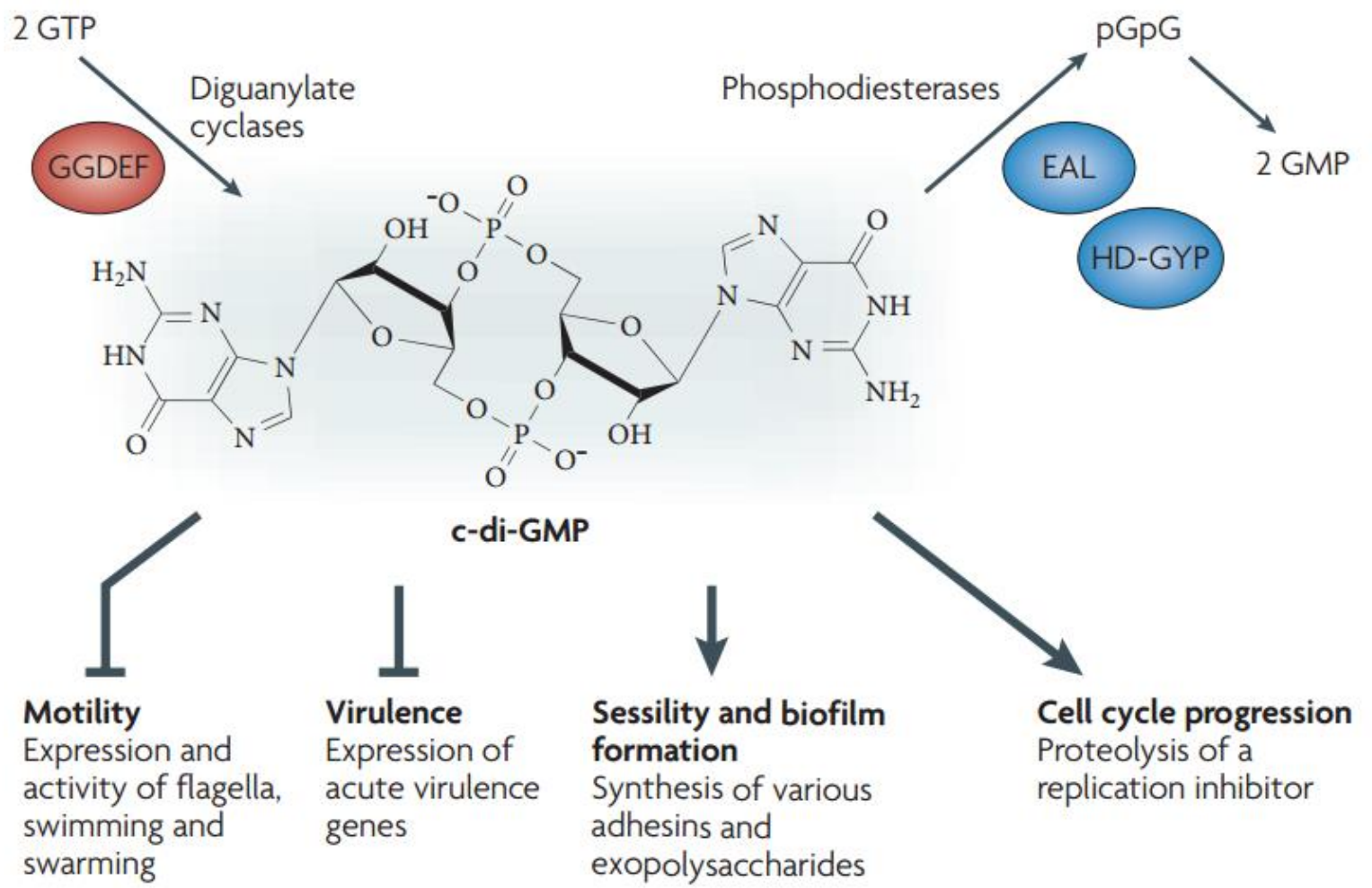

Figure 2.5. Structure and physiological function of c-di-GMP. Reproduced from (Hengge 2009) with permission from "Nature Reviews Microbiology".

The influence of c-di-GMP on S. oneidensis MR-1 biofilm is of particular interest as MR-1 is a metabolically versatile organism with great relevance in environmental remediation and bionanotechnology. Moreover, computational analysis predicts that the S. oneidensis MR-1 genome contains 51 diguanylate cyclases, 27 phosphodiesterases, and 20 hybrid diguanylate cyclase or phosphodiesterase proteins, which places $S$. oneidensis MR-1 into a group of sequenced microorganisms with the highest normalised number of c-di-GMP signalling proteins (Fredrickson, Romine et al. 2008).

\subsubsection{Biofilm Heterogeneity and Chemical Gradients}

The structure of biofilms is very much influenced by physical stress in the environment. Biofilms tend to be more compact and thinner under high hydrodynamic shear (Liu 
and Tay 2002). Moreover, various unique structural forms of biofilms, such as streamers, can be observed under different hydrodynamic conditions (Stoodley, Lewandowski et al. 1998). The structure of biofilms is said to be uneven, where the thickness, porosity and roughness differs at various sections of the biofilm matrix (Wimpenny, Manz et al. 2000). It is indeed this unevenness, or spatial heterogeneity, that allows various micro-environments to exist within biofilms which lies in seemingly homogeneous macro-environments.

There are many contributing factors to the spatial heterogeneity of biofilms, but it is unanimously agreed upon that chemical gradient, also known as diffusion gradient, plays a major role in orchestrating the formation of micro-environments within biofilms (Stewart and Franklin 2008). There are many reports on the chemical gradients within biofilm, and are mostly focused on metabolic substrates, intermediates and products. It is well documented that oxygen, a metabolic substrate, exhibits gradient of concentrations within biofilms. Table 2.2. shows the types of dissolved oxygen (DO) sensors used in biofilm studies, their advantages and disadvantages.

The oxygen gradient is resulted mainly from oxygen intake by actively respiring cells, where rate of oxygen consumption by respiration outstrip the rate of oxygen diffusion within the EPS matrix. This phenomenon produces micro-anoxic environments within biofilms which can accommodate strict anaerobes even under bulk aerobic conditions (Zhang, $\mathrm{Ng}$ et al. 2014). Similarly, the heterogenic distribution of metabolic products throughout biofilms also influences individual cell functions and cell-cell interactions, which may result in differentiated biological processes occurring at various depths and microenvironment within the biofilms. 
Table 2.2. Dissolved oxygen (DO) sensors used in biofilm studies.

\begin{tabular}{|c|c|c|c|}
\hline Type of sensor & Advantages & Disadvantages & Reference \\
\hline $\begin{array}{l}\text { Micro- } \\
\text { electrode }\end{array}$ & $\begin{array}{l}\text { Able to perform Spatial and temporal } \\
\text { measurements in 3D. }\end{array}$ & Invasive and destructive. & $\begin{array}{l}\text { (Nguyen, Cao et } \\
\text { al. 2012) }\end{array}$ \\
\hline Micro-optode & $\begin{array}{l}\text { Able to provide } 2 \mathrm{D} \text { maps of } \mathrm{DO} \text { concentrations } \\
\text { in contact with the micro-optode. }\end{array}$ & $\begin{array}{l}\text { Unable to sense DO within biofilms } \\
\text { that is not in contact with micro-optode. }\end{array}$ & $\begin{array}{l}\text { (Holst, Glud et al. } \\
\text { 1997) }\end{array}$ \\
\hline $\begin{array}{l}\text { Fluorescent } \\
\text { redox probe }\end{array}$ & $\begin{array}{l}\text { Able to perform high resolution spatial } \\
\text { measurements in 3D. }\end{array}$ & $\begin{array}{l}\text { Not suitable for temporal } \\
\text { measurements. Low sensitivity. }\end{array}$ & $\begin{array}{l}\text { (Rodriguez, Phipps } \\
\text { et al. 1992) }\end{array}$ \\
\hline $\begin{array}{l}\text { Microfluidic } \\
\text { chip }\end{array}$ & $\begin{array}{l}\text { Able to provide } 2 \mathrm{D} \text { maps of } \mathrm{DO} \text { concentrations } \\
\text { in contact with the chip. }\end{array}$ & $\begin{array}{l}\text { Unable to sense DO within biofilms } \\
\text { that is not in contact with the chip. }\end{array}$ & $\begin{array}{l}\text { (Skolimowski, } \\
\text { Nielsen et al. } \\
\text { 2010) }\end{array}$ \\
\hline
\end{tabular}




\subsubsection{Redox Activities of EPS}

Reduction and oxidation (redox) activities play an important role in extracellular processes for both planktonic or biofilm mode. One such process is extracellular electron transport (EET) by dissimilatory metal-reducing bacteria (DMRB), where electrons can be transported out of the cell to extracellular electron acceptors during respiration. Extracellular electron transport is facilitated by redox shuttles, such as flavins (Marsili, Baron et al. 2008, Von Canstein, Ogawa et al. 2008), phenazines (Hernandez, Kappler et al. 2004, Rabaey, Boon et al. 2005), humic acids (Lovley 1991, Lovley, Coates et al. 1996, Milliken and May 2007), and by EET chains such as MTR respiratory pathway (Shi, Squier et al. 2007, Fredrickson, Romine et al. 2008, Shi, Richardson et al. 2009, Richardson, Butt et al. 2012).

EPS may play a role to immobilise these electron shuttles close to the cells within the matrix, so as to extend the redox capability of the cells. Using 5-cyano-2,3-di-4-tolyltetrazolium chloride (CTC) as fluorescent redox sensor, it was found that EPS extracted from sludge samples exhibits redox activities, where such activities are postulated to facilitate transformation of organics matters for cellular metabolic uses (Wuertz, Pfleiderer et al. 1998). In another study, it was shown that EPS extracted from biofilm of environmental isolate Shewanella spp. contain at least 20 redox active proteins, where it is suggested that the EPS matrix forms a network of redox active proteins to facilitate extracellular electron transport between the cells and extracellular compounds within the matrix (Cao, Shi et al. 2011). Table 2.3 shows the recent studies on redox activity of biofilm. 
Table 2.3. Recent studies on redox activity of biofilm.

\begin{tabular}{|c|c|c|c|}
\hline Organism(s) & Reactor & Key findings & Reference \\
\hline $\begin{array}{l}\text { Pseudomonas } \\
\text { aeruginosa, } \\
\text { Aspergillus } \\
\text { fumigatus }\end{array}$ & Agar plates & $\begin{array}{l}\text { In coculture biofilms, Pseudomonas aeruginosa phenazine-derived } \\
\text { metabolites can influence the development of fungal Aspergillus } \\
\text { fumigatus by inducing asexual sporulation from initial weak vegetative } \\
\text { growth. }\end{array}$ & $\begin{array}{l}\text { (Zheng, Kim et } \\
\text { al. 2015) }\end{array}$ \\
\hline $\begin{array}{l}\text { Geobacter } \\
\text { sulfurreducens }\end{array}$ & $\begin{array}{l}\text { Interdigitated } \\
\text { microelectrode } \\
\text { array }\end{array}$ & $\begin{array}{l}\text { Redox gradient exists within Geobacter sulfurreducens biofilm, in which } \\
\text { the concentration of electrons residing within the proposed redox } \\
\text { cofactor network increases with increasing distance from the anode } \\
\text { surface. }\end{array}$ & $\begin{array}{l}\text { (Okamoto, } \\
\text { Hashimoto et } \\
\text { al. 2012) }\end{array}$ \\
\hline $\begin{array}{l}\text { Pseudomonas } \\
\text { aeruginosa }\end{array}$ & $\begin{array}{l}\text { Working electrode } \\
\text { array }\end{array}$ & $\begin{array}{l}\text { Integrated circuit-based electrochemical sensing platform, featuring an } \\
\text { array of working electrodes and parallel potentiostat channels, can be } \\
\text { used for the spatially resolved detection of phenazine produced by } \\
\text { biofilm, and allows in-situ study of redox activities within biofilms. }\end{array}$ & $\begin{array}{l}\text { (Bellin, Sakhtah } \\
\text { et al. 2014) }\end{array}$ \\
\hline
\end{tabular}




$\begin{array}{ll}\text { Shewanella 96-well plates } & \text { Redox sensitive fluorescence protein roGFP can be displayed onto cell (Sivakumar, } \\ \text { oneidensis } & \text { surface of } S \text {. oneidensis by fusing it to the C-terminus of BpfA, a large } \\ & \text { surface protein. The surface displayed roGFP can be used as a sensor al. 2014) } \\ & \text { to quantify the extracellular redox status in the matrix of } S \text {. oneidensis } \\ & \text { biofilms, which is a novel approach to non-destructive monitoring of } \\ & \text { extracellular redox status in microenvironments within biofilms. }\end{array}$

$\begin{array}{lll}\text { Pseudomonas } & \text { Bioelectrochemical } & \text { Different strains of Pseudomonas aeruginosa exhibit different } \\ \text { aeruginosa } & \text { cell } & \text { phenazine-dependent electroactivity, depending on the substrates } \\ & \text { used. Pseudomonas sp. KRP1, isolated from a microbial fuel cell } \\ & \text { enrichment, produced high electroactivity, while PA01 showed very low } \\ & \text { phenazine production and electrochemical activity. The difference may } \\ & \text { reflect their adaptability in different environments. }\end{array}$

(Bosire, Blank

et al. 2016) 
Besides electron shuttles, recent studies have attributed the contribution of bacterial nanowires for long-distance extracellular electron transfer for Shewanella and Geobacter that may facilitate energy distribution within biofilms (Gorby, Yanina et al. 2006, Reguera, Nevin et al. 2006). Bacterial nanowires are extracellular appendages that exhibit electrical conductivity. In S. oneidensis, it was found that mutant lacking outer membrane c-type cytochrome MtrC and OmcA do not produce nanowires that are conductive (El-Naggar, Wanger et al. 2010). Moreover, it was demonstrated that S. oneidensis MR-1 nanowires are cell membrane extensions of the extracellular electron transport components, such as MtrC and OmcA (Pirbadian, Barchinger et al. 2014). On the other hand, the nanowires of $G$. sulfurreducens are unilateral pili which are conductive regardless of the presence or absence of outer membrane c-type cytochrome (Reguera, Nevin et al. 2006).

The mechanism of electrical conductivity of bacterial nanowires is hotly debated, and two main models of nanowire's electron conductivity were established - multistep electron hopping and metal-like electron conduction. Evidences of multistep hopping of electrons are based on $S$. oneidensis studies, where outer membrane cytochromes MtrC and OmcA are found on the surface of nanowires and are directly responsible for the extracellular electron transfer along the nanowire (Pirbadian, Barchinger et al. 2014). In G. sulfurreducens, nanowires are comprised of pili that have metal-like electron conductivity attributed to overlapping pi-pi orbitals of aromatic amino acids (Malvankar and Lovley 2014).

The discovery of electron shuttles in EPS and bacterial nanowire furthers our knowledge on extracellular redox activity of bacteria and provides insights to possible electron 
transfer mechanisms within the biofilm matrix. Further investigation is required to understand the mechanistic details of redox activity and electron conductivity within biofilm in order to fine tune and optimise the use of biofilms for industrial catalytic processes or environmental remediation purposes.

\subsection{Immobilisation of nanoparticles in biofilm matrix}

The synthesis of biogenic metal nanomaterials using planktonic bacteria is rather well studied (Liu, Gorby et al. 2002, Hennebel, De Gusseme et al. 2009, Lloyd, Byrne et al. 2011, Durán and Seabra 2012, Sintubin, Verstraete et al. 2012). On the other hand, there are not much research on the use of biofilm to synthesize metal nanomaterials, even though it is potentially a more effective and efficient option as compared to the use of planktonic cells, as discussed in previous chapters. This is not surprising as the bulk of the biofilm research revolves around eradicating and controlling the growth of biofilm for medical and antifouling applications (Singh, Schaefer et al. 2000, Simões, Simões et al. 2010, Arciola, Campoccia et al. 2012, Burmølle, Ren et al. 2014). To be fair, there is a substantial amount of research on understanding and optimising the removal of nutrient from waste water by naturally occurring biofilm communities in the form of flocculants and granules (Dangcong, Bernet et al. 1999, Wuertz, Bishop et al. 2003, McSwain, Irvine et al. 2005), but not much studies were done to engineer the biofilms for other applications e.g. synthesis of metal nanomaterials. In this last section of the review, literature related to the use of biofilm to synthesize or immobilise nanomaterials will be discussed in detail.

In the first study, Serratia biofilm, grown on the polyurethane foam within in a continuous air-lift fermenter, was used to immobilise Pd nanoparticles reduced by hydrogen gas 
(Beauregard, Yong et al. 2010). The resultant biofilm-Pd was used as a catalyst to reduce soluble hexavalent chromium ion, $\mathrm{Cr}(\mathrm{VI})$, to insoluble trivalent chromium ion, $\mathrm{Cr}(\mathrm{III})$. Magnetic resonance imaging (MRI) technique was used to assess the $\mathrm{Cr}(\mathrm{VI})$ reduction as $\mathrm{MRI}$ is non-invasive and that $\mathrm{Cr}(\mathrm{III})$ is paramagnetic, which can be measured by magnetic resonance. Figure 2.6 shows the spatial and temporal magnetic resonance map of $\mathrm{Cr}(\mathrm{III})$ concentration from batch-mode reduction of $\mathrm{Cr}(\mathrm{VI})$ using biofilm-Pd catalyst.

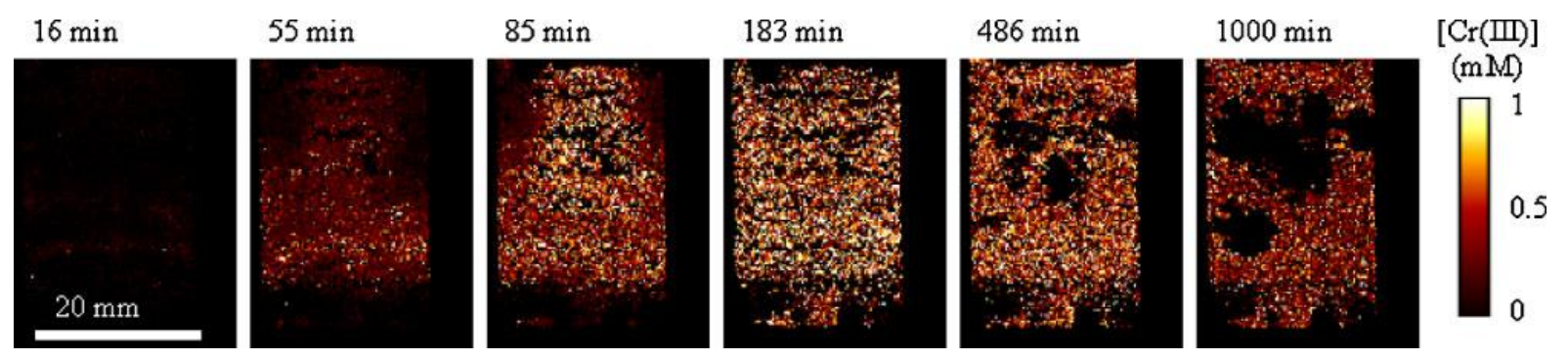

Figure 2.6. Spatial and temporal magnetic resonance map of $\mathrm{Cr}(\mathrm{III})$ concentration from batchmode reduction of $\mathrm{Cr}(\mathrm{VI})$ using biofilm-Pd catalyst. Concentration of $\mathrm{Cr}(\mathrm{III})$ decrease due to precipitation of solid $\mathrm{Cr}(\mathrm{OH})_{3}$ and building up of gas bubbles (black regions within the reactor). Reproduced from (Beauregard, Yong et al. 2010) with permission from "John Wiley and Sons".

However, it is important to note that the synthesis of $\mathrm{Pd}$ nanoparticles is not biofilmmediated. Hydrogen gas was used to reduce $\mathrm{Pd}(\mathrm{II})$ ions to $\mathrm{Pd}$ nanoparticles, while the biofilm act as a solid substrate or scaffold to immobilise the nanoparticles. The biofilm in this study is not directly involved in the Pd reduction process, where the $\mathrm{Pd}(\mathrm{II})$ ions were chemically reduced and not biologically reduced to form $\mathrm{Pd}$ nanoparticles. Many different types of scaffold, such as cellulose and amine-functionalised beads, can be used to immobilise metal nanoparticles that are synthesized by chemical reduction (De Corte, Bechstein et al. 2012, Baruah, Das et al. 2015). This study did not investigate the 
contribution of biofilm towards the reduction of $\mathrm{Pd}(\mathrm{II})$ and $\mathrm{Cr}(\mathrm{VI})$ beyond its role as a structural support. It did, however, showed that MRI is a great tool to measure and visualise spatial and temporal distribution of paramagnetic compounds within biological samples in a non-invasive manner.

In the second study, biofilms from anaerobic sludge are used to reduce silver ions, $\mathrm{Ag}(\mathrm{I})$, to silver (Ag) nanoparticles in $\mathrm{TiO}_{2}$ aqueous suspension (Khan, Ansari et al. 2013). The

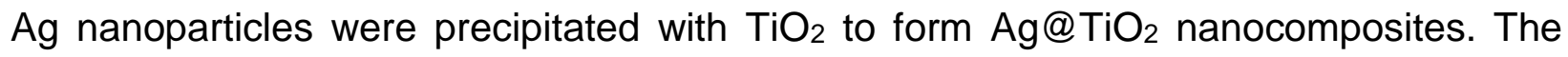
nanocomposites were used in photodecomposition of methylene blue (MB) in an aqueous solution under visible light irradiation, and the authors found that the nanocomposites showed much higher activity as compared to commercial $\mathrm{TiO}_{2}$ nanoparticles. For the reduction of $\mathrm{Ag}(\mathrm{II})$, the authors did controlled experiments and found that both the anaerobic sludge (biofilm) and sodium acetate, presumably a carbon source and electron donor, are required for the reaction to occur. This shows that the reduction of $\mathrm{Ag}(\mathrm{II})$ is a biofilm-mediated process, where the cells in biofilm used sodium acetate as electron donor and $A g(I)$ as electron acceptor to achieve anaerobic respiration. Figure 2.7 shows the proposed mechanism for the EAB-mediated synthesis of Ag@TiO2 nanocomposites. 


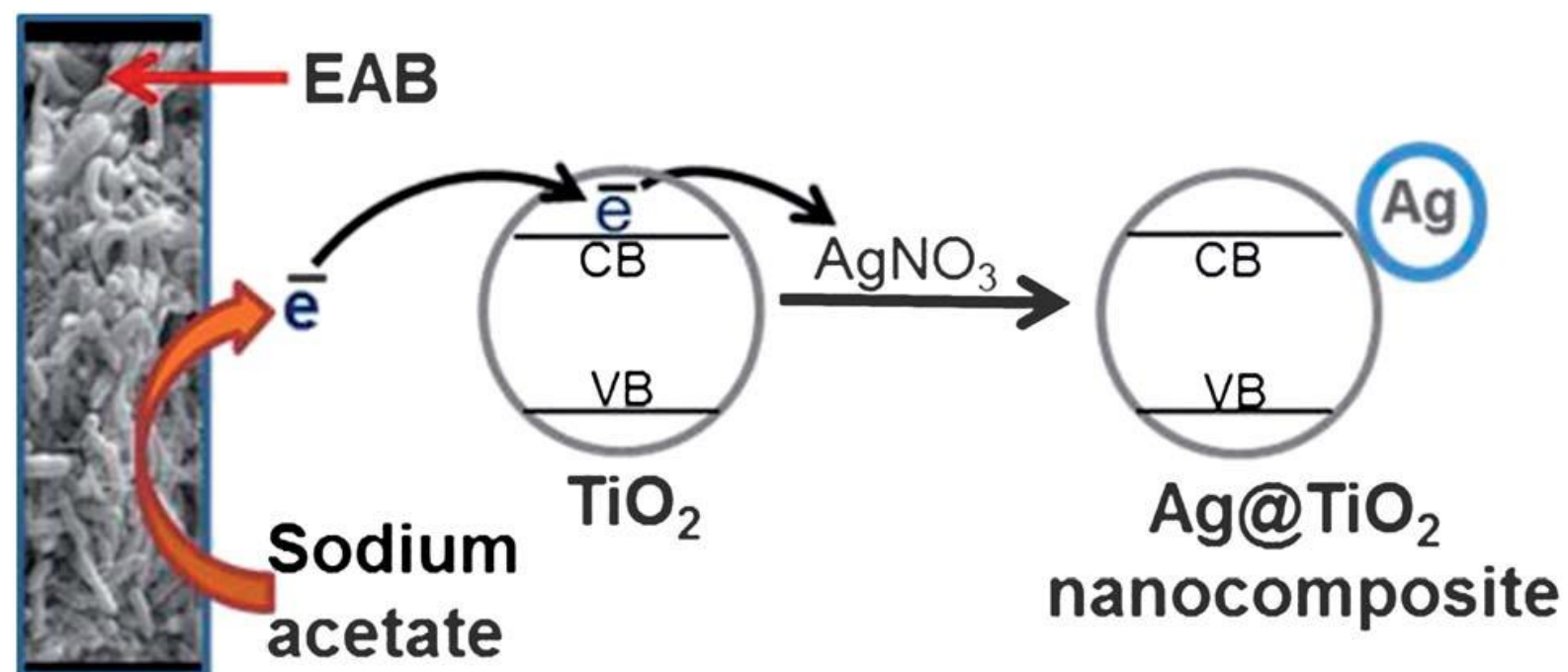

Figure 2.7. Proposed mechanism for the EAB-mediated synthesis of Ag@TiO2 nanocomposites. Reproduced from (Khan, Ansari et al. 2013) with permission from "The Royal Society of Chemistry".

One interesting observation is that the Ag nanoparticles were found to precipitate onto $\mathrm{TiO}_{2}$ in the bulk solution. According to the proposed mechanism, the electron transfer occurred primarily on the surface of the biofilm, and $\mathrm{TiO}_{2}$ facilitated the electron transfer from the biofilm to the $A g(I)$ for the reduction to occur. This may be possible due to the man-made anaerobic condition by purging the reactor with nitrogen gas. However, one would expect that the biofilm can transfer electrons directly to $A g(I)$ and that the $\mathrm{Ag}$ nanoparticles can be attached onto the surface or within the biofilm, instead of requiring $\mathrm{TiO}_{2}$ to act as an electron shuttle and that Ag nanoparticles are being attached onto the $\mathrm{TiO}_{2}$ in the bulk solution. It has been well-established that biofilms are able to directly facilitate electron transfer on its surface and within the biofilm (Templeton, Trainor et al. 2001, Richardson, Edwards et al. 2012, Shi, Dong et al. 2016). Unfortunately, the authors did not include any details regarding the state of biofilm after Ag reduction, nor the 
efficiency of the Ag reduction to support its proposed mechanism for Ag reduction. One possible explanation for the presence of $\mathrm{Ag} @ \mathrm{TiO}_{2}$ is that the $\mathrm{Ag}$ reduction may have occurred both within the biofilm and on the surface of biofilm, and that the authors may have neglected to account for the Ag nanoparticles that are deposited on the biofilm.

In both studies, the metal reduction process is done after purging nitrogen gas in order to create a man-made anaerobic condition within the reactor. The rationale is that metal reduction by planktonic cells is usually inhibited by oxygen and requires bulk anoxic conditions to occur (Lloyd, Byrne et al. 2011, Durán and Seabra 2012). As discussed in previous section, the heterogeneity nature of biofilms, coupled with an oxygen diffusion gradient, allows for anoxic microenvironments within biofilms under bulk oxic condition. It is uncertain if such anoxic microenvironment within biofilms can support bioreduction of metals. There are limited studies on the biofilm-mediated synthesis of metal nanomaterials and the biological mechanism of metal bioreduction by biofilm is poorly understood. More studies are needed to elucidate the mechanistic details of biofilmmediated syntheisis of nanomaterials to improve the feasibility of biofilm-based bioprocesses to be used in applications such as industrial fine-chemical synthesis and environmental remediation. 


\section{CHAPTER 3: INFLUENCE OF OUTER MEMBRANE C-TYPE CYTOCHROMES ON PARTICLE SIZE AND ACTIVITY OF EXTRACELLULAR NANOPARTICLES PRODUCED BY SHEWANELLA ONEIDENSIS}

This chapter has been published as $\mathrm{Ng}$ C K, Sivakumar K, Liu X, Madhaiyan M, Ji L, Yang L, Tang $C$, Song H, Kjelleberg S, and Cao B (2013) Influence of outer membrane c-type cytochromes on particle size and activity of extracellular nanoparticles produced by Shewanella oneidensis. Biotechnol. Bioeng., 110(7): 1831-1837. Permission has been granted by the licensed content publisher "John Wiley and Sons" to use the published content as a chapter in this thesis.

\subsection{Introduction}

Microorganisms have the potential to change the oxidation state of metals and these microbial processes have opened up a new window for novel applications including biosynthesis of metal nanomaterials (Gadd 2010, Lloyd, Byrne et al. 2011). Traditional approaches for the synthesis of metal nanomaterials, such as chemical, thermal, photochemical, sonochemical, electrochemical reduction, and ligand displacement and condensation of metal vapor, usually require harsh conditions and the use of toxic reagents and solvents (Dahl, Maddux et al. 2007). In contrast, microbial processes can synthesize nanomaterials in water under gentle and environmentally benign conditions. Hence, biological processes for the production of nanomaterials have become one of the attractive research focuses in current green nanotechnology towards sustainable development (Niemeyer 2001, Mandal, Bolander et al. 2006, Hennebel, De Gusseme et al. 2009, Durán, Marcato et al. 2011). 
A wide variety of microorganisms including bacteria, fungi, and yeast have been exploited to synthesize metal nanoparticles (NPs) (Li, Chung et al. 2003, Bigall, Reitzig et al. 2008, Suresh, Pelletier et al. 2010, Jain, Bhargava et al. 2011, K, R et al. 2011, Kumar and Mamidyala 2011, Jung, Park et al. 2012). Some microorganisms are capable of producing NPs extracellularly, giving relatively narrow size distribution and minimizing postproduction extraction and purification (Narayanan and Sakthivel 2010, Kalathil, Lee et al. 2011, Sintubin, Verstraete et al. 2012). Among these microorganisms, Shewanella oneidensis has attracted great interest because it is able to reduce a diverse range of metal ions and the extracellular electron transport chains responsible for transferring electrons across cell membranes have been relatively well characterized (Shi, Squier et al. 2007, Fredrickson, Romine et al. 2008, Shi, Richardson et al. 2009, Richardson, Edwards et al. 2012, Shi, Rosso et al. 2012). In S. oneidensis, the c-type cytochromes comprise a class of redox proteins that play a central role in metal reduction (Fredrickson, Romine et al. 2008). A large percentage of the membrane-bound c-type cytochromes were found to be associated with the outer membrane, including two best characterized outer membrane c-type cytochromes (OMCs) MtrC and OmcA (Shi, Chen et al. 2006). The most intriguing feature of OMCs is that they were also found to be associated with extracellular polymeric substances (EPS) secreted by $S$. oneidensis and contributed to extracellular formation of uranite NPs during $\mathrm{U}(\mathrm{VI})$ reduction (Marshall, Beliaev et al. 2006, Cao, Ahmed et al. 2011, Cao, Shi et al. 2011). Extensive studies have suggested an important role of OMCs in reduction of various metal(loid)s. However, how OMCs influence the particle size of extracellular NPs and their properties including antimicrobial, toxicological, catalytic, and optical features remains unknown. 
The objective of the current study was to investigate the influence of OMCs, that is, MtrC and OmcA, on the size and activity of the extracellular NPs using the production of silver NPs (AgNPs) and silver sulfide NPs ( $\left.\mathrm{Ag}_{2} \mathrm{~S} N P s\right)$ by $S$. oneidensis MR-1 as a model system. We used MR-1 cell suspensions of the wild-type (WT) and the mutant lacking OMCs to reduce $\mathrm{AgNO}_{3}$ or $\mathrm{AgNO}_{3}$ and $\mathrm{Na}_{2} \mathrm{~S}_{2} \mathrm{O}_{3}$ to generate $\mathrm{AgNPs}$ or $\mathrm{Ag}_{2} \mathrm{~S} \mathrm{NPs}$, respectively. Particle size of the extracellular NPs from the WT and the mutant was compared. Our results show that, comparing with the WT, the mutant lacking OMCs produced significantly smaller NPs. We further characterized the activity of the AgNPs and $\mathrm{Ag}_{2} \mathrm{~S}$ NPs. AgNPs have been demonstrated to exhibit biocidal activity towards a broad range of bacteria and have been termed as a new-generation of antimicrobial (Morones, Elechiguerra et al. 2005, Sintubin, Verstraete et al. 2012); thus, we characterized the influence of OMCs on the antibacterial activity of the biogenic AgNPs. $\mathrm{Ag}_{2} \mathrm{~S}$ NPs have a documented catalytic property in reducing methylviologen $\left(\mathrm{MV}^{2+}\right)$ (Kryukov, Stroyuk et al. 2004); hence, to investigate the impact of OMCs on the catalytic activity of the biogenic $\mathrm{Ag}_{2} \mathrm{~S} N \mathrm{NP}, \mathrm{MV}^{2+}$ reduction was used as a model catalytic reaction. Our results showed that the AgNPs and $\mathrm{Ag}_{2} \mathrm{~S}$ NPs produced by the mutant exhibited higher antibacterial activity and catalytic activity, respectively.

\subsection{Materials and Methods}

\subsubsection{Bacterial Strains and Growth Conditions}

S. oneidensis MR-1 WT and a mutant strain lacking MtrC and OmcA, that is, $\Delta$ (mtrC$o m c A$ ) were kindly provided by Dr. Liang Shi and Dr. Jim K. Fredrickson from Pacific Northwest National Laboratory, USA. Stock cultures were maintained in LB medium with 
$20 \%$ glycerol at $-80^{\circ} \mathrm{C}$. The cells were grown in LB medium containing $10 \mathrm{mM}$ ferric nitrilotriacetate (Fe(III)-NTA) anaerobically for $16 \mathrm{~h}$ at $30^{\circ} \mathrm{C}$ with shaking at $200 \mathrm{rpm}$.

\subsubsection{Extracellular Synthesis of Nanoparticles}

After $16 \mathrm{~h}$ incubation, cells were harvested through centrifugation at $6,000 \times \mathrm{g}$ for $10 \mathrm{~min}$, washed twice with $50 \mathrm{mM}$ MOPS buffer $(\mathrm{pH}$ 7.2) and re-suspended in MOPS buffer to a final cell density of ca. $1.2 \times 10^{9}$ cells $/ \mathrm{mL}$ containing (i) $10 \mathrm{mM}$ sodium lactate and $1 \mathrm{mM}$ $\mathrm{AgNO}_{3}$ (for AgNPs), or (ii) $10 \mathrm{mM}$ sodium lactate, $1 \mathrm{mM} \mathrm{AgNO}_{3}$, and $1 \mathrm{mM} \mathrm{Na}_{2} \mathrm{~S}_{2} \mathrm{O}_{3}$ (for $\mathrm{Ag}_{2} \mathrm{~S}$ NPs). Each cell suspension was flushed with $\mathrm{N}_{2}$ gas for 5 min and then incubated at $30^{\circ} \mathrm{C}$ on a rotary shaker $(\sim 200 \mathrm{rpm})$. After $120 \mathrm{~h}$, cell suspensions were centrifuged at $10,000 \mathrm{x} g$ for $20 \mathrm{~min}$ to remove cells and the supernatants were collected (Cao, Shi et al. 2011). UV-visible spectra $(600-360 \mathrm{~nm})$ of the supernatants were obtained. Extracellular NPs in the supernatant were further harvested by using ultracentrifugation at $100,000 \times \mathrm{g}$ for $30 \mathrm{~min}$, washed three times with MilliQ water and dried at $50^{\circ} \mathrm{C}$ under vacuum.

\subsubsection{Field Emission Scanning Electron Microscopy and Energy-Dispersive X-Ray Spectroscopy}

Cell pellets were washed twice and then re-suspended in MilliQ water. A portion of each suspension was dried under vacuum and then coated with platinum using a vacuum electric sputter coater (JEOL JFC-1300; JEOL Asia Pte Ltd., Singapore). SEM images were then taken using a field emission scanning electron microscope (FE-SEM, JSM7600; JEOL Asia Pte Ltd.) at a voltage of 2.0-5.0 kV. EDX spectrum was obtained using 
an energy-dispersive X-ray spectroscope (AZtecEnergy, Oxford Instruments, Oxfordshire, UK).

\subsubsection{Transmission Electron Microscopy}

About $3 \mu \mathrm{L}$ of the as-synthesized biogenic AgNPs from each supernatant was applied to a carbon-coated copper grid and dried in the air for transmission electron microscope (TEM) imaging using a Jeol JEM-1230 TEM instrument operated at an accelerating voltage of $120 \mathrm{kV}$.

\subsubsection{Size Distribution}

The hydrodynamic diameters of the extracellular AgNPs and $\mathrm{Ag}_{2} \mathrm{~S}$ NPs were determined using Zetasizer (Nano ZS, Malvern Instruments, Worcestershire, UK). In order to make sure that the extracellular NPs were uniformly dispersed, 15 min ultrasonication in an S450H Ultrasonic Bath $(50 / 60 \mathrm{~Hz}, 2000 \mathrm{~W}$; Fisher Scientific, Singapore) was employed before each measurement.

\subsubsection{Antibacterial Activity of Biogenic AgNPs}

\subsubsection{Minimal Inhibitory Concentration (MIC) Test}

The MIC, defined as the lowest concentration of a certain compound that inhibits the growth of an organism. Specifically, Escherichia coli (ATCC 8739) was used for the MIC test and the bacterial cultures in LB media containing varying concentration of the biogenic AgNPs were incubated for $12 \mathrm{~h}$. The minimal concentration at which no obvious cell growth could be observed $\left(\mathrm{OD}_{600}<0.1\right)$ was considered as the MIC. 


\subsubsection{Bactericidal Assay}

E. coli was used as a model organism to evaluate the toxicity of the biogenic AgNPs. LB cultures were prepared on a rotary shaker $(\sim 200 \mathrm{rpm})$ at $37^{\circ} \mathrm{C}$ and cells were harvested at the mid-exponential growth phase (after $\sim 12 \mathrm{~h}$ incubation). The harvested cells were washed twice and then resuspended in $0.9 \% \mathrm{NaCl}$ (final cell density $\sim 10^{8} \mathrm{cells} / \mathrm{mL}$ ). Bactericidal activity was tested in 96-well plates. Each well of the testing plate contained $100 \mu \mathrm{L}$ of the biogenic AgNPs suspension (final concentration of 0 to $10 \mathrm{mg} / \mathrm{L}$ ) and $100 \mu \mathrm{L}$ of cell suspension. Plates were incubated at $37^{\circ} \mathrm{C}$ for $24 \mathrm{~h}$. Cell viability was evaluated using a live/dead baclight bacterial viability kit (Molecular Probes, Eugene, OR). The percentage of live cells in each well was estimated based on green/red fluorescence ratio. Half maximal inhibitory concentration $\left(\mathrm{IC}_{50}\right)$ value, corresponding to the NPs concentration at which only $50 \%$ cells remain live after $24 \mathrm{~h}$ incubation, was calculated based on viability versus NPs concentration curves.

\subsubsection{Inductively Coupled Plasma Mass Spectrometry}

To determine the dissolution of $\mathrm{Ag}^{+}$from the biogenic AgNPs, the suspension of $100 \mu \mathrm{g} / \mathrm{mL}$ AgNPs in $0.9 \% \mathrm{NaCl}$ was filtered through a centrifugal filter unit (molecular weight cutoff $3 \mathrm{kDa}$; Amicon Ultra-4 3K). The total $\mathrm{Ag}^{+}$concentration was quantified using an inductively coupled plasma mass spectrometer (ICP-MS; ELAN DRC-e; Perkin Elmer, Waltham, MA) as described previously (Suresh, Pelletier et al. 2010). 


\subsubsection{Catalytic Activity of Biogenic $\mathrm{Ag}_{2} \mathrm{~S}$ NPs}

Both cell-associated $\mathrm{Ag}_{2} \mathrm{~S}$ NPs and supernatant $\mathrm{Ag}_{2} \mathrm{~S}$ NPs obtained from cell suspension were tested for catalytic activity in the reduction of methylviologen $\left(\mathrm{MV}^{2+}\right)$ to a cation-radical MV ${ }^{+}(\lambda \max =605 \mathrm{~nm}$ and molar extinction coefficient $\varepsilon 605=13,700$ $\mathrm{M}^{-1} \mathrm{~cm}^{-1}$ ). About $13 \mathrm{mg}$ cell pellet (cells and cell-associated $\mathrm{Ag}_{2} \mathrm{~S} \mathrm{NPs} ; 1 \mathrm{mg}$ dried biomass) or $360 \mu \mathrm{g}$ of dried extracellular $\mathrm{Ag}_{2} \mathrm{~S}$ NPs (harvested from the supernatant) was resuspended in $450 \mu \mathrm{L}$ of MilliQ water, which was then mixed with $500 \mu \mathrm{L}$ of $20 \mathrm{mM}$ $\mathrm{Na}_{2} \mathrm{~S}$ and $50 \mu \mathrm{L}$ of $20 \mathrm{mM} \mathrm{MV}^{2+}$. Upon addition of $\mathrm{MV}^{2+}$, optical density at wavelength of $605 \mathrm{~nm}\left(\mathrm{OD}_{605}\right)$ was monitored continuously $(1 \mathrm{~s}$ interval) for $5 \mathrm{~min}$.

\subsection{Results and Discussion}

\subsubsection{Biogenic AgNPs and $\mathrm{Ag}_{2} \mathrm{~S}$ NPs}

Extracellular biosynthesis of AgNPs and $\mathrm{Ag}_{2} \mathrm{~S}$ NPs using cells of S. oneidensis MR-1 WT has been reported (Suresh, Pelletier et al. 2010, Suresh, Pelletier et al. 2011), where the biogenic NPs have been extensively characterized. In our experiments, SEM-EDX confirmed the presence of AgNPs and $\mathrm{Ag}_{2} \mathrm{~S}$ NPs, respectively (data not shown). Here, in this study, we found that the strain lacking OMCs, that is, $\Delta(m t r C$-omcA) also produced extracellular AgNPs and $\mathrm{Ag}_{2} \mathrm{~S}$ NPs as indicated by a characteristic surface plasmon resonance (SPR) band at $410 \mathrm{~nm}$ in the UV-visible spectra (Mulvaney 1996, Magudapathy, Gangopadhyay et al. 2001, Suresh, Pelletier et al. 2010, Suresh, Pelletier et al. 2011) but with much lower SPR intensity, suggesting that the amount of extracellular NPs synthesized was significantly lower than using WT. The abiotic controls (buffer containing no cells) did not show the SPR absorbance band, confirming that the NPs 
obtained were biogenic. These results implied an important role of OMCs in extracellular $\mathrm{Ag}(\mathrm{I})$ reduction, which is also supported by previous observation of the formation of nanoscale $A g(0)$ deposits on cell surface during $A g(I)$ reduction by $S$. oneidensis (Wang, Law et al. 2010). Although both the WT and the OMCs mutant could generate extracellular NPs, the question is whether these biogenic NPs differ in terms of particle size and activity or not? To address it, we characterized the particle size and their activities of the extracellular NPs produced by WT and the mutant.

\subsubsection{Particle Size}

TEM analyses (Fig. 1A-D) revealed that the extracellular biogenic NPs from WT and the OMCs mutant were generally spherical in shape and significantly smaller particles were obtained from the mutant. Consistent with the TEM observations, quantitative analysis of the particle size distribution for the NPs from both strains showed that extracellular NPs produced by the OMCs mutant $\Delta(m t r C-o m c A)$ were significantly smaller than those produced by WT $(24.4 \pm 0.8 \mathrm{~nm}$ vs. $40.9 \pm 1.0 \mathrm{~nm}$ for AgNPs and $27.6 \pm 6.4$ vs. $53.4 \pm 12.4$ for $\mathrm{Ag}_{2} \mathrm{~S}$ NPs, respectively) (Figure 3.1). 

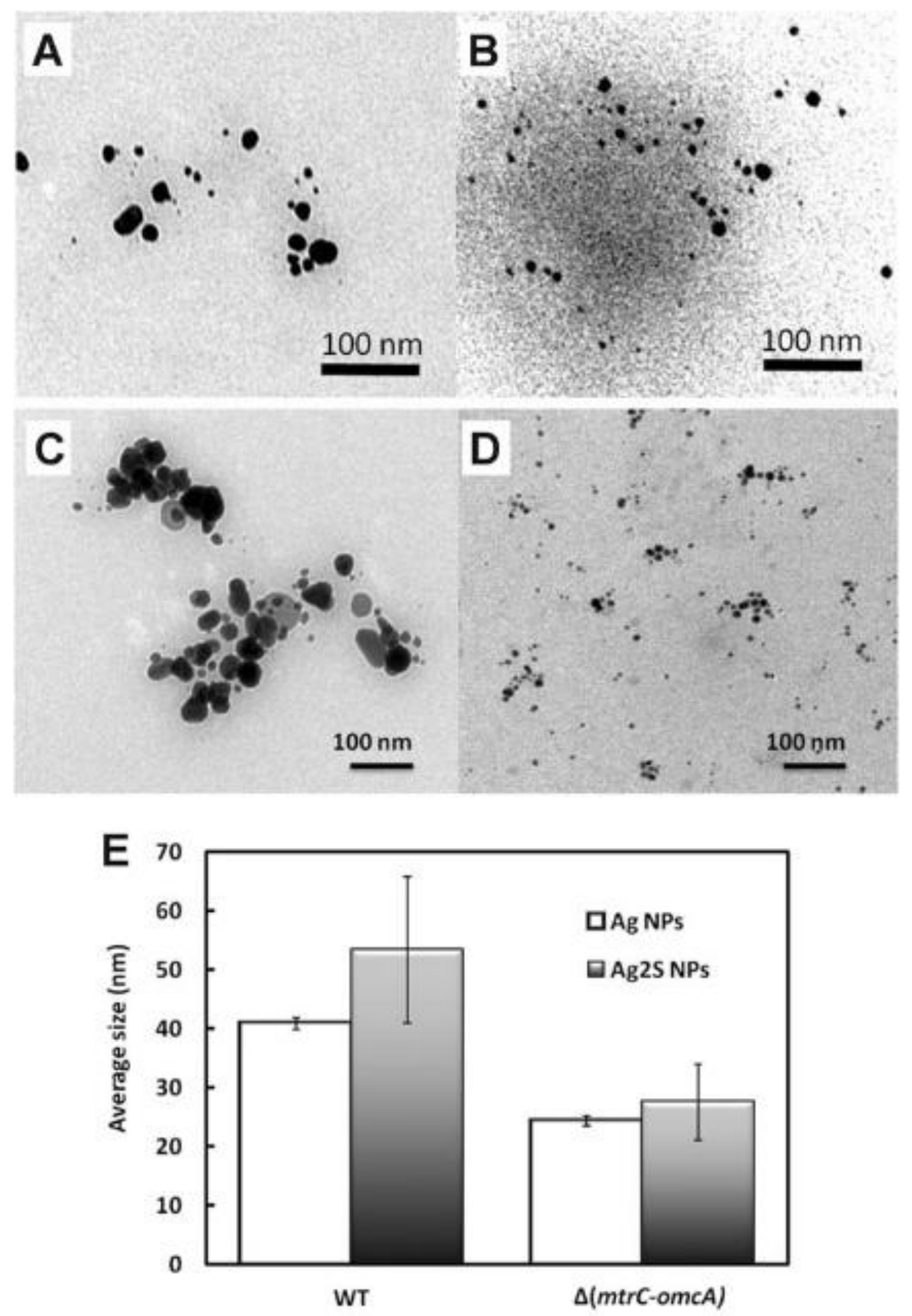

Figure 3.1. TEM images of the extracellular AgNPs (A and B), $\operatorname{Ag}_{2} \mathrm{~S}$ NPs (C and D) produced by different $S$. oneidensis strains: WT (A and C), $\Delta(m t r C$-omcA) $(\mathrm{B}$ and D), and the average $(\mathrm{n}=3)$ hydrodynamic diameters of the biogenic NPs (E). 
Since many physicochemical and toxicological properties of NPs are size-dependent (Pal, Tak et al. 2007, Jiang, KimBetty et al. 2008, Park, Lim et al. 2011, Søbjerg, Lindhardt et al. 2011, Perez-Alonso, McCarthy et al. 2012), controlling the particle size in biosynthesis of NPs is critically important, which remains one of the main challenges. It has been reported that, by choosing different microbial systems, the desirable size of the NPs produced could be obtained (Sintubin, Verstraete et al. 2012). However, this strategy is not suitable for scalable biotechnological processes, where frequent change of workhorse is not sustainable. It would be ideal if the size of the extracellular NPs produced in microbial processes can be controlled through genetic manipulations of the microorganisms used for the synthesis. Here, our results show that the lack of OMCs on S. oneidensis cell surface decreased the particle size of the extracellular biogenic AgNPs and $\mathrm{Ag}_{2} \mathrm{~S} N$ Ns, suggesting that it may be possible to control particle size of the extracellular biogenic NPs via controlled expression of the genes encoding surface proteins.

\subsubsection{Antibacterial Activity of AgNPs}

We have shown that the particle size of the NPs from WT and the mutant lacking OMCs was different. The next question is whether the NPs from these two strains have different activities. For the biogenic AgNPs, we conducted a bacterial toxicity study using E. coli as a model organism to evaluate the bactericidal activity of the NPs from the WT and the OMCs mutant.

The MIC of the biogenic AgNPs from the WT and the mutant was determined to be 16 and $12 \mu \mathrm{g} / \mathrm{mL}$, respectively, implying the AgNPs produced by the mutant were more toxic 
to $E$. coli than those produced using the WT. To further elucidate the bactericidal activity, $\mathrm{IC}_{50}$ of these biogenic AgNPs was determined. The $\mathrm{IC}_{50}$ value of the AgNPs produced by WT and the OMCs mutant was estimated as $2.1 \pm 0.2$ and $1.2 \pm 0.3 \mu \mathrm{g} / \mathrm{mL}$, respectively (Figure 3.2). The $\mathrm{IC}_{50}$ test was consistent with the observations in MIC assay and also suggested that the biogenic AgNPs produced using the OMCs mutant were more toxic.

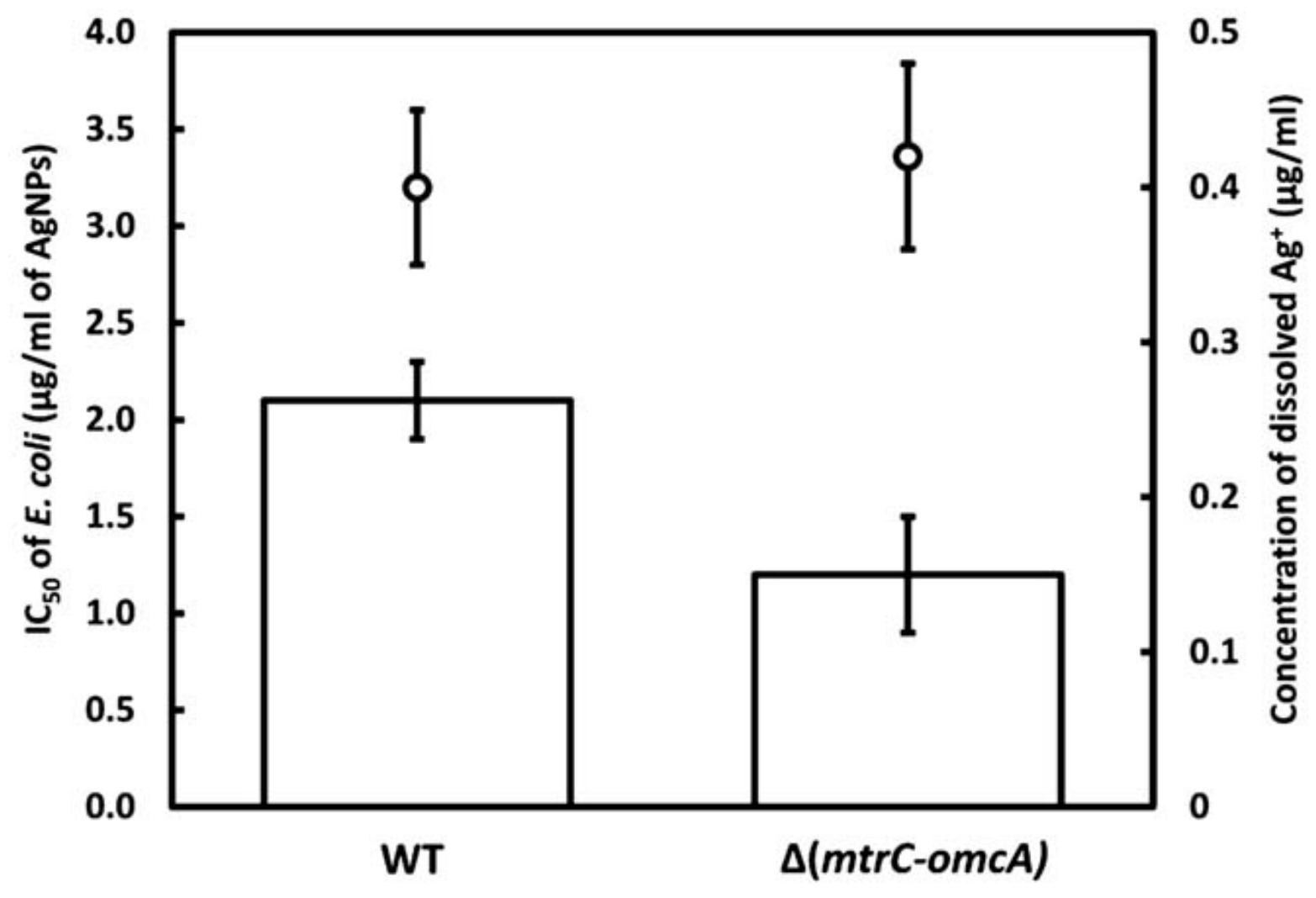

Figure 3.2. IC 50 values $(\mathrm{n}=8)$ of the biogenic AgNPs produced by WT and $\Delta$ (mtrC-omcA) (bars), and the dissolution of $\mathrm{Ag}^{+}(\mathrm{n}=3$; circles $)$.

To investigate whether the difference in toxicity was caused by dissolution of $\mathrm{Ag}^{+}$from the biogenic AgNPs, we quantified $\mathrm{Ag}^{+}$concentration in buffers containing $100 \mu \mathrm{g} / \mathrm{mL}$ AgNPs (approximately five- to eightfold higher than the MIC, $\sim 50$ - to 80 -fold higher than 
the $\mathrm{IC}_{50}$ ) after $24 \mathrm{~h}$ incubation (Figure 3.2). Concentrations of $\mathrm{Ag}^{+}$dissolved from the biogenic AgNPs produced by WT and the OMCs mutant were $0.40 \pm 0.05$ and $0.42 \pm 0.06 \mu \mathrm{g} / \mathrm{mL}$, respectively. There was no difference in the measured dissolution of $\mathrm{Ag}^{+}$from the AgNPs produced by WT and the mutant, indicating that the relative increased toxicity of the biogenic AgNPs from the mutant was not due to the dissolution of $\mathrm{Ag}^{+}$. Particle size could be one of the factors that may have contributed to the observed difference in toxicity. It has been reported that smaller AgNPs (especially particles $<5 \mathrm{~nm}$ ) with higher surface areas could compromise cell membrane more effectively allowing more $\mathrm{Ag}$ atoms to attack or enter the cells (Morones, Elechiguerra et al. 2005, Nel, Xia et al. 2006, Choi and Hu 2008). Our results on the toxicity of the biogenic AgNPs are consistent with these recent findings obtained from chemically synthesized NPs.

\subsubsection{Catalytic activity of $\mathrm{Ag}_{2} \mathrm{~S}$ NPS}

For the biogenic $\mathrm{Ag}_{2} \mathrm{~S} N P s$, we used the reduction of $\mathrm{MV}^{2+}$ to $\mathrm{MV}{ }^{+}$as a model reaction to evaluate their catalytic activity. Figure 3.3 shows $\mathrm{MV}^{2+}$ reduction catalysed by the $\mathrm{Ag}_{2} \mathrm{~S}$ NPs produced by WT. 


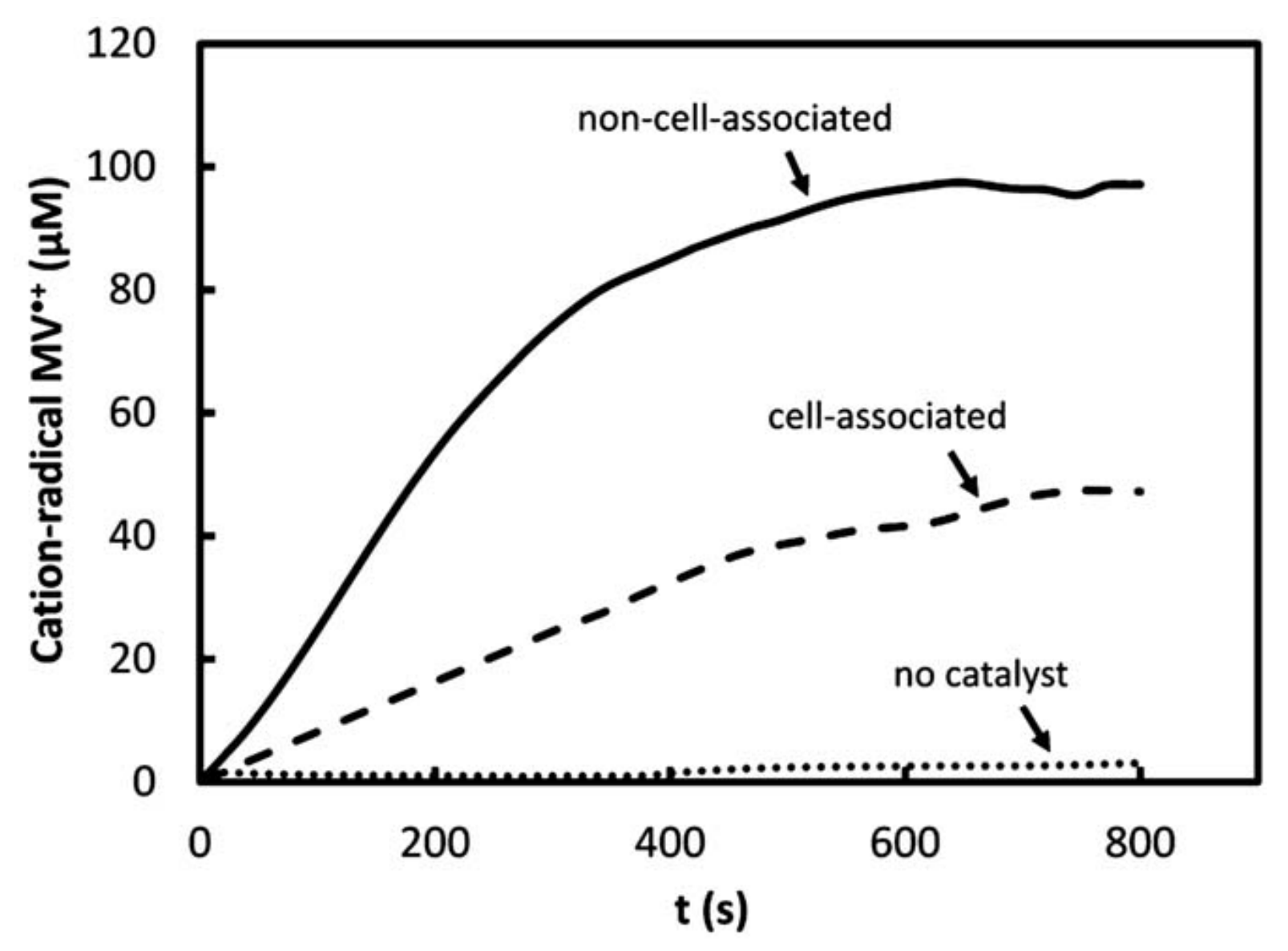

Figure 3.3 Kinetic curves of the accumulation of $\mathrm{MV}^{++}$in solutions containing $\mathrm{Na}_{2} \mathrm{~S}$ in the absence of $\mathrm{Ag}_{2} \mathrm{~S}$ NPs, and in the presence of cell-associated or non-cell-associated $\mathrm{Ag}_{2} \mathrm{~S}$ NPs produced by S. oneidensis MR-1 WT.

In aqueous phase without $\mathrm{Ag}_{2} \mathrm{~S}$ NPs as the catalyst, $\mathrm{MV}^{2+}$ reduction by $\mathrm{Na}_{2} \mathrm{~S}$ is a very slow process. Both the $\mathrm{Ag}_{2} \mathrm{~S}$ NPs associated with cells and the $\mathrm{Ag}_{2} \mathrm{~S}$ NPs extracted from the supernatant fraction substantially accelerated the $\mathrm{MV}^{2+}$ reduction process. The concentration of a key reduction product $\mathrm{MV} \cdot{ }^{+}$rapidly increased within the first $5-10 \mathrm{~min}$ and then reached an equilibrium state due to a reverse reaction between reduction products that has been described elsewhere (Kryukov, Stroyuk et al. 2004). Surprisingly, the $\mathrm{Ag}_{2} \mathrm{~S}$ NPs extracted from supernatant fraction exhibited significantly higher catalytic 
activity than the $\mathrm{Ag}_{2} \mathrm{~S}$ NPs associated with the cells as indicated by an initial reduction rate of $0.26 \mu \mathrm{M} / \mathrm{s}$ (non-cell-associated) and $0.09 \mu \mathrm{M} / \mathrm{s}$ (cell-associated), respectively. In traditional biosynthesis of metallic NPs, the cell-associated NPs (or "metalised" cells) are harvested as potential bio-NPs catalysts, excluding non-cell-associated NPs. "Metalised" cells such as "palladized" cells have been used to catalyse a variety of reactions, including reduction of $\mathrm{Cr}(\mathrm{VI}), \mathrm{ClO}$, trichloroethylene (TCE), and polychlorobiphenyls (PCB) as well as synthesis of organic compounds (Hennebel, De Gusseme et al. 2009, Sobjerg, Gauthier et al. 2009, Gauthier, Søbjerg et al. 2010, De Corte, Hennebel et al. 2012, Hennebel, De Corte et al. 2012). Here, our results reveal that the usually neglected fraction of non-cell-associated NPs in culture supernatants showed high catalytic activity. In fact, a threefold increase in the catalytic activity could be expected by retaining the non-cell-associated NPs. Our findings highlight the need of novel methods that can potentially retain extracellular NPs effectively in the NPs biosynthesis processes. One promising strategy to achieve this could be the use of biofilms, surface-associated microbial communities encased in self-produced extracellular polymeric matrix, to immobilise in situ generated NPs via associations with both the cells and the biofilm matrix.

To better understand the catalytic activity of these non-cell-associated NPs, we further investigated how their catalytic activity is influenced by the OMCs. Figure 3.4 shows that the non-cell-associated $\mathrm{Ag}_{2} \mathrm{~S}$ NPs from the mutant lacking OMCs exhibited higher catalytic activity than those from the WT. The initial reduction rate was 0.80 and $0.30 \mu \mathrm{M} / \mathrm{s}$ for the $\mathrm{Ag}_{2} \mathrm{~S}$ NPs from the OMCs mutant and the WT, respectively. The results suggest that it may be possible to enhance catalytic activity of the extracellular biogenic NPs via manipulating the genes encoding surface proteins. 


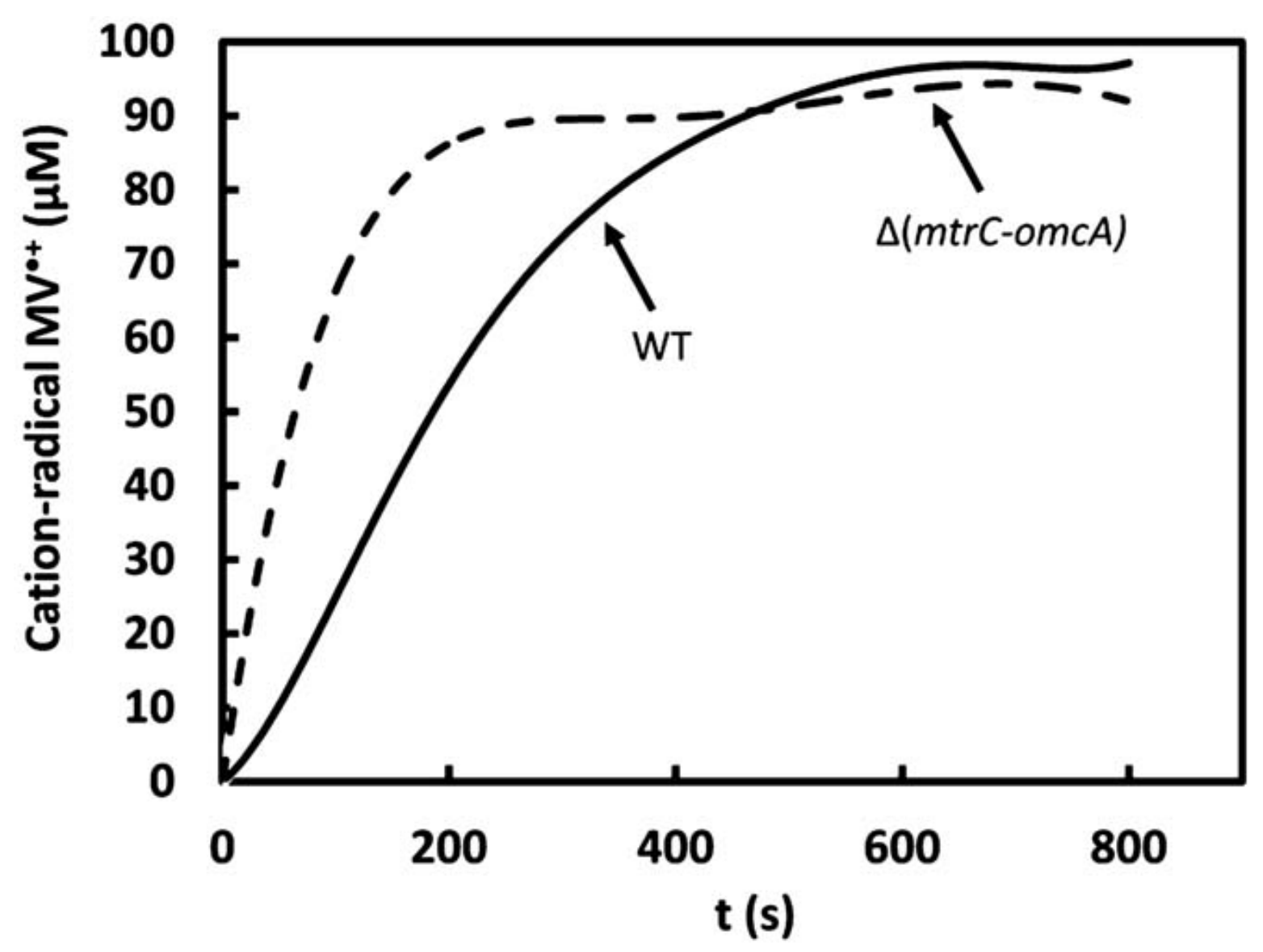

Figure 3.4. Kinetic curves of the accumulation of $\mathrm{MV}^{++}$in solutions containing $\mathrm{Na}_{2} \mathrm{~S}$ in the presence of non-cell-associated $\mathrm{Ag}_{2} \mathrm{~S}$ NPs produced by $S$. oneidensis MR-1 WT and $\Delta(\mathrm{mtrC}$ omcA).

\subsection{Conclusion}

In this study, we show that OMCs influence the particle size of extracellular NPs and their activities: (i) the lack of OMCs on S. oneidensis cell surface decreased the particle size of the extracellular biogenic AgNPs and $\mathrm{Ag}_{2} \mathrm{~S}$ NPs; (ii) the biogenic AgNPs from the OMCs mutant showed higher antibacterial activity than those from the WT; and (iii) the biogenic $\mathrm{Ag}_{2} \mathrm{~S}$ NPs from the OMCs mutant exhibited higher catalytic activity. Our results suggest that it may be possible to control particle size and activity of the extracellular 
biogenic NPs via controlled expression of the genes encoding surface proteins. In addition, we also reveal that in extracellular biosynthesis of NPs the usually neglected non-cell-associated NPs could have high catalytic activity, highlighting the need of novel methods that can efficiently retain extracellular NPs in the biosynthesis processes. 


\section{CHAPTER 4: REDUCTIVE FORMATION OF PALLADIUM NANOPARTICLES BY SHEWANELLA ONEIDENSIS: ROLE OF OUTER MEMBRANE CYTOCHROMES AND HYDROGENASES}

This chapter has been published as Ng CK, Tan TKC, Song H, \& Cao B (2013). Reductive formation of palladium nanoparticles by Shewanella oneidensis: role of outer membrane cytochromes and hydrogenases. RSC Adv., 3(44): 22498-22503. Permission has been granted by the licensed content publisher "Royal Society of Chemistry" to use the published content as a chapter in this thesis.

\subsection{Introduction}

Dissimilatory metal-reducing bacteria (DMRB) are a group of microorganisms capable of using various metal(loid)s as terminal electron acceptors for anaerobic respiration (Lovley 1993, Nealson 1997). In natural environments, DMRB-mediated reduction of iron and other metal(loid)s in the Earth's crust plays an important role in biogeochemical cycles of these metals and in the fate of organic matter (Lovley 1993, Nealson 1997, Lovley and Anderson 2000). In engineered settings, there have been many attempts at harnessing the power of DMRB for various applications including bioremediation of environmental contaminants, generation of power or high value products in bioelectrochemical devices (Fredrickson, Romine et al. 2008, Nealson and Finkel 2011, Lovley 2012).

DMRB are capable of changing the oxidation state of metals and these microbial processes have opened up a new window for novel applications including biosynthesis of metal nanomaterials (Gadd 2010, Lloyd, Byrne et al. 2011). Because the synthesis of nanomaterials using DMRB usually occurs in water under gentle and environmentally 
benign conditions, it has become one attractive research focus in current green nanotechnology (Mandal, Bolander et al. 2006, Hennebel, De Gusseme et al. 2009). Among the DMRB most often used in biosynthesis of nanomaterials, Shewanella oneidensis has attracted great interest because it is able to reduce a diverse range of metal ions and the extracellular electron transport chains responsible for transferring electrons across cell membranes have been relatively well characterized (Myers and Nealson 1988, Heidelberg, Paulsen et al. 2002, Fredrickson, Romine et al. 2008). S. oneidensis has been used to synthesize various nanomaterials including catalytic palladium $(\mathrm{Pd})$ nanoparticles with great potentials for applications in the treatment of environmental pollutants and in chemical synthesis (De Corte, Hennebel et al. 2012, Hennebel, De Corte et al. 2012). However, the primary molecular sites responsible for Pd reduction have not been elucidated, which limits further enhancement of Pd reduction and the design of controllable and reproducible bioprocesses.

S. oneidensis MR-1 genome possesses 42 c-type cytochromes many of which are known to be involved in extracellular electron transfer (Fredrickson, Romine et al. 2008). The metal-reducing (MTR)-pathway consisting of a set of proteins including c-type cytochromes CymA and MtrC/OmcA is a well-characterized extracellular electron transport chain responsible for transferring electrons across cell membranes (Richardson, Butt et al. 2012, Shi, Rosso et al. 2012). CymA is required to electrically charge the outer membrane cytochromes (OMCs), i.e., MtrC and OmcA. Extensive studies have suggested an essential role of $\mathrm{MtrC} / \mathrm{OmcA}$ in the reduction of various metals including $\mathrm{Fe}(\mathrm{III}), \mathrm{Cr}(\mathrm{VI}), \mathrm{Tc}(\mathrm{VII})$ and U(VI) (Marshall, Beliaev et al. 2006, Belchik, Kennedy et al. 2011). In addition to c-type cytochromes, hydrogenases comprise another class of redox 
proteins that play a central role in microbial reduction of metals in S. oneidensis. The genome of $\mathrm{S}$. oneidensis MR-1 encodes both a [FeFe]-hydrogenase HydAB and a [NiFe]hydrogenase HyaAB (Heidelberg, Paulsen et al. 2002). HydA functions as a hydrogenforming hydrogenase, while HyaB can function either in formation or oxidation of hydrogen as a bidirectional hydrogenase (Meshulam-Simon, Behrens et al. 2007). Previous studies have shown that the [NiFe]-hydrogenase of MR-1 was involved in $\mathrm{H}_{2}-$ driven reduction of $\mathrm{Tc}(\mathrm{VII})$ to $\mathrm{Tc}(\mathrm{IV}) / \mathrm{Tc}(\mathrm{V})$ (Marshall, Plymale et al. 2008, Shi, Belchik et al. 2011). However, the contribution of OMCs and hydrogenases to Pd bioreduction in S. oneidensis has not been well elucidated.

The objective of the current study was to investigate the role of hydrogenases, i.e. HydA and $\mathrm{HyaB}$, and OMCs, i.e., MtrC and OmcA, in bioreductive formation of $\mathrm{Pd}$ nanoparticles by S. oneidensis MR-1. We compared the rates of Pd reduction in the wild-type (WT) and the mutants lacking OMCs and [NiFe]-hydrogenase. We demonstrated that the reduction of Pd by S. oneidensis can be well described by the first-order model. Our results showed that there is no significant difference in Pd reduction rates of WT and mutant lacking OMCs, while the reduction rate was significantly lower in the mutant lacking [NiFe]hydrogenase HyaB than in the WT. Taken together, we report for the first time that outer membrane c-type cytochromes MtrC/OmcA do not play an essential role in $\mathrm{Pd}(\mathrm{II})$ reduction, while [NiFe]-hydrogenase $\mathrm{HyaB}$ facilitates $\mathrm{Pd}(\mathrm{II})$ reduction, suggesting that HyaB may serve as a potential target for molecular manipulation in S. oneidensis towards an improved performance in reductive formation of $\mathrm{Pd}$ nanoparticles. 


\subsection{Materials and Methods}

\subsubsection{Bacterial Strains and Growth Conditions}

S. oneidensis MR-1 wild-type (WT) and mutants lacking selected c-type cytochrome or hydrogenase (Table 4.1) were used in this study. Stock cultures were maintained in LB medium with $20 \%$ glycerol at $-80{ }^{\circ} \mathrm{C}$. The bacterial cells were grown in LB medium or modified M1 medium under aerobic or anaerobic conditions. The modified M1 medium $(\mathrm{pH} \sim 7.0)$ consisted of $3.00 \mathrm{mM}$ PIPES, $7.50 \mathrm{mM} \mathrm{NaOH}, 26.04 \mathrm{mM} \mathrm{NH}_{4} \mathrm{Cl}, 1.34 \mathrm{mM} \mathrm{KCl}$, $4.35 \mathrm{mM} \mathrm{NaH}_{2} \mathrm{PO}_{4}$ and $0.68 \mathrm{mM} \mathrm{CaCl}_{2}$ supplemented with trace amounts of minerals, vitamins, and amino acids (Cao, Shi et al. 2011). For bacterial growth in M1 medium, 20 $\mathrm{mM}$ sodium lactate or sodium formate was used as an electron donor and the sole carbon source. For growth under anaerobic conditions, the medium containing $10 \mathrm{mM}$ ferric nitrilotriacetate (Fe(III)-NTA) as an electron acceptor was bubbled with nitrogen gas for 5 min and the headspace in the culture was less than $3 \%$ of the total volume.

Table 4.1. S. oneidensis strains used in this study

\begin{tabular}{|c|c|c|}
\hline Strains & Description & Reference \\
\hline MR-1 (WT) & Manganese-reducing strain & $\begin{array}{l}\text { (Myers and Nealson } \\
1988)\end{array}$ \\
\hline$\Delta m t r C \Delta o m c A$ & $\begin{array}{l}\text { Deletion of S01778 (mtrC)-SO1779 } \\
\text { (omcA) }\end{array}$ & $\begin{array}{l}\text { (Reardon, Dohnalkova et } \\
\text { al. 2010) }\end{array}$ \\
\hline$\Delta c y m A$ & $\begin{array}{l}\text { SO4591 (cymA) deletion derivative of } \\
\text { MR-1 }\end{array}$ & $\begin{array}{l}\text { (Marshall, Plymale et al. } \\
\text { 2008) }\end{array}$ \\
\hline
\end{tabular}




\begin{tabular}{lll}
\hline $\boldsymbol{\Delta} \boldsymbol{h y d \boldsymbol { A }}$ & SO3920 (hydA) deletion derivative of & (Meshulam-Simon, \\
& MR-1 & Behrens et al. 2007) \\
\hline $\boldsymbol{\Delta h y a B}$ & SO2098 (hyaB) deletion derivative of & (Meshulam-Simon, \\
& MR-1 & Behrens et al. 2007) \\
\hline $\boldsymbol{\Delta h y a B \Delta h y d \boldsymbol { A }}$ & Deletion of SO2098 (hyaB)-SO3920 & (Marshall, Plymale et al. \\
& $($ hydA $)$ & 2008) \\
\hline
\end{tabular}

\subsection{2. $\mathrm{Pd}(\mathrm{II})$ reduction by resting cells}

All chemicals were from Sigma Aldrich, unless otherwise stated. Anaerobic cultures of various S. oneidensis strains (Table 4.1) were incubated with sodium fumarate as an electron acceptor for 16 hours at $30{ }^{\circ} \mathrm{C}$ with shaking at $200 \mathrm{rpm}$. Cells were harvested through centrifugation (6000 $\times \mathrm{g}$ for $30 \mathrm{~min})$, washed twice with HEPES buffer ( $30 \mathrm{mM}$, $\mathrm{pH}$ 7.0), and resuspended in the same buffer. Ten $\mathrm{ml}$ of the cell suspension was mixed with $5 \mathrm{ml}$ of HEPES buffer ( $30 \mathrm{mM}, \mathrm{pH} 7.0)$ in an anaerobic tube capped with butyl rubber stopper, and bubbled with nitrogen gas for 5 min. Sodium formate and sodium tetrachloropalladate $\left(\mathrm{Na}_{2} \mathrm{PdCl}_{4}\right)(\mathrm{Pd}(\mathrm{II}))$ were introduced into the anaerobic tube through syringe needles to a final concentration of $20 \mathrm{mM}$ and $1 \mathrm{mM}$, respectively. Aliquots of each cell suspension were incubated at $90{ }^{\circ} \mathrm{C}$ for $10 \mathrm{~min}$ and were used as controls containing heat-killed cells. Each experiment was carried out in triplicates.

\subsubsection{Quantification of $\mathrm{Pd}(\mathrm{II})$}

Samples ( $\sim 1 \mathrm{ml}$ each) were taken using a syringe needle at pre-determined time points. Each sample was centrifuged at $10000 \times \mathrm{g}$ for $5 \mathrm{~min}$ to remove the cells and the 
concentration of $\mathrm{Pd}(\mathrm{II})$ was quantified using a colorimetric method (Rotaru, Jiang et al. 2012). Briefly, $100 \mu \mathrm{l}$ of sample was mixed with $500 \mu \mathrm{l}$ of EDTA-NaOH buffer (100 mM, $\mathrm{pH} 10.4)$ and $50 \mu \mathrm{l}$ 4-(2-pyridylazo)-resorcinol (0.1\%, $\mathrm{pH} 10.5)$ followed by $10 \mathrm{~min}$ incubation at $80{ }^{\circ} \mathrm{C}$ and then at $4{ }^{\circ} \mathrm{C}$ for $20 \mathrm{~min}$. The mixture was then diluted 10 times using MilliQ water and the optical density at $515 \mathrm{~nm}$ was measured.

\subsubsection{Epifluorescence microscopy}

One drop of the cell suspension was placed on a glass microscope slide and dried in an oven at $70{ }^{\circ} \mathrm{C}$. The dried sample was then stained using 4'-6-diamidino-2-phenylindole (DAPI) (Bunge, Søbjerg et al. 2010). Briefly, $5 \mu$ l of DAPI solution (1 $\mathrm{mg} \mathrm{ml}^{-1}$ ) was dropped onto the sample and incubated at room temperature, in the dark, for $45 \mathrm{~min}$. The glass slide was then rinsed with ultrapure water to remove excess DAPI. The stained samples were examined using an inverted epifluorescence microscope (Microscope Axio Observer.Z1, Carl Zeiss).

\subsubsection{Transmission electron microscopy (TEM)}

For TEM imaging, samples were fixed, dehydrated and embedded in LR white (Electron Microscopy Sciences, Hatfield, PA) following protocols reported elsewhere (Belchik, Kennedy et al. 2011). Briefly, the sample was fixed in $2.5 \%$ glutaraldehyde overnight and centrifuged at $5000 \times \mathrm{g}$ for $5 \mathrm{~min}$, and the supernatant was discarded. The cells were resuspended and washed three times with $10 \mathrm{mM}$ PIPES buffer $(\mathrm{pH} \mathrm{6.8)}$ at $5000 \times \mathrm{g}$ for 5 min. Gradual dehydration was carried out in an ethanol series of $30,50,75$, and $90 \%$ for 30 min each and then $100 \%$ ethanol three times for $1 \mathrm{~h}$ each. The cell pellet was further washed for $30 \mathrm{~min}$ in a 50:50 mixture of ethanol and LR white (Electron Microscopy 
Sciences, Hatfield, PA). Finally, the cell pellet was washed three times using resin for 1 $\mathrm{h}$ each, and centrifuged at $5000 \mathrm{rpm}$ for $5 \mathrm{~min}$. After the final wash with resin, the resin was discarded, and the Eppendorf tube containing the cell pellet was filled with fresh resin to about $75 \%$ of the tube's volume and incubated at $60{ }^{\circ} \mathrm{C}$ overnight. The polymerized block of cell pellets was sectioned with a diamond knife (Diatome, Biehl, Switzerland) to a thickness of $70 \mathrm{~nm}$ and mounted on a Cu grid and sputtered with carbon. These sections were examined using a Jeol JEM-1230 TEM instrument operated at an accelerating voltage of $120 \mathrm{kV}$.

\subsection{Results and Discussion}

\subsubsection{Pd(II) reduction by resting cells follows first-order Monod model}

Upon exposure to $\mathrm{Pd}(\mathrm{II})$, cell suspension of the WT gradually turned black, suggesting that $\mathrm{Pd}(\mathrm{II})$ was reduced by $S$. oneidensis to $\mathrm{Pd}(0)$, which was further confirmed by the decrease in $\mathrm{Pd}(\mathrm{II})$ concentration in the aqueous phase and the formation of $\mathrm{Pd}(0)$ crystals in the cultures revealed by energy-dispersive X-ray spectroscopy and X-ray diffraction. Experiments conducted with various initial $\mathrm{Pd}(\mathrm{II})$ concentrations showed that the $\mathrm{Pd}(\mathrm{II})$ reduction rate by MR-1 cell suspension increased with increasing initial $\mathrm{Pd}(\mathrm{II})$ concentrations (Figure 4.1). 


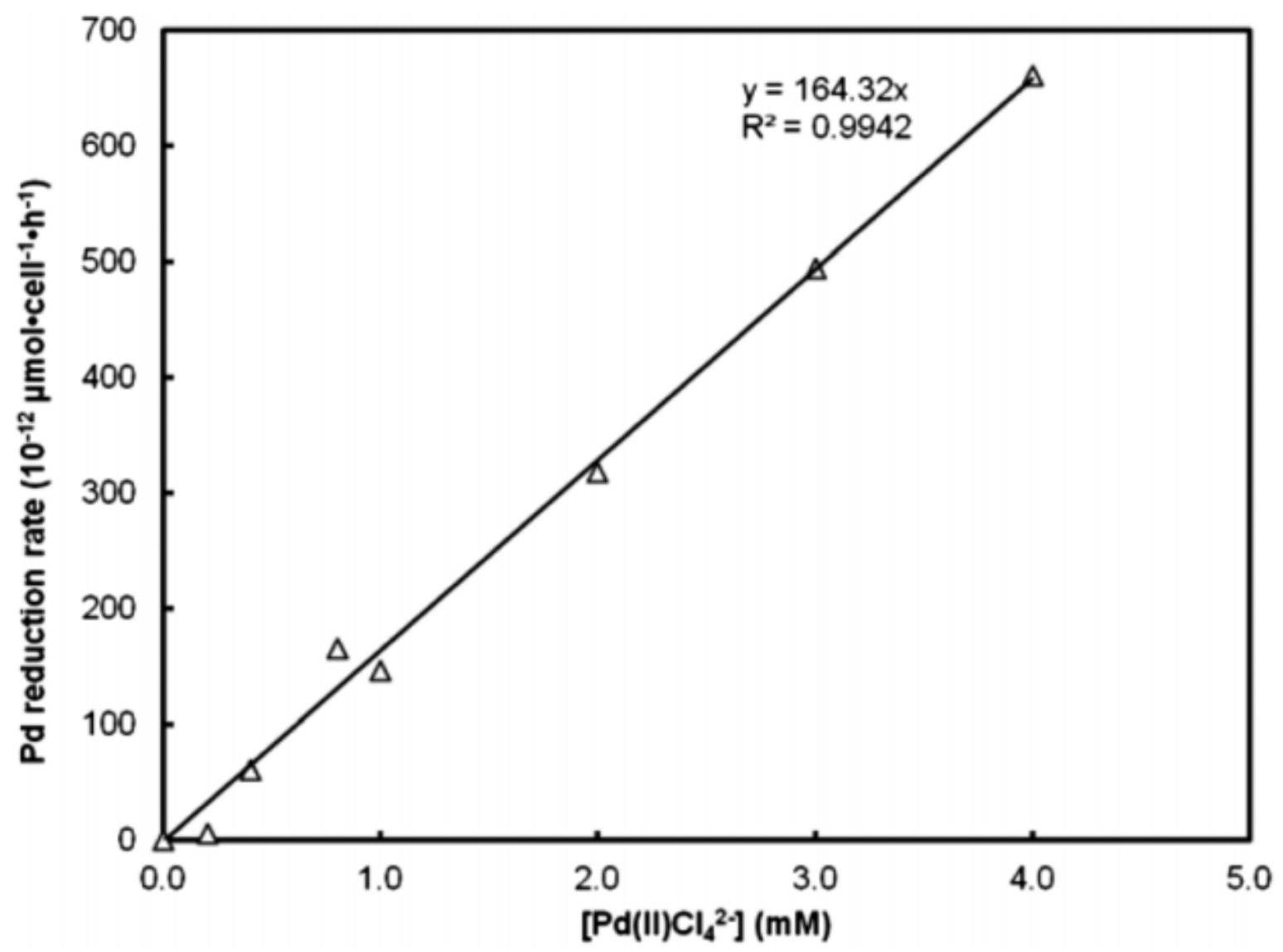

Figure 4.1. The rate of $\mathrm{Pd}(\mathrm{II})$ reduction by $S$. oneidensis with formate as an electron donor measured as a function of initial $\mathrm{Pd}(\mathrm{II})$ concentration at $30{ }^{\circ} \mathrm{C}$. The solid line represents the best fit. The rate of Pd reduction can be well described by a first-order model $-\mathrm{d}[\mathrm{Pd}(\mathrm{II})] / \mathrm{dt}=\mathrm{k}_{1} \times$ $[\operatorname{Pd}(\mathrm{II})]$ where the parameter $\mathrm{k}_{1}$ was determined to be $164.3 \mathrm{~h}^{-1}$ per cell in the reduction of $\operatorname{Pd}(\mathrm{II})$ within the concentration range of $0-4 \mathrm{mM}$.

Monod model and its derivatives under no-growth conditions have been used to describe the bioreduction kinetics for metals such as $\mathrm{Fe}(\mathrm{III}), \mathrm{Co}(\mathrm{II}), \mathrm{U}(\mathrm{VI}), \mathrm{Cr}(\mathrm{VI})$ and $\mathrm{Tc}(\mathrm{VII})$ ( $\mathrm{Liu}$, Gorby et al. 2002). Reductive formation of $\mathrm{Pd}(0)$ nanoparticles by $S$. oneidensis has been previously reported (Windt, Aelterman et al. 2005, De Windt, Boon et al. 2006) and the biogenic $\operatorname{Pd}(0)$ nanoparticles have been characterized and applied to various applications 
(De Corte, Hennebel et al. 2012, Hennebel, De Corte et al. 2012). However, bioreduction kinetics for $\mathrm{Pd}(\mathrm{II})$ reduction has never been elucidated. Here, we demonstrated that $\mathrm{Pd}(\mathrm{II})$ reduction by $S$. oneidensis could be well described by a first-order model derived from the Monod model. No inhibition effects were incorporated in the first-order model, suggesting that the (by)products of the $\mathrm{Pd}(\mathrm{II})$ reduction have no significant effects on the bioreduction activity. Although the first-order model fits our macroscopic $\mathrm{Pd}(\mathrm{II})$ reduction results well, a fundamental understanding of the reduction mechanisms is required for a better interpretation of the kinetics. Bioreduction of $\mathrm{Pd}(\mathrm{II})$ by microorganisms in the presence of an electron donor is believed to occur in three concomitant steps: (i) biosorption of $\operatorname{Pd}(\mathrm{II})$ onto cell surfaces, (ii) bioreduction of $\operatorname{Pd}(\mathrm{II})$ to $\operatorname{Pd}(0)$, and (iii) autocatalytic reduction of $\operatorname{Pd}(\mathrm{II})$ on $\operatorname{Pd}(0)$ nuclei (Rotaru, Jiang et al. 2012). Thus, the macroscopic reduction results are most likely a combination of enzyme-mediated bioreduction and $\mathrm{Pd}(0)$-based autocatalytic reduction. Enzymatic reduction is expected to play an important role, especially at the initial stage and under conditions with high cellto- $\mathrm{Pd}(\mathrm{II})$ ratios. The complex biochemical and redox properties of bacterial surfaces pose a significant challenge to comprehensively uncover the underlying $\mathrm{Pd}(\mathrm{II})$ bioreduction mechanisms.

\subsubsection{Outer membrane c-type cytochromes MtrC/OmcA do not play an essential role in $\mathrm{Pd}(\mathrm{II})$ reduction}

The cell suspension was further examined using light microscopy by overlay of brightfield and fluorescence imaging of DAPI-stained cells as well as using TEM. Representative images are shown in Figure 4.2. In Figure 4.2A, the black precipitates with a size of hundreds $\mathrm{nm}$ could be the aggregates of nanoparticles. The black 
precipitates were further extracted and the particle size distribution was analyzed. We found that, after ultrasonication, the size of the nanoparticles was in the range of $8-50$ $\mathrm{nm}$ with the majority in the range of $10-20 \mathrm{~nm}$ in diameter. Figure $4.2 \mathrm{~B}$ shows that the nanoparticles could be formed in the cell membrane.

A

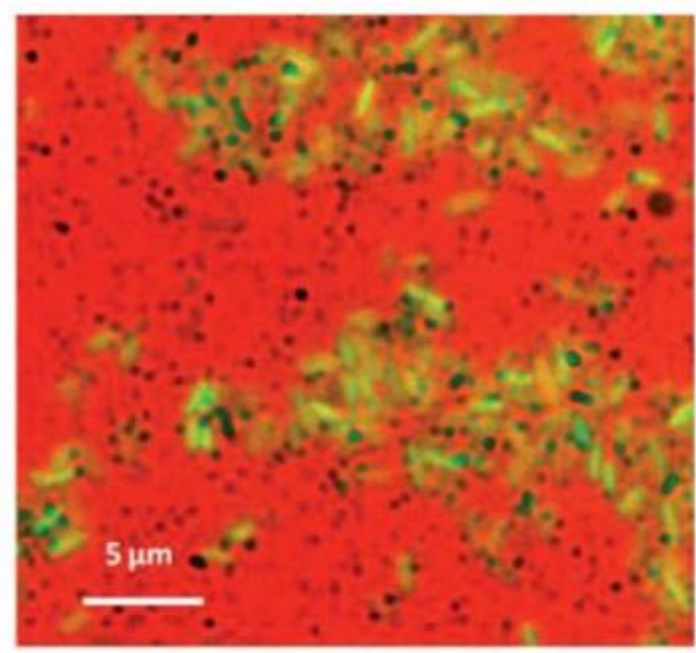

B

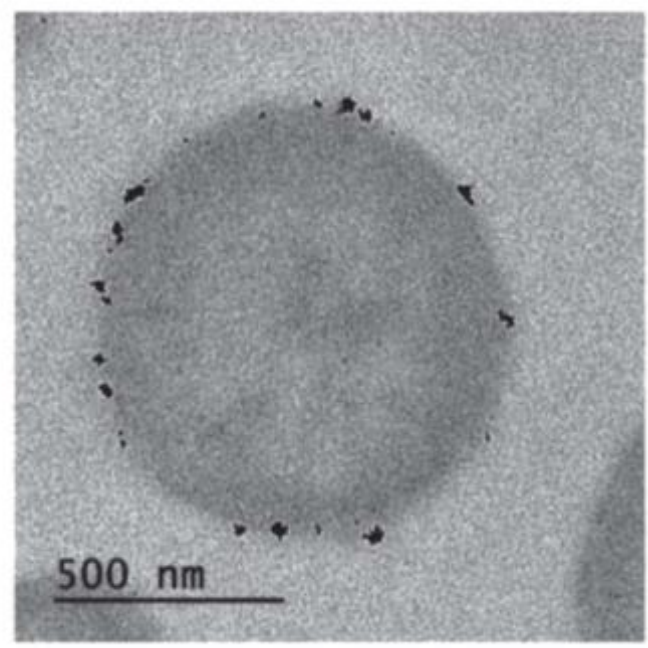

Figure 4.2. (A) Dispersion of $\operatorname{Pd}(0)$ nanoparticles (black) in a suspension of cells (green). Cells were stained with DAPI. For enhanced clarity, the image was pseudo-colored. (B) TEM image showing the association of $\operatorname{Pd}(0)$ nanoparticles with $S$. oneidensis MR-1.

A significant amount of $\mathrm{Pd}(0)$ nanoparticles were found in the cell exterior and associated with cell membrane, suggesting an important role of extracellular and/or membranebound proteins in $\mathrm{Pd}(\mathrm{II})$ reduction.

Previous studies have shown that OMCs, i.e., MtrC and OmcA, play an essential role in the reduction of various metals including $\mathrm{Fe}(\mathrm{III}), \mathrm{Cr}(\mathrm{VI}), \mathrm{Tc}(\mathrm{VII})$ and $\mathrm{U}(\mathrm{VI})$ (Marshall, Beliaev et al. 2006, Belchik, Kennedy et al. 2011). To elucidate whether the OMCs, i.e., MtrC and OmcA, facilitate $\mathrm{Pd}(\mathrm{II})$ reduction, we compared $\mathrm{Pd}(\mathrm{II})$ reduction by S. oneidensis 
MR-1 WT and the cytochrome mutants with lactate or formate as electron donors and the results are shown in Figure 4.3.

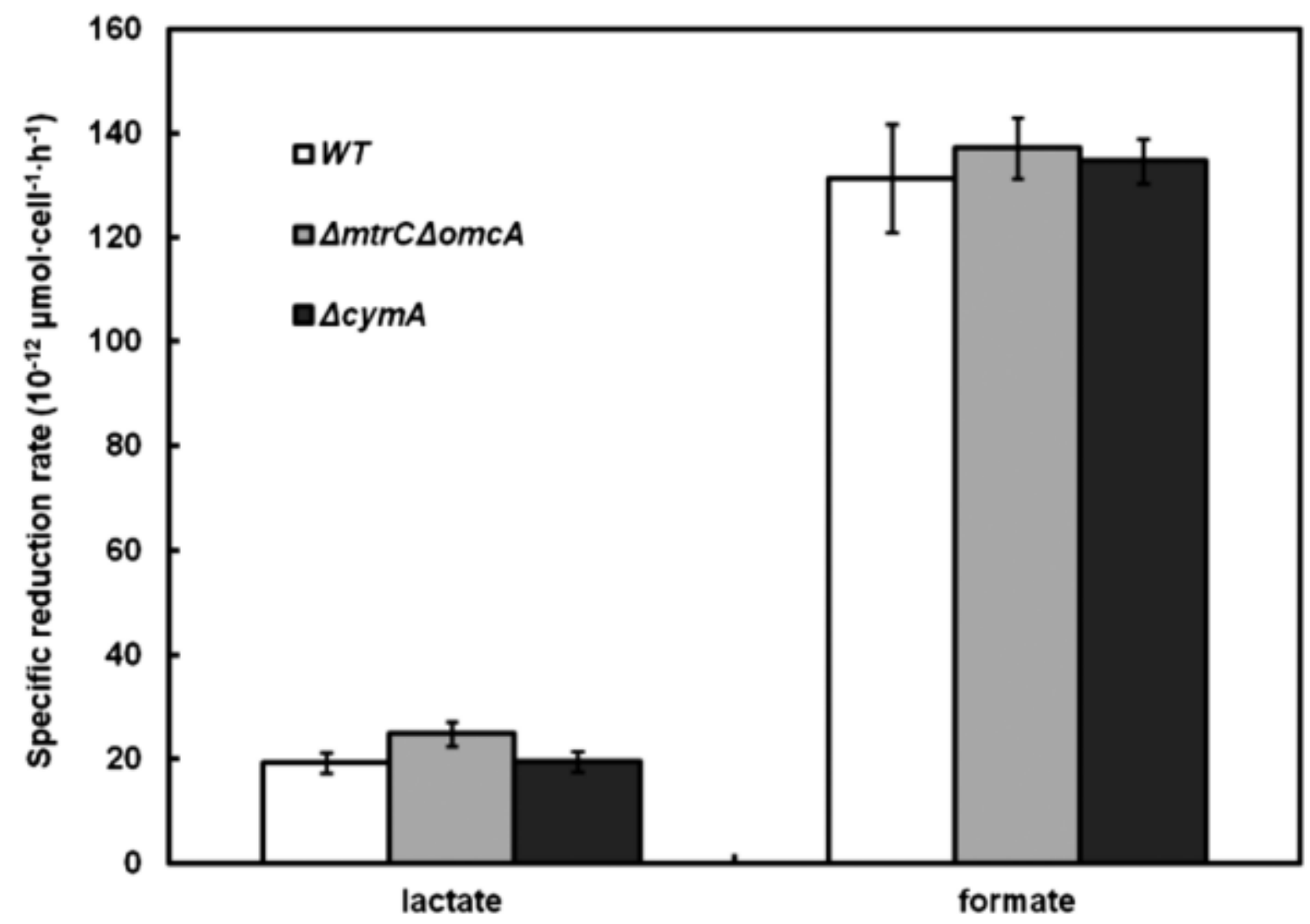

Figure 4.3. Specific rates of Pd(II) reduction (determined for the first 3 h) by S. oneidensis MR-1 WT and OMC mutants with $20 \mathrm{mM}$ lactate or formate as electron donors in $30 \mathrm{mM}$ HEPES buffer (pH 7.0) under no-growth conditions. Data represent the mean and standard deviation $(\mathrm{n}=3)$.

The experimental data demonstrated that no significant $\mathrm{Pd}(\mathrm{II})$ reduction occurs in the absence of live cells, suggesting an important role of enzymatic reduction. Intriguingly, our results showed that the mutants lacking MtrC/OmcA have a comparable capability of $\mathrm{Pd}$ (II) reduction with that of the WT, implying that the OMCs, MtrC/OmcA, do not play an essential role in $\mathrm{Pd}(\mathrm{II})$ reduction under our tested conditions. In a recent study, Bucking 
et al. reported a OMCs-independent reduction of extracellular electron acceptors in $S$. oneidensis, where two point mutations in MtrA and MtrB were found to regain the ability of the mutant lacking OMCs to grow as a dissimilatory metal reducer (Bücking, Piepenbrock et al. 2012). Hence, we further tested the mutant lacking CymA, a cytochrome transferring electrons to $\mathrm{Mtr} A$, in $\mathrm{Pd}(\mathrm{II})$ reduction. Interestingly, the mutant $\triangle$ cymA reduced $\mathrm{Pd}(\mathrm{II})$ as fast as the $\mathrm{WT}$, suggesting that the MTR-pathway does not play an essential role in $\mathrm{Pd}(\mathrm{II})$ reduction by $\mathrm{S}$. oneidensis. As one well-characterized extracellular electron transport chain in S. oneidensis, the MTR-pathway getting electrons from the quinone pool through CymA has been reported to be responsible for transferring electrons across cell membranes to a wide variety of extracellular electron acceptors, especially insoluble electron acceptors such as ferrihydrite (Shi, Squier et al. 2007, Shi, Rosso et al. 2012). Here we show that the MTR-pathway is not essential for Pd(II) reduction, implying that the electrons for $\mathrm{Pd}(\mathrm{II})$ reduction are taken from the upstream of the electron carrier CymA, possibly at the quinone pool level.

\subsection{3. [NiFe]-hydrogenase HyaB facilitates $P d(I I)$ reduction}

In addition to OMCs, hydrogenases comprise another class of redox proteins that can take electrons from the quinone pool and they have also been shown to be involved in the reduction of $\mathrm{Tc}(\mathrm{VII})$ to $\mathrm{Tc}(\mathrm{IV}) / \mathrm{Tc}(\mathrm{V})$ (Marshall, Plymale et al. 2008, Belchik, Kennedy et al. 2011). The redox potential of the $[\mathrm{Pd}(\mathrm{II}) \mathrm{Cl} 4 \mathrm{~d}] 2-/ \mathrm{Pd}(0)(\mathrm{s})$ couple is $600 \mathrm{mV}$ at the standard state (Atkins 2010). The [4Fe-4S] clusters of the [NiFe]-hydrogenase have mid-

point potentials of around $-300 \mathrm{mV}$ (Teixeira, Moura et al. 1989), indicating that it is thermodynamically feasible for hydrogenases to reduce $\operatorname{Pd}(\mathrm{II})$ to $\mathrm{Pd}(0)$. 
To test the involvement of hydrogenases in $\mathrm{Pd}(\mathrm{II})$ reduction in S. oneidensis, the capability of the mutants lacking hydrogenases in reducing $\mathrm{Pd}(\mathrm{II})$ in the presence of formate as electron donors was compared with that of the WT (Figure 4.4).

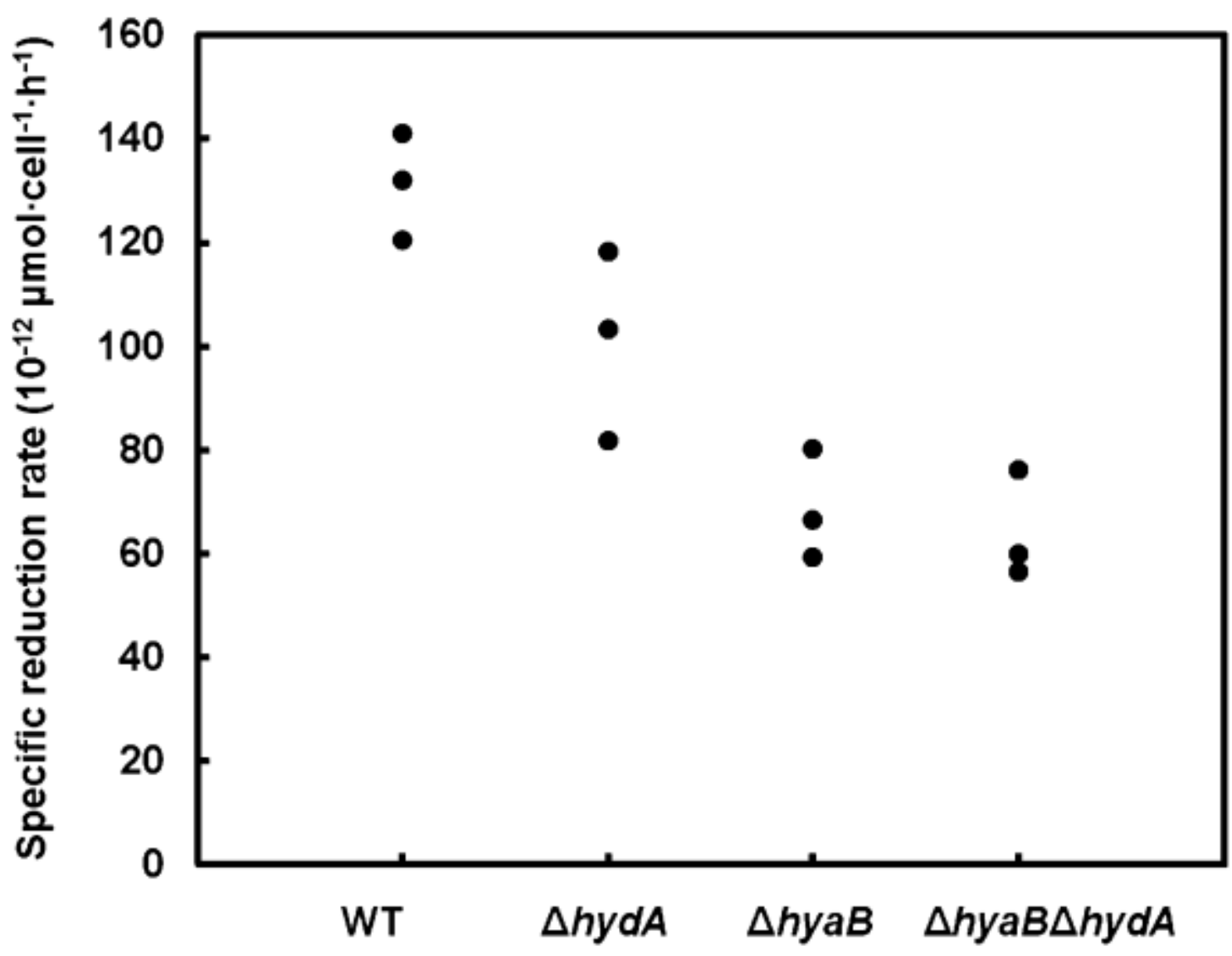

Figure 4.4. Specific rates of Pd(II) reduction by S. oneidensis MR-1 WT and hydrogenase mutants with $20 \mathrm{mM}$ formate as electron donors in $30 \mathrm{mM}$ HEPES buffer $(\mathrm{pH}$ 7.0) under no-growth conditions. Specific reduction rate was determined for the first $3 \mathrm{~h}$ of $\mathrm{Pd}(\mathrm{II})$ reduction.

The [FeFe]-hydrogenase mutant $(\Delta \mathrm{hyd} A)$ exhibited a comparable reduction rate to the WT, while both deletions of the [NiFe]-hydrogenase ( $\triangle$ hyaB and $\Delta h y a B-\Delta h y d A$ ) have significantly lower reduction rates than the WT. The results suggested that the $[\mathrm{NiFe}]-$ hydrogenase HyaB is a key enzyme facilitating $\mathrm{Pd}(\mathrm{II})$ reduction by $\mathrm{S}$. oneidensis. 
The involvement of unspecified hydrogenases in $\mathrm{Pd}(\mathrm{II})$ reduction by Desulfovibrio desulphuricans has been implicated by the inhibition of the bioreduction with $0.5 \mathrm{mM} \mathrm{Cu}^{2+}$, a hydrogenase inhibitor (Lloyd, Yong et al. 1998). However, the presence of $\mathrm{Cu}^{2+}$ could lead to conformational changes in proteins in general (Vardanyan and Trchounian 2010); hence, the inhibition might not be specific for hydrogenases. The direct evidence supporting the involvement of hydrogenases in bioreduction of $\mathrm{Pd}(\mathrm{II})$ by $D$. fructosivorans and E. coli was reported using mutant strains lacking hydrogenases (Mikheenko, Rousset et al. 2008, Deplanche, Caldelari et al. 2010). Here in this study, we showed that the periplasmic [NiFe]-hydrogenase $\mathrm{HyaB}$ played an important role in mediating $\mathrm{Pd}(\mathrm{II})$ reduction. It should be noted that, although [NiFe]-hydrogenase HyaB plays an important role in facilitating $\mathrm{Pd}(\mathrm{II})$ reduction, other enzymes may also mediate $\mathrm{Pd}(\mathrm{II})$ reduction as suggested by $\sim 50 \%$ of reduction capability remaining in the mutant strain lacking HyaB (Figure 4.4).

\subsubsection{Proposed mechanisms of hydrogenase-facilitated Pd(II) reduction}

Based on our results, we proposed a working model for the mechanisms of hydrogenasefacilitated $\mathrm{Pd}(\mathrm{II})$ reduction in S. oneidensis (Figure 4.5). 


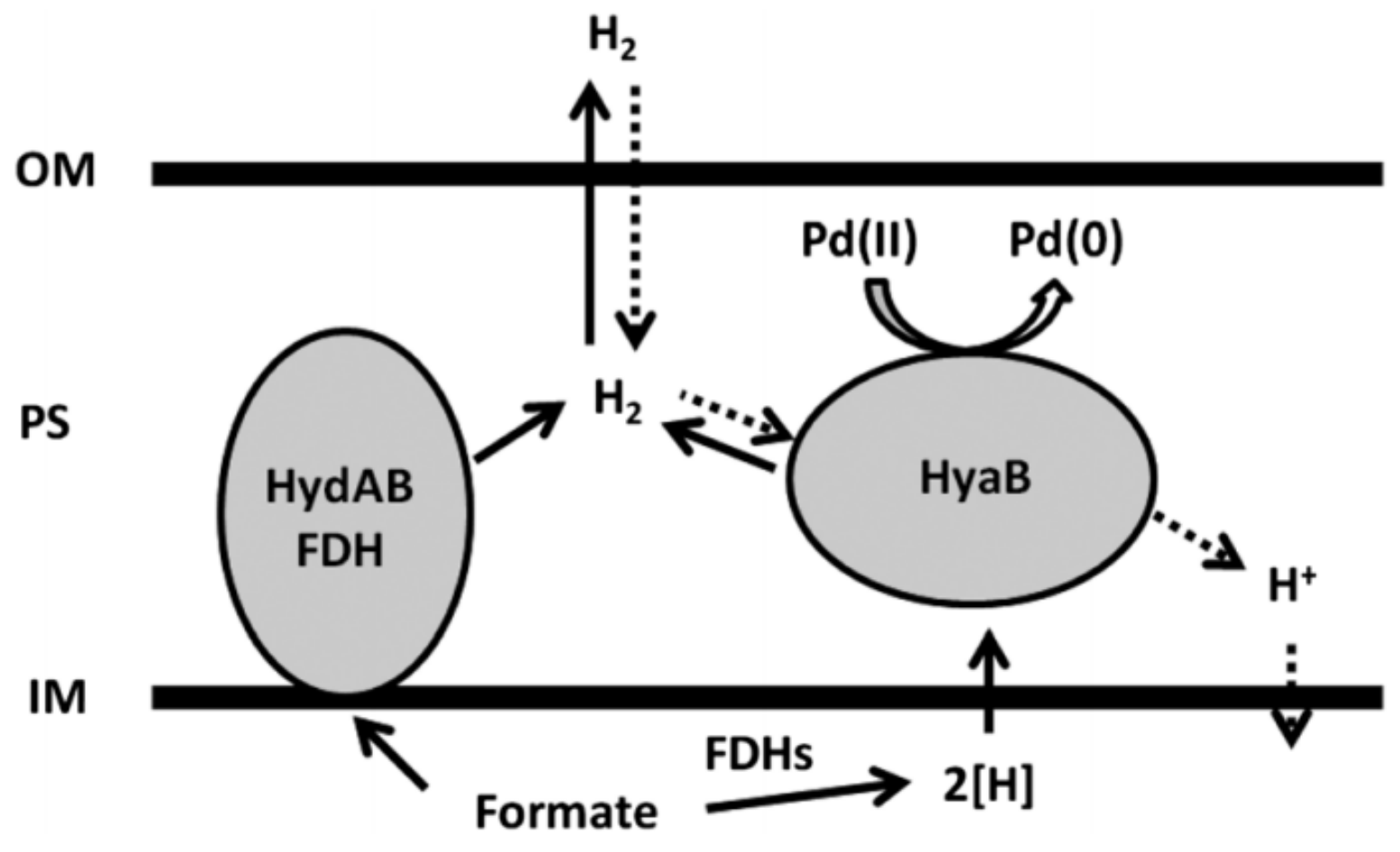

Figure 4.5. Model of hydrogenase-facilitated $\mathrm{Pd}(\mathrm{II})$ reduction by $S$. oneidensis with formate as electron donors.

The hydrogenases of $S$. oneidensis are located in the periplasm (Meshulam-Simon, Behrens et al. 2007, Marshall, Plymale et al. 2008, Shi, Belchik et al. 2011). The [FeFe]hydrogenase HydAB and a putative formate dehydrogenase FDH form a formatehydrogen lyase $(\mathrm{FHL})$ complex, mediating the conversion of formate to hydrogen, while the [NiFe]-hydrogenase HyaB can function bidirectionally in both formation and oxidation of hydrogen (Meshulam-Simon, Behrens et al. 2007). Using formate as electron donors, the cells may produce hydrogen via the FHL activity as well as the FDHs and HyaB activity. Hydrogen can be oxidized by HyaB coupling to the reduction of $\mathrm{Pd}(\mathrm{II})$. The reduced $\mathrm{Pd}$ products, presumably $\operatorname{Pd}(0)$ nanoparticles, are most likely accumulated in the periplasm. 
The released protons are then transported into the cytoplasm by proton transporters such as ATP synthase located in the inner membrane.

\subsection{Conclusion}

The reduction of $\mathrm{Pd}(\mathrm{II})$ by $S$. oneidensis can be well described by a first-order model. The OMCs, i.e., MtrC/OmcA, do not play an essential role in $\mathrm{Pd}(\mathrm{II})$ reduction under our tested conditions, while [NiFe]-hydrogenase (HyaB) facilitates $\mathrm{Pd}(\mathrm{II})$ reduction using lactate or formate as electron donors. Our findings suggest that [NiFe]-hydrogenase HyaB may serve as a potential target for molecular manipulation in $S$. oneidensis towards an improved performance in reductive formation of $\mathrm{Pd}$ nanoparticles. 


\section{CHAPTER 5: ENGINEERING BIOFILM WITH NANOCATALYTIC ACTIVITY THROUGH IN SITU BIOREDUCTIVE FORMATION OF PALLADIUM NANOPARTICLES IN THE BIOFILM MATRIX}

A portion of this chapter has been presented in oral format as $\mathrm{Ng} C K$ and Cao B (2016). Engineering biofilm for remediation of environmental Chromium(VI) contamination. 6th International Conference on Environment Science and Biotechnology, Kyoto, Japan and in poster format as $\mathrm{Ng} C K$, Ding Y and Cao B (2014). Understanding and harnessing the power of biofilm matrix: What we have learned from Shewanella biofilms. Biofilm6, Vienna, Austria.

\subsection{Introduction}

Biocatalysis using enzymes or microbial cells is an environmentally friendly process that has been increasingly applied to biotransformation in chemical industry (Bornscheuer, Huisman et al. 2012). Application of whole cells as biocatalysts is often preferred over isolated enzymes primarily because of higher catalyst stability, readily available selfgenerated cofactors, and relatively lower cost for whole cell biocatalysts (Woodley 2006). However, although whole cell biocatalysis has been extensive studied, it is so far mainly limited to batch and fed-batch processes where planktonic cells are used as the workhorse (Rosche, Li et al. 2009). The performance of biocatalysis is often hampered by chemical toxicity imposed by substrate and/or product (Gross, Hauer et al. 2007). In addition, cell retention and long-term viability are among the challenges that are posed to more cost effective continuous bioprocesses (Rosche, Li et al. 2009).

Microbial biofilms might deliver a solution. Biofilms are structured, surface-associated, microbial communities that are prevalent in most natural environments, engineering 
systems and clinical settings. One of the most important features of a biofilm is the presence of extracellular polymeric substances (EPS) that form a matrix and encase the cells in the biofilm. Extensive studies have demonstrated a wide range of advantages of the presence of EPS matrix for the biofilm mode of life (Flemming and Wingender 2010, Flemming 2011). Thanks to the EPS matrix, cells in biofilms often form structurally stable communities and show a remarkable resistance against various biocides. In biofilm-based biocatalysis, EPS matrix may offer the biocatalysts the advantages of self-immobilisation and long-term activity. In addition, the robust structures of biofilms might render them capable of tolerating harsh physicochemical conditions such as toxic reactants or solvents, allowing continuous biocatalysis for reactions that are biologically challenging for planktonic cells (Rosche, Li et al. 2009, Halan, Schmid et al. 2010). To date, the use of biofilms in biocatalysis processes has been largely confined to wastewater treatment (Cohen 2001, Wuertz, Bishop et al. 2003, Singh, Paul et al. 2006). The exploration of applying biofilms as biocatalysts in chemical industry is still in its infancy due to the fact that the analyses and control of biofilms-based bioprocesses are very challenging because of the intrinsic highly heterogeneous and spatiotemporally dynamic properties of biofilms (Rosche, Li et al. 2009, Halan, Schmid et al. 2010). With an enhanced understanding of biofilm biology, the use of biofilms as biocatalysts for the synthesis of simple organic compounds such as converting benzaldehyde to benzyl alcohol and styrene to (S)-styrene oxide has been reported (Li, Webb et al. 2006, Gross, Hauer et al. 2007, Halan, Schmid et al. 2010). To further engineer the catalytic activities of the biofilms, recombinant bacterial strains capable of producing certain enzymes for specific biotransformation have been explored (Tsoligkas, Winn et al. 2011, Winn, Foulkes et al. 
2012). For industrial applications, multifunctional catalysts are usually required. To this end, constructing biofilms containing multiple species catalysing a series of reactions in a type of reaction cascade has been suggested as an interesting approach (Stubblefield, Howery et al. 2010). However, the development of robust, functionally reproducible and controllable multispecies biofilms is hampered by limited understanding of dynamic interspecies interactions in biofilms.

The ability of certain microorganisms to reduce metal ions to zero-valent metallic nanoparticles may provide a novel strategy for developing multifunctional biocatalysts. Precious metals such as palladium (Pd) have been widely used as catalysts for numerous reactions in chemical, pharmaceutical, automotive and electronics industries (Das 2010). Microorganisms have the potential to reduce soluble Pd species to zero-valent Pd, i.e., $\operatorname{Pd}(0)$, resulting in the formation of highly reactive $\mathrm{Pd}(0)$ nanoparticles that may be directly used in various nanocatalysis conversions (Hennebel, De Gusseme et al. 2009, Gadd 2010, Lloyd, Byrne et al. 2011, De Corte, Hennebel et al. 2012, Hennebel, De Corte et al. 2012). Hence, we hypothesize that it may be possible to engineer biofilms with nanocatalytic activities through bioreduction of $\mathrm{Pd}$ and biofilm matrix-facilitated immobilisation of the reduction products, i.e., $\mathrm{Pd}(0)$ nanoparticles.

To test this hypothesis, we used Shewanella oneidensis as a model organism because it is a well-documented metal-reducing bacterium capable of reducing a wide range of metal ions including Pd and the extracellular electron transport chains responsible for moving electrons across cell membrane have been relatively well characterized (Shi, Squier et al. 2007, Fredrickson, Romine et al. 2008, Shi, Richardson et al. 2009, Richardson, Edwards et al. 2012, Shi, Rosso et al. 2012). The objectives of this study were (i) to explore the 
reductive formation of $\mathrm{Pd}(0)$ nanoparticles in biofilms (or "nanocatalysation") under ambient conditions, (ii) to understand the metabolic responses of the biofilms during the "nanocatalysation" process, (iii) to develop a robust nanocatalytic biofilm through genetic engineering. This study demonstrated for the first time the engineering of biofilms for nanocatalytic activity through in situ formation of nanocatalysts in biofilm matrix and influencing the robustness of the biofilm via increasing intracellular cyclic-di-GMP level. This study provided the basis for a novel strategy to develop robust, multifunctional biofilm-based biocatalysts.

\subsection{Materials and Methods}

\subsubsection{Bacterial strains and growth conditions}

E. coli and S. oneidensis MR-1 wild-type (WT) and mutants used in this study are described in Table 5.1. Stock cultures were maintained in LB medium with $20 \%$ glycerol at $-80^{\circ} \mathrm{C}$. The bacterial cells were grown in LB medium or modified M1 medium under aerobic or anaerobic conditions. The modified M1 medium $(\mathrm{pH} \sim 7.0)$ consisted of 3.00 mM PIPES, $7.50 \mathrm{mM} \mathrm{NaOH}, 26.04 \mathrm{mM} \mathrm{NH}_{4} \mathrm{Cl}, 1.34 \mathrm{mM} \mathrm{KCl}, 4.35 \mathrm{mM} \mathrm{NaH}_{2} \mathrm{PO}_{4}$ and $0.68 \mathrm{mM} \mathrm{CaCl} 2$ supplemented with trace amounts of minerals, vitamins, and amino acids (Cao, Shi et al. 2011). For bacterial growth in M1 medium, $20 \mathrm{mM}$ sodium lactate or sodium formate was used as an electron donor and the sole carbon source. For growth under anaerobic conditions, the medium containing $10 \mathrm{mM}$ ferric nitrilotriacetate ( $\mathrm{Fe}(\mathrm{III})$ NTA) as an electron acceptor was bubbled with nitrogen gas for 5 min and the headspace in the culture was less than $3 \%$ of the total volume. 
Table 5.1. S. oneidensis strains used in this study.

\section{Strains / Plasmid Description References}

\section{Strains}

S. oneidensis Manganese-reducing strain (Myers and Nealson

MR-1

1988)

$\Delta \boldsymbol{m t r C} \quad$ Deletion derivative of S01778 (Marshall, Plymale et al.

( $m$ trC) within MR-1 2008)

AomcA Deletion derivative of S01779 (Marshall, Plymale et al.

(omcA) within MR-1 2008)

E. coli DH5a Laboratory strain (Zhang, $\mathrm{Ng}$ et al. 2014)

\section{Plasmids}

pYedQ2 Gm ; pBBR1MCS3 carrying the (Gjermansen, Ragas et

YedQ gene al. 2006)

pRK600 Cmº oriColE1 RK2-Mob+ RK2- (Kessler, Lorenzo et al.

$\mathrm{Tra}^{+}$; helper vector for conjugation 1992) 


\subsubsection{Construction of c-di-GMP mutants}

YedQ (previously known as $y h c K$ ) gene from E. coli is cloned from the $p Y e d Q$ plasmid in HindIII/BamHI side of pBBR1MCS-5 plasmid vector to make the pYedQ2 plasmid.

The S. oneidensis MR-1 mutant that overexpresses c-di-GMP was constructed via plate mating as follows: S. oneidensis MR-1, Escherichia coli containing RK600, Escherichia coli -DH5a- $p$ YedQ2 were grown using LB media overnight in shaking incubator (200 rpm) at $30{ }^{\circ} \mathrm{C}, 37^{\circ} \mathrm{C}$ and $37{ }^{\circ} \mathrm{C}$ respectively. Antibiotics such as chloramphenicol and gentamicin were used in cell culturing when necessary. $1 \mathrm{ml}$ of the culture from each of the three strains was washed two times with fresh LB medium, using centrifugation at $10000 \times \mathrm{g}$ for 3 minutes. The cell pellets from each of the three strains was resuspended and mixed at 1:1:1 ratio in $1 \mathrm{ml}$ of LB media. Centrifugation was done to obtain a cell pellet containing cells from all three strains in equal proportions. The cell pellet was transferred to a LB agar plate and incubated in $30^{\circ} \mathrm{C}$ for 5 hours. The cells were harvested from the plate via washing with $1 \mathrm{ml}$ of $0.9 \%$ sodium chloride solution (saline). $100 \mathrm{ul}$ of cells were spread on a LB agar plate containing $20 \mathrm{ug} / \mathrm{ml}$ tellurite and $60 \mathrm{ug} / \mathrm{ml}$ gentamicin, and kept in incubator at $30^{\circ} \mathrm{C}$ until transposon mutant colonies appeared. Gel electrophoresis was run with the plasmid extracted from the selected mutant as a confirmation that the selected mutant indeed contains the $p Y e d Q 2$ plasmid. Swim plate experiments were done in LB agar plates. All swim plates experiments were conducted with five replicates. 


\subsubsection{Growth of S. oneidensis biofilms and $\mathrm{Pd}(\mathrm{II})$ reduction}

Three independent biofilms of S. oneidensis MR-1 WT and c-di-GMP mutants were grown in tubular biofilm reactors ( $\sim 25 \mathrm{~cm}$ of 16 " silicon tubings) using 10 times diluted LB medium containing $10 \mathrm{mM}$ lactate continuously supplied through a peristaltic pump at a flow rate of $8 \mathrm{ml} / \mathrm{h}$. The flow system was assembled and prepared as described previously (Sternberg and Tolker-Nielsen 2006). Each tubular reactor was inoculated by injecting 2 $\mathrm{ml}$ overnight culture (diluted to an $\mathrm{OD}_{600}$ of 0.01 ) using a syringe. After inoculation, the medium flow was stopped for $1 \mathrm{~h}$ to allow initial attachment followed by continuous media flow with a flow rate of $8 \mathrm{ml} / \mathrm{h}$.

The $S$. oneidensis biofilms were allowed to grow for $72 \mathrm{~h}$, and then the feed medium was loaded with $1 \mathrm{mM} \mathrm{Pd(II).} \mathrm{Effluent} \mathrm{samples} \mathrm{were} \mathrm{collected} \mathrm{and} \mathrm{the} \mathrm{concentration} \mathrm{of} \mathrm{Pd}(\mathrm{II})$ was determined using the colorimetric method described above. The same setup with no biofilms growing in it served as a control. The amount of $\mathrm{Pd}$ accumulated in the biofilms was estimated by subtracting the total amount of $\mathrm{Pd}(\mathrm{II})$ introduced into the biofilm reactors by the amount of $\mathrm{Pd}(\mathrm{II})$ remained in the effluents. Samples from the media effluents were taken periodically and cell detachment was evaluated by counting colony forming unit (CFU) using the drop-plate method described elsewhere (Chen, Nace et al. 2003).

Dissolved oxygen (DO) concentration was continuously monitored (5 s interval) using a flow-through optical oxygen microsensor (Pyro-Science OXFTC, Aachen, Germany) connected to the outlet of the tubular biofilm reactor. The signal from the microsensor was processed by the sensor meter (Pyro-Science FireSting O2-4, Aachen, Germany). Before starting measurements, two-point calibration was carried out in anoxic water and air- 
saturated water. DO concentration at different depth in the biofilms was measured using a retractable needle-type oxygen microsensor (tip diameter ca. $50 \mu \mathrm{m}$ ) (Pyro-Science OXR50, Aachen, Germany) connected to a micromanipulator (Pyro-Science MUX2, Aachen, Germany).

\subsubsection{Biofilm viscosity}

The viscosity of biofilm samples was measured using a Physica MCR 301 rheometer (Anton Paar). Biofilms of WT and c-di-GMP mutant were prepared by dropping $100 \mathrm{ul}$ of overnight cultures $\left(\mathrm{OD}_{600} \sim 1.5\right)$ onto $0.45 \mu \mathrm{m}$ filter membranes (diameter $87 \mathrm{~mm}$, Schleicher \& Schuell, Dassel, Germany) placing on LB agar and incubating at $30^{\circ} \mathrm{C}$ for $24 \mathrm{~h}$. The membranes with biofilms were then transferred to the rheometer and the viscosity of each biofilm was determined as previously described (Lieleg, Caldara et al. 2011, Powell, Sowedan et al. 2013).

\subsubsection{Epifluorescence microscopy}

After continuously exposing to $\mathrm{Pd}(\mathrm{II})$ for 2 days, the biofilm-Pd association was harvested and a portion of the biofilms were resuspended in HEPES buffer $(30 \mathrm{mM}, \mathrm{pH} 7.0)$ to a final cell density of $\sim 10^{9} \mathrm{cells} / \mathrm{ml}$. One drop of the suspension was placed on a piece of microscopy glass slide and was dried in an oven at $70^{\circ} \mathrm{C}$. The dried sample was then stained using 4'-6-Diamidino-2-phenylindole (DAPI). Briefly, $5 \mu \mathrm{l}$ of DAPI solution (1 $\mathrm{mg} / \mathrm{mL}$ ) was dropped onto the sample and incubated at room temperature in dark for 45 min. The glass slide was then rinsed with ultrapure water to remove excess DAPI. Then the stained samples were examined under an inverted epifluorescence microscope (Microscope Axio Observer.Z1, Carl Zeiss). 


\subsubsection{Field emission scanning electron microscopy and energy-dispersive $X$-ray spectroscopy}

Biofilm samples were re-suspended in MilliQ water. A portion of each suspension was dried under vacuum and then coated with platinum using a vacuum electric sputter coater (JEOL JFC-1300, JEOL Asia Pte. Ltd., Singapore). SEM images were then taken using a Field Emission Scanning Electron Microscope (FE-SEM, JSM-7600, JEOL Asia Pte. Ltd., Singapore) at a voltage of 2.0-5.0 kV. EDX spectrum was obtained using an energydispersive X-ray spectroscope (AZtecEnergy, Oxford Instruments, Oxfordshire, UK).

\subsubsection{X-ray diffraction}

To further characterize the Pd associated with the biofilms, X-ray diffraction (XRD) analysis of the dried biofilms-Pd association was performed using a Brag-Brentano diffractometer (Bruker D8 Advanced) in $\theta-2 \theta$ configuration with a Cu Ka line at 0.15418 $\mathrm{nm}$ as a source generated by a copper X-ray tube with power $2.2 \mathrm{~kW}(40 \mathrm{kV}, 40 \mathrm{~mA})$. Measurements were performed in the range of $2 \theta=20-90$ degrees.

\subsubsection{Biofilm-associated Pd nanoparticles}

The biofilm-Pd association was resuspended in HEPES buffer (30 mM, pH 7.0) and the cell suspensions were centrifuged at $10,000 \times \mathrm{g}$ for $5 \mathrm{~min}$. The pellet contained cells and cell-associated Pd nanoparticles. Matrix-associated Pd nanoparticles in the supernatants were further harvested by using ultracentrifugation at $100,000 \times \mathrm{g}$ for $30 \mathrm{~min}$, washed three times with MilliQ water and dried at $50^{\circ} \mathrm{C}$ under vacuum. Both the cell- and matrixassociated nanoparticles were subjected to further analyses. 


\subsubsection{Size distribution and zeta-potential measurements}

The hydrodynamic diameters and the zeta potential of the matrix-associated Pd nanoparticles were determined using a Zetasizer (Nano ZS, Malvern Instruments; Worcestershire, UK). For the size distribution measurement, the nanoparticles were first suspended in ultrapure water and subjected to ultrasonication for $10 \mathrm{~min}$ before the sample was transferred into a cuvette. Three readings were taken for each sample, and each reading was made up of the average of 12 to 21 individual measurements. For the zeta-potential measurement, each reading was made up of the average of 3 individual measurements.

\subsubsection{Transmission electron microscopy}

For the matrix-associated Pd nanoparticles, about $3 \mu \mathrm{l}$ was applied to a carbon-coated copper grid and dried in the air for transmission electron microscope (TEM) imaging using a Jeol JEM-1230 TEM instrument operated at an accelerating voltage of $120 \mathrm{kV}$. For biofilms, samples were fixed in $2.5 \%$ glutaraldehye overnight and centrifuged at $5000 \times \mathrm{g}$ for $5 \mathrm{~min}$, and the supernatant was discarded. The cells were resuspended and washed with $10 \mathrm{mM}$ PIPES buffer ( $\mathrm{pH}$ 6.8) at $5000 \times \mathrm{g}$ for $5 \mathrm{~min}$ (repeated three times). Gradual dehydration was carried out in ethanol series $30,50,75,90 \%$ for 30 min each and then $100 \%$ ethanol 3 times for $1 \mathrm{~h}$ each. The cell pellet was further washed for $30 \mathrm{~min}$ in ethanol and LR white (Electron Microscopy Sciences, Hatfield, PA) (50:50). Finally, the cell pellet was washed 3 times using resin for $1 \mathrm{~h}$ each (at 5,000 $\mathrm{xg}$ for $5 \mathrm{~min}$ ). After the final wash with resin, the resin was discarded, and the Eppendorf tube containing the cell pellet was filled with fresh resin ( $\sim 3 / 4$ volume) and incubated at $60^{\circ} \mathrm{C}$ overnight. The polymerized 
block of cell pellets was sectioned with a diamond knife (Diatome, Biehl, Switzerland) to a thickness of $70 \mathrm{~nm}$ and mounted on a Cu grid and sputtered with carbon. These sections were examined using a Jeol JEM-1230 TEM instrument operated at an accelerating voltage of $120 \mathrm{kV}$.

\subsubsection{Catalytic activity of the biofilms}

The harvested biofilms were suspended in HEPES buffer (30 mM, pH 7.0), centrifuged at $6,000 \times \mathrm{g}$ for $20 \mathrm{~min}$, and washed with the same buffer. Both the cell- and matrixassociated fractions of the nanoparticles were evaluated for their catalytic activities in dechlorination reaction. Each fraction $(\sim 10 \mathrm{mg}, 2 \mathrm{mg}$ and $12 \mathrm{mg}$ for cell-nanoparticles, matrix-nanoparticles and biofilm-nanoparticles associations, respectively) was added into an anaerobic bottle containing $20 \mu \mathrm{M}$ sodium formate and $40 \mathrm{mM}$ trichloroethylene (TCE) in HEPES buffer (30 mM, pH 7.0). The reaction system was flushed with nitrogen gas before incubating at room temperature on a shaker (200 rpm). An air-tight syringe was used to draw an aliquot of headspace from the anaerobic glass tubes at different time points. The concentration of TCE was determined using a gas chromatography as previously described (Hennebel, Simoen et al. 2009).

\subsubsection{Proteomics analysis}

\subsubsection{Preparation of cellular proteins}

LB cultures of $S$. oneidensis at the mid-exponential growth phase were exposed to 1,5 , and $10 \mathrm{mM} \mathrm{Pd}(\mathrm{II})$. After 30-min exposure, each culture was pelleted by centrifugation at $5,000 \times \mathrm{g}$ for $20 \mathrm{~min}$, and the pellet was then washed twice using PBS buffer. One set of 
cultures with no $\mathrm{Pd}(\mathrm{II})$ exposure was used as control $(0 \mathrm{mM})$. The harvested cells were lysed at $4{ }^{\circ} \mathrm{C}$ in lysis buffer $(0.1 \%$ SDS, $0.5 \mathrm{M} \mathrm{TEAB}, 50 \mathrm{mM}$ protease inhibitor tablet) with intermittent vortexing and sonication. The lysate was centrifuged at $20,000 \times \mathrm{g}$ for $1 \mathrm{~h}$ at $4{ }^{\circ} \mathrm{C}$ and supernatant will be stored at $-80^{\circ} \mathrm{C}$. Protein concentration was estimated using BCA assay.

\subsubsection{2. iTRAQ labelling}

Proteins $(25 \mu \mathrm{g})$ of each sample was reduced with $53 \mathrm{mM}$ TCEP (tris(2-carboxyethyl) phosphine) for $30 \mathrm{~min}$ at $37^{\circ} \mathrm{C}$ and alkylated using $10 \mathrm{mM}$ iodoacetamide for $30 \mathrm{~min}$ at room temperature in the dark. After reduction and alkylation, each sample was then digested with sequencing-grade porcine modified trypsin (Promega, Madison, WI, USA) at a trypsin to protein ratio of $1: 10$ at $37^{\circ} \mathrm{C}$ for $16 \mathrm{~h}$. The iTRAQ 4-plex kit (AB SCIEX, Foster City, CA, USA) was used to label the 4 samples according to the manufacturer's instructions. Protein samples from the cultures exposed to $0,1,5$ and $10 \mathrm{mM} \mathrm{Pd}(\mathrm{II})$ were labelled with iTRAQ reagents 114, 115, 116 and 117, respectively. After $1 \mathrm{~h}$ incubation at room temperature, the 4 labelled samples were pooled into one set. To remove any unbound labels, excess trypsin and SDS, the sample was cleaned using strong cation exchange (SCX) chromatography followed by reverse phase (RP) chromatography using an Opti-Lynx cartridge holder (Applied Biosystems, Foster City, CA, USA) and a syringe pump (KD Scientific, Holliston, MA, USA) at a flow rate of $9.5 \mathrm{ml} / \mathrm{h}$. The eluent was vacuum-dried and the peptides were re-dissolved in $0.05 \%$ heptafluorobutyric acid (HFBA) $/ 1 \%$ formic acid. 


\subsubsection{3. $L C-M S / M S$ and data analysis}

Solubilised peptides were chromatographed twice (2 separate injections to provide technical replicates) by online strong cation exchange (SCX) and nano-C18 LC using an Ultimate HPLC, Switchos and Famos autosampler system (LC-Packings, Amsterdam, Netherlands). Peptide samples were loaded onto a small SCX micro trap (500 $\mu \mathrm{m} \times 12$ $\mathrm{mm}$, Poros S10, AB SCIEX, Foster City, CA, USA) and were eluted sequentially with 5 , $10,15,20,25,30,40,50,100,250,500$, and $1,000 \mathrm{mM}$ ammonium acetate $(20 \mu \mathrm{l})$. The initial unbound fraction and each salt step fraction were concentrated and desalted onto a micro-C18 pre-column ( $500 \mu \mathrm{m} \times 2 \mathrm{~mm}$; Michrom Bioresources, Auburn, CA, USA) at 15 $\mu \mathrm{l} / \mathrm{min}$. After a 10-min wash, the pre-column was switched (Valco 10 port valve, Dionex) in line with a fritless nano analytical column $(75 \mu \mathrm{m} \times 10 \mathrm{~cm})$ containing $\mathrm{C} 18$ reverse phase media (5 $\mu \mathrm{m}, 200 \AA$ A, Magic, Michrom Bioresources, Auburn, CA, USA) eluted with a linear gradient of acetonitrile $(\mathrm{ACN})$ in $0.1 \%(\mathrm{v} / \mathrm{v})$ formic acid from $2 \%$ to $36 \% \mathrm{ACN}$ for $74 \mathrm{~min}$, followed by $1 \mathrm{~min}$ at $90 \% \mathrm{ACN}$ at $\sim 300 \mathrm{nl} / \mathrm{min}$. The column was connected via a fused silica capillary to a low-volume tee (Upchurch Scientific, Oak Harbor, WA, USA) where high voltage $(2,300 \mathrm{~V})$ was applied and the column tip was positioned $\sim 1 \mathrm{~cm}$ from the orifice of a QStar Elite mass spectrometer (AB SCIEX, Foster City, CA, USA). The QStar was operated in information-dependent acquisition mode. A time-of-flight (TOF) MS survey scan was acquired (m/z 350-1750). The 3 most abundant multiply charged ions (counts $>25$ ) were sequentially selected by the quadrupole for Tof MS/MS analysis. Tandem mass spectra were accumulated for up to $2.5 \mathrm{~s}(\mathrm{~m} / \mathrm{z} 65-2,000)$ using the Advanced IDA parameters automatic MS/MS accumulation (set to 20) and automatic collision energy. Protein identification and relative abundance of proteins were 
determined using the ParagonTM algorithm in ProteinPilotTM 4.0 software (AB SCIEX, Foster City, CA, USA). Each MS/MS spectrum was compared with known sequences in

the NCBI non-redundant. Search parameters were set to: sample type, iTRAQ 4-plex (peptide labeled); cysteine alkylation, iodoacetamide; digestion, trypsin; identification focus, biological modifications; search effort, thorough ID. Ratios of the areas under the peaks at $114,115,116$ and 117 Da were calculated to determine a protein's relative abundance across all samples in the iTRAQ set. The following criteria were imposed on the data to identify significantly differentially abundant proteins: an unused protein score > 1.3 , which corresponds to a confidence limit of $95 \%$; at least 2 unique peptides with confidence $>95 \%$ detected; $p<0.05$ (Student's t-test, assuming equal variance) and relative abundance changes greater than 2 -fold. To correct for small differences in protein loading, the generated ratios of all detected proteins were normalised by bias correction with the ProteinPilotTM software.

\subsubsection{Static Biofilm assay and Motility assay}

Overnight cultures $(1 \mathrm{uL})$ of $S$. oneidensis MR-1 WT and c-di-GMP mutant were inoculated into 96-well plate containing 200 uL of Lysogeny Broth (LB) medium. 40 replicates of WT, 40 replicates of c-di-GMP mutant and 16 replicates of abiotic control were setup in the 96-well plate. The cultures were allowed to grow for 12 hours and 18 hours respectively before static biofilm assay was done for the two setups, in accordance to the microtiter plate biofilm assay protocol (Merritt, Kadouri et al. 2005).

In short, the 96-well plates were briefly washed with water to remove planktonic cells. $1 \%$ crystal violet were added to stain the biofilm attached to the walls of the well for 10 minutes. 
Excess crystal violet was washed away using water, and the crystal violet-stained biofilms were solubilised in $70 \%$ ethanol $(200 \mathrm{uL})$. The resultant mixture was transferred into corresponding wells in a separate, clean 96 -well plate to be analysed by a microtiter plate reader for optical density at wavelength of $550 \mathrm{~nm}\left(\mathrm{OD}_{550}\right)$. Using similar 96-well plate setup, WT and mutant cultures were allowed to incubate in $30^{\circ} \mathrm{C}$ under no-shaking condition, and $\mathrm{OD}_{600}$ readings were taken every 5 minutes for 20 hours.

\subsubsection{C-di-GMP extraction and quantification}

Three replicates of $S$. oneidensis MR-1 WT and mutant were grown for a specific duration according to the condition of the experiment. An aliquot $(2 \mathrm{ml})$ was taken from each culture and centrifuged for three minutes. The supernatant was discarded and the cell pellets were washed with $1 \mathrm{mM}$ ice-cold ammonium acetate. The respective cell suspensions were homogenized by passing five-times through a 20 -guage needle. After centrifugation, the cell pellets were suspended in 2-3 pellet volume of ice cold solution comprising of acetonitrile, methanol and water at 2:2:1 ratio. The resultant cell suspensions undergo ultrasound probe treatment at high power for 5 minutes in ice filled bath. The resultant cell suspensions were centrifuged and the supernatants were retained. The volume of the supernatants was reduced initially by temperature controlled speedvac to around $1 \mathrm{~mL}$, while the remaining solutions were subjected to lyophilisation. The samples were then suspended in 100-200 uL of $1 \mathrm{mM}$ ammonium acetate, sonicated for 10 minutes in ice

cold bath, and centrifuged for 5 minutes at $10000 \mathrm{rpm}$. The supernatants were transferred to glass inserts for analysis using Liquid Chromatography as previously described (Kuchma, Ballok et al. 2010). 


\subsubsection{Iron reduction and quantification}

Overnight cultures of $S$. oneidensis MR-1 WT and c-di-GMP mutant were subjected to centrifugation (10000 $\mathrm{xg}$ for 10 minutes), and the cell pellets were harvested and washed thrice using $30 \mathrm{mM}$ HEPES buffer. The cells were suspended in the HEPES buffer, and the final $\mathrm{OD}_{600}$ of 0.1 were achieved for all the cell suspensions. The cell suspensions were placed in anaerobic glass tubes capped with butyl rubber, with three replicates each for WT and c-di-GMP mutant, and each setup was bubbled with $\mathrm{N}_{2}$ gas for 10 minutes. Sodium lactate and Fe-NTA were subsequently added into the set-up in an anaerobic chamber (Shel Lab, Cornelius, USA), to a final concentration of $20 \mathrm{mM}$ and $10 \mathrm{mM}$ respectively. Iron quantification was done using Ferrozine Assay as previously described (Riemer, Hoepken et al. 2004).

\subsubsection{Western blotting}

Culture of $S$. oneidensis MR-1 WT and c-di-GMP mutant were grown in LB media (10 ml) for 8 hours on a temperature-controlled shaking incubator $\left(30^{\circ} \mathrm{C}, 200 \mathrm{rpm}\right)$. The cells were harvested and washed thrice using PBS buffer. The cell pellet was suspended in $200 \mu \mathrm{l}$ of SDS-PAGE loading buffer, boiled for $10 \mathrm{~min}$ at $70^{\circ} \mathrm{C}$, cooled to room temperature, and incubated with $2 \mu \mathrm{l}$ of DNase 1 for $10-15 \mathrm{~min}$ at $37^{\circ} \mathrm{C}$. Samples were then directly subjected to NuPAGE ( $8 \%$ Tris-Acetate gels) followed by dry protein transfer onto a nitrocellulose membrane using the iBlot system (InVitrogen). Membranes were developed using a standard Western blot protocol [primary antibody: Rabbit $\lg G(\mathrm{H}+\mathrm{L})$, dilution 1:3,000; secondary antibody: anti-rabbit horseradish peroxidase, dilution 
1:16,000]. Membranes were imaged using a Fuji LAS-1000 system and Image reader for LAS-1000 Pro (Fujifilm, Tokyo, Japan).

\subsubsection{Biofilm extraction and quantification}

Three replicates of tubing biofilm reactors for WT and c-di-GMP mutant each were set up using silicon tubing (Masterflex L/S 16, i.d. $3.2 \mathrm{~mm}$ ) for biofilms to attach and grow in the interior wall. The lengths of all the tubing were kept constant at $20 \mathrm{~cm}$, and the weights of each tubing were noted. Each tubing reactor was inoculated using diluted overnight cultures in LB medium $\left(\mathrm{OD}_{600} \sim 0.15\right)$ followed by 2-h stop-flow to allow cells to attach onto the walls of the tubing. 1/10 LB medium was then continuously supplied with a flow rate of $4 \mathrm{ml} / \mathrm{h}$ for biofilm growth. After $120 \mathrm{~h}$, biofilms formed in the tubing biofilm reactors were evaluated. Biomass from the tubing were dried and weighed together with the tubing to obtain the dry mass of the biomass.

\subsubsection{RNA extraction, sequencing and analysis}

S. oneidensis MR-1 WT and c-di-GMP mutant cultures are inoculated in LB medium, with three biological replicates each, and incubated aerobically for 8 hours at $30^{\circ} \mathrm{C}$ with shaking at $200 \mathrm{rpm}$. This was followed by the isolation of RNA from MR-1 WT and mutant, using RNeasy mini Kit (Qiagen, Germany), with the DNA being depleted using RNAsefree DNAse set (Qiagen, Germany). All isolation procedures were conducted according to the manufacturer's instructions. No depletion of ribosomal RNA was done for this experiment. The concentration of RNA in each samples were determined using Nanodrop 2000 spectrophotometer (Thermo Scientific, USA) and were further confirmed using Qubit 
2.0 Fluorometer (Life Technologies, Germany). All RNA samples were promptly stored at $-80^{\circ} \mathrm{C}$ until further use.

3 biological replicates per strain were used in this experiment. 3 analytical replicates were further generated for each biological replicates to be sequenced. A total of 18 RNA samples from MR-1 WT and c-di-GMP mutant are sequenced by the Singapore Centre on Environmental Life Sciences Engineering (SCELSE). Quality of the RNA samples was determined using the Quant-iT ${ }^{\mathrm{TM}}$ RiboGreen® RNA Assay Kit (Invitrogen) and QuantiT $^{\mathrm{TM}}$ PicoGreen $\circledast$ dsDNA Assay Kit (Invitrogen) on a Bioanalyzer RNA 6000 Nano Chip (Agilent). Next-generation sequencing library preparation was performed by following TruSeq RNA Sample Preparation v2 protocol (Illumina) with modifications: The mRNA purification step was omitted and instead, $200 \mathrm{ng}$ of total RNA was directly added to the elute-fragment-prime step. The PCR amplification step, which selectively enriches for library fragments that have adapters ligated on both ends, was performed according to the manufacturer's recommendation but the number of amplification cycles was reduced to 12. Each library was uniquely tagged with one of Illumina's TruSeq LT RNA barcodes to allow library pooling for sequencing. Library quantitation was performed using Invitrogen's Picogreen assay and the average library size was determined by running the libraries on a Bioanalyzer DNA 1000 chip (Agilent). Library concentration was normalised to $2 \mathrm{nM}$ and the concentration was validated by qPCR on a ViiA-7 real-time thermocycler (Applied Biosystems), using qPCR primers recommended in Illumina's qPCR protocol and Illumina's PhiX control library as a standard. Libraries were then pooled at equal volumes and sequenced in two lanes of an Illumina HiSeq2500 rapid run at a final concentration of $7.2 \mathrm{pM}$ and a read-length of $101 \mathrm{bp}$ paired-end. 
The Illumina reads were functionally assigned by mapping against the published genome of S. oneidensis MR-1 using CLC Genomics Workbench (CLC bio, Aarhus, Denmark). CLC Genomics workbench is a commercially-available program which is able to calculate gene expression levels, using an approach previously described (Mortazavi, Williams et al. 2008). The mRNA reads were normalised using the RPKM (reads assigned per kilobase of target per million mapped read) method. A t-test using RPKM normalised values with FDR (False Discovery Rate) p-value correction were performed and genes with $p$ value equal or more than 0.01 are rejected. Genes with the $n$-fold changes were computed using the RPKM values, converted into Log2-scale, and only those genes with 2-fold Log2-scale changes in expression were considered significant.

\subsection{Results and discussion}

\subsubsection{Biofilms reduce $P d(I I)$ and accumulate $P d(0)$ nanoparticles under aerobic conditions}

It has been shown that hydrogenase HyaB but not the outer membrane c-type cytochromes MtrC/OmcA plays significant roles in mediating $\mathrm{Pd}(\mathrm{II})$ reduction ( $\mathrm{Ng}$, Cai Tan et al. 2013). MtrC and OmcA can be expressed under both aerobic and anaerobic condtions, while HyaB is expressed only under anaerobic conditions. Further, under aerobic conditions, oxygen competes strongly with $\mathrm{Pd}(\mathrm{II})$ for electrons. Thus, one would expect that creating anaerobic conditions may enhance $\operatorname{Pd}(\mathrm{II})$ reduction. Highly heterogeneous microenvironments in biofilms might provide favourable conditions for $\mathrm{Pd}(\mathrm{II})$ reduction even under aerobic conditions. To test the idea of engineering biofilms via $\mathrm{Pd}(\mathrm{II})$ reduction under aerobic conditions, we grew $S$. oneidensis MR-1 biofilms in 
tubular reactors and then exposed the biofilms to $\mathrm{Pd}(\mathrm{II})$. Anoxic zones with low or no dissolved oxygen were observed in the biofilms grown under aerobic conditions (Figure 5.1), which supports our hypothesis that favourable conditions for $\mathrm{Pd}(\mathrm{II})$ reduction may develop in biofilms even under aerobic conditions.
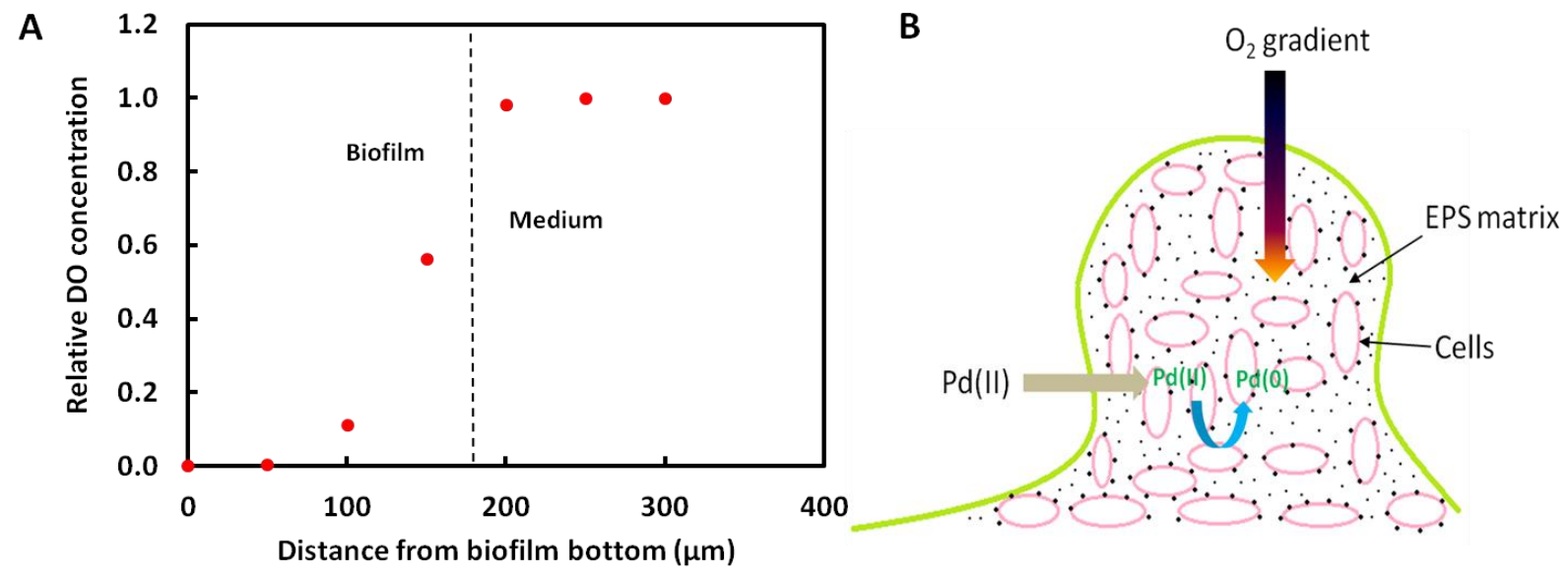

Figure 5.1. A) Graph showing dissolved oxygen (DO) concentration from various distance from the bottom of the biofilm. B) Schematic diagram showing the reduction of $\operatorname{Pd}(\mathrm{II})$ ions to $\operatorname{Pd}(0)$ nanoparticles within the biofilm under bulk oxic condition.

The biofilms were grown in tubular biofilm reactors for 3 days and the 3-day old biofilms were then exposed to $1 \mathrm{mM} \mathrm{Pd}(\mathrm{II})$ ( $\mathrm{t}=72 \mathrm{~h}$ onwards). The experimental results demonstrated that $\mathrm{Pd}(\mathrm{II})$ was continuously removed from the aqueous phase by the biofilms as indicated by the decrease in $\mathrm{Pd}(\mathrm{II})$ concentration in the effluent and the linearly increasing amount of $\mathrm{Pd}$ immobilised in the biofilms. The removal of $\mathrm{Pd}(\mathrm{II})$ from the aqueous phase and the accumulation of Pd in the biofilms are shown in Figure 5.2. 


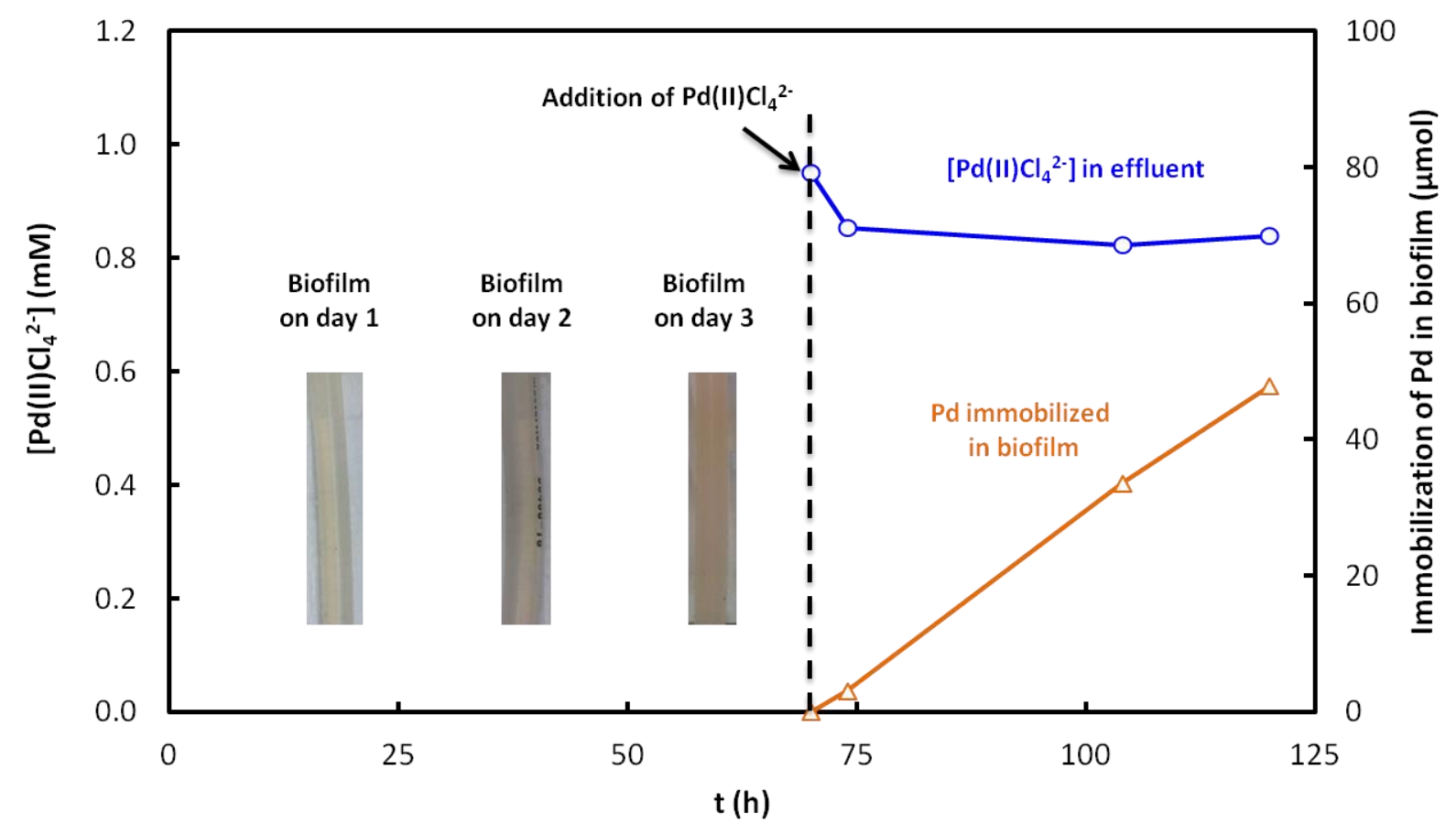

Figure 5.2. Immobilisation of $\mathrm{Pd}$ in $S$. oneidensis MR-1 biofilms. Each data point represents the average of three replicates. Insets show the growth of S. oneidensis biofilms (pink color) in the first 3 days.

To check whether the accumulated $\mathrm{Pd}$ in the biofilms was $\mathrm{Pd}(0)$ resulted from $\mathrm{Pd}(\mathrm{II})$ reduction, the biofilms with 2-day exposure to $\mathrm{Pd}(\mathrm{II})$ were harvested and further characterized. A representative FE-SEM image and an EDX spectrum of the biofilms confirmed the presence of $\mathrm{Pd}$ precipitates in the biofilms (Figure 5.3A). The XRD spectrum of the biofilms showed peaks at around $40^{\circ}, 46^{\circ}, 68^{\circ}, 82^{\circ}$, and $86^{\circ}$ corresponding to the (111), (200), (220), (311), and (222) planes of an fcc lattice, respectively (card 05-0681 in the JCPDS file) (Figure 5.3B). The XRD pattern indicated that the Pd associated with the biofilms was in the form of $\mathrm{Pd}(0)$ crystals (De Windt, Boon et al. 2006). 

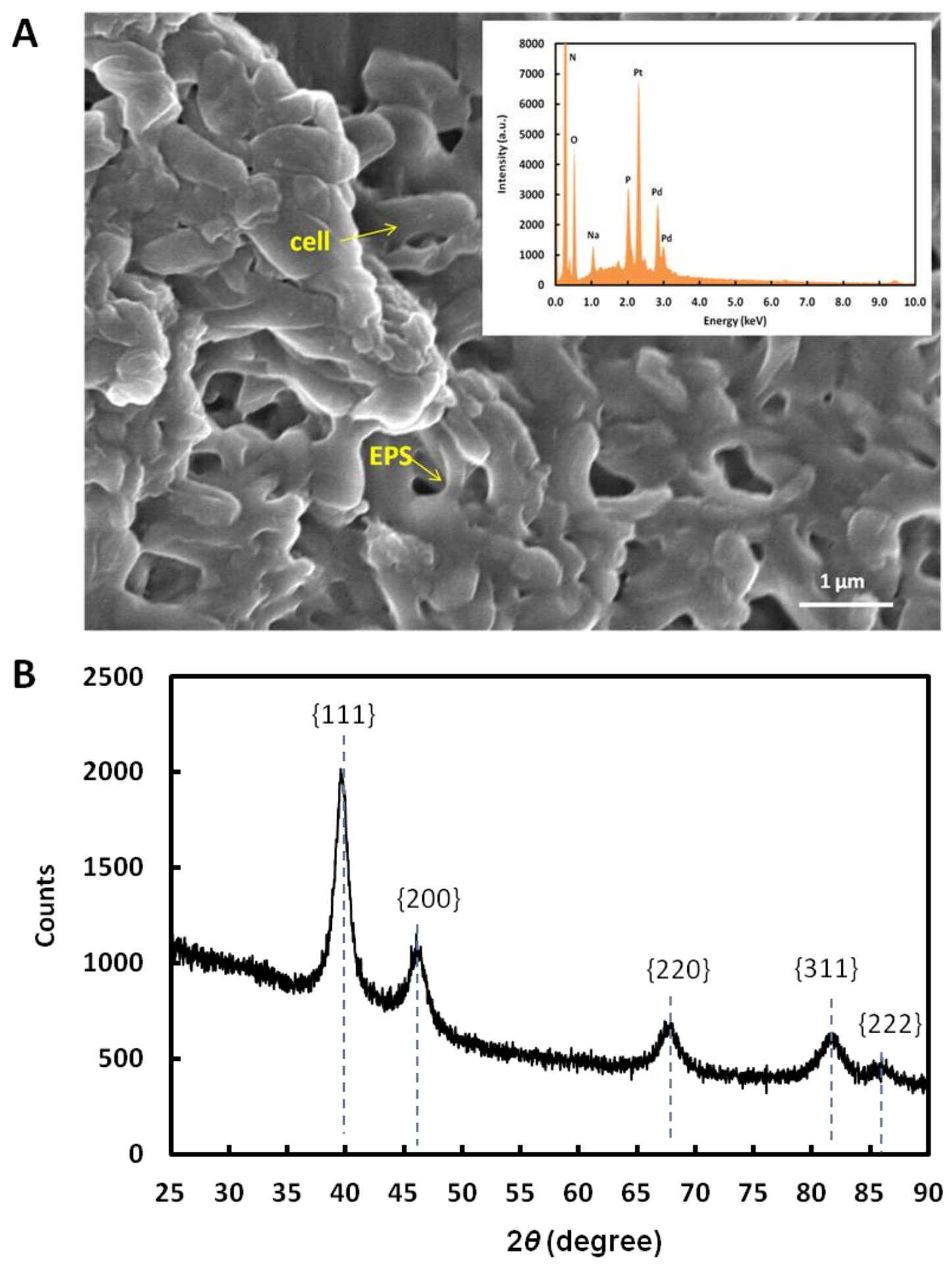

Figure 5.3. (A) FE-SEM image and a representative EDX spectrum of the biofilm-Pd association; (B) XRD pattern of the biofilm-Pd association: peaks at around $40^{\circ}, 46^{\circ}, 68^{\circ}, 82^{\circ}$, and $86^{\circ}$ correspond to the (111), (200), (220), (311), and (222) planes of an fcc lattice, respectively. 
We have shown that the biofilms reduced $\mathrm{Pd}(\mathrm{II})$ and accumulated $\mathrm{Pd}(0)$ crystals, but where did the $\operatorname{Pd}(0)$ crystals localise in the biofilms, i.e., in biofilm matrix or inside cells? We examined the resuspended biofilms using light microscopy by overlay of bright-field and fluorescence imaging of DAPI-stained cells (Figure 5.4A) and found a significant amount of extracellular nano-sized $\operatorname{Pd}(0)$ crystals in the biofilms, presumably immobilised by the biofilm matrix. The EPS matrix of Shewanella biofilms has been shown to contain many redox active components including electron carriers that could potentially reduce metal ions (Cao, Shi et al. 2011). The contribution of EPS matrix to the extracellular formation of uraninite nanoparticles during $\mathrm{U}(\mathrm{VI})$ reduction has been reported (Marshall, Beliaev et al. 2006, Cao, Ahmed et al. 2011, Cao, Shi et al. 2011). It is likely that certain redox components in the biofilm matrix might have contributed to $\mathrm{Pd}(\mathrm{II})$ reduction at the cell exterior. 


\section{A}

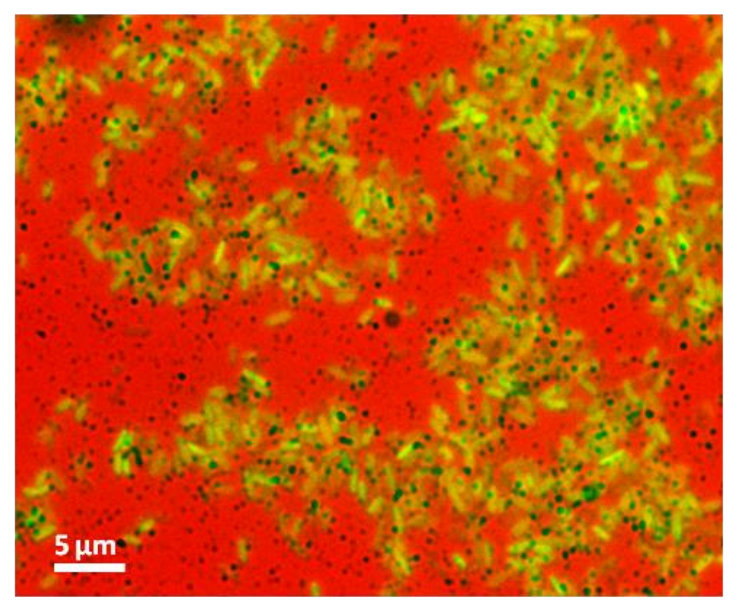

C

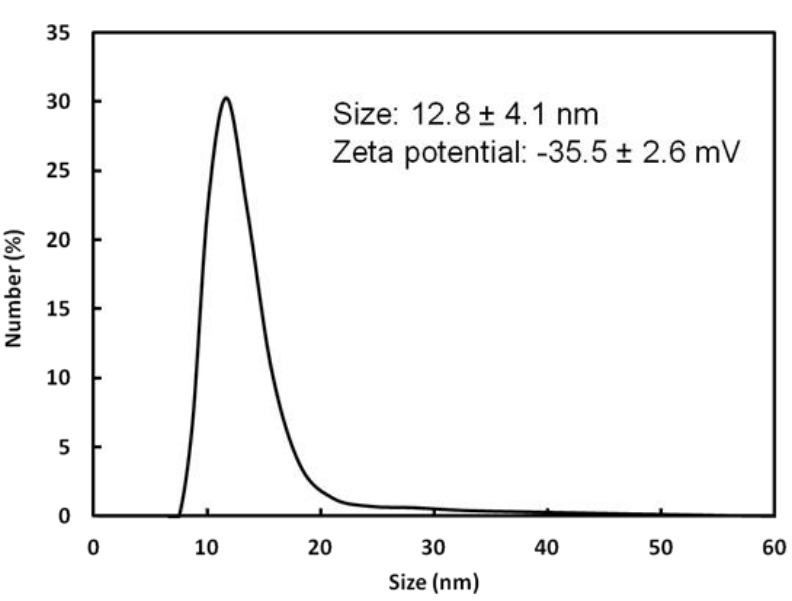

B

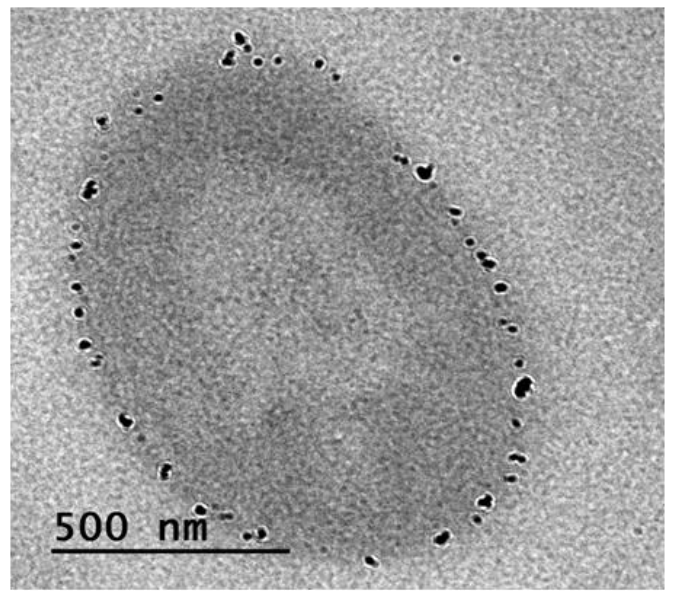

D

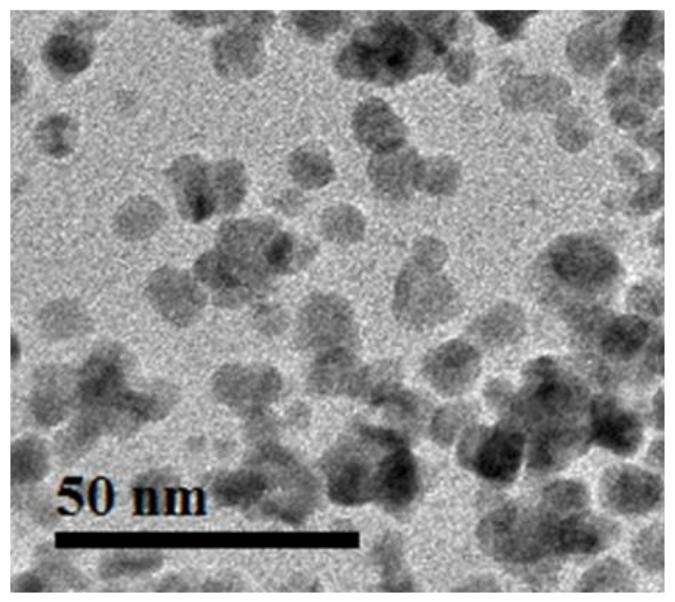

Figure 5.4. (A) Dispersion of $\operatorname{Pd}(0)$ nanoparticles (black) in suspension of cells (green) from the biofilms visualised by overlay of bright-field and fluorescence imaging. Cells were stained with DAPI. For better image clarity, the image has been pseudo-colored. (B) TEM image showing the association of $\operatorname{Pd}(0)$ nanoparticles with bacterial cells at the single-cell scale. (C) Size distribution and zeta potential and (D) a representative TEM micrograph of the non-cell-associated $\operatorname{Pd}(0)$ nanoparticles in the biofilm- $\mathrm{Pd}(0)$ association.

The extracellular $\operatorname{Pd}(0)$ nanocrystals in the biofilms were separated from the bacterial cells and both fractions were further characterized. The cells from the biofilms were 
examined by TEM at the single-cell level (Fig. 4B). Fine black (electron dense) nanoparticles $(<20 \mathrm{~nm})$ were found in the cell membrane while no nanoparticles were observed in the cytoplasm, suggesting an essential role of membrane-bound enzymes in $\mathrm{Pd}(\mathrm{II})$ reduction. Noted that the hydrogenase HyaB is in the periplasm, the formation of $\operatorname{Pd}(0)$ nanoparticles in the cell membrane could be, at least partially, due to the HyaB activity. The extracellular $\operatorname{Pd}(0)$ nanocrystals exhibited a narrow size distribution in the range of $8-50 \mathrm{~nm}$ with the majority has the diameter of $10-20 \mathrm{~nm}$ (Figure $5.4 \mathrm{C}$ and D). The zeta-potential of the particles was determined to be $-33.5 \pm 2.6 \mathrm{mV}$. High surface charge could be a possible reason why no large aggregates were found for these $\operatorname{Pd}(0)$ nanocrystals. Since many physicochemical properties such as catalytic activities of nanoparticles are size-dependent (Pal, Tak et al. 2007, Jiang, Kim et al. 2008, Park, Lim et al. 2011, Sobjerg, Lindhardt et al. 2011, Perez-Alonso, McCarthy et al. 2012), controlling the particle size in biosynthesis of nanoparticles is critically important. Our results demonstrated that the bioreductive formation of $\mathrm{Pd}(0)$ nanoparticles in the biofilms resulted in a relatively narrow particle size distribution, suggesting that biofilms could be a promising biocatalystic system for the synthesis of biogenic nanoparticles. Further, the $\operatorname{Pd}(0)$ nanoparticles with a narrow size distribution formed in biofilm matrix makes the biofilms a promising nanocatalytic system.

\subsubsection{Biofilms with in situ generated $P d(0)$ nanocrystals have nanocatalytic activity}

The catalytic activity of the two fractions of the biofilms, i.e., the extracellular matrixassociated $\operatorname{Pd}(0)$ nanoparticles and the cells (cell- $\operatorname{Pd}(0)$ association), was assessed by testing their activity in dechlorination reaction. Dechlorination rates of trichloroethylene (TCE) are shown in Figure 5.5. 


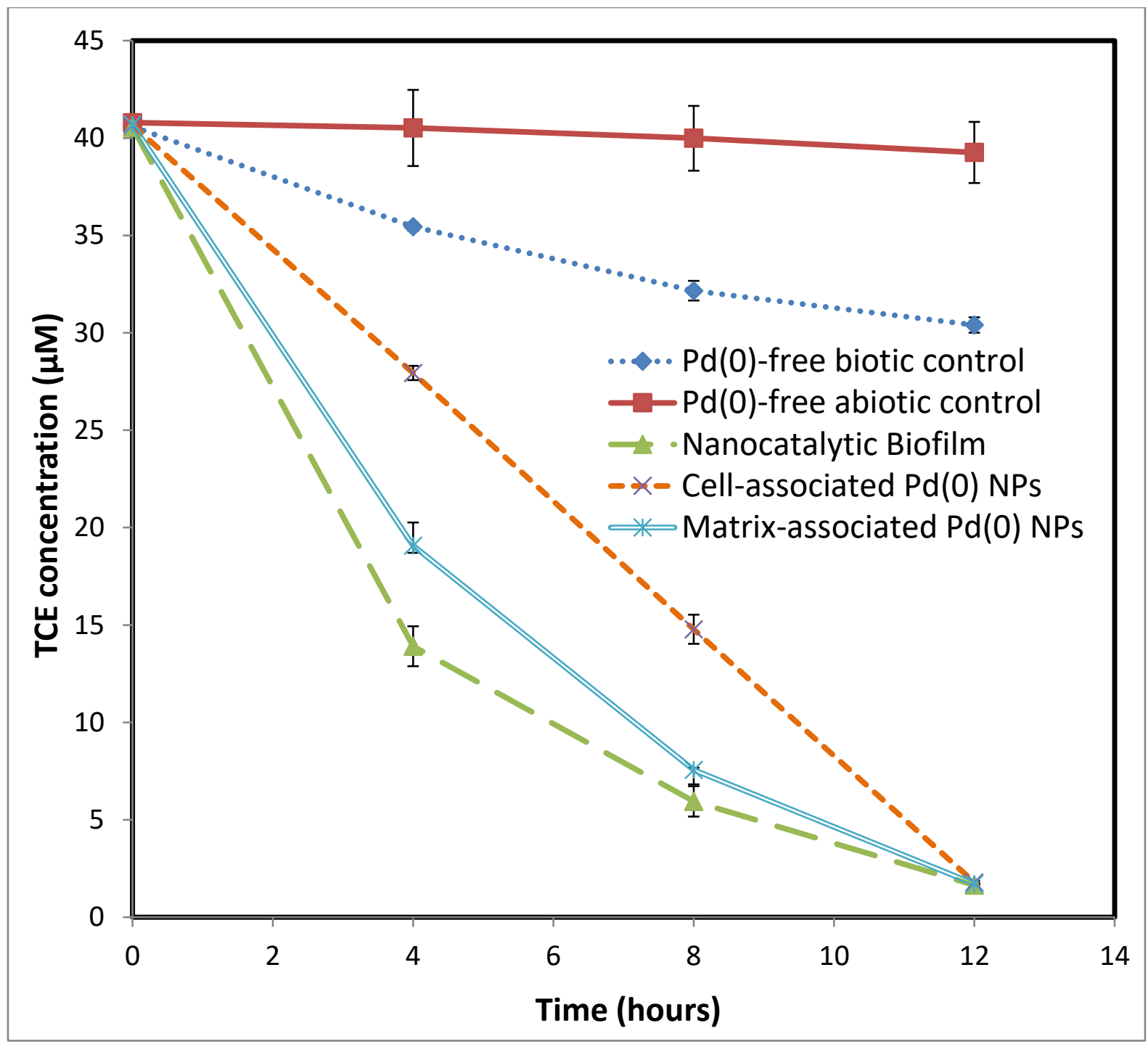

Figure 5.5. TCE dechlorination rate by nanocatalytic biofilms and its various fractions, namely matrix-associated $\operatorname{Pd}(0)$ NPs and cell-associated $\operatorname{Pd}(0)$ NPs are shown in the graph. $\operatorname{Pd}(0)$-free abiotic and biotic control were also conducted.

The $\operatorname{Pd}(0)$-free abiotic and biotic control reaction has a dechlorination rate of $0.689 \pm 0.31$ $\mu \mathrm{M} / \mathrm{h}$ and $12.8 \pm 0.71 \mu \mathrm{M} / \mathrm{h}$, while TCE dechlorination rates for the reactions catalysed by the fraction of cell-associated $\operatorname{Pd}(0) \mathrm{NPs}$ and the fraction of matrix-associated $\operatorname{Pd}(0) \mathrm{NPs}$ were $18.9 \pm 0.93$ and $41.2 \pm 0.32 \mu \mathrm{M} / \mathrm{h}$, respectively. When both fractions are used 
together, also termed nanocatalytic biofilm, the TCE dechlorination rate is $53.8 \pm 1.21$ $\mu \mathrm{M} / \mathrm{h}$. Table 5.2 shows the dechlorination rate of the nanocatalytic biofilm and its various fractions.

Table 5.2. The catalytic activity of the nanocatalytic biofilm and its two fractions of biofilmsassociated $\operatorname{Pd}(0)$ nanoparticles are compared in the table.

Rate of TCE Dechlorination

(umol TCE / mg catalyst / h)

Nanocatalytic biofilms

Cell-associated Pd(0) NPs
4.48

1.89

\section{Matrix-associated Pd(0) NPs}

20.59

Altogether, our results demonstrated that the biofilms with in situ formation of $\operatorname{Pd}(0)$ nanocrystals through bioreduction of $\mathrm{Pd}(\mathrm{II})$ were catalytically active and could be used as a novel biofilm-based biocatalysts. Further, our results reveal that, in addition to the cellassociated $\operatorname{Pd}(0)$ nanoparticles, the fraction of matrix-associated nanoparticles also showed high catalytic activity. Hence, effectively retaining nanoparticles could significantly improve the catalytic property of the biofilm-based biocatalysts, highlighting the critical role of EPS matrix in engineering biofilms for nanocatalysis.

\subsection{3. $\mathrm{Pd}(\mathrm{II})$ inhibits cellular respiration and energy metabolism: risk of biofilm detachment}


We have demonstrated the engineering of $S$. oneidensis biofilms for nanocatalysis via in situ bioreductive formation of $\operatorname{Pd}(0)$ nanocatalysts in biofilm matrix. Since $\mathrm{Pd}(\mathrm{II})$ is highly toxic (Melber, Keller et al. 2002), one important question would be how do the biofilms respond to $\mathrm{Pd}(\mathrm{II})$ during the engineering of biofilms for nanocatalysis. The answer may provide the basis for making the engineered biofilms more robust. To this end, we continuously monitored the dissolved oxygen concentration in the effluents at the outlet of the biofilm reactors (Figure 5.6).

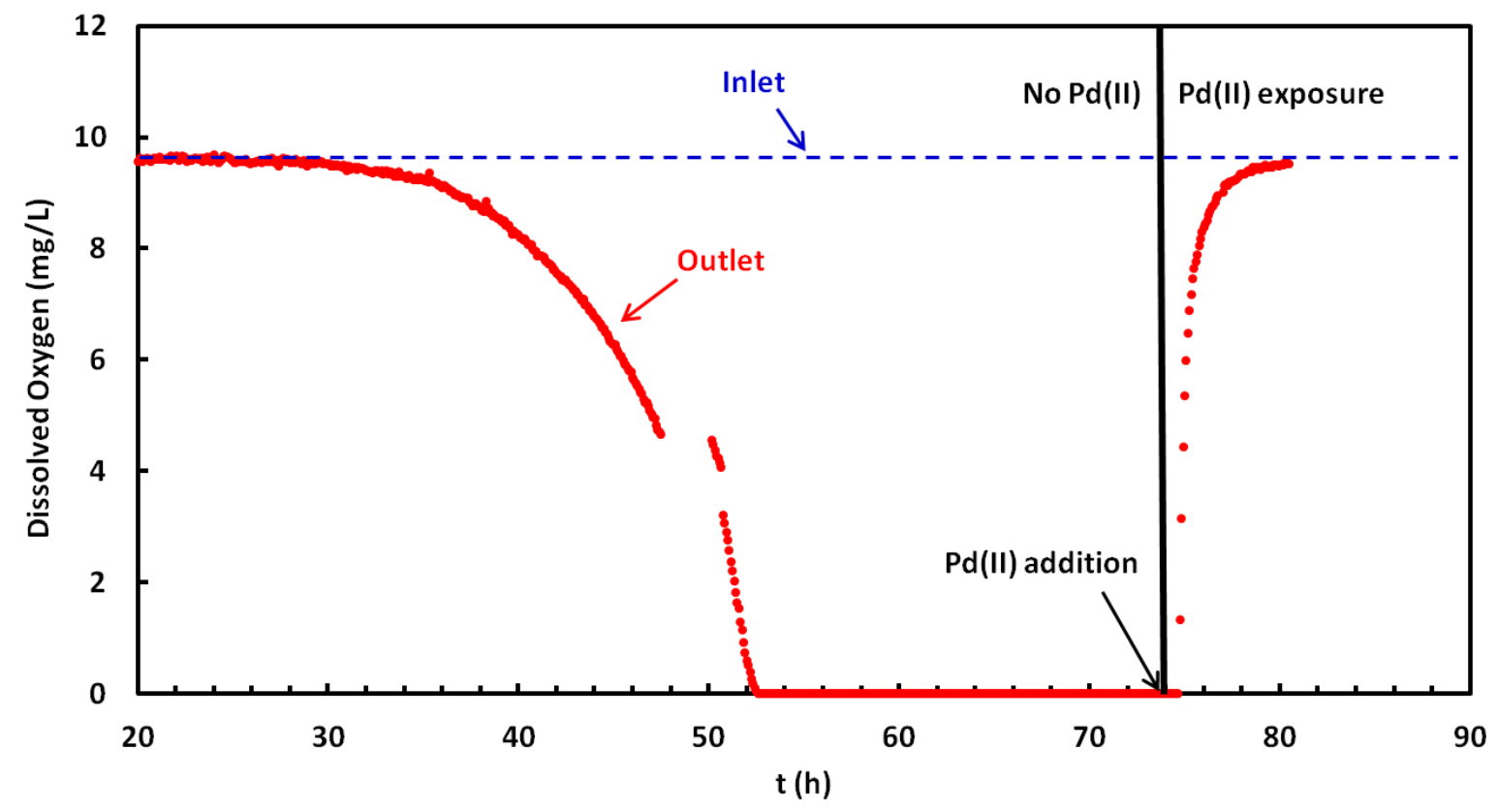

Figure 5.6. A representative temporal profile of the dissolved oxygen concentration in the outlet of a biofilm reactor with $S$. oneidensis biofilms growing it.

Our results showed that the dissolved oxygen concentration in the outlet decreased with time and the dissolved oxygen was depleted on the third day ( $52 \mathrm{~h}$ onwards), suggesting that the overall aerobic respiration activity of the biofilms was high and oxygen became a limiting nutrient from $52 \mathrm{~h}$ onwards. After $\mathrm{Pd}(\mathrm{II})$ was introduced into the biofilm reactors, 
dissolved oxygen concentration in the effluent increased drastically from depleted oxygen condition to nearly inlet oxygen level within $\sim 5 \mathrm{~h}$, indicating an inhibition of the aerobic respiration of the biofilms by $\mathrm{Pd}(\mathrm{II})$.

To further elucidate the metabolic responses of $S$. oneidensis cells to $\mathrm{Pd}(\mathrm{II})$ exposure, iTRAQ-based quantitative proteomics analysis was carried out. Down-regulation of proteins involved in energy metabolism was observed in the presence of 1,5 and $10 \mathrm{mM}$ Pd(II) (Table 5.3). These proteins had annotated subrole functions in metabolism of amino acids and amines (IvdF, Ldh), electron transport (Azu, TrxA, SO4048, MtrA, PetA, CytcB), anaerobic energy metabolism (NrfA), and central intermediary metabolism (Icd, Fbp, Pgk). The down-regulation of these proteins, especially the electron carriers involved in the electron transport, suggest a reconfiguration of energy metabolism by the cells in response to $\mathrm{Pd}(\mathrm{II})$ exposure, which is consistent with the observation of significant inhibition in aerobic respiration. The down-regulation of these energy metabolism proteins was dosage-dependent with a general trend of more repression in the presence of higher concentration of $\mathrm{Pd}(\mathrm{II})$. 
Table 5.3. Selected down-regulated proteins involved in energy metabolism.

\begin{tabular}{|c|c|c|c|c|c|c|}
\hline Locus tag & Gene & Protein description & \#Peptides / Coverage & $1: 0$ & $5: 0$ & 10:0 \\
\hline SO0406 & $\operatorname{tr} x A$ & Thioredoxin 1 TrxA & $14 / 82.4 \%$ & 0.17 & 0.17 & 0.12 \\
\hline SO0608 & $\operatorname{pet} A$ & Ubiquinol-cytochrome $\mathrm{c}$ reductase FeS subunit PetA & $5 / 33.7 \%$ & 0.24 & 0.13 & 0.04 \\
\hline SO0809 & $a z u$ & Periplasmic azurin Azu & $3 / 34.8 \%$ & 0.08 & 0.21 & 0.20 \\
\hline SO0932 & $p g k$ & Phosphoglycerate kinase Pgk & $16 / 51.2 \%$ & 0.29 & 0.15 & 0.14 \\
\hline SO1682 & $i v d F$ & 3-hydroxyisobutyrate dehydrogenase IvdF & $5 / 23.7 \%$ & 0.24 & 0.10 & 0.22 \\
\hline SO1777 & $m t r A$ & Periplasmic decaheme cytochrome c component MtrA & $2 / 11.4 \%$ & 0.40 & 0.25 & 0.04 \\
\hline SO2629 & icd & Isocitrate dehydrogenase NADP-dependent Icd & $17 / 39.4 \%$ & 0.46 & 0.22 & 0.06 \\
\hline
\end{tabular}




\begin{tabular}{|c|c|c|c|c|c|c|}
\hline SO2638 & Idh & Leucine dehydrogenase Ldh & $19 / 61.9 \%$ & 0.47 & 0.15 & 0.06 \\
\hline SO3980 & nrfA & Ammonia-forming nitrite reductase $\mathrm{NrfA}$ & $11 / 39 \%$ & 0.24 & 0.28 & 0.06 \\
\hline SO3991 & $f b p$ & Fructose-16-bisphosphatase Fbp & $3 / 20.9 \%$ & 0.15 & 0.28 & 0.44 \\
\hline SO4048 & - & Diheme cytochrome c4 & $4 / 28.9 \%$ & 0.22 & 0.09 & 0.06 \\
\hline SO4666 & cytcB & Diheme cytochrome c4 CytcB & $5 / 45.4 \%$ & 0.13 & 0.09 & 0.03 \\
\hline
\end{tabular}


The inhibition of oxygen respiration and down-regulation of energy metabolism of the cells exposing to $\mathrm{Pd}(\mathrm{II})$ suggest that the cells could obtain only significantly less metabolic energy comparing to those prior to $\mathrm{Pd}(\mathrm{II})$ exposure. The stability of $S$. oneidensis biofilms has been shown to be energy-dependent and metabolic energy is required for maintaining cell attachment (Saville, Rakshe et al. 2011). Inhibition of energy metabolism could lead to biofilm dispersal. We quantified cell detachment from the biofilms before and after $\mathrm{Pd}(\mathrm{II})$ exposure and found that the detachment rate after $12 \mathrm{~h}$ exposure to $\mathrm{Pd}(\mathrm{II})$ was $2.07 \pm 0.26 \times 10^{9} \mathrm{cell} \mathrm{s} / \mathrm{h} / \mathrm{cm}^{2}$, which was significantly higher than that prior to $\mathrm{Pd}(\mathrm{II})$ exposure $\left(1.30 \pm 0.11 \times 10^{9} \mathrm{cells} / \mathrm{h} / \mathrm{cm}^{2}\right)$. The results implied the risk of biofilm detachment during engineering biofilms for nanocatalysis via exposure to $\mathrm{Pd}(\mathrm{II})$. A comprehensive understanding of biofilm detachment will be required towards the development of robust biofilm-based biocatalysts for continuous bioprocesses, which warrants further investigation.

\subsubsection{Genetic engineering of intracellular c-di-GMP for robust nanocatalytic} biofilm

A novel method and a comprehensive understanding of biofilm detachment will be required towards the development of robust biofilm-based biocatalysts for continuous bioprocesses. To this end, we deployed genetic engineering to alter the intracellular c-di-GMP level to influence biofilm-related processes for better biofilm performance. Bis-(3'-5')-cyclic dimeric guanosine monophosphate (c-di-GMP) functions as an important second messenger in microbial systems (Hengge 2009). C-di-GMP is synthesized by diguanylate cyclases (containing a GGDEF domain) and degraded by phosphodiesterase. There had been previous reports that c-di-GMP influence the switching of sessile biofilm and motile planktonic mode of life in many microbes, 
stimulating the secretion of various EPS components, and affect their motility and virulent capabilities (Gjermansen, Ragas et al. 2006, Jenal and Malone 2006, Wolfe and Visick 2008, Broberg, Calder et al. 2011, Spurbeck, Tarrien et al. 2012). Hence, we feel that c-di-GMP is a suitable candidate for this study as a regulator of the formation and detachment of microbial biofilm.

\subsection{5. c-di-GMP quantification in MR-1 WT vs c-di-GMP mutant}

To determine whether c-di-GMP mutant produce higher amount of cytoplasmic c-diGMP as compared to the WT, we quantified the amount of cytoplasmic c-di-GMP using LC with commercial c-di-GMP standards. We normalised the amount of c-di-GMP by the amount of cytoplasmic proteins to prevent any discrepancy arise due to cell lysing efficiency. We found that c-di-GMP mutant has $\sim 10$ times higher cytoplasmic c-diGMP level compared to WT. This verifies that we are able to produce c-di-GMP mutant that indeed has higher level of c-di-GMP in the cytoplasm via insertion of $p Y e d Q 2$ into the S. oneidensis MR-1.

\subsubsection{Transcriptomic analysis: Influence of increasing c-di-GMP on Mtr pathway in $M R-1$}

In order to shed light on the physiological difference between S. oneidensis MR-1 WT and c-di-GMP mutant, total RNA from the cells was extracted from 8-hour mid logphase cultures of the respective strains. There were 444 genes that were expressed significantly different at the transcript level in the c-di-GMP mutant compared to the WT. Among those up-regulated in c-di-GMP mutant, we found that the all the genes encoding the five primary protein components of MTR pathway have higher expression at the transcript level in c-di-GMP mutant compared to the WT, as shown (Table 5.4). 
Table 5.4. Transcriptomic data of MTR-pathway-related gene expression in S. oneidensis MR-1 WT and c-di-GMP mutant.

\begin{tabular}{|c|c|c|c|c|c|}
\hline $\begin{array}{l}\text { gene } \\
\text { symbol }\end{array}$ & locus tag & gene description & gene ontology & $\begin{array}{l}\text { normalised } p- \\
\text { value }\end{array}$ & $\log 2$ ratio \\
\hline omcA & SO_1779 & $\begin{array}{l}\text { extracelllular iron oxide respiratory } \\
\text { system surface decaheme } \\
\text { cytochrome c component OmcA }\end{array}$ & electron carrier activity & $2.244 \mathrm{E}-12$ & 3.728 \\
\hline $\mathrm{mtrC}$ & SO_1778 & $\begin{array}{l}\text { extracellular iron oxide respiratory } \\
\text { system surface decaheme } \\
\text { cytochrome c component MtrC }\end{array}$ & electron carrier activity & $6.693 \mathrm{E}-10$ & 2.796 \\
\hline mtrA & SO_1777 & $\begin{array}{l}\text { extracelllular iron oxide respiratory } \\
\text { system periplasmic decaheme } \\
\text { cytochrome c component MtrA }\end{array}$ & electron carrier activity & $3.203 E-10$ & 2.241 \\
\hline
\end{tabular}




\begin{tabular}{|l|l|l|l|l|l|}
\hline cymA & SO_4591 & membrane anchored tetraheme & electron carrier activity, & $1.165 \mathrm{E}-08$ \\
nitrate reductase activity, \\
succinate dehydrogenase \\
mtrB & SO_1776 & extracellular iron oxide respiratory & activity & 2.202 \\
& system outer membrane & component MtrB & $1.489 \mathrm{E}-09$ & 1.684 \\
\hline
\end{tabular}


The Mtr pathway consists of 5 primary protein components, namely OmcA, MtrC, MtrB, MtrA and CymA. It is one of the most well-studied extracellular electron transport chain modules in $S$. oneidensis MR-1, and plays an important role on cellular respiration using mineral oxides, e.g. Hematite, as extracellular terminal electron acceptors ( $\mathrm{Ng}$, Cai Tan et al. 2013). The MTR pathway is also important in the area of bioremediation, specifically in the conversion of environmental contaminants to an insoluble and less harmful form. Examples include reduction of $\mathrm{Cr}(\mathrm{VI})$ to $\mathrm{Cr}$ (III) (Belchik, Kennedy et al. 2011), $\mathrm{U}(\mathrm{VI})$ to $\mathrm{U}(\mathrm{IV})$ (Lovley, Phillips et al. 1991), $\mathrm{Tc}(\mathrm{VII}) \mathrm{O}_{4}^{-}(\mathrm{aq})$ to $\mathrm{Tc}(\mathrm{IV}) \mathrm{O}_{2}(\mathrm{~s})$ (Marshall, Plymale et al. 2008) and $\mathrm{Ag}^{+}$to $\mathrm{Ag}(0)(\mathrm{Ng}$, Sivakumar et al. 2013) etc. The MTR pathway, which confer $S$. oneidensis MR-1 its ability to perform extracellular electron transfer, is also essential in electricity generation in microbial fuel cells (Harris, El-Naggar et al. 2012, Okamoto, Hashimoto et al. 2012).

With the increase in gene expression of MTR pathway-related genes at transcript level, we are interested to know whether there are any increases in amount of functional MTR pathway protein and/or changes in the effectiveness of the MTR pathway. We performed $\mathrm{Fe}$ (III) reduction using resting cells assay, and found that under similar condition, c-di-GMP mutant is able to reduce Fe(III) about two time faster compared to the WT (Figure 5.7). 


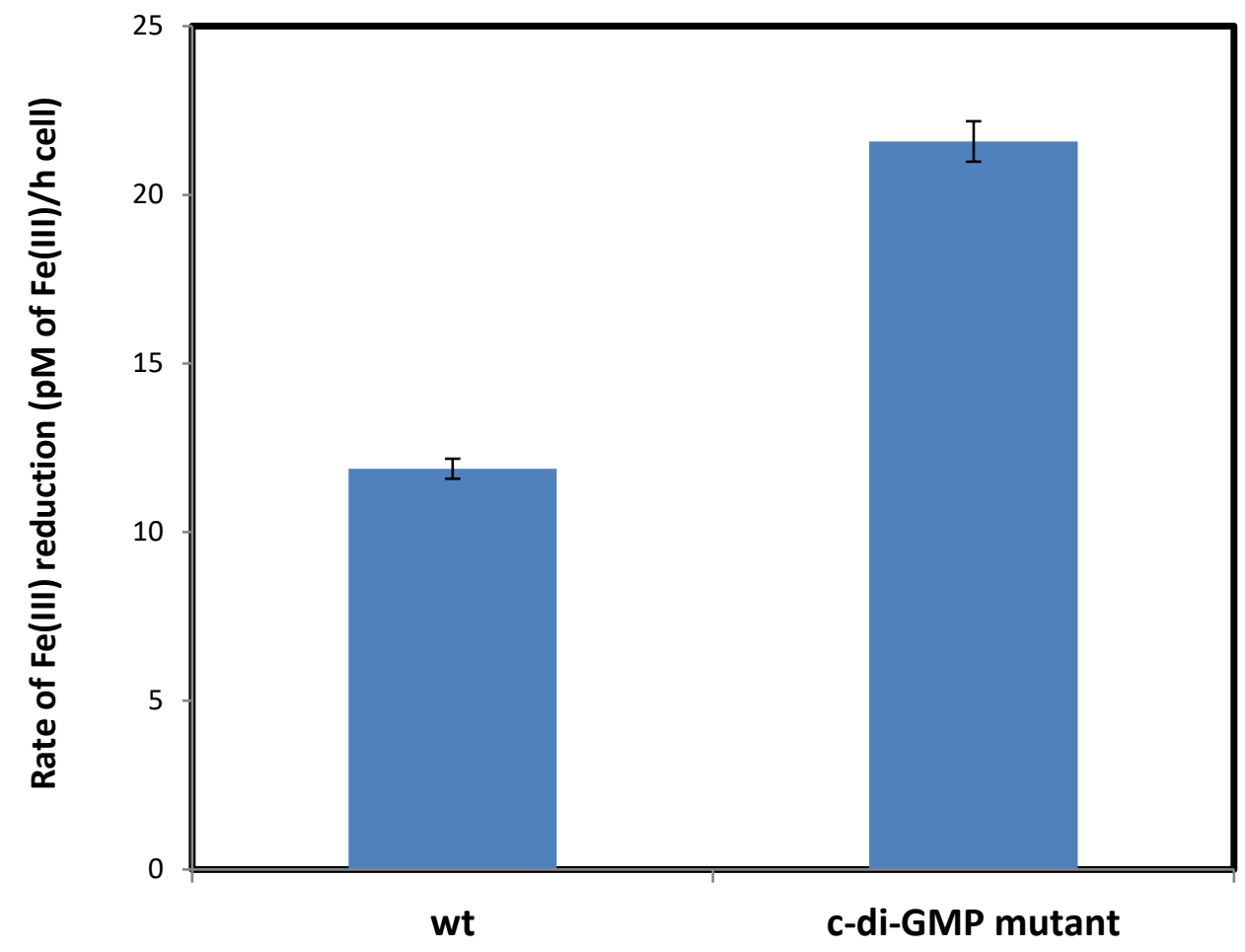

Figure 5.7. Rate of Fe(III) reduction by $S$. oneidensis MR-1 WT and c-di-GMP mutant.

This shows that there are either more functional MTR proteins in c-di-GMP mutant, which allow for higher rate of extracellular electron transfer per cell, or the MTR proteins are functioning at a higher efficiency.

To further verify this observation, we performed western blot to determine the relative amount of MtrC and OmcA proteins in WT and c-di-GMP mutants, using MR-1 mutant strain lacking gene encoding the protein $\mathrm{MtrC}$ and $\mathrm{OmcA}$, i.e. $\triangle m t r C$ and $\triangle o m c A$, as a negative control. We found that there is indeed an increase amount of outer membrane c-type cytochrome MtrC and OmcA in the c-di-GMP mutant as compared to the WT, as shown (Figure 5.8). 
A

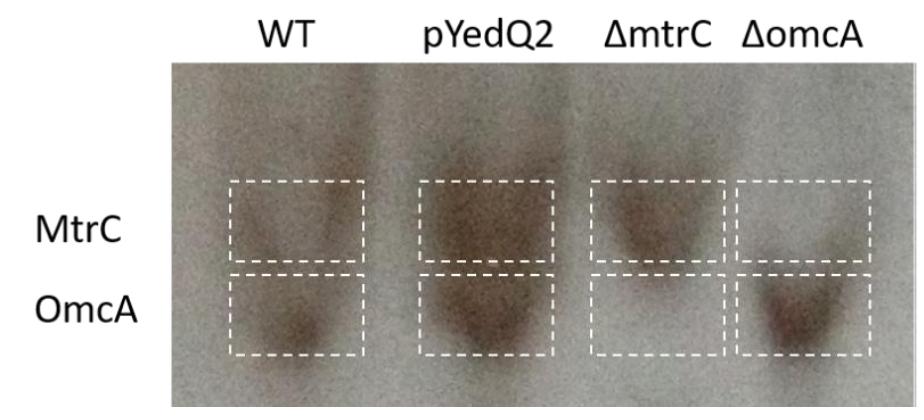

B

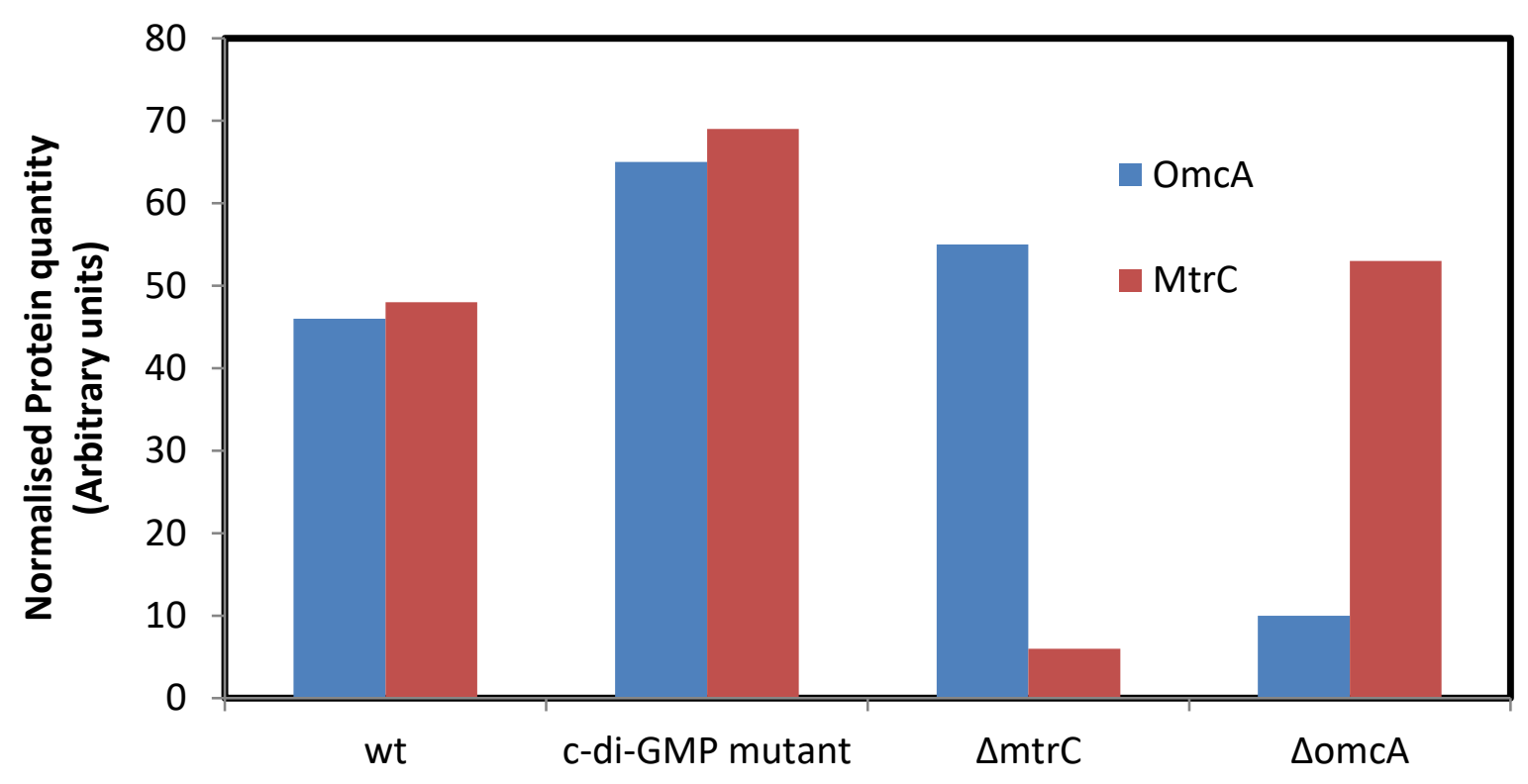

Figure 5.8. Western Blot: Quantification of outer-membrane c-type cytochrome MtrC and OmcA in S. oneidensis MR-1 WT and c-di-GMP, with mutant lacking MtrC (e.g. $\Delta m t r C$ ) and OmcA (e.g. $\triangle o m c A$ ) as negative control, in the form of (A) Gel image (B) Bar chart.

\subsubsection{Transcriptomic analysis: Influence of increasing c-di-GMP on Motility in} MR-1.

We found that 21 genes encoding motility-related proteins are significantly downregulated in c-d-GMP mutant as compared to the WT (Table 5.5). This suggests that an increase in the level of cytoplasmic c-di-GMP leads to a decrease in cellular motility in S. oneidensis MR-1. 
Table 5.5. Transcriptomic data of motility-related gene expression in S. oneidensis MR-1 WT and c-di-GMP mutant.

\begin{tabular}{|l|l|l|l|l|l|}
\hline Gene & Locus tag & Gene description & Gene ontology & Normalised & Log2 ratio \\
\hline flhA & SO_3213 & flagellar export protein FlhA & ciliary or bacterial-type flagellar motility & $1.246 E-06$ & -2.243 \\
\hline flgE & SO_3247 & flagellar hook protein FlgE & structural molecule activity, ciliary or & $5.027 E-08$ & -2.369 \\
\hline fliS & SO_3233 & chaperone for FliC flagellin FliS & ciliary or bacterial-type flagellar motility & $3.302 E-06$ & -2.373 \\
\hline flgG & SO_3244 & flagellar component of cell-distal & structural molecule activity, ciliary or & $3.655 E-06$ & -2.418 \\
\hline
\end{tabular}




\begin{tabular}{|c|c|c|c|c|c|}
\hline flgl & SO_3242 & flagellar P-ring protein Flgl & $\begin{array}{l}\text { structural molecule activity, ciliary or } \\
\text { bacterial-type flagellar motility }\end{array}$ & $1.252 \mathrm{E}-04$ & -2.495 \\
\hline$f l g L$ & SO_3239 & $\begin{array}{l}\text { flagellar hook-associated protein } \\
\text { FlgL }\end{array}$ & $\begin{array}{l}\text { structural molecule activity, ciliary or } \\
\text { bacterial-type flagellar motility }\end{array}$ & 1.867E-05 & -2.500 \\
\hline$f \mid r B$ & SO_3231 & $\begin{array}{l}\text { two component signal transduction } \\
\text { system controlling flagellar } \\
\text { biosynthesis histidine kinase with } \\
\text { PAS sensory domain FIrB }\end{array}$ & $\begin{array}{l}\text { phosphorelay sensor kinase activity, } \\
\text { protein kinase activity, ciliary or } \\
\text { bacterial-type flagellar motility, } \\
\text { phosphorelay signal transduction } \\
\text { system }\end{array}$ & $2.241 \mathrm{E}-06$ & -2.613 \\
\hline$f l g C$ & SO_3249 & $\begin{array}{l}\text { flagellar basal-body rod protein } \\
\text { FlgC }\end{array}$ & $\begin{array}{l}\text { structural molecule activity, ciliary or } \\
\text { bacterial-type flagellar motility }\end{array}$ & 4.951E-05 & -2.710 \\
\hline
\end{tabular}




\begin{tabular}{|c|c|c|c|c|c|}
\hline fliC & SO_3238 & flagellin FliC & $\begin{array}{l}\text { structural molecule activity, ciliary or } \\
\text { bacterial-type flagellar motility }\end{array}$ & $1.446 \mathrm{E}-10$ & -2.735 \\
\hline flik & SO_3223 & $\begin{array}{l}\text { flagellar hook-length control protein } \\
\text { FliK }\end{array}$ & ciliary or bacterial-type flagellar motility & $1.282 \mathrm{E}-09$ & -2.845 \\
\hline $\operatorname{mot} Y$ & SO_2754 & $\begin{array}{l}\text { smf-dependent flagellar motor } \\
\text { protein MotY }\end{array}$ & $\begin{array}{l}\text { motor activity, ciliary or bacterial-type } \\
\text { flagellar motility }\end{array}$ & $2.160 \mathrm{E}-06$ & -2.967 \\
\hline flic & SO_3237 & flagellin FliC & $\begin{array}{l}\text { structural molecule activity, ciliary or } \\
\text { bacterial-type flagellar motility }\end{array}$ & 3.249E-11 & -3.043 \\
\hline flgJ & SO_3241 & $\begin{array}{l}\text { flagellar rod cap protein and } \\
\text { peptidoglycan hydrolase FlgJ }\end{array}$ & $\begin{array}{l}\text { catalytic activity, ciliary or bacterial- } \\
\text { type flagellar motility, outer membrane- } \\
\text { bounded periplasmic space }\end{array}$ & $9.000 \mathrm{E}-08$ & -3.235 \\
\hline
\end{tabular}




\begin{tabular}{|c|c|c|c|c|c|}
\hline$f l g D$ & SO_3248 & $\begin{array}{l}\text { flagellar hook assembly protein } \\
\text { FlgD }\end{array}$ & ciliary or bacterial-type flagellar motility & 2.906E-08 & -3.264 \\
\hline$f \lg M$ & SO_3254 & $\begin{array}{l}\text { flagellar biosynthesis anti-sigma } \\
\text { factor FlgM }\end{array}$ & $\begin{array}{l}\text { ciliary or bacterial-type flagellar } \\
\text { motility, regulation of transcription, } \\
\text { DNA-dependent }\end{array}$ & 2.906E-08 & -3.398 \\
\hline $\operatorname{flg} B$ & SO_3250 & $\begin{array}{l}\text { flagellar basal-body rod protein } \\
\text { FlgB }\end{array}$ & $\begin{array}{l}\text { structural molecule activity, ciliary or } \\
\text { bacterial-type flagellar motility }\end{array}$ & $1.552 \mathrm{E}-07$ & -3.439 \\
\hline$f l g N$ & SO_3255 & $\begin{array}{l}\text { secretion chaperone for FlgK and } \\
\text { FlgL FlgN }\end{array}$ & ciliary or bacterial-type flagellar motility & 3.897E-09 & -3.494 \\
\hline fliD & SO_3235 & $\begin{array}{l}\text { flagellar filament capping protein } \\
\text { FliD }\end{array}$ & $\begin{array}{l}\text { structural molecule activity, ciliary or } \\
\text { bacterial-type flagellar motility }\end{array}$ & 1.704E-12 & -3.520 \\
\hline
\end{tabular}




\begin{tabular}{|c|c|c|c|c|c|}
\hline$f l g F$ & SO_3245 & $\begin{array}{l}\text { flagellar component of cell- } \\
\text { proximal portion of basal-body rod } \\
\text { FlgF }\end{array}$ & $\begin{array}{l}\text { structural molecule activity, ciliary or } \\
\text { bacterial-type flagellar motility }\end{array}$ & 2.025E-09 & -3.541 \\
\hline fliF & SO_3228 & $\begin{array}{l}\text { flagellar basal-body MS-ring and } \\
\text { collar protein FliF }\end{array}$ & $\begin{array}{l}\text { structural molecule activity, ciliary or } \\
\text { bacterial-type flagellar motility, } \\
\text { bacterial-type flagellum basal body }\end{array}$ & 2.078E-10 & -3.544 \\
\hline fliE & SO_3229 & $\begin{array}{l}\text { flagellar basal-body component } \\
\text { FliE }\end{array}$ & $\begin{array}{l}\text { structural molecule activity, ciliary or } \\
\text { bacterial-type flagellar motility }\end{array}$ & 1.503E-05 & -3.570 \\
\hline
\end{tabular}


With this hypothesis in mind, we proceed with swimming motility test using LB plate with $0.3 \%$ agar to determine if the swimming motility of the c-di-GMP mutant is really compromised. We found that colonies formed from c-di-GMP mutant have an average of about $40 \%$ shorter diameter compared to those from WT, as shown (Figure 5.9).

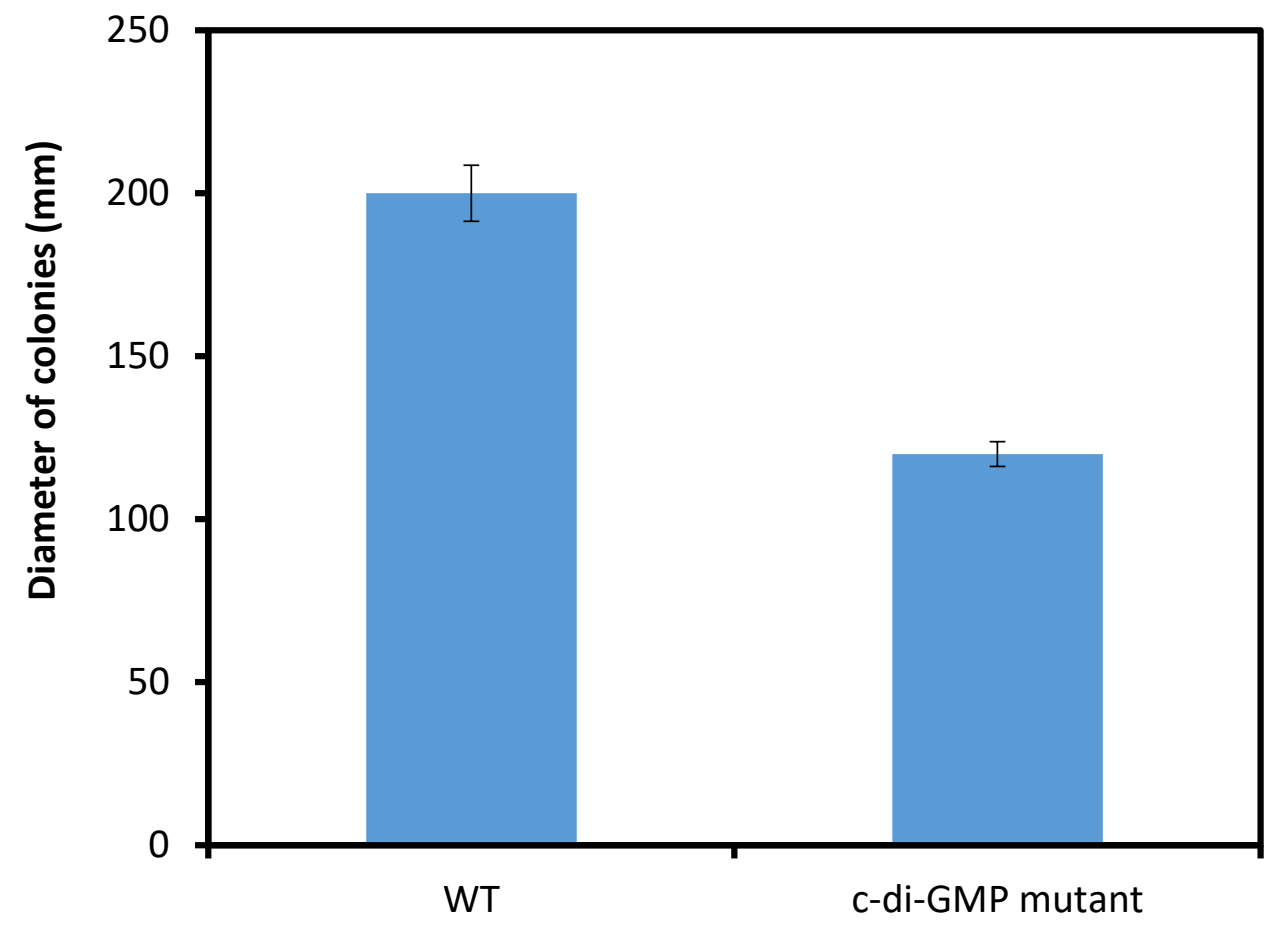

Figure 5.9. Swimming Motility Assay: Comparison of colony diameter between S. oneidensis MR-1 WT and c-di-GMP mutant.

There have been many reports on the influence of c-di-GMP on cellular motility. Vibrio cholerae uses its transcriptional regulator VpsT to directly sense c-di-GMP and regulate cell motility. The sensing is done by a change in oligomerisation of VpsT when it binds to c-di-GMP (Krasteva, Fong et al. 2010). In E. coli and Salmonella, a c-diGMP binding protein YcrG interacts with flagella switch-complex proteins to induce motility inhibition by reducing the torque generated by the flagella in the presence of c-di-GMP (Paul, Nieto et al. 2010). In Pseudomonas aeruginosa PA14, bifA gene 
(PA4367) encodes both GGDEF and EAL domains. Deletion of the bifA gene leads to increased cellular c-di-GMP level and a severe defect in swarming motility compared to PA14 WT (Kuchma, Brothers et al. 2007). Our result is in line with previous literatures which indirectly proposed a similar trend in S. oneidensis MR-1 (Thormann, Duttler et al. 2006, Rakshe, Leff et al. 2011, Chao, Rakshe et al. 2013). However, when coupled with the quantification of cytoplasmic c-di-GMP level, this study validates directly for the first time that an increase in the level of cytoplasmic c-di-GMP leads to a decrease in swimming motility in S. oneidensis MR-1.

\subsubsection{Influence of increasing c-di-GMP on biofilm formation and detachment in} MR-1.

C-di-GMP mutant appears to have a stronger binding adhesiveness as compared to WT, which was suggested by the formation of biofilm (cell-solid substratum adhesion) in planktonic culture. It is also observed that c-di-GMP mutant biofilm has much higher viscosity compared to WT (Figure 5.10). 


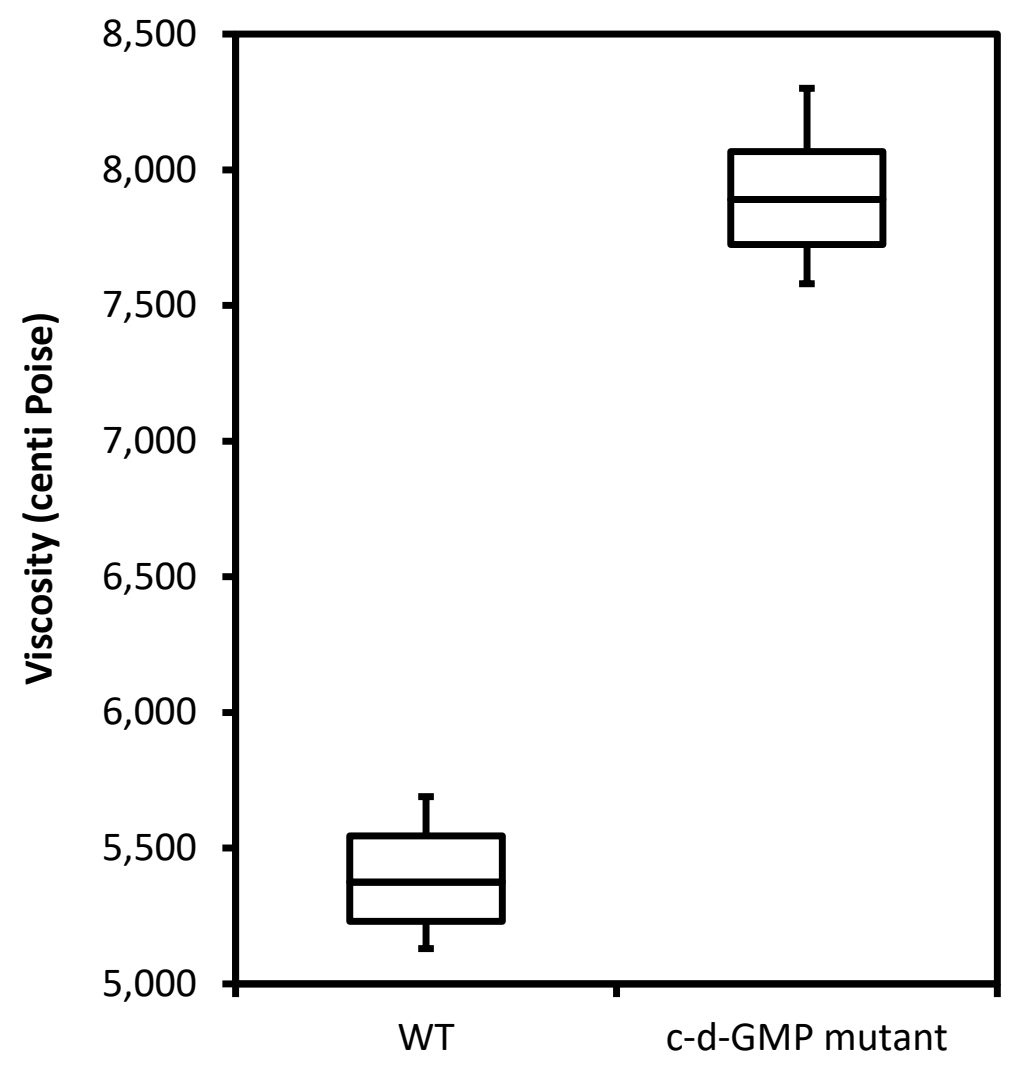

Figure 5.10. Viscosity measurement of $S$. oneidensis MR-1 WT and c-di-GMP mutant biofilm.

To determine whether biofilm formation is affected by the increase in cytoplasmic cdi-GMP, we grow S. oneidensis MR-1 WT and c-di-GMP mutant in a 96-well plate and flow cell system to examine static and hydrodynamic biofilm growth respectively. Static biofilm assay is a high throughput method to screen bacteria according to their biofilmforming capability in a hydrostatic environment. In this study, we measured the biofilm formation and amount of planktonic cells in 96 well-plates, and observed higher biofilm growth and lower amount of planktonic cells in c-di-GMP mutant when compared to WT, as shown (Figure 5.11). The total amount of cells in each well (planktonic and biofilm) was quantified via CFU, which showed no significant difference between WT and c-di-GMP mutant. 


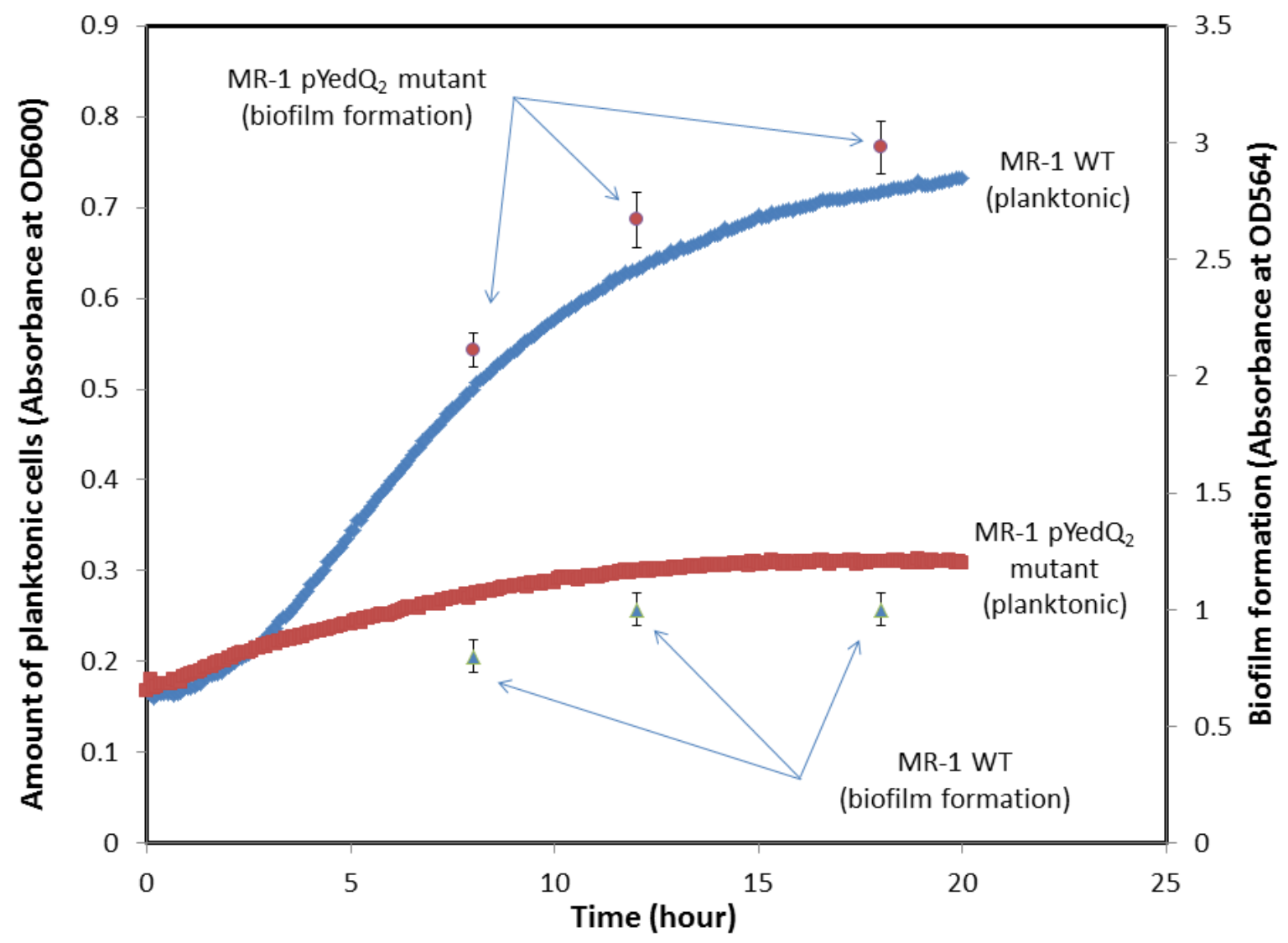

Figure 5.11. $\mathrm{OD}_{600}$ measurement (left y-axis) and static biofilm assay (right y-axis), showing the relative amount of planktonic cells and biofilm of $S$. oneidensis MR-1 WT and c-di-GMP mutant, respectively.

We then proceeded with the flow cell biofilm experiment and found that c-di-GMP mutant formed thicker biofilms (Figure 5.12). In a tubing biofilm set-up, we found that c-di-GMP has much lower biofilm detachment rate compared to WT, as shown (Table 5.6). 


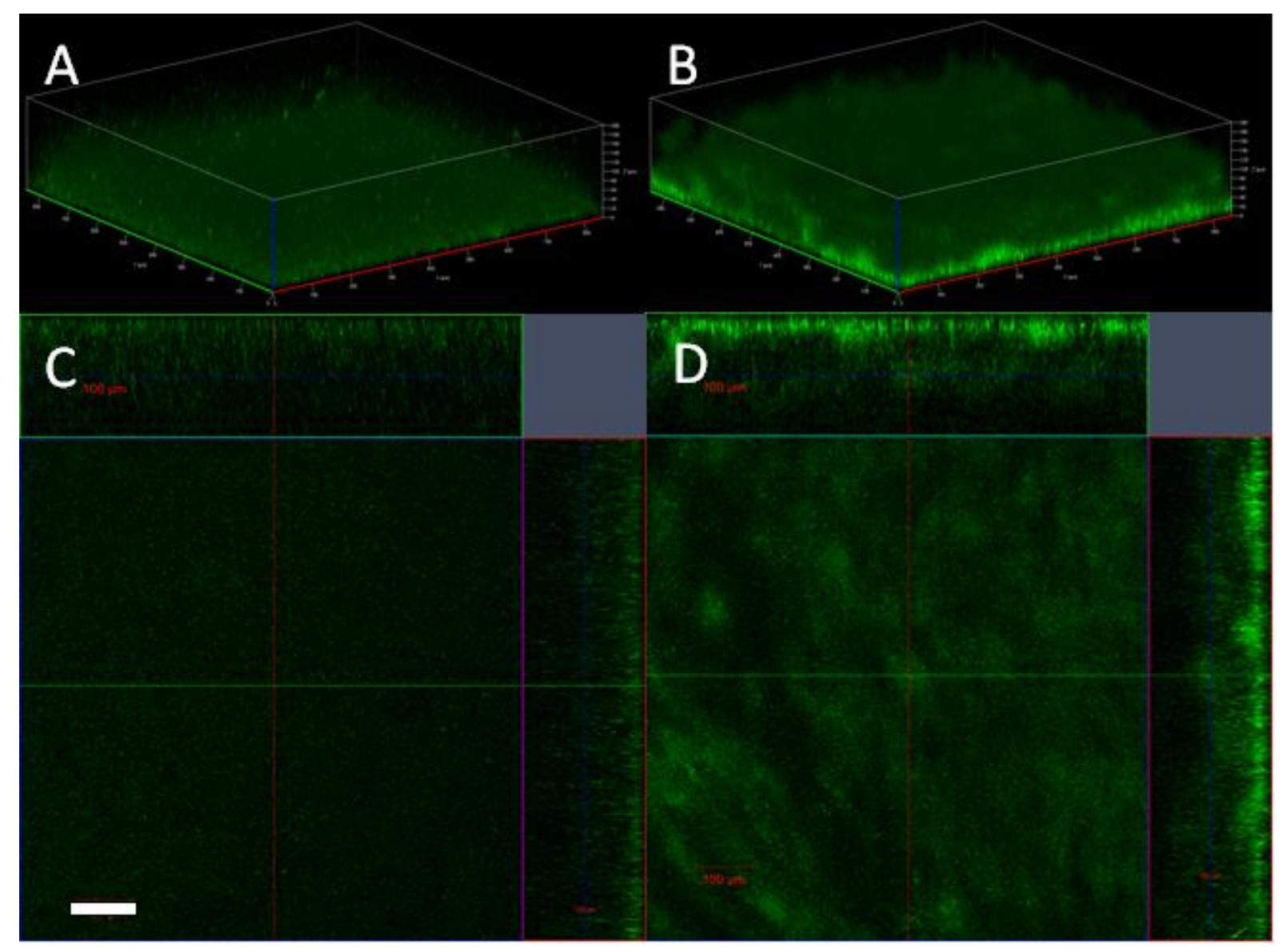

Figure 5.12. Flow cell biofilm: CLSM 3D images and orthogonal views of $S$. oneidensis MR-

1 WT (A and C) and c-di-GMP mutant (B and D) respectively, showing biofilm formation after

72 hours of growth under hydrodynamic conditions. The white bar represents $100 \mu \mathrm{m}$. 
Table 5.6. Rate of cell detachment from flow cell biofilms of S. oneidensis MR-1 WT and c-di-GMP mutant.

\begin{tabular}{|c|c|c|c|c|}
\hline & \multicolumn{4}{|c|}{ Cell detachment rate (cells $\mathrm{h}^{-1} \mathrm{mg}^{-1}$ ) } \\
\hline & $60^{\text {th }}$ hour & $66^{\text {th }}$ hour & $78^{\text {th }}$ hour & $84^{\text {th }}$ hour \\
\hline MR-1 WT & $1.8 \pm 0.24 \times 10^{8}$ & $1.7 \pm 0.37 \times 10^{8}$ & $3.2 \pm 0.26 \times 10^{8}$ & $3.1 \pm 0.46 \times 10^{8}$ \\
\hline $\begin{array}{l}\text { MR-1 c-di-GMP } \\
\text { mutant }\end{array}$ & $3.2 \pm 0.35 \times 10^{7}$ & $3.1 \pm 0.38 \times 10^{7}$ & $5.5 \pm 0.31 \times 10^{7}$ & $5.2 \pm 0.62 \times 10^{7}$ \\
\hline
\end{tabular}


We isolated the biofilm and measured the dry biomass, and found that the biomass of WT and c-di-GMP is in the ratio of 1:15 respectively. This difference in amount of cell mass between WT and c-di-GMP biofilm under hydrodynamic condition is much more prominent than in the static biofilm set-up. This difference, coupled with the lower cell detachment rate in c-di-GMP mutant biofilm compared to WT, suggests that biofilm containing cells with higher c-di-GMP level are able to resist detachment and are less adversely affected by the toxicity of $\mathrm{Pd}(\mathrm{II})$ ions.

Our results show for the first time that biofilm formation in $S$. oneidensis MR-1 can be promoted via insertion of plasmid carrying the $y e d Q$ gene to elevate the production of c-di-GMP in the cytoplasm. This is an important step forward, especially in the area of bioremediation and biofilm-related industrial processes. The ability to form robust biofilms is essential for processes that occur in hydrodynamic environment, such bioremediation of a contaminated site or biosynthesis of fine chemicals in a continuous-mode industrial reactor. There are many bacteria that can convert contaminants to benign substances, but are impractical to use in bioremediation due to weak attachment to the contaminated surface, short active period and low tolerance to the concentration of contaminant. The ability to genetically engineer the bacteria to form biofilm more readily, via e.g. insertion of $p Y e d Q 2$, will make it more feasible to use those bacteria for bioremediation purposes, and lowers the criteria to allow a wider variety of bacteria to be used for the same.

\subsubsection{Influence of increasing c-di-GMP on activity of nanocatalytic biofilm.}

Biofilms of MR-1 wt and c-di-GMP mutant were use to produced Pd NPs after three days of growth. The resultant nanocatalytic biofilm of MR-1 wt and c-di-GMP, 
normalized by biomass, were test for their activity using Chromium(VI) reduction as model reaction as shown in Figure 5.13.

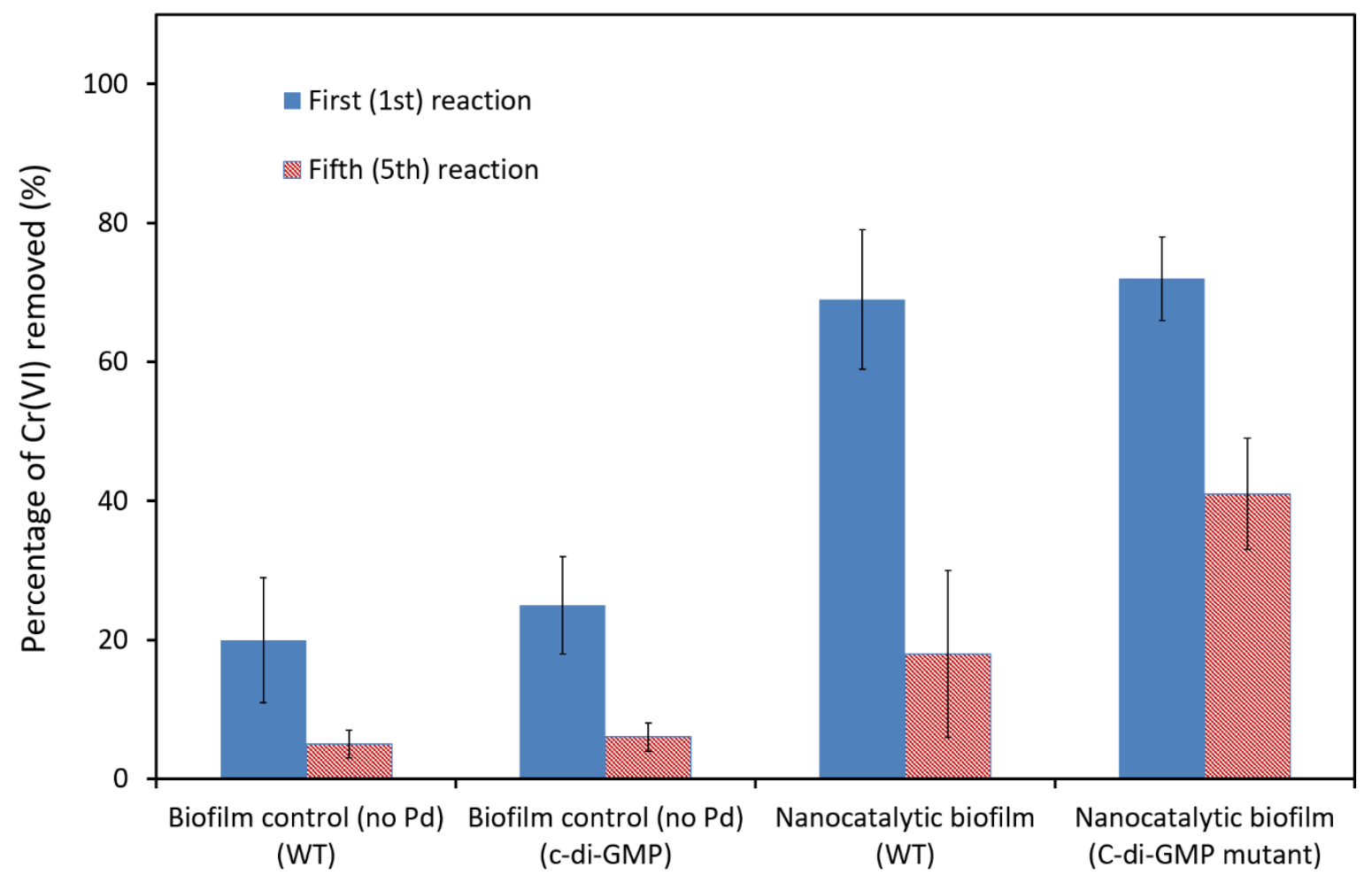

Figure 5.13. Percentage of $\mathrm{Cr}(\mathrm{VI})$ removed by various biofilm samples, namely biofilm control (no Pd) of wt and c-di-GMP mutant and nanocatalytic biofilm wt and c-di-GMP mutant in the first and fifth reaction with catalyst recycling. All experiments are done in triplicates.

There are relatively low $\mathrm{Cr}(\mathrm{VI})$ removal by the biofilm control (no Pd) of both WT and c-di-GMP mutant, where the amount of $\mathrm{Cr}(\mathrm{VI})$ removed is around $20 \%$ and $25 \%$ respectively. $\mathrm{Cr}(\mathrm{VI})$ removal in nanocatalytic biofilm of wt and c-di-GMP mutant were relatively similar, where the amount of $\mathrm{Cr}(\mathrm{VI})$ removed is around $69 \%$ and $72 \%$ respectively. $\mathrm{Cr}(\mathrm{VI})$ reduction was repeated five times using the same samples, namely biofilm control (no Pd) of wt and c-di-GMP mutant and nanocatalytic biofilm wt and c-di-GMP mutant. It was observed that the amount of $\mathrm{Cr}(\mathrm{VI})$ removed across all samples decreased significantly. Interestingly, amount of $\mathrm{Cr}(\mathrm{VI})$ removed for 
nanocatalytic biofilm wt decreased by $74 \%$ while that of nanocatalytic biofilm c-di-GMP mutant decreased only by $43 \%$. This shows that although nanocatalytic biofilm wt and c-di-GMP mutant have similar activity, the c-di-GMP mutant showed much lower loss of activity over multiple reactions as compared to wt. This can be attributed to the lower cell detachment rate in nanocatalytic biofilm c-di-GMP mutant, and hence a slower rate of $\mathrm{Pd}$ leaching as compared to wt.

\subsection{Conclusions}

In this study, we show that (i) the $S$. oneidensis biofilms reduce $\mathrm{Pd}(\mathrm{II})$ and accumulate $\operatorname{Pd}(0)$ nanocrystals with a size of $10-20 \mathrm{~nm}$ in the biofilm matrix and in the cell membrane even under aerobic conditions; (ii) the $S$. oneidensis biofilms with $\operatorname{Pd}(0)$ nanocrystals formed and immobilised in situ in the biofilms exhibit nanocatalytic activity; (iii) Pd(II) exposure inhibits cellular respiration and energy metabolism of $S$. oneidensis cells, posing a risk of biofilm detachment; (iv) increasing the intracellular level of cyclic-di-GMP in S. oneidensis MR-1 can reduce the biofilm detachment; and (v) c-di-GMP is an upstream signalling molecule which influence several key cellular processes, such as cellular motility, extracellular electron transport, iron uptake and biofilm formation in $S$. oneidensis MR-1. Our results suggest a novel strategy for engineering biofilms towards the development of biofilm-based multifunctional biocatalysts for continuous bioprocesses. Since the formation of nanocatalysts in biofilms is a mild and environment-friendly biological process in aqueous media, the strategy of engineering biofilms for nanocatalysis also reflects the sustainable development in chemical industry. 


\section{CHAPTER 6: SYNTHESIS OF ROBUST BIOFILM-TEMPLATED HETEROATOM- DOPED CARBON-PALLADIUM NANOCOMPOSITE CATALYST FOR HEXAVALENT CHROMIUM REDUCTION}

A portion of this chapter has been presented in oral format as $\mathrm{Ng} C K$ and Cao B (2016). Engineering biofilm for remediation of environmental chromium(VI) contamination. 6th International Conference on Environment Science and Biotechnology (ICESB 2016), Kyoto, Japan.

\subsection{Introduction}

Chromium is commonly used in various industries, such as electroplating, mining and hydrocarbon processing (Barnhart 1997). Its widespread use has contributed to its release via wastewater into the environment, mainly in the form of trivalent chromium [Cr(III)] and hexavalent chromium [Cr(VI)] (Costa 2003). Cr(VI), mainly in the form of $\mathrm{Cr}_{2} \mathrm{O}_{7}{ }^{2-}$ and $\mathrm{CrO}_{4}{ }^{2-}$, is toxic and hazardous to living organisms and can cause serious consequences to aquatic ecosystems due to its high water solubility and mobility in the environment (Leonard and Lauwerys 1980, Katz and Salem 1993, O’Brien, Ceryak et al. 2003, Costa and Klein 2006, Salnikow and Zhitkovich 2008). Cr(VI) can cause chronic health problems to human and is classified as a group 1 carcinogen by the International Agency for Research on Cancer (International Agency for Research on Cancer 1987). On the other hand, $\mathrm{Cr}(\mathrm{III})$ is much less toxic than $\operatorname{Cr}(\mathrm{VI})$, has low solubility in water under circumneutral $\mathrm{pH}$, and can be easily removed from the environment through precipitation or adsorption on various adsorbents (Belchik, Kennedy et al. 2011, Ali 2012, Chebeir and Liu 2016). As such, it has been suggested that effective and efficient remediation of $\mathrm{Cr}(\mathrm{VI})$ can be achieved via the reduction of 
$\mathrm{Cr}(\mathrm{VI})$ to the less toxic $\mathrm{Cr}(\mathrm{III})$, followed by its adsorption and/or precipitation (Blowes, Ptacek et al. 1997, Ponder, Darab et al. 2000, Chai, Huang et al. 2009).

Current strategies for the reduction of $\mathrm{Cr}(\mathrm{VI})$ to $\mathrm{Cr}(\mathrm{III})$ involves electro-reduction, chemical reduction, photocatalytic reduction and biological reduction (Lai and Lo 2008, Wang, Wang et al. 2008, Huang, Ma et al. 2012, Ding, Peng et al. 2013). For instance, Nazuhat and Hu et al developed a plant-microbial fuel cell for the reduction of $\mathrm{Cr}(\mathrm{VI})$ to $\mathrm{Cr}(\mathrm{III})$, and found that both the $\mathrm{Cr}(\mathrm{VI})$ removal rates and the removal efficiencies increased with the increasing initial $\mathrm{Cr}(\mathrm{VI})$ concentration (Habibul, Hu et al. 2016). Lai et al demonstrated $\mathrm{Cr}(\mathrm{VI})$ bioreduction using methane $\left(\mathrm{CH}_{4}\right)$ as the sole electron donor in a membrane biofilm reactor, and $\mathrm{Cr}(\mathrm{VI})$ removal at the end of the 90-day test reached $95 \%$ at an influent $\mathrm{Cr}(\mathrm{VI})$ concentration of $3 \mathrm{mg} \mathrm{Cr} / \mathrm{L}$ and a surface loading of $0.37 \mathrm{~g}_{\text {of }} \mathrm{Cr} \mathrm{m}^{-2}$ day $^{-1}$ (Lai, Zhong et al. 2016).

A hybrid between biological and chemical reduction approaches, biogenic noble metal nanoparticles (NPs) have gained increasing attention as a viable environmental catalyst suitable for $\mathrm{Cr}(\mathrm{VI})$ reduction (Hennebel, De Gusseme et al. 2009, Gadd 2010, De Corte, Hennebel et al. 2011, Lloyd, Byrne et al. 2011, De Corte, Hennebel et al. 2012, Hennebel, De Corte et al. 2012, Hosseinkhani, Hennebel et al. 2014). Zerovalent palladium is a commonly used catalyst for the reduction of $\mathrm{Cr}(\mathrm{VI})$, while low cost electron donors such as hydrogen $\left(\mathrm{H}_{2}\right)$ and formate ions can be used to facilitate the reduction process (Omole, K'Owino et al. 2007, Chidambaram, Hennebel et al. 2010). Biogenic palladium nanoparticles (Pd NPs) that are produced from bacteria, such as S. oneidensis MR-1, have high catalytic properties (De Windt, Boon et al. 2006, Hennebel, Simoen et al. 2009, Hennebel, De Corte et al. 2010, De Corte, Hennebel et al. 2011, De Corte, Sabbe et al. 2012). However, metal NPs synthesized from 
planktonic bacteria may be subjected to leaching and the bacteria cells may lose viability due to high toxicity from the metal ions ( $\mathrm{Ng}$, Cai Tan et al. 2013, $\mathrm{Ng}$, Sivakumar et al. 2013). Several studies have pointed to biofilm, a structured, surface-associated, microbial community, as a potential biomaterial and structural support for the synthesis of metal NPs, with benefits such as reduced leaching of metal nanoparticles, increased tolerance to toxic metal ions etc (Gross, Hauer et al. 2007, Gross, Lang et al. 2010, Halan, Buehler et al. 2012). There have also been studies which suggested that metal nanoparticles formed on mesoporous structures may exhibit increased catalytic activity and long-term stability (Matveeva, Valetsky et al. 2011, Scirè and Liotta 2012, Yates, Cusick et al. 2014). It is important to explore various methods that may potentially increase the efficiency and effectiveness of $\mathrm{Cr}(\mathrm{VI})$ reduction.

In this study, we first synthesized Pd NPs on living S. oneidensis MR-1 biofilm supported on inert carbon felt. The nano-Pd biofilm were then subjected to controlled pyrolysis to obtain a mesoporous carbon-palladium (C-Pd) nanocomposite. The nano$\mathrm{Pd}$ biofilm and the C-Pd nanocomposite were then characterized and tested for their catalytic activity on the reduction of $\mathrm{Cr}(\mathrm{VI})$. The reusability of both catalytic systems was also evaluated. To the best of our knowledge, there have been no studies to characterize and compare the catalytic activities and the robustness of palladium nanoparticles synthesized on living biofilm and pyrolysed mesoporous carbon support for the reduction of $\operatorname{Cr}(\mathrm{VI})$ to $\mathrm{Cr}(\mathrm{III})$ in an aqueous environment. This study demonstrated for the first time the sustainable engineering of biofilms for nanocatalytic activity through in situ formation of nanocatalysts in biofilm matrix and influencing the robustness of the catalyst via controlled pyrolysis for the application of environmental contaminant removal. 


\subsection{Materials and Methods}

\subsubsection{Chemicals, Bacterial strains and growth conditions}

$\mathrm{Na}_{2} \mathrm{PdCl}_{4}, \mathrm{~K}_{2} \mathrm{Cr}_{2} \mathrm{O}_{7}, \mathrm{Pd}$ nanopowder $(<25 \mathrm{~nm}$ particle size (TEM), $\geqslant 99.5 \%$ trace metals basis) and all other chemicals were purchased from Sigma Aldrich and were used without further purification. Stock cultures $S$. oneidensis MR-1 wild-type (WT) and high c-di-GMP strain $p Y e d Q_{2}$ were maintained in LB medium with $20 \%$ glycerol at $-80^{\circ} \mathrm{C}$. The bacterial cells were grown in LB medium or modified M1 medium under aerobic or anaerobic conditions. The modified M1 medium ( $\mathrm{pH} \sim 7.0)$ consisted of 3.00 mM PIPES, $7.50 \mathrm{mM} \mathrm{NaOH}, 26.04 \mathrm{mM} \mathrm{NH}_{4} \mathrm{Cl}, 1.34 \mathrm{mM} \mathrm{KCl}, 4.35 \mathrm{mM} \mathrm{NaH}_{2} \mathrm{PO}_{4}$ and $0.68 \mathrm{mM} \mathrm{CaCl} 2$ supplemented with trace amounts of minerals, vitamins, and amino acids (Cao, Shi et al. 2011). For bacterial growth in M1 medium, $20 \mathrm{mM}$ sodium lactate or sodium formate was used as an electron donor and the sole carbon source. For growth under anaerobic conditions, the medium containing $10 \mathrm{mM}$ ferric nitrilotriacetate ( $\mathrm{Fe}(\mathrm{III})-\mathrm{NTA})$ as an electron acceptor was bubbled with nitrogen gas for 5 min and the headspace in the culture was less than $3 \%$ of the total volume.

\subsubsection{Growth of S. oneidensis biofilms and Pd(II) reduction}

Three replicates of submerged biofilm reactors were set up using 3-ml syringes (LuerLok tip, latex free; BD) loosely packed with carbon felt (3.18mm thick, 99\%; VWR, Singapore) for biofilms to attach and grow using modified M1 medium containing 10 $\mathrm{mM}$ formate continuously supplied through a peristaltic pump at a flow rate of $8 \mathrm{ml} / \mathrm{h}$. The biofilm reactor system was assembled and prepared as described previously (Ding, Peng et al. 2013). Each biofilm reactor was inoculated by injecting $2 \mathrm{ml}$ overnight culture (diluted to an $\mathrm{OD}_{600}$ of 0.1 ) using a syringe. After inoculation, the 
medium flow was stopped for $1 \mathrm{~h}$ to allow initial attachment followed by continuous media flow with a flow rate of $8 \mathrm{ml} / \mathrm{h}$.

The $S$. oneidensis biofilms were allowed to grow for $72 \mathrm{~h}$, and then the feed medium was loaded with $1 \mathrm{mM} \mathrm{Pd(II).} \mathrm{Effluent} \mathrm{samples} \mathrm{were} \mathrm{collected} \mathrm{and} \mathrm{the} \mathrm{concentration}$ of $\mathrm{Pd}(\mathrm{II})$ was determined using the colorimetric method described previously (Rotaru, Jiang et al. 2012). The same setup with no biofilms growing in it served as a control. The amount of Pd accumulated in the biofilms was estimated by subtracting the total amount of $\mathrm{Pd}(\mathrm{II})$ introduced into the biofilm reactors by the amount of $\mathrm{Pd}(\mathrm{II})$ remained in the effluents. Samples from the media effluents were taken periodically and cell detachment was evaluated by counting colony forming unit (CFU) using the drop-plate method described elsewhere (Chen, Nace et al. 2003).

\subsubsection{Field emission scanning electron microscopy and energy-dispersive $X$ - ray spectroscopy}

Samples were re-suspended in MilliQ water. A portion of each suspension was dried under vacuum and then coated with platinum using a vacuum electric sputter coater (JEOL JFC-1300, JEOL Asia Pte. Ltd., Singapore). SEM images were then taken using a Field Emission Scanning Electron Microscope (FE-SEM, JSM-7600, JEOL Asia Pte. Ltd., Singapore) at a voltage of 2.0-5.0 kV. EDX spectrum was obtained using an energy-dispersive X-ray spectroscope (AZtecEnergy, Oxford Instruments, Oxfordshire, UK).

\subsubsection{Controlled pyrolysis of biofilm-nanopalladium catalyst}

Biofilms supported with carbon fiber felt substrates were pyrolysed yielding C-Pd nanocomposite catalysts. Typically, samples were put in ceramic boats and were 
subjected to $850{ }^{\circ} \mathrm{C}$ inside sealed quartz tubes under the flow of ultrapure argon (20 sccm, 99.9999\%, Soxal). Heating profile of carbonisation process was as follows: 1 ) heating with $\sim 1^{\circ} \mathrm{C} / \mathrm{min}$ from ambient temperature up to $850^{\circ} \mathrm{C}, 2$ ) with isothermal hold at $850^{\circ} \mathrm{C}$ for $4 \mathrm{~h}$, and 3) cooling down to room temperature under argon stream.

\subsubsection{X-ray diffraction}

To further characterize the Pd associated with the biofilms before and after pyrolysis, X-ray diffraction (XRD) analysis of the dried samples was performed using a BragBrentano diffractometer (Bruker D8 Advanced) in $\theta-2 \theta$ configuration with a Cu Ka line at $0.15418 \mathrm{~nm}$ as a source generated by a copper X-ray tube with power $2.2 \mathrm{~kW}$ (40 $\mathrm{kV}, 40 \mathrm{~mA}$ ). Measurements were performed in the range of $2 \theta=20-90$ degrees.

\subsubsection{Chromium reduction of the catalytic systems}

Samples testing for chromium reduction activity was added into a $50 \mathrm{ml}$ eppendorf tube containing $25 \mathrm{ml}$ of the following reaction media: $1 \%$ formic acid and $0.05 \mathrm{mM}$ potassium dichromate $\left(\mathrm{K}_{2} \mathrm{Cr}_{2} \mathrm{O}_{7}\right)$, i.e., $0.1 \mathrm{mM} \mathrm{Cr}(\mathrm{VI})$, in HEPES buffer $(30 \mathrm{mM}$, pH 7.0). The reaction system was incubated at room temperature on a shaker (200 rpm) in the dark. The concentration of $\mathrm{Cr}(\mathrm{VI})$ was determined using a previously reported s-diphenylcarbazide colorimetric method (Guha, Jayachandran et al. 2001). Briefly, a $0.8 \mathrm{ml}$ sample was mixed with $0.1 \mathrm{ml}$ of $0.5 \mathrm{~g} /$ liter s-diphenylcarbazide in $10 \%$ methanol-12.5 $\mathrm{mM} \mathrm{H}_{2} \mathrm{SO}_{4}$ followed by $\mathrm{OD}_{540}$ measurement after a 20-min incubation. The presence of $\mathrm{Cr}(\mathrm{III})$ as the reaction product was confirmed using sodium and ammonium hydroxide. An excess of sodium hydroxide solution was added to a solution of $\mathrm{Cr}(\mathrm{III})$ ions, a green solution of hexahydroxochromate(III) ions was produced confirming the presence of $\mathrm{Cr}(\mathrm{III})$. 


\subsection{Results and Discussion}

\subsubsection{Formation of abiotic biofilm-templated heteroatom (N and P)-doped carbon-palladium nanocomposite via controlled pyrolysis}

S. oneidensis MR-1 biofilm can reduce $\mathrm{Pd}(\mathrm{II})$ and immobilise $\mathrm{Pd}(0)$ nanoparticles on the cell surface and within the EPS matrix under aerobic conditions (Figure 6.1).

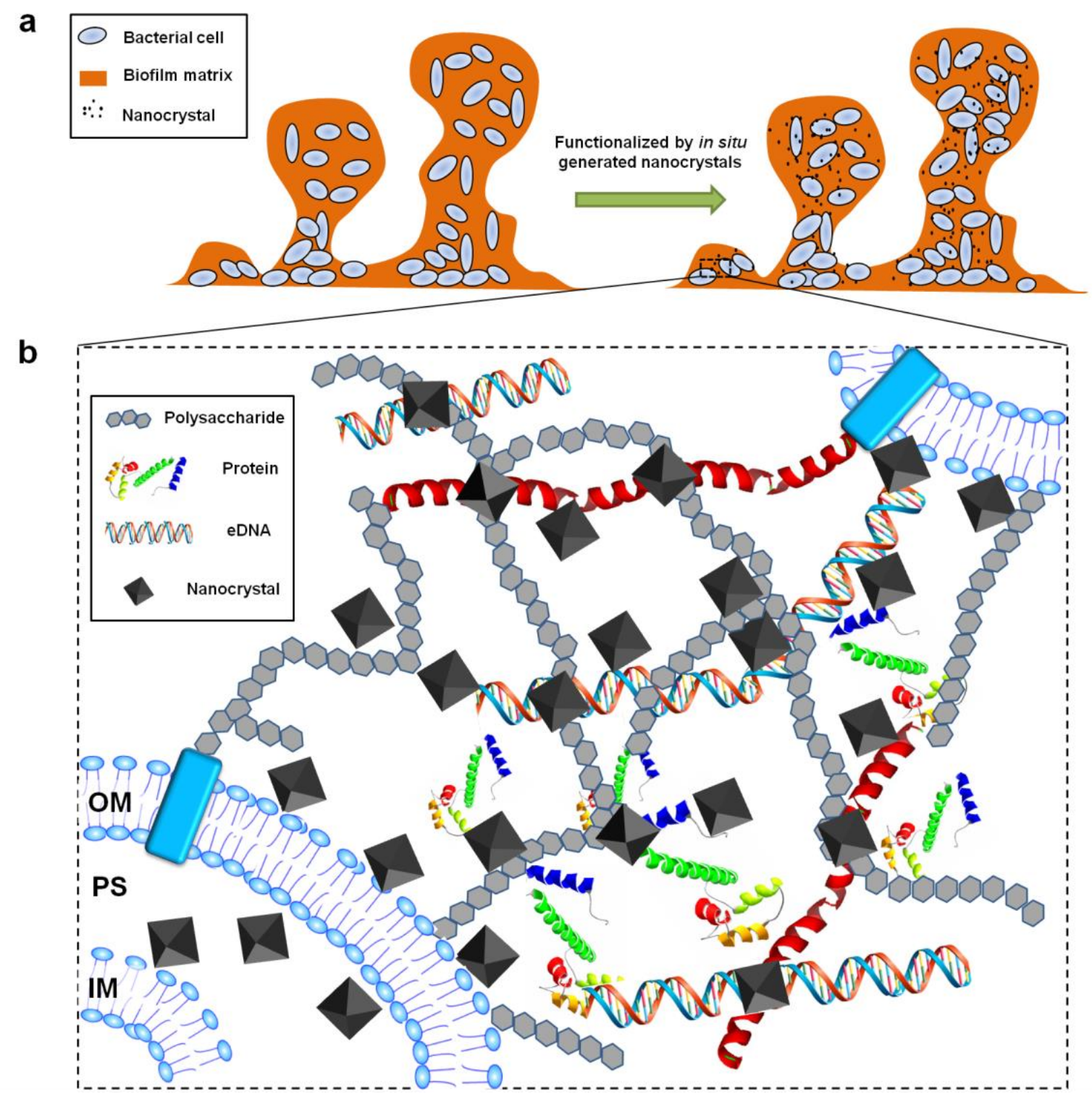

Figure 6.1. Schematic diagram of (A) functionalising biofilm with Pd NPs, resulting in nanocatalytic biofilm and (B) possible interaction between Pd NPs and EPS components. 
However, toxic $\operatorname{Pd}(\mathrm{II})$ exposure leads to biofilm detachment, where loss of biomass and potential leeching of Pd nanoparticles may result. While genetic manipulation can partially overcome this problem, maintenance of biotic nanocatalytic biofilm in term of nutrient uptake and controlling biofilm-related processes (e.g. natural biofilm dispersal) are still some of the major barriers which prevent the widespread use of biofilm-based catalyst for large-scale industrial applications. A novel method is needed to engineer the biofilm-based catalyst that is robust and feasible for large-scale industrial use. As such we propose the pyrolysis of the nanocatalytic biofilm to form an abiotic catalyst which might alleviate the bottlenecks of a biotic catalyst.

Previous study has suggested that biotemplated palladium catalysts can be stabilised on support materials (Yates and Logan 2014). In this study, carbon felt was selected to be the support material as it is inert to both biofilm growth and pyrolysis treatment. To prevent the leeching of Pd from the biofilm through cell detachment and drastically improve the robustness of the catalyst, we attempted controlled pyrolysis of the biofilm-nanopalladium catalyst of MR-1 c-di-GMP mutant to form abiotic C-Pd nanocomposite using carbon felt as support material (Figure 6.2). 

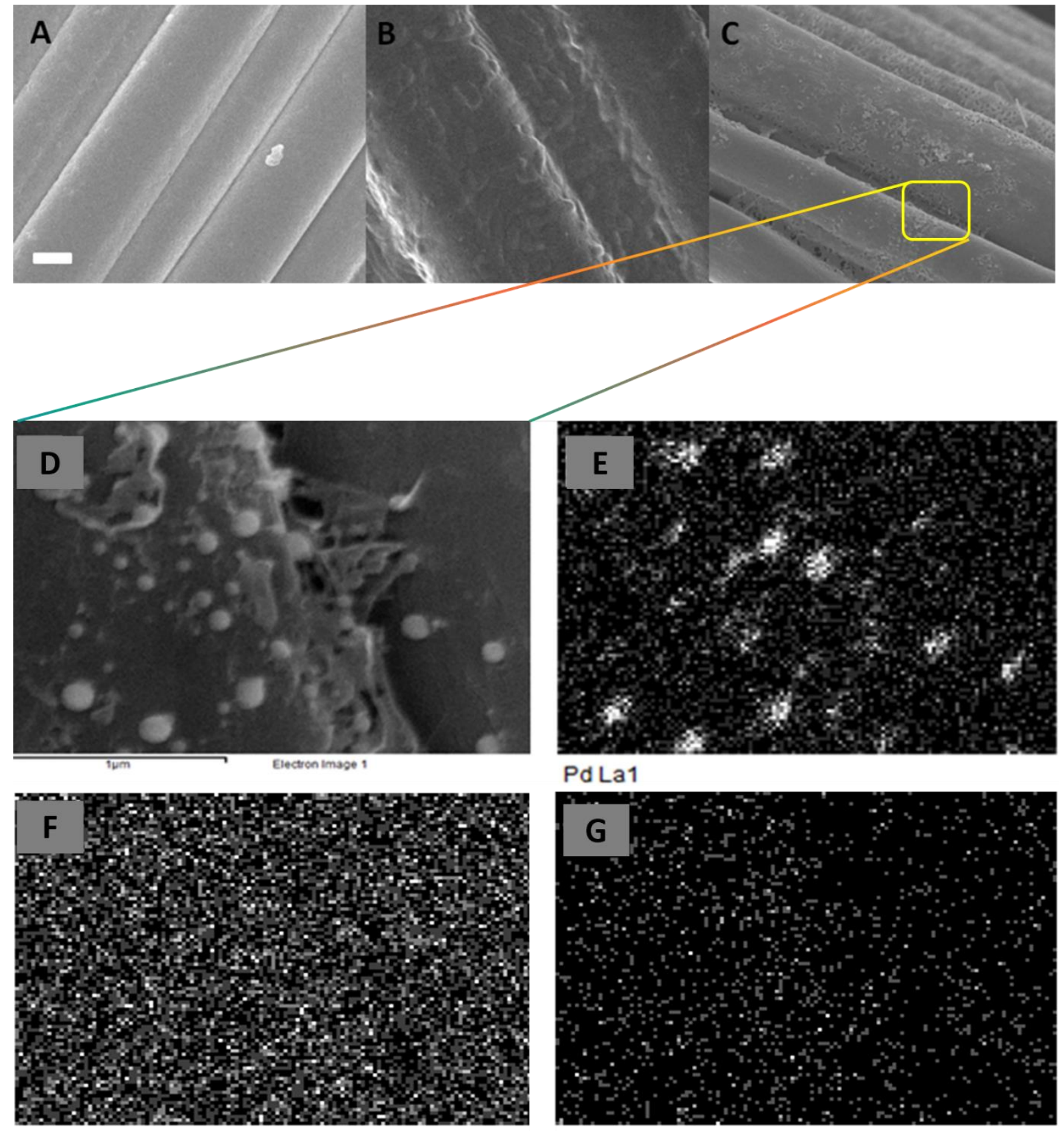

Pd La1

P Ka1

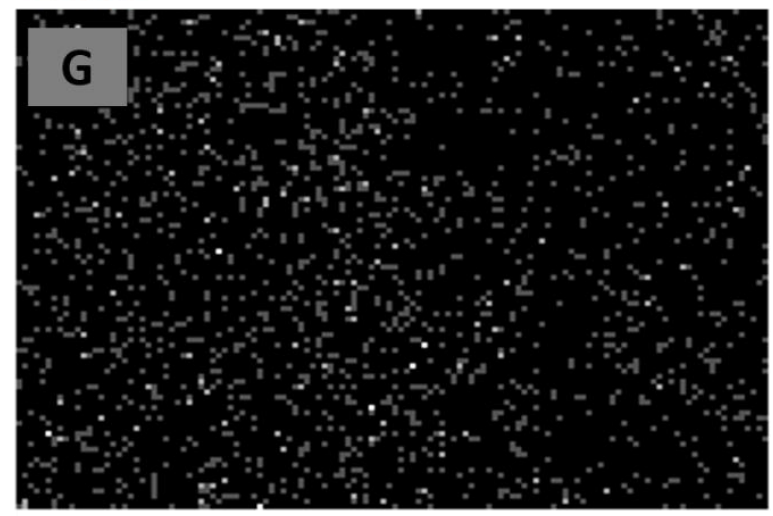

NKa1_2

Figure 6.2. SEM image of (A) carbon felt, (B) biofilm-nanopalladium catalyst on carbon felt, (C) pyrolysed biofilm-templated carbon-palladium nanocomposite on carbon felt. White bar represents $1 \mu \mathrm{m}$. Images are taken with the same magnification (x 5000). SEM-EDX image of (D) an area of interest of the biofilm-templated C-Pd nanocomposite, and EDX-profile of the area of interest of $(\mathrm{E})$ palladium, $(\mathrm{F})$ phosphorus and $(\mathrm{G})$ nitrogen 
XRD measurement on the C-Pd nanocomposite confirmed the presence of crystalline $\mathrm{Pd}$, while SEM-EDX revealed the presence of palladium, phosphorus and nitrogen on the C-Pd composite (Figure 6.2E, F and G). Phosphorus and nitrogen were not present in the original carbon felt, which indicates that biofilm is the sole source of heteroatoms ( $\mathrm{N}$ and $\mathrm{P}$ ) found in the pyrolysis product. Phosphorus and nitrogen can be found naturally in most, if not, all bacterial biofilms. Main sources of phosphorus are extracellular DNA (eDNA) and cell membranes, while main sources of nitrogen are polypeptides (Flemming and Wingender 2010).

EDX image showed that palladium tends to form nanoparticles (Figure 6.2E) while phosphorus and nitrogen are evenly distributed over the sample area (Figure 6.2F and G). The SEM image of the C-Pd nanocomposite showed a rough, porous structure on the surface of the carbon felt (Figure $6.2 \mathrm{C}$ and $\mathrm{D}$ ). Together, these findings may suggest that the C-Pd nanocomposite coated evenly throughout the carbon felt and the palladium retained nanocrystalline structure after pyrolysis. The carbonized biofilm form mesoporous nanocomposite structures with high surface to volume ratio, possibly improving the catalyst's functionality to remediate $\mathrm{Cr}(\mathrm{VI})$.

\subsection{2. $\mathrm{Cr}(\mathrm{VI})$ reduction and catalyst recycling}

We assessed the $\mathrm{Cr}(\mathrm{VI})$ reduction ability of the pyrolyed biofilm with and without palladium, along with non-pyrolyed biofilm-nanoPd catalyst and biofilm-only samples using $0.1 \mathrm{mM}$ of $\mathrm{Cr}(\mathrm{VI})$ with $1 \%$ formic acid as election donor over 10 minutes of reaction. We found that the $\mathrm{Cr}(\mathrm{VI})$ reduction ability of the C-Pd nanocomposite is significantly much higher than biofilm-nanoPd and biofilm samples (Figure 6.3). Formic acid alone cannot reduce $\mathrm{Cr}(\mathrm{VI})$ under our experimental condition. 


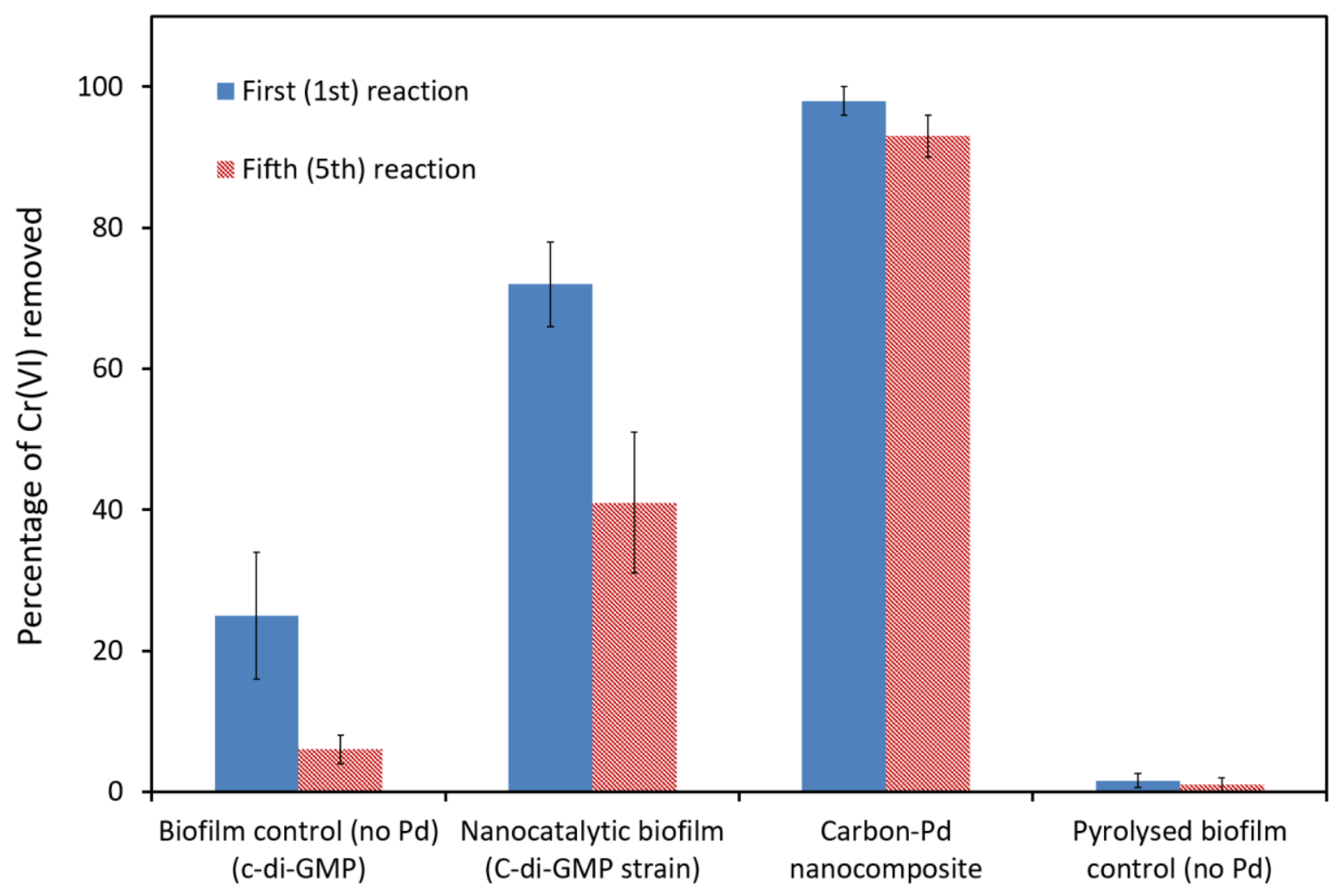

Figure 6.3. $\mathrm{Cr}(\mathrm{VI})$ reduction of C-Pd nanocomposite, nanocatalytic biofilm (c-di-GMP strain), no-Pd biofilm control (c-di-GMP) and pyrolyzed biofilm control (no Pd) samples on the $1^{\text {st }}$ and $5^{\text {th }}$ catalytic reaction. Initial concentration of $0.1 \mathrm{mM} \mathrm{Cr}(\mathrm{VI})$ was introduced into the system, and formic acid (1\%) was used as electron donor. All $\mathrm{Cr}(\mathrm{VI})$ reduction experiment are conducted in triplicates.

The no-Pd biofilm control (c-di-GMP strain) is able to remove around $20 \%$ of the $\mathrm{Cr}(\mathrm{VI})$, which is due to the $\mathrm{Cr}(\mathrm{VI})$ bioreduction ability of $\mathrm{S}$. oneidensis MR-1 bacteria and also the adsorption of $\mathrm{Cr}(\mathrm{VI})$ within the biofilm matrix, which was shown in previous studies (Quintelas, Sousa et al. 2006, Quintelas, Fernandes et al. 2008, Ding, Peng et al. 2013). We also tested pyrolysed biofilm samples (without Pd) and found negligible $\mathrm{Cr}(\mathrm{VI})$ reduction activity, which strongly suggests that palladium nano-crystal is the active catalytic component that performed $\mathrm{Cr}(\mathrm{VI})$ reduction in the biofilm-templated $\mathrm{C}$ Pd nanocomposite catalyst. 
Although we have shown that C-Pd nanocomposite is an effective catalyst for $\mathrm{Cr}(\mathrm{VI})$ reduction, it is also important to investigate its robustness. To this end, we examined the $\mathrm{Cr}(\mathrm{VI})$ reduction ability of various catalysts over 5 catalytic reactions (Figure 6.4).

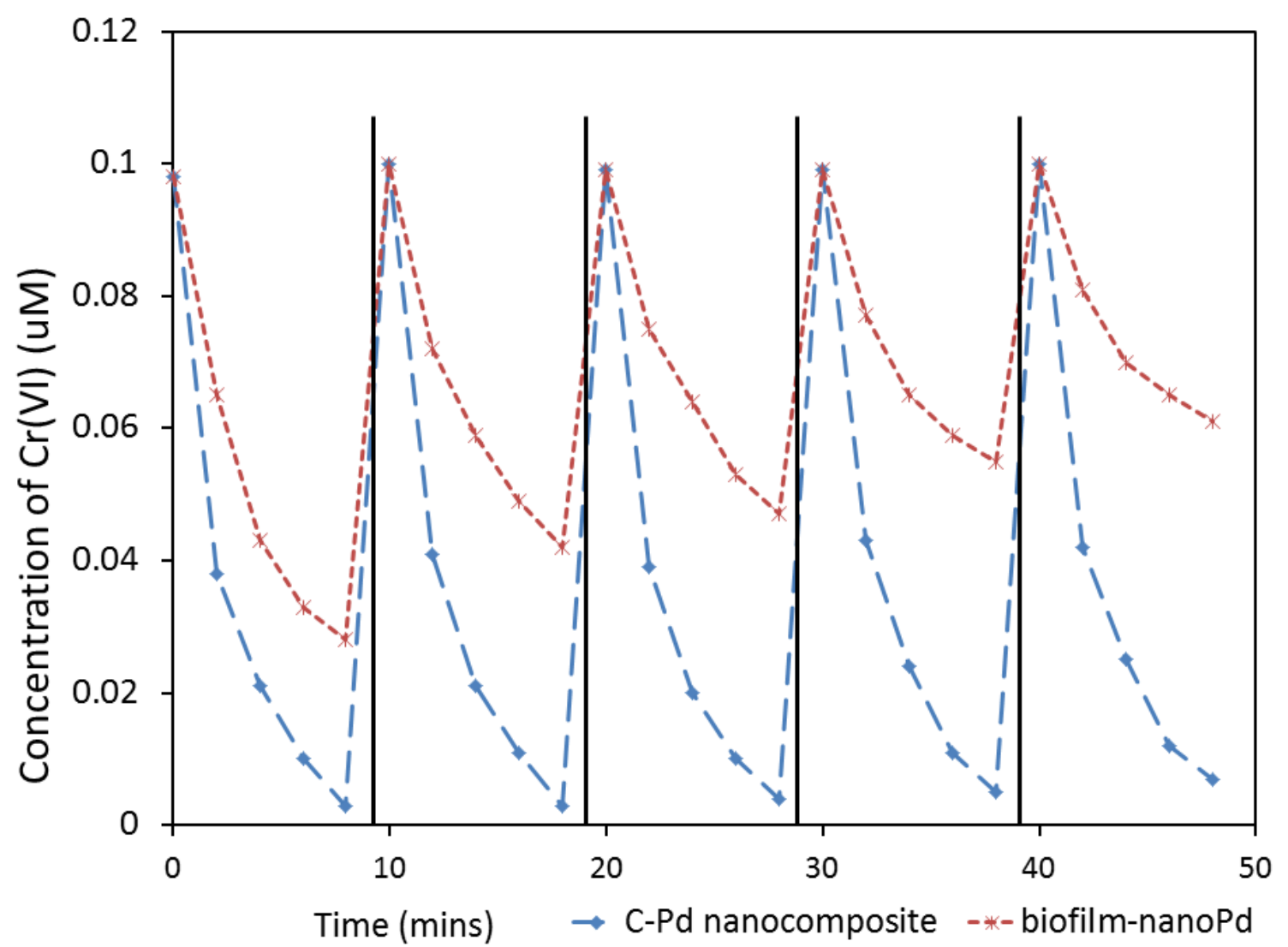

Figure 6.4. Representative $\mathrm{Cr}(\mathrm{VI})$ reduction of C-Pd nanocomposite and biofilm-nanoPd (cdi-GMP) samples over 5 catalytic reactions. Initial concentration of $0.1 \mathrm{mM} \mathrm{Cr}(\mathrm{VI})$ and formic acid (1\%) was introduced into the system every 10 minutes.

Surprisingly, we did not observe a significant drop in catalytic activity in C-Pd nanocomposite on the $5^{\text {th }}$ catalytic reaction. C-Pd nanocomposite retained $93.6 \%$ of its initial $\mathrm{Cr}(\mathrm{VI})$ reduction capability while biofilm-nanoPd retained only about $46.2 \%$ of its initial $\mathrm{Cr}(\mathrm{VI})$ reduction capability after 5 catalytic reactions. The significant drop in catalytic activity of the biofilm-nanoPd (c-di-GMP) might be due to the cell 
detachments and partial biofilm dispersal throughout the reaction process. On the other hand, there catalytic activity of C-Pd nanocomposite remained relatively constant over 5 catalytic reactions, which led us to believe that there is no significant leeching of palladium from the C-Pd nanocomposite during the reaction process. For biofilmonly samples, we did not observe much catalytic activity in the $5^{\text {th }}$ catalytic cycle, possibly due to the exhaustion of adsorption site for $\mathrm{Cr}(\mathrm{VI})$ within the biofilm and loss of viability of the $\mathrm{S}$. oneidensis bacteria to perform bioreduction of $\mathrm{Cr}(\mathrm{VI})$.

The high performance of C-Pd nanocomposite may be contributed by various factors, such higher surface to volume ratio and porous structure of the nanocomposite to increase the availability of catalytic sites. One interesting observation is that sulfur, unlike nitrogen and phosphorus, is below the detection limit when we analysed the pyrolyed C-Pd nanocomposite sample using EDX. The possible removal of sulfur, a known palladium catalyst deactivator or poison (Albers, Pietsch et al. 2001), during pyrolysis might be beneficial to the performance of the C-Pd nanocomposite.

The formation of biotemplated catalyst via pyrolysis has been studied previously. Biofilm was used as a template to form catalytic mesoporous $\mathrm{Pd}$ electrodes via complete pyrolysis, where the biotemplated electrode is able to achieve a higher stable current density compared to electrochemically plated control electrode (Yates, Cusick et al. 2014). Adapting the idea, we chose to deploy a controlled pyrolysis so that we can retain some heteroatom-dope carbon that is attached to the palladium nanoparticles. Besides the fact that partial pyrolysis uses much lower energy as compared to complete pyrolysis, heteroatom-doped carbon may be catalytically active on specific reactions that can be useful in other applications. Many studies have looked at the catalytic effect of heteroatom doped carbon, especially its electrocatalytic 
activity in oxygen reduction reaction and applications in energy and storage (Choi, Park et al. 2011, Yang, Jiang et al. 2011, Paraknowitsch and Thomas 2013, Zhu, Yin et al. 2013). Other studies have shown that metal catalyst that are supported on heteroatom-doped carbon have enhanced catalytic activity $\mathrm{Wu}$, Swaidan et al. 2008, Imran Jafri, Rajalakshmi et al. 2010, Zhou, Neyerlin et al. 2010). Although, in this study, pyrolyed biofilm (heteroatom-doped carbon) without palladium showed negligible $\mathrm{Cr}(\mathrm{VI})$ reduction, it is unknown if the heteroatoms ( $\mathrm{P}$ and $\mathrm{N})$ enhanced the catalytic effect of C-Pd nanocomposite.

To this end, we tested the $\mathrm{Cr}(\mathrm{VI})$ reduction activity of $\mathrm{C}-\mathrm{Pd}$ nanocomposite against commercial Pd nanopowder of similar particle size $(<25 \mathrm{~nm})$ and Pd loading $(\sim 1 \mathrm{mg})$. Surprisingly, we found that the C-Pd nanocomposite exhibit $17 \%$ higher $\mathrm{Cr}(\mathrm{VI})$ reduction activity as compared to the commercial Pd nanopowder after 10 mins of reaction. Catalytic activity of commercial Pd nanopowder over multiple catalytic cycles was tested but it is not feasible to reuse the Pd nanopowder without loss of substantial amount $\mathrm{Pd}$ nanopowder during transferring of samples and that the catalyst recovery process used high energy intensive methods. We are currently unsure how the heteroatom-doped carbon support enhances the $\mathrm{Pd}$ nanocrystals' $\mathrm{Cr}(\mathrm{VI})$ reduction activity in our C-Pd nanocomposite catalytic system. Previous studies have attributed the catalytic enhancement of heteroatom-doped carbon support to increased catalyst particle dispersion (larger active sites), modified electronic structure of the catalyst (improved intrinsic catalytic activity) and better support/catalyst chemical bonding (improved durability) (Zhou, Neyerlin et al. 2010). This is an interesting question that is beyond the scope of this study, and warrants further investigation. 


\subsubsection{Environmental applications}

In this study, we showed that MR-1 biofilms reduced $\mathrm{Pd}(\mathrm{II})$ to form $\mathrm{Pd}(0)$ nanocrystals $(\sim 10-20 \mathrm{~nm})$ that were immobilised in the biofilm matrix and in cell membrane even under room temperature and bulk aerobic conditions. However, the introduction of $\mathrm{Pd}(\mathrm{II})$ increases the rate of cell detachment from the biofilm which posed a risk of biofilm dispersal and leeching of $\mathrm{Pd}$. To create a more robust catalyst, we proceeded with controlled pyrolysis which leads to the carbonisation of biofilm and formation of abiotic heteroatom ( $\mathrm{N}$ and $\mathrm{P}$ )-doped $\mathrm{C}-\mathrm{Pd}$ nanocomposite catalyst. We assessed the catalytic capability of the pyrolysed biofilm-templated C-Pd catalyst which showed high $\mathrm{Cr}(\mathrm{VI})$ reduction, and maintained high reduction rate even on the $5^{\text {th }}$ catalyst cycle, with possibly little or negligible amount of palladium leeching. Compared to the initial biofilm-Pd catalyst, the pyrolyed C-Pd nanocomposite does not have the problem of cell detachment due to high cytotoxicity of the reactants, nutrient requirement or uncontrollable biofilm growth and/or dispersal. The reusability of the pyrolyed heterogeneous catalyst greatly boosts the feasibility to deploy it in a fed-batch or continuous mode for the treatment of $\mathrm{Cr}(\mathrm{VI})$ contaminated water. We also showed that although the heteroatom-doped carbon support on its own have no $\mathrm{Cr}(\mathrm{VI})$ reduction activity, it may enhance the catalytic activity of the Pd nanocrystals in the C-Pd nanocomposite. Together, our results demonstrated an interdisciplinary and novel strategy for engineering biofilms towards the development of heteroatom-doped C-Pd nanocomposite catalyst that is applicable in $\mathrm{Cr}(\mathrm{VI})$ remediation. Using our study as a proof of concept, we propose that it may be possible to use a combination of organisms and reactive nano-metals to achieve desirable reactions for environmental remediation beyond $\mathrm{Cr}(\mathrm{VI})$ reduction, and possibly even fine chemical synthesis. 


\subsubsection{Conclusion}

In this study, we propose an interdisciplinary and novel strategy towards the development of biofilm-templated heteroatom-doped catalytic system through bioreduction and biofilm matrix-facilitated immobilisation of the in situ formed catalytic nanoparticles followed by controlled pyrolysis. Using S. oneidensis MR-1 as a model organism and palladium as a model precious metal, we showed that controlled pyrolysis leads to carbonisation of biofilm and formation of stable, abiotic heteroatom ( $\mathrm{N}$ and $\mathrm{P}$ )-doped $\mathrm{C}-\mathrm{Pd}$ nanocomposite catalyst. Moreover, the pyrolysed biofilmtemplated C-Pd nanocomposite catalyst showed high $\mathrm{Cr}(\mathrm{VI})$ reduction, and maintained high reduction rate even on the $5^{\text {th }}$ catalyst cycle. Although the heteroatomdoped carbon support on its own have no $\mathrm{Cr}(\mathrm{VI})$ reduction activity, it enhances the catalytic activity of the $\mathrm{Pd}$ nanocrystals in the C-Pd nanocomposite. Our results demonstrated an interdisciplinary and novel strategy for engineering biofilms towards the development of nanocomposite catalyst that is applicable in $\mathrm{Cr}(\mathrm{VI})$ reduction and other environmental remediation processes. 


\section{CHAPTER 7: CONCLUSIONS AND FUTURE RECOMMENDATIONS}

\subsection{Summary and Conclusions}

The study aims to understand the mechanism of microbial synthesis of metal nanoparticles and develop biofilm-based nanocatalyst for multidimensional catalysis. Biofilm-based nanocatalysts were engineered via genetic manipulation and controlled pyrolysis to enhance robustness and reusability, for applications on environmental remediation such as TCE dechlorination and hexavalent chromium reduction.

In synthesis of metal nanomaterials by $S$. oneidensis MR-1, our result (Chapter 3 and 4) shows that outer membrane c-type cytochromes influence the size and activity of silver and silver sulfide NPs while [NiFe]-hydrogenases contribute to the synthesis of Pd NPs (Ng, Cai Tan et al. 2013). Moreover, we also reveal that in extracellular biosynthesis of NPs the usually neglected non-cell-associated NPs could have high catalytic activity, highlighting the need of novel methods, such as the use of biofilm that can efficiently retain extracellular NPs in the biosynthesis processes $(\mathrm{Ng}$, Sivakumar et al. 2013).

The biofilm-mediated in situ synthesis and immobilisation of Pd NPs was achieved under bulk aerobic conditions, and the resultant nanocatalytic biofilm exhibit catalytic activity (Chapter 5). However, $\mathrm{Pd}(\mathrm{II})$ exposure inhibits cellular respiration and energy metabolism of $S$. oneidensis cells, posing a risk of biofilm detachment and decreased catalytic activity over time. The nanocatalytic biofilm was engineered to enhance its robustness and reusability via two approaches - genetic manipulation and physical alteration. 
In previous studies, c-di-GMP has been reported to be able to influence the production of EPS and influence biofilm processes such as cell dispersal. In our study (Chapter $5)$, we showed that the insertion of plasmid $p Y e d Q 2$ can increase the production of cytoplasmic c-di-GMP in S. oneidensis MR-1, and this resulted in an increase in production of EPS and alleviate the problem of the biofilm detachment during the biofilm's exposure to $\mathrm{Pd}(\mathrm{II})$.

Further, we also showed that controlled pyrolysis leads to carbonisation of biofilm and formation of stable, abiotic biofilm-templated heteroatom ( $\mathrm{N}$ and $\mathrm{P}$ )-doped $\mathrm{C}-\mathrm{Pd}$ nanocomposite catalyst (Chapter 6). Moreover, the pyrolysed biofilm-templated C-Pd nanocomposite catalyst exhibit high $\mathrm{Cr}(\mathrm{VI})$ reduction activity, and maintained high reduction rate even on the $5^{\text {th }}$ catalyst cycle. Although the heteroatom-doped carbon support on its own have no $\mathrm{Cr}(\mathrm{VI})$ reduction activity, it seems to enhance the catalytic activity of the Pd nanoparticles in the C-Pd nanocomposite.

While both genetic manipulation and physical alteration of the nanocatalytic biofilm produces promising results, there are various advantages and disadvantages of these approach as shown in Table 7.1.

Table 7.1. Comparison of genetic manipulation and physical alteration approach on performance of nanocatalytic biofilm.

\begin{tabular}{|l|l|l|}
\hline & $\begin{array}{l}\text { Genetic manipulation via } \\
\text { C-di-GMP pathway }\end{array}$ & $\begin{array}{l}\text { Physical alteration via } \\
\text { controlled pyrolysis }\end{array}$ \\
\hline $\begin{array}{l}\text { Catalytic activity against } \\
\text { nanocatalytic biofilm }(\mathrm{wt})\end{array}$ & No significant difference & Significantly higher \\
\hline
\end{tabular}




\begin{tabular}{|l|l|l|}
\hline $\begin{array}{l}\text { Production cost against } \\
\text { nanocatalytic biofilm (wt) }\end{array}$ & No significant difference & Significantly higher \\
\hline Catalyst recyclability & Low recyclability & High recyclability \\
\hline $\begin{array}{l}\text { Retain innate biofilm } \\
\text { bioremediation process }\end{array}$ & Yes & No \\
\hline $\begin{array}{l}\text { Adsorption of } \\
\text { contaminants }\end{array}$ & EPS and cell biomass can & Poor adsorbent \\
\hline Scalability & Easily scalable & Poor scalabilty \\
\hline
\end{tabular}

Comparing with existing chemical and physical synthesis methods, there is a lack of precise control of the size and shape of nanoparticles using biofilm-based synthesis. However, as demonstrated, it is possible to influence the size and activity of the nanoparticles via genetic manipulation of the extracellular electron transport pathway of the biofilm-based synthesis of nanoparticle. One of the critical issues to be addressed is the scalability of this technology. While the use of genetic manipulation on the biofilm cells can be easily scalable, the same cannot be said for physical alteration due to technical difficulty of large-scale controlled pyrolysis. Hence, additional investigation, such as a pilot study, is needed to further this technology towards potential application.

This study adds on to the existing knowledge about the mechanistic details of microbial synthesis of metal nanomaterials. It also demonstrates that biofilm can be used to 
synthesize Pd NPs, and the resultant nanocatalytic biofilm can be engineered to be more robust and feasible for large-scale industrial applications.

\subsection{Future recommendation}

The findings of this thesis work are a proof of concept where biofilms can be functionalised by in situ synthesized and immobilised Pd nanocatalyst within the EPS, and further engineered to enhance its robustness and reusability via genetic manipulations and physical alterations. Future recommendations involve integration of biofilm-based nanocatalyst with membrane technology and the exploration of biofilm-based nanocatalyst in other applications such as energy production.

\subsubsection{Integration of biofilm-based nanocatalyst with membrane technology for environmental applications}

Biofilm-based nanocatalysts that we have developed have shown to be able to remediate water micro-contaminants such as TCE and $\operatorname{Cr}(\mathrm{VI})$. Another important micro-contaminant is endocrine disrupting chemicals, such as $17 \alpha$-ethynylestradiol (EE2). EE2, a synthetic hormone, have received much attention due to its widespread occurrence and adverse effects on aquatic animals (Colborn, vom Saal et al. 1993). The removal of EE2 from water has been very challenging mostly because of its low concentration in environmental waters (Lange, Paull et al. 2009, Flores-Valverde, Horwood et al. 2010). Membrane technologies such as reverse osmosis and nanofiltration can remove EE2, but are energy and cost intensive. We have developed a relatively inexpensive and novel approach for concentrating EE2 through adsorption and elution using microporous polyethersulfone (PES) hollow fiber membrane in a cross-flow filtration system, which can be easily scalable for practical applications $(\mathrm{Ng}$, Bope et al. 2017). 
Previous studies have showed that estrogens can be degraded using oxidizing agent peroxymonosulfate (PMS), and the reaction can be catalysed by a PMS activator (Brienza, Ahmed et al. 2014). By coupling our biofilm-based nanocatalysts with microporous PES hollow fiber membrane system, our preliminary data shows that our biofilm-templated C-Pd nanocomposite, but not biotic nanocatalytic biofilm, is able to activate PMS to degrade the concentrated EE2 obtained from our adsorption-based filtration system. PMS is relatively unreactive until it is activated, in this case by the CPd nanocomposite, to produce strong oxidising agents such as reactive oxygen species (ROS) and radicals. The EPS component of the nanocatalytic biofilm contains many organic compounds which may quench the ROS and radicals. The optimisation of such coupling of the biofilm-based nanocatalyst and the microporous PES hollow fiber membrane system warrants further investigation (Figure 7.1).

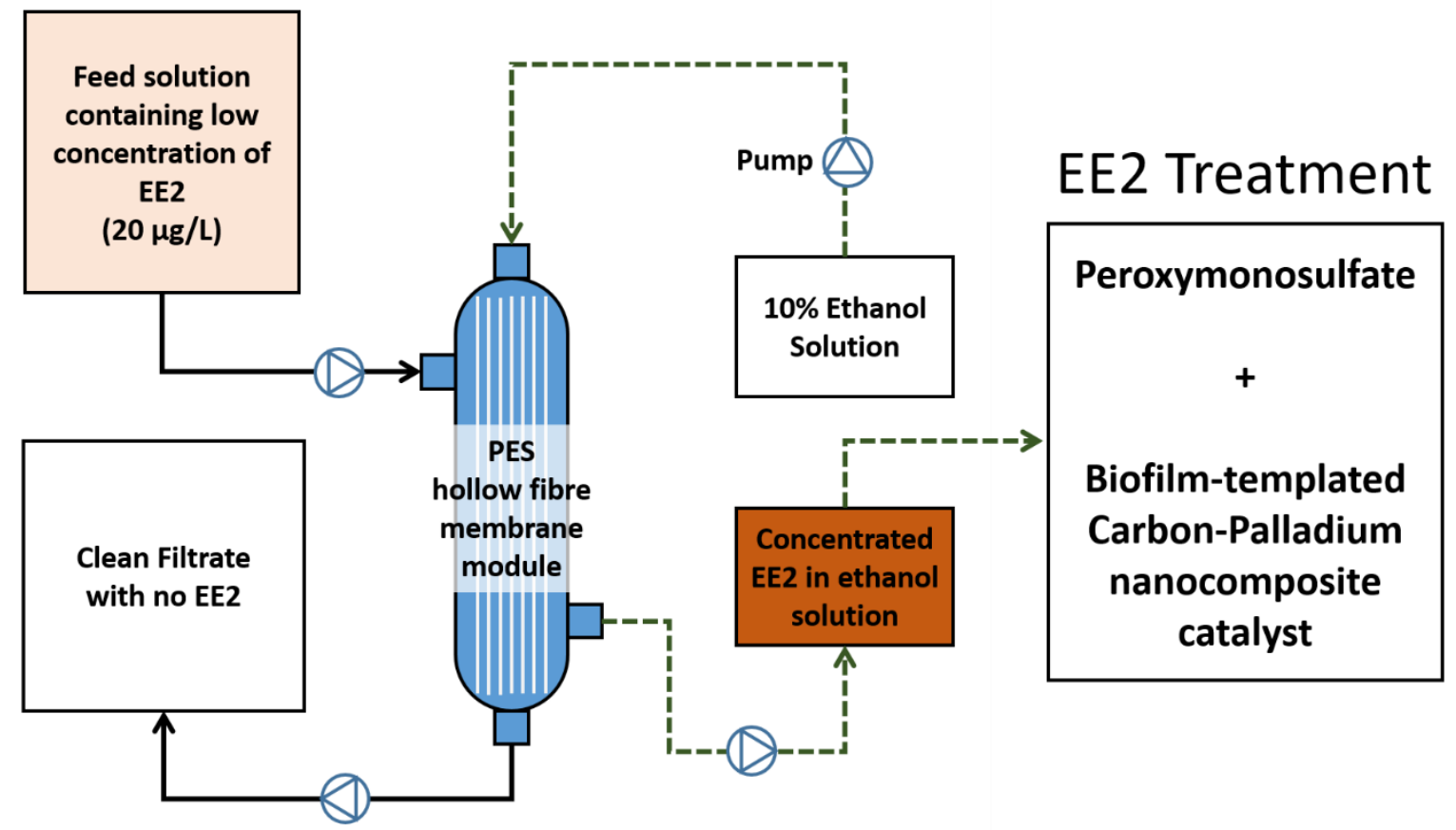

Figure 7.1. Schematic diagram of the couping of biofilm-templated C-Pd nanocomposite catalyst with microporous PES hollow fiber membrane system. 
The use of biofilm-based nanocatalyst may be further integrated with other type of membrane system. Membranes with large pore sizes may be coated with reactive nanocatalytic biofilm for continuous reactions. Inert membranes, such as those made of ceramic, can even act as support for nanocatalytic biofilm and undergo controlled pyrolysis as an approach to functionalise the membrane with catalytic biofilmtemplated C-Pd nanocomposite. Such processes need to be optimised to be feasible for large-scale industrial processes.

\subsubsection{Biofilm-based nanocatalyst for energy-related applications}

Current research on microbial synthesis of nanoparticles focus on environmental remediation applications, such as TCE dechlorination (Chapter 5) and hexavalent chromium reduction (Chapter 6). However, little emphasis is placed on other exotic applications such as energy production and storage. Besides silver and Pd, the biofilm-based synthesis of metal nanoparticles can theoretically be extended to many other metal or metalloid materials. This creates new opportunities for novel energyrelated applications involving the use of highly catalytic nanoparticles.

Up to date, microbial fuel cells have been shown to produce energy by harnessing the metabolic energy of biofilms (Liu, Ramnarayanan et al. 2004), but little is known about how functionalising biofilm with reactive nanoparticles can aid electron transfer between the biofilm and the electrode. Conductive metal(loid) nanoparticles that are synthesized and immobilised within the EPS may reduce the overall electrical impedance of the biofilm and aid the extracellular electron transfer between the biofilm and the electrode. The heteroatoms ( $\mathrm{N}$ and $\mathrm{P})$ within the biofilm-templated $\mathrm{C}-\mathrm{Pd}$ 
nanocomposite may also improve the conductivity and catalytic activity of the catalyst which require further extensive studies. 


\section{REFERENCES}

Adav, S. S. and D.-J. Lee (2008). "Extraction of extracellular polymeric substances from aerobic granule with compact interior structure." Journal of hazardous materials 154(1): 1120-1126.

Albers, P., J. Pietsch and S. F. Parker (2001). "Poisoning and deactivation of palladium catalysts." Journal of Molecular Catalysis A: Chemical 173(1-2): 275-286.

Ali, I. (2012). "New Generation Adsorbents for Water Treatment." Chemical Reviews 112(10): 5073-5091.

Arciola, C. R., D. Campoccia, P. Speziale, L. Montanaro and J. W. Costerton (2012). "Biofilm formation in Staphylococcus implant infections. A review of molecular mechanisms and implications for biofilm-resistant materials." Biomaterials 33(26): 5967-5982.

Aris, A. Z., A. S. Shamsuddin and S. M. Praveena (2014). "Occurrence of 17aethynylestradiol (EE2) in the environment and effect on exposed biota: a review." Environment International 69: 104-119.

Atkins, P. (2010). Shriver and Atkins' inorganic chemistry, Oxford University Press, USA.

Bai, H.-J., B.-S. Yang, C.-J. Chai, G.-E. Yang, W.-L. Jia and Z.-B. Yi (2011). "Green synthesis of silver nanoparticles using Rhodobacter Sphaeroides." World Journal of Microbiology and Biotechnology 27(11): 2723.

Bansal, R. C. and M. Goyal (2005). Activated carbon adsorption, $\underline{\text { CRC press. }}$ 
Barnhart, J. (1997). "Occurrences, Uses, and Properties of Chromium." Regulatory Toxicology and Pharmacology 26(1): S3-S7.

Baruah, D., R. N. Das, S. Hazarika and D. Konwar (2015). "Biogenic synthesis of cellulose supported $\mathrm{Pd}(0)$ nanoparticles using hearth wood extract of Artocarpus lakoocha Roxb - A green, efficient and versatile catalyst for Suzuki and Heck coupling in water under microwave heating." Catalysis Communications $72:$ 73-80.

Beauregard, D. A., P. Yong, L. E. Macaskie and M. L. Johns (2010). "Using noninvasive magnetic resonance imaging (MRI) to assess the reduction of $\mathrm{Cr}(\mathrm{VI})$ using a biofilm-palladium catalyst." Biotechnology and Bioengineering 107(1): 11-20.

Belchik, S. M., D. W. Kennedy, A. C. Dohnalkova, Y. Wang, P. C. Sevinc, H. Wu, Y. Lin, H. P. Lu, J. K. Fredrickson and L. Shi (2011). "Extracellular Reduction of Hexavalent Chromium by Cytochromes MtrC and OmcA of Shewanella oneidensis MR-1." Applied and Environmental Microbiology 77(12): 4035-4041.

Bellin, D. L., H. Sakhtah, J. K. Rosenstein, P. M. Levine, J. Thimot, K. Emmett, L. E. P. Dietrich and K. L. Shepard (2014). "Integrated circuit-based electrochemical sensor for spatially resolved detection of redox-active metabolites in biofilms." Nature Communications 5: 3256.

Bennett, J. A., I. P. Mikheenko, K. Deplanche, I. J. Shannon, J. Wood and L. E. Macaskie (2013). "Nanoparticles of palladium supported on bacterial biomass: New re-usable heterogeneous catalyst with comparable activity to homogeneous colloidal Pd in the Heck reaction." Applied Catalysis B: Environmental 140-141(0): 700-707. 
Berendsen, H. J. C., J. P. M. Postma, W. F. Van Gunsteren, A. DiNola and J. R. Haak (1984). "Molecular dynamics with coupling to an external bath." J. Chem. Phys 81: 3684-3690.

Berendsen, H. J. C., J. P. M. Postma, W. F. van Gunsteren and H. J. (1981). "Interaction models for water in relation to protein hydration. ." In Intermolecular Forces, B. Pullman (ed), Dordrecht, The Netherlands: 331-332.

Bigall, N. C., M. Reitzig, W. Naumann, P. Simon, K.-H. van Pée and A. Eychmüller (2008). "Fungal Templates for Noble-Metal Nanoparticles and Their Application in Catalysis." Angewandte Chemie International Edition 47(41): 78767879.

Bishop, P. L., T. C. Zhang and Y.-C. Fu (1995). "Effects of biofilm structure, microbial distributions and mass transport on biodegradation processes." Water Science and Technology 31(1): 143-152.

Blowes, D. W., C. J. Ptacek and J. L. Jambor (1997). "In-Situ Remediation of Cr(VI)-Contaminated Groundwater Using Permeable Reactive Walls: Laboratory Studies." Environmental Science \& Technology 31(12): 3348-3357.

Bornscheuer, U., G. Huisman, R. Kazlauskas, S. Lutz, J. Moore and K. Robins (2012). "Engineering the third wave of biocatalysis." Nature 485: 185-194.

Bosire, E. M., L. M. Blank and M. A. Rosenbaum (2016). "Strain and substrate dependent redox mediator and electricity production by Pseudomonas aeruginosa." Applied and Environmental Microbiology. 
Branda, S. S., Å. Vik, L. Friedman and R. Kolter (2005). "Biofilms: the matrix revisited." Trends in microbiology 13(1): 20-26.

Brienza, M., M. M. Ahmed, A. Escande, G. Plantard, L. Scrano, S. Chiron, S. Bufo and V. Goetz (2014). "Relevance of a photo-Fenton like technology based on peroxymonosulphate for $17 \beta$-estradiol removal from wastewater." Chemical Engineering Journal 257: 191-199.

Broberg, C. A., T. J. Calder and K. Orth (2011). "Vibrio parahaemolyticus cell biology and pathogenicity determinants." Microbes and Infection 13(12-13): $992-$ 1001.

Bücking, C., A. Piepenbrock, A. Kappler and J. Gescher (2012). "Outermembrane cytochrome-independent reduction of extracellular electron acceptors in Shewanella oneidensis." Microbiology 158(Pt 8): 2144-2157.

Bunge, M., L. S. Søbjerg, A.-E. Rotaru, D. Gauthier, A. T. Lindhardt, G. Hause, K. Finster, P. Kingshott, T. Skrydstrup and R. L. Meyer (2010). "Formation of palladium(0) nanoparticles at microbial surfaces." Biotechnology and Bioengineering 107(2): 206-215.

Burmølle, M., D. Ren, T. Bjarnsholt and S. J. Sørensen (2014). "Interactions in multispecies biofilms: do they actually matter?" Trends in microbiology.

Bussi, G., D. Donadio and M. Parrinello (2007). "Canonical sampling through velocity rescaling." J. Chem. Phys 126: 014101-014107.

Cao, B., B. Ahmed, D. W. Kennedy, Z. Wang, L. Shi, M. J. Marshall, J. K. Fredrickson, N. G. Isern, P. D. Majors and H. Beyenal (2011). "Contribution of 
extracellular polymeric substances from Shewanella sp. HRCR-1 biofilms to U(VI) immobilization." Environmental Science and Technology 45(13): 5483-5490.

Cao, B., B. Ahmed, D. W. Kennedy, Z. Wang, L. Shi, M. J. Marshall, J. K. Fredrickson, N. G. Isern, P. D. Majors and H. Beyenal (2011). "Contribution of extracellular polymeric substances from Shewanella sp. HRCR-1 biofilms to U(VI) immobilization." Environmental Science \& Technology 45(13): 5483-5490.

Cao, B., L. Shi, R. N. Brown, Y. Xiong, J. K. Fredrickson, M. F. Romine, M. J. Marshall, M. S. Lipton and H. Beyenal (2011). "Extracellular polymeric substances from Shewanella sp. HRCR-1 biofilms: characterization by infrared spectroscopy and proteomics." Environmental Microbiology 13(4): 1018-1031.

Cao, B., L. Shi, R. N. Brown, Y. Xiong, J. K. Fredrickson, M. F. Romine, M. J. Marshall, M. S. Lipton and H. Beyenal (2011). "Extracellular polymeric substances from Shewanella sp. HRCR-1 biofilms: characterization by infrared spectroscopy and proteomics." Environmental Microbiology 13(4): 1018-1031.

Cao, B., L. Shi, R. N. Brown, Y. J. Xiong, J. K. Fredrickson, M. F. Romine, M. J. Marshall, M. S. Lipton and H. Beyenal (2011). "Extracellular polymeric substances from Shewanella sp HRCR-1 biofilms: characterization by infrared spectroscopy and proteomics." Environmental Microbiology 13(4): 1018-1031.

Cartinella, J. L., T. Y. Cath, M. T. Flynn, G. C. Miller, K. W. Hunter and A. E. Childress (2006). "Removal of Natural Steroid Hormones from Wastewater Using Membrane Contactor Processes." Environmental Science \& Technology 40(23): 7381-7386. 
Carvalho, R., L. Ceriani, A. Ippolito and T. Lettieri (2015). "Development of the First Watch List under the Environmental Quality Standards Directive." European Commission Joint Research Center, Ispra, Italy.

Chai, L., S. Huang, Z. Yang, B. Peng, Y. Huang and Y. Chen (2009). "Cr (VI) remediation by indigenous bacteria in soils contaminated by chromium-containing slag." Journal of Hazardous Materials 167(1-3): 516-522.

Chao, L., S. Rakshe, M. Leff and A. M. Spormann (2013). "PdeB, a Cyclic DiGMP-Specific Phosphodiesterase That Regulates Shewanella oneidensis MR-1 Motility and Biofilm Formation." Journal of Bacteriology 195(17): 3827-3833.

Chebeir, M. and H. Liu (2016). "Kinetics and Mechanisms of $\mathrm{Cr}(\mathrm{VI})$ Formation via the Oxidation of $\mathrm{Cr}(\mathrm{III})$ Solid Phases by Chlorine in Drinking Water." Environmental Science \& Technology 50(2): 701-710.

Chen, C.-Y., G. Nace and P. Irwin (2003). "A 6x6 drop plate method for simultaneous colony counting and MPN enumeration of Campylobacter jejuni, Listeria monocytogenes, and Escherichia coli." Journal of Microbiological Methods 55: $475-479$.

Chidambaram, D., T. Hennebel, S. Taghavi, J. Mast, N. Boon, W. Verstraete, D. van der Lelie and J. P. Fitts (2010). "Concomitant Microbial Generation of Palladium Nanoparticles and Hydrogen To Immobilize Chromate." Environmental Science \& Technology 44(19): 7635-7640.

Choi, C. H., S. H. Park and S. I. Woo (2011). "Heteroatom doped carbons prepared by the pyrolysis of bio-derived amino acids as highly active catalysts for oxygen electro-reduction reactions." Green Chemistry 13(2): 406-412. 
Choi, O. and Z. Hu (2008). "Size Dependent and Reactive Oxygen Species Related Nanosilver Toxicity to Nitrifying Bacteria." Environmental Science \& Technology 42(12): 4583-4588.

Coe, T. S., P. B. Hamilton, D. Hodgson, G. C. Paull, J. R. Stevens, K. Sumner and C. R. Tyler (2008). "An Environmental Estrogen Alters Reproductive Hierarchies, Disrupting Sexual Selection in Group-Spawning Fish." Environmental Science \& Technology 42(13): 5020-5025.

Cohen, Y. (2001). "Biofiltration - the treatment of fluids by microorganisms immobilized into the filter bedding material: a review." Bioresource technology 77(3): 257-274.

Colborn, T., F. S. vom Saal and A. M. Soto (1993). "Developmental effects of endocrine-disrupting chemicals in wildlife and humans." Environmental health perspectives 101(5): 378.

Coleman, H. M., E. J. Routledge, J. P. Sumpter, B. R. Eggins and J. A. Byrne (2004). "Rapid loss of estrogenicity of steroid estrogens by UVA photolysis and photocatalysis over an immobilised titanium dioxide catalyst." Water Research 38(14-15): 3233-3240.

Comerton, A. M., R. C. Andrews, D. M. Bagley and C. Hao (2008). "The rejection of endocrine disrupting and pharmaceutically active compounds by NF and RO membranes as a function of compound and water matrix properties." Journal of Membrane Science 313(1-2): 323-335.

Comte, S., G. Guibaud and M. Baudu (2006). "Relations between extraction protocols for activated sludge extracellular polymeric substances (EPS) and EPS 
complexation properties: Part I. Comparison of the efficiency of eight EPS extraction methods." Enzyme and Microbial Technology 38(1): 237-245.

Corbos, E. C., P. R. Ellis, J. Cookson, V. Briois, T. I. Hyde, G. Sankar and P. T. Bishop (2013). "Tuning the properties of PdAu bimetallic nanocatalysts for selective hydrogenation reactions." Catalysis Science \& Technology 3(11): 2934-2943.

Costa, M. (2003). "Potential hazards of hexavalent chromate in our drinking water." Toxicology and Applied Pharmacology 188(1): 1-5.

Costa, M. and C. B. Klein (2006). "Toxicity and carcinogenicity of chromium compounds in humans." Critical reviews in toxicology 36(2): 155-163.

Dahl, J. A., B. L. S. Maddux and J. E. Hutchison (2007). "Toward Greener Nanosynthesis." Chemical Reviews 107(6): 2228-2269.

Dangcong, P., N. Bernet, J.-P. Delgenes and R. Moletta (1999). "Aerobic granular sludge—a case report." Water Research 33(3): 890-893.

Darden, T., D. York and L. Pedersen (1993). "Particle mesh Ewald: An N. log(N) method for Ewald sums." J. Chem. Phys 98: 10089-10092.

Das, N. (2010). "Recovery of precious metals through biosorption - A review." Hydrometallurgy 103(1-4): 180-189.

De Corte, S., S. Bechstein, A. R. Lokanathan, J. Kjems, N. Boon and R. L. Meyer (2012). "Comparison of bacterial cells and amine-functionalized abiotic surfaces as support for Pd nanoparticle synthesis." Colloids and Surfaces B: Biointerfaces 102: 898-904. 
De Corte, S., T. Hennebel, B. De Gusseme, W. Verstraete and N. Boon (2012). "Bio-palladium: From metal recovery to catalytic applications." Microbial Biotechnology 5(1): 5-17.

De Corte, S., T. Hennebel, J. P. Fitts, T. Sabbe, V. Bliznuk, S. Verschuere, D. Van Der Lelie, W. Verstraete and N. Boon (2011). "Biosupported bimetallic Pd-Au nanocatalysts for dechlorination of environmental contaminants." Environmental Science and Technology 45(19): 8506-8513.

De Corte, S., T. Hennebel, S. Verschuere, C. Cuvelier, W. Verstraete and N. Boon (2011). "Gold nanoparticle formation using Shewanella oneidensis: A fast biosorption and slow reduction process." Journal of Chemical Technology and Biotechnology 86(4): 547-553.

De Corte, S., T. Sabbe, T. Hennebel, L. Vanhaecke, B. De Gusseme, W. Verstraete and N. Boon (2012). "Doping of biogenic Pd catalysts with Au enables dechlorination of diclofenac at environmental conditions." Water Research 46(8): 2718-2726.

De Gusseme, B., T. Hennebel, E. Christiaens, H. Saveyn, K. Verbeken, J. P. Fitts, N. Boon and W. Verstraete (2011). "Virus disinfection in water by biogenic silver immobilized in polyvinylidene fluoride membranes." Water Research 45(4): 1856-1864.

De Windt, W., N. Boon, J. Van den Bulcke, L. Rubberecht, F. Prata, J. Mast, T. Hennebel and W. Verstraete (2006). "Biological control of the size and reactivity of catalytic $\mathrm{Pd}(0)$ produced by Shewanella oneidensis." Antonie van Leeuwenhoek, International Journal of General and Molecular Microbiology 90(4): 377-389. 


\section{Deplanche, K., I. Caldelari, I. P. Mikheenko, F. Sargent and L. E. Macaskie}

(2010). "Involvement of hydrogenases in the formation of highly catalytic $\mathrm{Pd}(0)$ nanoparticles by bioreduction of $\mathrm{Pd}(\mathrm{II})$ using Escherichia coli mutant strains." Microbiology 156(9): 2630-2640.

Deplanche, K., M. L. Merroun, M. Casadesus, D. T. Tran, I. P. Mikheenko, J. A. Bennett, J. Zhu, I. P. Jones, G. A. Attard, J. Wood, S. Selenska-Pobell and L. E. Macaskie (2012). "Microbial synthesis of core/shell gold/palladium nanoparticles for applications in green chemistry." Journal of the Royal Society Interface 9(72): 17051712.

Ding, Y., N. Peng, Y. Du, L. Ji and B. Cao (2013). "Disruption of Putrescine Biosynthesis in Shewanella oneidensis Enhances Biofilm Cohesiveness and Performance in $\mathrm{Cr}(\mathrm{VI})$ Immobilization." Applied and Environmental Microbiology.

Durán, N., P. D. Marcato, M. Durán, A. Yadav, A. Gade and M. Rai (2011). "Mechanistic aspects in the biogenic synthesis of extracellular metal nanoparticles by peptides, bacteria, fungi, and plants." Applied Microbiology and Biotechnology 90(5): 1609-1624.

Durán, N. and A. Seabra (2012). "Metallic oxide nanoparticles: state of the art in biogenic syntheses and their mechanisms." Applied Microbiology and Biotechnology 95(2): 275-288.

El-Naggar, M. Y., G. Wanger, K. M. Leung, T. D. Yuzvinsky, G. Southam, J. Yang, W. M. Lau, K. H. Nealson and Y. A. Gorby (2010). "Electrical transport along bacterial nanowires from Shewanella oneidensis MR-1." Proceedings of the National Academy of Sciences 107(42): 18127-18131. 
Essmann, U., L. Perera, M. L. Berkowitz, T. Darden, H. Lee and L. Pedersen

(1995). "A smooth particle mesh Ewald method." J. Chem. Phys 103: 8577-8593.

Flemming, H.-C. (2011). "The perfect slime." $\underline{\text { Colloids and Surfaces B: Biointerfaces }}$ 86(2): 251-259.

Flemming, H.-C. and J. Wingender (2010). "The biofilm matrix." Nature Reviews Microbiology 8(9): 623-633.

Flemming, H. (2011). "The perfect slime." Colloids and Surfaces B: Biointerfaces 86: 251-259.

Flemming, H. and J. Wingender (2010). "The biofilm matrix." Nature Reviews in Microbiology 8: 623-633.

Flores-Valverde, A. M., J. Horwood and E. M. Hill (2010). "Disruption of the Steroid Metabolome in Fish Caused by Exposure to the Environmental Estrogen 17a-Ethinylestradiol." Environmental Science \& Technology 44(9): 3552-3558.

Forrez, I., M. Carballa, G. Fink, A. Wick, T. Hennebel, L. Vanhaecke, T. Ternes, N. Boon and W. Verstraete (2011). "Biogenic metals for the oxidative and reductive removal of pharmaceuticals, biocides and iodinated contrast media in a polishing membrane bioreactor." Water Research 45(4): 1763-1773.

Fredrickson, J. K., M. F. Romine, A. S. Beliaev, J. M. Auchtung, M. E. Driscoll, T. S. Gardner, K. H. Nealson, A. L. Osterman, G. Pinchuk, J. L. Reed, D. A. Rodionov, J. L. M. Rodrigues, D. A. Saffarini, M. H. Serres, A. M. Spormann, I. B. Zhulin and J. M. Tiedje (2008). "Towards environmental systems biology of Shewanella." Nature Reviews Microbiology 6(8): 592-603. 
Fu, H., R. P. S. Suri, R. F. Chimchirian, E. Helmig and R. Constable (2007).

"Ultrasound-Induced Destruction of Low Levels of Estrogen Hormones in Aqueous

Solutions." Environmental Science \& Technology 41(16): 5869-5874.

Gadd, G. M. (2010). "Metals, minerals and microbes: geomicrobiology and bioremediation." Microbiology 156(3): 609-643.

Gaulke, L. S., S. E. Strand, T. F. Kalhorn and H. D. Stensel (2009). "Estrogen Biodegradation Kinetics and Estrogenic Activity Reduction for Two Biological Wastewater Treatment Methods." Environmental Science \& Technology 43(18): 7111-7116.

Gauthier, D., L. S. Søbjerg, K. M. Jensen, A. T. Lindhardt, M. Bunge, K. Finster, R. L. Meyer and T. Skrydstrup (2010). "Environmentally benign recovery and reactivation of palladium from industrial waste by using gram - negative bacteria." ChemSusChem 3(9): 1036-1039.

Gjermansen, M., P. Ragas and T. Tolker-Nielsen (2006). "Proteins with GGDEF and EAL domains regulate Pseudomonas putida biofilm formation and dispersal." FEMS Microbiology Letters 265(2): 215-224.

Gorby, Y. A., S. Yanina, J. S. McLean, K. M. Rosso, D. Moyles, A. Dohnalkova, T. J. Beveridge, I. S. Chang, B. H. Kim, K. S. Kim, D. E. Culley, S. B. Reed, M. F. Romine, D. A. Saffarini, E. A. Hill, L. Shi, D. A. Elias, D. W. Kennedy, G. Pinchuk, K. Watanabe, S. i. Ishii, B. Logan, K. H. Nealson and J. K. Fredrickson (2006). "Electrically conductive bacterial nanowires produced by Shewanella oneidensis strain MR-1 and other microorganisms." Proceedings of the National Academy of Sciences 103(30): 11358-11363. 
Green, C., R. Williams, R. Kanda, J. Churchley, Y. He, S. Thomas, P. Goonan, A. Kumar and S. Jobling (2013). "Modeling of Steroid Estrogen Contamination in UK and South Australian Rivers Predicts Modest Increases in Concentrations in the Future." Environmental Science \& Technology 47(13): 7224-7232.

Gross, R., B. Hauer, K. Otto and A. Schmid (2007). "Microbial biofilms: New catalysts for maximizing productivity of long-term biotransformations." Biotechnology and Bioengineering 98(6): 1123-1134.

Gross, R., K. Lang, K. Bühler and A. Schmid (2010). "Characterization of a biofilm membrane reactor and its prospects for fine chemical synthesis." Biotechnology and Bioengineering 105(4): 705-717.

Grover, D. P., J. L. Zhou, P. E. Frickers and J. W. Readman (2011). "Improved removal of estrogenic and pharmaceutical compounds in sewage effluent by full scale granular activated carbon: Impact on receiving river water." Journal of Hazardous Materials 185(2-3): 1005-1011.

Guha, H., K. Jayachandran and F. Maurrasse (2001). "Kinetics of chromium (VI) reduction by a type strain Shewanella alga under different growth conditions." Environmental Pollution 115(2): 209-218.

Habibul, N., Y. Hu, Y.-K. Wang, W. Chen, H.-Q. Yu and G.-P. Sheng (2016). "Bioelectrochemical Chromium(VI) Removal in Plant-Microbial Fuel Cells." Environmental Science \& Technology 50(7): 3882-3889.

Halan, B., K. Buehler and A. Schmid (2012). "Biofilms as living catalysts in continuous chemical syntheses." Trends in Biotechnology 30(9): 453-465. 
Halan, B., A. Schmid and K. Buchler (2010). "Maximizing the Productivity of Catalytic Biofilms on Solid Supports in Membrane Aerated Reactors." Biotechnology and bioengineering 106(4): 516-527.

Hammer, B. K. and B. L. Bassler (2003). "Quorum sensing controls biofilm formation in Vibrio cholerae." Molecular Microbiology 50(1): 101-104.

Han, J., W. Qiu, Z. Cao, J. Hu and W. Gao (2013). "Adsorption of ethinylestradiol (EE2) on polyamide 612: Molecular modeling and effects of water chemistry." Water Research 47(7): 2273-2284.

Hanselman, T. A., D. A. Graetz and A. C. Wilkie (2003). "Manure-Borne Estrogens as Potential Environmental Contaminants: A Review." Environmental Science \& Technology 37(24): 5471-5478.

Harris, H. W., M. Y. El-Naggar and K. H. Nealson (2012). "Shewanella oneidensis MR-1 chemotaxis proteins and electron-transport chain components essential for congregation near insoluble electron acceptors." Biochemical Society Transactions 40(6): 1167-1177.

He, S., Z. Guo, Y. Zhang, S. Zhang, J. Wang and N. Gu (2007). "Biosynthesis of gold nanoparticles using the bacteria Rhodopseudomonas capsulata." Materials Letters 61(18): 3984-3987.

Heidelberg, J. F., I. T. Paulsen, K. E. Nelson, E. J. Gaidos, W. C. Nelson, T. D. Read, J. A. Eisen, R. Seshadri, N. Ward and B. Methe (2002). "Genome sequence of the dissimilatory metal ion-reducing bacterium Shewanella oneidensis." Nature biotechnology 20(11): 1118-1123. 
Hengge, R. (2009). "Principles of c-di-GMP signalling in bacteria." Nature Reviews Microbiology 7(4): 263-273.

Hennebel, T., S. De Corte, L. Vanhaecke, K. Vanherck, I. Forrez, B. De Gusseme, P. Verhagen, K. Verbeken, B. Van der Bruggen, I. Vankelecom, N. Boon and W. Verstraete (2010). "Removal of diatrizoate with catalytically active membranes incorporating microbially produced palladium nanoparticles." Water Research 44(5): 1498-1506.

Hennebel, T., S. De Corte, W. Verstraete and N. Boon (2012). "Microbial production and environmental applications of Pd nanoparticles for treatment of halogenated compounds." Current Opinion in Biotechnology.

Hennebel, T., B. De Gusseme, N. Boon and W. Verstraete (2009). "Biogenic metals in advanced water treatment." Trends in Biotechnology 27(2): 90-98.

Hennebel, T., H. Simoen, W. De Windt, M. Verloo, N. Boon and W. Verstraete (2009). "Biocatalytic dechlorination of trichloroethylene with bio-palladium in a pilotscale membrane reactor." Biotechnology and Bioengineering 102(4): 995-1002.

Hennebel, T., S. Van Nevel, S. Verschuere, S. De Corte, B. De Gusseme, C. Cuvelier, J. P. Fitts, D. Van der Lelie, N. Boon and W. Verstraete (2011). "Palladium nanoparticles produced by fermentatively cultivated bacteria as catalyst for diatrizoate removal with biogenic hydrogen." Applied Microbiology \& Biotechnology 91(5): 1435-1445.

Hentzer, M. and M. Givskov (2003). "Pharmacological inhibition of quorum sensing for the treatment of chronic bacterial infections." The Journal of Clinical Investigation 112(9): $1300-1307$. 
Heo, J., L. K. Boateng, J. R. Flora, H. Lee, N. Her, Y.-G. Park and Y. Yoon (2013). "Comparison of flux behavior and synthetic organic compound removal by forward osmosis and reverse osmosis membranes." Journal of membrane science 443: 6982.

Hernandez, M. E., A. Kappler and D. K. Newman (2004). "Phenazines and other redox-active antibiotics promote microbial mineral reduction." Applied and environmental microbiology 70(2): 921-928.

Hess, B., H. Bekker, H. J. C. Berendsen and J. G. E. M. Fraaije (1997). "LINCS: a Linear Constraint Solver for Molecular Simulation." J. Comput. Chem 18: 1463-1472.

Heugebaert, T. S. A., S. De Corte, T. Sabbe, T. Hennebel, W. Verstraete, N. Boon and C. V. Stevens (2012). "Biodeposited Pd/Au bimetallic nanoparticles as novel Suzuki catalysts." Tetrahedron Letters 53(11): 1410-1412.

Holst, G., R. N. Glud, M. Kühl and I. Klimant (1997). "A microoptode array for finescale measurement of oxygen distribution." Sensors and Actuators B: Chemical 38(1-3): 122-129.

Hosseinkhani, B., T. Hennebel, S. Van Nevel, S. Verschuere, M. M. Yakimov, S. Cappello, M. Blaghen and N. Boon (2014). "Biogenic Nanopalladium Based Remediation of Chlorinated Hydrocarbons in Marine Environments." Environmental Science \& Technology 48(1): 550-557.

Huang, Y., H. Ma, S. Wang, M. Shen, R. Guo, X. Cao, M. Zhu and X. Shi (2012). "Efficient Catalytic Reduction of Hexavalent Chromium Using Palladium Nanoparticle-Immobilized Electrospun Polymer Nanofibers." ACS Applied Materials \& Interfaces 4(6): 3054-3061. 
Hub, S. J., L. B. De Groot and D. Van der Spee (2010). "g_wham- A Free Weighted Histogram Analysis Implemented Including Robust Error and Autocorrelation Estimation." J. Chem. Theory Comput 6: 3713-3720.

International Agency for Research on Cancer (1987). "Overall evaluations of carcinogenicity: an updating of IARC monographs" Volumes 1 to 42 . Lyon: IARC.

Hung, Y.-T., H. H. Lo, L. K. Wang, J. R. Taricska and K. H. Li (2005). Granular activated carbon adsorption. Physicochemical treatment processes, Springer: 573633.

Imran Jafri, R., N. Rajalakshmi and S. Ramaprabhu (2010). "Nitrogen doped graphene nanoplatelets as catalyst support for oxygen reduction reaction in proton exchange membrane fuel cell." Journal of Materials Chemistry 20(34): 7114-7117.

Irmak, S., O. Erbatur and A. Akgerman (2005). "Degradation of 17 $\beta$-estradiol and bisphenol $A$ in aqueous medium by using ozone and ozone/UV techniques." Journal of Hazardous Materials 126(1-3): 54-62.

Jahn, A. and P. Nielsen (1995). "Extraction of extracellular polymeric substances (EPS) from biofilms using a cation exchange resin." Water Science and Technology 32(8): 157-164.

Jain, N., A. Bhargava, S. Majumdar, J. C. Tarafdar and J. Panwar (2011). "Extracellular biosynthesis and characterization of silver nanoparticles using Aspergillus flavusNJP08: A mechanism perspective." Nanoscale 3(2): 635-641.

Jenal, U. and J. Malone (2006). "Mechanisms of Cyclic-di-GMP Signaling in Bacteria." Annual Review of Genetics 40(1): 385-407. 
Jiang, W., B. Kim, J. Rutka and W. Chan (2008). "Nanoparticle-mediated cellular response is size-dependent." Nature Nanotechnology 3: 145-150.

Jiang, W., Y. S. KimBetty, J. T. Rutka and C. W. ChanWarren (2008).

"Nanoparticle-mediated cellular response is size-dependent." Nat Nano 3(3): 145150.

Johnson, A. C. (2010). "Natural Variations in Flow Are Critical in Determining Concentrations of Point Source Contaminants in Rivers: An Estrogen Example." Environmental Science \& Technology 44(20): 7865-7870.

Jorgensen, W. L. and J. Tirado Rives (1988). "The OPLS [optimized potential for liquid simulations] potential functions for proteins, energy minimizations for crystals of cyclic peptides and crambin." J. Am. Chem. Soc 110: 1657-1666.

Juibari, M. M., S. Abbasalizadeh, G. S. Jouzani and M. Noruzi (2011). "Intensified biosynthesis of silver nanoparticles using a native extremophilic Ureibacillus thermosphaericus strain." Materials Letters 65(6): 1014-1017.

Jung, J. H., T. J. Park, S. Y. Lee and T. S. Seo (2012). "Homogeneous Biogenic Paramagnetic Nanoparticle Synthesis Based on a Microfluidic Droplet Generator." Angewandte Chemie 124(23): 5732-5735.

K, S. K., A. R, P. Arumugam and S. Berchmans (2011). "Synthesis of Gold Nanoparticles: An Ecofriendly Approach Using Hansenula anomala." ACS Applied Materials \& Interfaces 3(5): 1418-1425. 
Kalathil, S., J. Lee and M. H. Cho (2011). "Electrochemically active biofilmmediated synthesis of silver nanoparticles in water." Green Chemistry 13(6): 14821485.

Kalimuthu, K., R. Suresh Babu, D. Venkataraman, M. Bilal and S. Gurunathan (2008). "Biosynthesis of silver nanocrystals by Bacillus licheniformis." Colloids and Surfaces B: Biointerfaces 65(1): 150-153.

\section{Kalishwaralal, K., V. Deepak, S. Ram Kumar Pandian, M. Kottaisamy, S.}

BarathManiKanth, B. Kartikeyan and S. Gurunathan (2010). "Biosynthesis of silver and gold nanoparticles using Brevibacterium casei." $\underline{\text { Colloids and Surfaces B: }}$ Biointerfaces 77(2): 257-262.

Katz, S. A. and H. Salem (1993). "The toxicology of chromium with respect to its chemical speciation: A review." Journal of Applied Toxicology 13(3): 217-224.

Kessler, B., V. Lorenzo and K. Timmis (1992). "A general system to integratelacZ fusions into the chromosomes of gram-negative eubacteria: regulation of thePm promoter of theTOL plasmid studied with all controlling elements in monocopy." Molecular and General Genetics MGG 233(1-2): 293-301.

Khan, M. M., S. A. Ansari, M. I. Amal, J. Lee and M. H. Cho (2013). "Highly visible light active Ag@TiO2 nanocomposites synthesized using an electrochemically active biofilm: a novel biogenic approach." Nanoscale 5(10): 4427-4435.

Khan, M. M., J. Lee and M. H. Cho (2013). "Electrochemically active biofilm mediated bio-hydrogen production catalyzed by positively charged gold nanoparticles." International Journal of Hydrogen Energy 38(13): 5243-5250. 
Kim, J.-H., D.-C. Choi, K.-M. Yeon, S.-R. Kim and C.-H. Lee (2011). "EnzymeImmobilized Nanofiltration Membrane To Mitigate Biofouling Based on Quorum Quenching." Environmental Science \& Technology 45(4): 1601-1607.

Kolter, R. and E. P. Greenberg (2006). "Microbial sciences: the superficial life of microbes." Nature 441(7091): 300-302.

Konishi, Y., T. Tsukiyama, T. Tachimi, N. Saitoh, T. Nomura and S. Nagamine (2007). "Microbial deposition of gold nanoparticles by the metal-reducing bacterium Shewanella algae." Electrochimica Acta 53(1): 186-192.

Krasteva, P. V., J. C. N. Fong, N. J. Shikuma, S. Beyhan, M. V. A. S. Navarro, F. H. Yildiz and H. Sondermann (2010). "Vibrio cholerae VpsT Regulates Matrix Production and Motility by Directly Sensing Cyclic di-GMP." Science 327(5967): 866868.

Kryukov, A. I., A. L. Stroyuk, N. N. Zin'chuk, A. V. Korzhak and S. Y. Kuchmii (2004). "Optical and catalytic properties of $\mathrm{Ag}_{2} \mathrm{~S}$ nanoparticles." Journal of Molecular Catalysis A: Chemical 221(1-2): 209-221.

Kuchma, S. L., A. E. Ballok, J. H. Merritt, J. H. Hammond, W. Lu, J. D.

Rabinowitz and G. A. O'Toole (2010). "Cyclic-di-GMP-Mediated Repression of Swarming Motility by Pseudomonas aeruginosa: the pilY1 Gene and Its Impact on Surface-Associated Behaviors." Journal of Bacteriology 192(12): 2950-2964.

Kuchma, S. L., K. M. Brothers, J. H. Merritt, N. T. Liberati, F. M. Ausubel and G. A. O'Toole (2007). "BifA, a Cyclic-Di-GMP Phosphodiesterase, Inversely Regulates Biofilm Formation and Swarming Motility by Pseudomonas aeruginosa PA14." Journal of Bacteriology 189(22): 8165-8178. 
Kumar, C. G. and S. K. Mamidyala (2011). "Extracellular synthesis of silver nanoparticles using culture supernatant of Pseudomonas aeruginosa." Colloids and Surfaces B: Biointerfaces 84(2): 462-466.

Lai, C.-Y., L. Zhong, Y. Zhang, J.-X. Chen, L.-L. Wen, L.-D. Shi, Y.-P. Sun, F. Ma, B. E. Rittmann, C. Zhou, Y. Tang, P. Zheng and H.-P. Zhao (2016). "Bioreduction of Chromate in a Methane-Based Membrane Biofilm Reactor." Environmental Science \& Technology 50(11): 5832-5839.

Lai, K. C. K. and I. M. C. Lo (2008). "Removal of Chromium (VI) by Acid-Washed Zero-Valent Iron under Various Groundwater Geochemistry Conditions." Environmental Science \& Technology 42(4): 1238-1244.

Landini, P., D. Antoniani, J. G. Burgess and R. Nijland (2010). "Molecular mechanisms of compounds affecting bacterial biofilm formation and dispersal." Applied Microbiology and Biotechnology 86(3): 813-823.

Lange, A., G. C. Paull, T. S. Coe, Y. Katsu, H. Urushitani, T. Iguchi and C. R. Tyler (2009). "Sexual Reprogramming and Estrogenic Sensitization in Wild Fish Exposed to Ethinylestradiol." Environmental Science \& Technology 43(4): 12191225.

Law, N., S. Ansari, F. R. Livens, J. C. Renshaw and J. R. Lloyd (2008). "Formation of Nanoscale Elemental Silver Particles via Enzymatic Reduction by Geobacter sulfurreducens." Applied and Environmental Microbiology 74(22): 70907093. 
Lengke, M. F., M. E. Fleet and G. Southam (2007). "Biosynthesis of Silver Nanoparticles by Filamentous Cyanobacteria from a Silver(I) Nitrate Complex." Langmuir 23(5): 2694-2699.

Leonard, A. and R. Lauwerys (1980). "Carcinogenicity and mutagenicity of chromium." Mutation Research/Reviews in Genetic Toxicology 76(3): 227-239.

\section{Li, X. Z., J. S. Webb, S. Kjelleberg and B. Rosche (2006). "Enhanced} benzaldehyde tolerance in Zymomonas mobilis biofilms and the potential of biofilm applications in fine-chemical production." Applied and environmental microbiology 72(2): 1639-1644.

Li, Z., S.-W. Chung, J.-M. Nam, D. S. Ginger and C. A. Mirkin (2003). "Living Templates for the Hierarchical Assembly of Gold Nanoparticles." Angewandte Chemie 115(20): 2408-2411.

Lieleg, O., M. Caldara, R. Baumgartel and K. Ribbeck (2011). "Mechanical robustness of Pseudomonas aeruginosa biofilms." Soft Matter 7(7): 3307-3314.

Liu, C., Y. A. Gorby, J. M. Zachara, J. K. Fredrickson and C. F. Brown (2002). "Reduction kinetics of $\mathrm{Fe}(\mathrm{III}), \mathrm{Co}(\mathrm{III}), \mathrm{U}(\mathrm{VI}), \mathrm{Cr}(\mathrm{VI})$, and $\mathrm{Tc}(\mathrm{VII})$ in cultures of dissimilatory metal-reducing bacteria." Biotechnology and Bioengineering 80(6): 637649.

Liu, H. and H. H. Fang (2002). "Extraction of extracellular polymeric substances (EPS) of sludges." Journal of Biotechnology 95(3): 249-256. 
Liu, H., R. Ramnarayanan and B. E. Logan (2004). "Production of electricity during wastewater treatment using a single chamber microbial fuel cell." Environmental science \& technology 38(7): 2281-2285.

Liu, Y. and J.-H. Tay (2002). "The essential role of hydrodynamic shear force in the formation of biofilm and granular sludge." Water Research 36(7): 1653-1665.

Lloyd, J. R., J. M. Byrne and V. S. Coker (2011). "Biotechnological synthesis of functional nanomaterials." Current Opinion in Biotechnology 22(4): 509-515.

Lloyd, J. R., P. Yong and L. E. Macaskie (1998). "Enzymatic Recovery of Elemental Palladium by Using Sulfate-Reducing Bacteria." Applied and Environmental Microbiology 64(11): 4607-4609.

Lovley, D. R. (1991). "Dissimilatory Fe(III) and Mn(IV) reduction." Microbiological Reviews 55(2): 259-287.

Lovley, D. R. (1993). "Dissimilatory metal reduction." Annual Reviews in Microbiology 47(1): 263-290.

Lovley, D. R. (2012). "Electromicrobiology." Annual review of microbiology 66: 391409.

Lovley, D. R. and R. T. Anderson (2000). "Influence of dissimilatory metal reduction on fate of organic and metal contaminants in the subsurface." Hydrogeology Journal 8(1): 77-88.

Lovley, D. R., J. D. Coates, E. L. Blunt-Harris, E. J. Phillips and J. C. Woodward (1996). "Humic substances as electron acceptors for microbial respiration." Nature 382(6590): 445-448. 
Lovley, D. R., E. J. P. Phillips, Y. A. Gorby and E. R. Landa (1991). "Microbial reduction of uranium." Nature 350(6317): 413-416.

Magudapathy, P., P. Gangopadhyay, B. Panigrahi, K. Nair and S. Dhara (2001). "Electrical transport studies of Ag nanoclusters embedded in glass matrix." Physica B: Condensed Matter 299(1): 142-146.

Malvankar, N. S. and D. R. Lovley (2014). "Microbial nanowires for bioenergy applications." Current Opinion in Biotechnology 27: 88-95.

Mandal, D., M. E. Bolander, D. Mukhopadhyay, G. Sarkar and P. Mukherjee (2006). "The use of microorganisms for the formation of metal nanoparticles and their application." Applied Microbiology and Biotechnology 69(5): 485-492.

Marsh, H. and F. R. Reinoso (2006). Activated carbon, Elsevier.

Marshall, M. J., A. S. Beliaev, A. C. Dohnalkova, D. W. Kennedy, L. Shi, Z. Wang, M. I. Boyanov, B. Lai, K. M. Kemner, J. S. McLean, S. B. Reed, D. E. Culley, V. L. Bailey, C. J. Simonson, D. A. Saffarini, M. F. Romine, J. M. Zachara and J. K. Fredrickson (2006). "c-Type cytochrome-dependent formation of U(IV) nanoparticles by Shewanella oneidensis." PLoS Biology 4(9): e268.

Marshall, M. J., A. E. Plymale, D. W. Kennedy, L. Shi, Z. Wang, S. B. Reed, A. C. Dohnalkova, C. J. Simonson, C. Liu, D. A. Saffarini, M. F. Romine, J. M. Zachara, A. S. Beliaev and J. K. Fredrickson (2008). "Hydrogenase- and outer membrane c-type cytochrome-facilitated reduction of technetium(VII) by Shewanella oneidensis MR-1." Environmental Microbiology 10(1): 125-136. 
Marsili, E., D. B. Baron, I. D. Shikhare, D. Coursolle, J. A. Gralnick and D. R.

Bond (2008). "Shewanella secretes flavins that mediate extracellular electron

transfer." Proceedings of the National Academy of Sciences 105(10): 3968-3973.

Matveeva, V. G., P. M. Valetsky, M. G. Sulman, L. M. Bronstein, A. I. Sidorov, V.

Y. Doluda, A. V. Gavrilenko, L. Z. Nikoshvili, A. V. Bykov, M. V. Grigorjev and E.

M. Sulman (2011). "Nanosized Pt-, Ru-, and Pd-containing catalysts for organic

synthesis and solution of environmental issues." Catalysis in Industry 3(3): 260-270.

McDougald, D., S. A. Rice, N. Barraud, P. D. Steinberg and S. Kjelleberg (2012).

"Should we stay or should we go: mechanisms and ecological consequences for biofilm dispersal." Nat Rev Micro 10(1): 39-50.

McMurry, J. (1996). "Organic Chemistry, Brooks." Cole, New York: 657.

McSwain, B. S., R. L. Irvine, M. Hausner and P. A. Wilderer (2005). "Composition and Distribution of Extracellular Polymeric Substances in Aerobic Flocs and Granular Sludge." Applied and Environmental Microbiology 71(2): 1051-1057.

Melber, C., D. Keller and I. Mangelsdorf (2002). Environmental Health Criteria 226: Palladium. Geneva, World Health Organization.

Merritt, J. H., D. E. Kadouri and G. A. O'Toole (2005). Growing and Analyzing Static Biofilms. Current Protocols in Microbiology, John Wiley \& Sons, Inc.

Meshulam-Simon, G., S. Behrens, A. D. Choo and A. M. Spormann (2007). "Hydrogen Metabolism in Shewanella oneidensis MR-1." Applied and Environmental Microbiology 73(4): 1153-1165. 
Mikheenko, I. P., M. Rousset, S. Dementin and L. E. Macaskie (2008).

"Bioaccumulation of Palladium by Desulfovibrio fructosivorans Wild-Type and Hydrogenase-Deficient Strains." Applied and Environmental Microbiology 74(19): 6144-6146.

Milliken, C. and H. May (2007). "Sustained generation of electricity by the sporeforming, Gram-positive, Desulfitobacterium hafniense strain DCB2." Applied

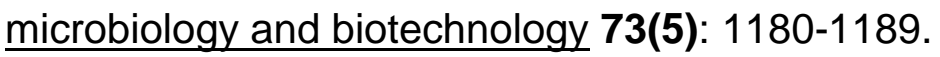

Mohammed Fayaz, A., M. Girilal, M. Rahman, R. Venkatesan and P. T. Kalaichelvan (2011). "Biosynthesis of silver and gold nanoparticles using thermophilic bacterium Geobacillus stearothermophilus." Process Biochemistry 46(10): 1958-1962.

Morones, J. R., J. L. Elechiguerra, A. Camacho, K. Holt, J. B. Kouri, J. T.

Ramírez and M. J. Yacaman (2005). "The bactericidal effect of silver nanoparticles." Nanotechnology 16(10): 2346.

Mortazavi, A., B. A. Williams, K. McCue, L. Schaeffer and B. Wold (2008). "Mapping and quantifying mammalian transcriptomes by RNA-Seq." Nature methods 5(7): $621-628$.

Mulvaney, P. (1996). "Surface plasmon spectroscopy of nanosized metal particles." Langmuir 12(3): 788-800.

Myers, C. R. and K. H. Nealson (1988). "Bacterial Manganese Reduction and Growth with Manganese Oxide as the Sole Electron-Acceptor." Science 240(4857): 1319-1321. 
Myers, C. R. and K. H. Nealson (1988). "Bacterial manganese reduction and growth with manganese oxide as the sole electron acceptor." Science $\mathbf{2 4 0}$.

Nanda, A. and M. Saravanan (2009). "Biosynthesis of silver nanoparticles from Staphylococcus aureus and its antimicrobial activity against MRSA and MRSE." Nanomedicine: Nanotechnology, Biology and Medicine 5(4): 452-456.

Narayanan, K. B. and N. Sakthivel (2010). "Biological synthesis of metal nanoparticles by microbes." Advances in Colloid and Interface Science 156(1-2): 113.

Nealson, K. H. (1997). "Sediment bacteria: who's there, what are they doing, and what's new?" Annual Review of Earth and Planetary Sciences 25(1): 403-434.

Nealson, K. H. and S. E. Finkel (2011). "Electron flow and biofilms." MRS Bulletin 36(05): 380-384.

Nel, A., T. Xia, L. Mädler and N. Li (2006). "Toxic Potential of Materials at the Nanolevel." Science 311(5761): 622-627.

Ng, C. K., C. D. Bope, A. Nalaparaju, Y. Cheng, L. Lu, R. Wang and B. Cao (2017). "Concentrating synthetic estrogen 17a-ethinylestradiol using microporous polyethersulfone hollow fiber membranes: Experimental exploration and molecular simulation." Chemical Engineering Journal 314: 80-87.

Ng, C. K., T. K. Cai Tan, H. Song and B. Cao (2013). "Reductive formation of palladium nanoparticles by Shewanella oneidensis: role of outer membrane cytochromes and hydrogenases." RSC Advances 3(44): 22498-22503. 
Ng, C. K. and B. Cao (2015). "What Exactly Are You Filtering Out?" Environmental Science \& Technology 49(9): 5259-5260.

Ng, C. K., K. Sivakumar, X. Liu, M. Madhaiyan, L. Ji, L. Yang, C. Tang, H. Song, S. Kjelleberg and B. Cao (2013). "Influence of outer membrane c-type cytochromes on particle size and activity of extracellular nanoparticles produced by Shewanella oneidensis." Biotechnology and Bioengineering 110(7): 1831-1837.

Nguyen, H. D., B. Cao, B. Mishra, M. I. Boyanov, K. M. Kemner, J. K.

Fredrickson and H. Beyenal (2012). "Microscale geochemical gradients in Hanford 300 Area sediment biofilms and influence of uranium." Water Research 46(1): 227234.

Niemeyer, C. M. (2001). "Nanoparticles, Proteins, and Nucleic Acids: Biotechnology Meets Materials Science." Angewandte Chemie International Edition 40(22): 41284158.

O'Toole, G. A. and R. Kolter (1998). "Flagellar and twitching motility are necessary for Pseudomonas aeruginosa biofilm development." Molecular Microbiology 30(2): 295-304.

O'Brien, T. J., S. Ceryak and S. R. Patierno (2003). "Complexities of chromium carcinogenesis: role of cellular response, repair and recovery mechanisms." Mutation Research/Fundamental and Molecular Mechanisms of Mutagenesis 533(12): 3-36.

O’Loughlin, C. T., L. C. Miller, A. Siryaporn, K. Drescher, M. F. Semmelhack and B. L. Bassler (2013). "A quorum-sensing inhibitor blocks Pseudomonas aeruginosa 
virulence and biofilm formation." Proceedings of the National Academy of Sciences 110(44): 17981-17986.

Ohko, Y., K.-i. Iuchi, C. Niwa, T. Tatsuma, T. Nakashima, T. Iguchi, Y. Kubota and A. Fujishima (2002). "17ß-Estradiol Degradation by TiO2 Photocatalysis as a Means of Reducing Estrogenic Activity." Environmental Science \& Technology 36(19): 4175-4181.

Okamoto, A., K. Hashimoto and R. Nakamura (2012). "Long-range electron conduction of Shewanella biofilms mediated by outer membrane C-type cytochromes." Bioelectrochemistry 85: 61-65.

Omole, M. A., I. O. K’Owino and O. A. Sadik (2007). "Palladium nanoparticles for catalytic reduction of $\mathrm{Cr}(\mathrm{VI})$ using formic acid." Applied Catalysis B: Environmental 76(1-2): 158-167.

Owen, R. and S. Jobling (2012). "Environmental science: The hidden costs of flexible fertility." Nature 485(7399): 441-441.

Pal, S., Y. Tak and J. Song (2007). "Does the antibacterial activity of silver nanoparticles depend on the shape of the nanoparticle? A study of the gramnegative bacterium Escherichia coli." Applied and Environmental Microbiology 73(6): 1712-1720.

Paraknowitsch, J. P. and A. Thomas (2013). "Doping carbons beyond nitrogen: an overview of advanced heteroatom doped carbons with boron, sulphur and phosphorus for energy applications." Energy \& Environmental Science 6(10): 28392855. 
Park, J., D.-H. Lim, H.-J. Lim, T. Kwon, J.-s. Choi, S. Jeong, I.-H. Choi and J. Cheon (2011). "Size dependent macrophage responses and toxicological effects of Ag nanoparticles." Chemical Communications 47(15): 4382-4384.

Park, J., D.-H. Lim, H.-J. Lim, T. Kwon, J. Choi, S. Jeong, I.-H. Choi and J. Cheon (2011). "Size dependent macrophage responses and toxicological effects of Ag nanoparticles." Chemical Communications 47: 4382-4384.

Patey, G. M. and J. P. Valleau (1973). " The free energy of spheres with dipoles: Monte Carlo with multiscale sampling." J. Chem. Phys. Lett 21.

Paul, K., V. Nieto, W. C. Carlquist, D. F. Blair and R. M. Harshey (2010). "The cdi-GMP Binding Protein YcgR Controls Flagellar Motor Direction and Speed to Affect Chemotaxis by a Backstop Brake Mechanism." Molecular cell 38(1): 128-139.

Perdrew, J. P. and Y. Wang (1992). "Accurate and simple analytic representation of the electron-gas correlation energy." J. Phys. Chem. B 45: 13244 - 13249.

Perez-Alonso, F. J., D. N. McCarthy, A. Nierhoff, P. Hernandez-Fernandez, C. Strebel, I. E. Stephens, J. H. Nielsen and I. Chorkendorff (2012). "The effect of size on the oxygen electroreduction activity of mass-selected platinum nanoparticles." Angewandte Chemie 51(19): 4641-4643.

Perez-Alonso, F. J., D. N. McCarthy, A. Nierhoff, P. Hernandez-Fernandez, C. Strebel, I. E. L. Stephens, J. H. Nielsen and I. Chorkendorff (2012). "The Effect of Size on the Oxygen Electroreduction Activity of Mass-Selected Platinum Nanoparticles." Angewandte Chemie International Edition 51(19): 4641-4643. 
Pirbadian, S., S. E. Barchinger, K. M. Leung, H. S. Byun, Y. Jangir, R. A.

Bouhenni, S. B. Reed, M. F. Romine, D. A. Saffarini, L. Shi, Y. A. Gorby, J. H.

Golbeck and M. Y. El-Naggar (2014). "Shewanella oneidensis MR-1 nanowires are outer membrane and periplasmic extensions of the extracellular electron transport components." Proceedings of the National Academy of Sciences.

Ponder, S. M., J. G. Darab and T. E. Mallouk (2000). "Remediation of Cr(VI) and $\mathrm{Pb}$ (II) Aqueous Solutions Using Supported, Nanoscale Zero-valent Iron." Environmental Science \& Technology 34(12): 2564-2569.

Powell, L. C., A. Sowedan, S. Khan, C. J. Wright, K. Hawkins, E. Onsøyen, R. Myrvold, K. E. Hill and D. W. Thomas (2013). "The effect of alginate oligosaccharides on the mechanical properties of Gram-negative biofilms." Biofouling 29(4): 413-421.

Pratt, L. A. and R. Kolter (1998). "Genetic analysis of Escherichia coli biofilm formation: roles of flagella, motility, chemotaxis and type I pili." Molecular microbiology 30(2): 285-293.

Prigent - Combaret, C., G. Prensier, T. T. Le Thi, O. Vidal, P. Lejeune and C. Dorel (2000). "Developmental pathway for biofilm formation in curli - producing Escherichia coli strains: role of flagella, curli and colanic acid." Environmental microbiology 2(4): 450-464.

Prouty, A. M., W. H. Schwesinger and J. S. Gunn (2002). "Biofilm Formation and Interaction with the Surfaces of Gallstones by Salmonella spp." Infection and Immunity 70(5): 2640-2649. 
Quintelas, C., B. Fernandes, J. Castro, H. Figueiredo and T. Tavares (2008). "Biosorption of $\mathrm{Cr}(\mathrm{VI})$ by a Bacillus coagulans biofilm supported on granular activated carbon (GAC)." Chemical Engineering Journal 136(2-3): 195-203.

Quintelas, C., E. Sousa, F. Silva, S. Neto and T. Tavares (2006). "Competitive biosorption of ortho-cresol, phenol, chlorophenol and chromium(VI) from aqueous solution by a bacterial biofilm supported on granular activated carbon." Process Biochemistry 41(9): 2087-2091.

Rabaey, K., N. Boon, M. Höfte and W. Verstraete (2005). "Microbial phenazine production enhances electron transfer in biofuel cells." Environmental science \& technology 39(9): 3401-3408.

Rakshe, S., M. Leff and A. M. Spormann (2011). "Indirect Modulation of the Intracellular c-Di-GMP Level in Shewanella oneidensis MR-1 by MxdA." Applied and Environmental Microbiology 77(6): 2196-2198.

Raman, D. R., E. L. Williams, A. C. Layton, R. T. Burns, J. P. Easter, A. S. Daugherty, M. D. Mullen and G. S. Sayler (2004). "Estrogen Content of Dairy and Swine Wastes." Environmental Science \& Technology 38(13): 3567-3573.

Raveendran, P., J. Fu and S. L. Wallen (2003). "Completely "Green" Synthesis and Stabilization of Metal Nanoparticles." Journal of the American Chemical Society 125(46): 13940-13941.

Reardon, C. L., A. C. Dohnalkova, P. Nachimuthu, D. W. Kennedy, D. A. Saffarini, B. W. Arey, L. Shi, Z. Wang, D. Moore, J. S. McLean, D. Moyles, M. J. Marshall, J. M. Zachara, J. K. Fredrickson and A. S. Beliaev (2010). "Role of 
outer-membrane cytochromes MtrC and OmcA in the biomineralization of ferrihydrite by Shewanella oneidensis MR-1." Geobiology 8(1): 56-68.

Redwood, M. D., K. Deplanche, V. S. Baxter-Plant and L. E. Macaskie (2008). "Biomass-supported palladium catalysts on Desulfovibrio desulfuricans and Rhodobacter sphaeroides." Biotechnology and Bioengineering 99(5): 1045-1054.

Reguera, G., K. P. Nevin, J. S. Nicoll, S. F. Covalla, T. L. Woodard and D. R. Lovley (2006). "Biofilm and Nanowire Production Leads to Increased Current in Geobacter sulfurreducens Fuel Cells." Applied and Environmental Microbiology 72(11): 7345-7348.

Richardson, D. J., J. N. Butt, J. K. Fredrickson, J. M. Zachara, L. Shi, M. J. Edwards, G. White, N. Baiden, A. J. Gates, S. J. Marritt and T. A. Clarke (2012). "The 'porin-cytochrome' model for microbe-to-mineral electron transfer." Molecular Microbiology.

Richardson, D. J., M. J. Edwards, G. F. White, N. Baiden, R. S. Hartshorne, J. Fredrickson, L. Shi, J. Zachara, A. J. Gates, J. N. Butt and T. A. Clarke (2012). "Exploring the biochemistry at the extracellular redox frontier of bacterial mineral Fe(III) respiration." Biochemical Society Transactions 40(3): 493-500.

Riemer, J., H. H. Hoepken, H. Czerwinska, S. R. Robinson and R. Dringen (2004). "Colorimetric ferrozine-based assay for the quantitation of iron in cultured cells." Analytical Biochemistry 331(2): 370-375.

Rodriguez, G. G., D. Phipps, K. Ishiguro and H. F. Ridgway (1992). "Use of a fluorescent redox probe for direct visualization of actively respiring bacteria." Applied and Environmental Microbiology 58(6): 1801-1808. 
Romero, D., C. Aguilar, R. Losick and R. Kolter (2010). "Amyloid fibers provide structural integrity to Bacillus subtilis biofilms." Proceedings of the National Academy of Sciences 107(5): 2230-2234.

Rosche, B., X. Z. Li, B. Hauer, A. Schmid and K. Buehler (2009). "Microbial biofilms: a concept for industrial catalysis?" Trends in biotechnology 27(11): 636-643.

Rosenfeldt, E. J. and K. G. Linden (2004). "Degradation of Endocrine Disrupting Chemicals Bisphenol A, Ethinyl Estradiol, and Estradiol during UV Photolysis and Advanced Oxidation Processes." Environmental Science \& Technology 38(20): 5476-5483.

Rotaru, A. E., W. Jiang, K. Finster, T. Skrydstrup and R. L. Meyer (2012). "Nonenzymatic palladium recovery on microbial and synthetic surfaces." Biotechnology and Bioengineering.

Ryder, C., M. Byrd and D. J. Wozniak (2007). "Role of polysaccharides in Pseudomonas aeruginosa biofilm development." Current opinion in microbiology 10(6): 644-648.

Ryu, J.-H. and L. R. Beuchat (2005). "Biofilm formation by Escherichia coli O157: $\mathrm{H} 7$ on stainless steel: effect of exopolysaccharide and curli production on its resistance to chlorine." Applied and Environmental Microbiology 71(1): 247-254.

Salnikow, K. and A. Zhitkovich (2008). "Genetic and Epigenetic Mechanisms in Metal Carcinogenesis and Cocarcinogenesis: Nickel, Arsenic, and Chromium." Chemical Research in Toxicology 21(1): 28-44. 
Salta, M., J. A. Wharton, P. Stoodley, S. P. Dennington, L. R. Goodes, S.

Werwinski, U. Mart, R. J. K. Wood and K. R. Stokes (2010). "Designing biomimetic antifouling surfaces." Philosophical Transactions of the Royal Society A: Mathematical, Physical and Engineering Sciences 368(1929): 4729-4754.

Sander, P., P. Szilard, S. Roland, L. Per, B. Par, A. Rossen, R. S. Michael, C. S. Jeremy, P. M. Kasson, S. David van der, H. Berk and L. Erik (2013). "GROMACS 4.5: a high-throughput and higly parallel open source molecular simulation toolkit." Bioinformatics 29: 845-854.

Saville, R., S. Rakshe, J. Haagensen, S. Shukla and A. Spormann (2011). "Energy-dependent Stability of Shewanella oneidensis MR-1 Biofilms." Journal of Bacteriology 193(13): 3253-3264.

Schäfer, A., L. Nghiem and T. Waite (2003). "Removal of the natural hormone estrone from aqueous solutions using nanofiltration and reverse osmosis." Environmental Science \& Technology 37(1): 182-188.

Schäfer, A. I., L. D. Nghiem and T. D. Waite (2003). "Removal of the Natural Hormone Estrone from Aqueous Solutions Using Nanofiltration and Reverse Osmosis." Environmental Science \& Technology 37(1): 182-188.

Scirè, S. and L. F. Liotta (2012). "Supported gold catalysts for the total oxidation of volatile organic compounds." Applied Catalysis B: Environmental 125: 222-246.

Setiawan, L., R. Wang, K. Li and A. G. Fane (2012). "Fabrication and characterization of forward osmosis hollow fiber membranes with antifouling NF-like selective layer." Journal of Membrane Science 394-395: 80-88. 
Shi, J., S. Fujisawa, S. Nakai and M. Hosomi (2004). "Biodegradation of natural and synthetic estrogens by nitrifying activated sludge and ammonia-oxidizing bacterium Nitrosomonas europaea." Water Research 38(9): 2323-2330.

Shi, L., S. M. Belchik, A. E. Plymale, S. Heald, A. C. Dohnalkova, K. Sybirna, H. Bottin, T. C. Squier, J. M. Zachara and J. K. Fredrickson (2011). "Purification and characterization of the [NiFe]-Hydrogenase of Shewanella oneidensis MR-1." Applied and Environmental Microbiology 77(16): 5584-5590.

Shi, L., B. Chen, Z. Wang, D. A. Elias, M. U. Mayer, Y. A. Gorby, S. Ni, B. H. Lower, D. W. Kennedy, D. S. Wunschel, H. M. Mottaz, M. J. Marshall, E. A. Hill, A. S. Beliaev, J. M. Zachara, J. K. Fredrickson and T. C. Squier (2006). "Isolation of a High-Affinity Functional Protein Complex between OmcA and MtrC: Two Outer Membrane Decaheme c-Type Cytochromes of Shewanella oneidensis MR-1." Journal of Bacteriology 188(13): 4705-4714.

Shi, L., H. Dong, G. Reguera, H. Beyenal, A. Lu, J. Liu, H.-Q. Yu and J. K. Fredrickson (2016). "Extracellular electron transfer mechanisms between microorganisms and minerals." Nat Rev Micro 14(10): 651-662.

Shi, L., D. J. Richardson, Z. Wang, S. Kerisit, K. M. Rosso, J. M. Zachara and J. K. Fredrickson (2009). "The roles of outer membrane cytochromes of Shewanella and Geobacter in extracellular electron transfer." Environmental Microbiology Reports 1(4): 220-227.

Shi, L., K. M. Rosso, T. A. Clarke, D. J. Richardson, J. M. Zachara and J. K. Fredrickson (2012). "Molecular Underpinnings of Fe(III) Oxide Reduction by Shewanella oneidensis MR-1." Frontiers in Microbiology 3: 50. 
Shi, L., T. C. Squier, J. M. Zachara and J. K. Fredrickson (2007). "Respiration of metal (hydr)oxides by Shewanella and Geobacter: a key role for multihaem c-type cytochromes." Molecular Microbiology 65(1): 12-20.

Simm, R., M. Morr, A. Kader, M. Nimtz and U. Römling (2004). "GGDEF and EAL domains inversely regulate cyclic di-GMP levels and transition from sessility to motility." Molecular Microbiology 53(4): 1123-1134.

Simões, M., L. C. Simões and M. J. Vieira (2010). "A review of current and emergent biofilm control strategies." LWT - Food Science and Technology 43(4): $573-583$.

Singh, P. K., A. L. Schaefer, M. R. Parsek, T. O. Moninger, M. J. Welsh and E. P. Greenberg (2000). "Quorum-sensing signals indicate that cystic fibrosis lungs are infected with bacterial biofilms." Nature 407(6805): 762-764.

Singh, R., D. Paul and R. K. Jain (2006). "Biofilms: implications in bioremediation." Trends in microbiology 14(9): 389-397.

Sintubin, L., W. De Windt, J. Dick, J. Mast, D. van der Ha, W. Verstraete and N. Boon (2009). "Lactic acid bacteria as reducing and capping agent for the fast and efficient production of silver nanoparticles." Applied Microbiology and Biotechnology 84(4): 741-749.

Sintubin, L., W. Verstraete and N. Boon (2012). "Biologically produced nanosilver: Current state and future perspectives." Biotechnology and Bioengineering.

Sivakumar, K., M. Mukherjee, C. Hsin - I, Z. Yingdan, L. Ji and B. Cao (2014). "Surface display of roGFP for monitoring redox status of extracellular 
microenvironments in Shewanella oneidensis biofilms." Biotechnology and bioengineering.

Skolimowski, M., M. W. Nielsen, J. Emneus, S. Molin, R. Taboryski, C.

Sternberg, M. Dufva and O. Geschke (2010). "Microfluidic dissolved oxygen gradient generator biochip as a useful tool in bacterial biofilm studies." Lab on a Chip 10(16): 2162-2169.

Snyder, S. A., D. L. Villeneuve, E. M. Snyder and J. P. Giesy (2001). "Identification and Quantification of Estrogen Receptor Agonists in Wastewater Effluents." Environmental Science \& Technology 35(18): 3620-3625.

Sobjerg, L. S., D. Gauthier, A. T. Lindhardt, M. Bunge, K. Finster, R. L. Meyer and T. Skrydstrup (2009). "Bio-supported palladium nanoparticles as a catalyst for Suzuki-Miyaura and Mizoroki-Heck reactions." Green Chemistry 11(12): 2041-2046.

Søbjerg, L. S., A. T. Lindhardt, T. Skrydstrup, K. Finster and R. L. Meyer (2011). "Size control and catalytic activity of bio-supported palladium nanoparticles." $\underline{\text { Colloids }}$ and Surfaces B: Biointerfaces 85(2): 373-378.

Spurbeck, R. R., R. J. Tarrien and H. L. T. Mobley (2012). "Enzymatically Active and Inactive Phosphodiesterases and Diguanylate Cyclases Are Involved in Regulation of Motility or Sessility in Escherichia coli CFT073." mBio 3(5).

Srivastava, S. K. and M. Constanti (2012). "Room temperature biogenic synthesis of multiple nanoparticles ( $\mathrm{Ag}, \mathrm{Pd}, \mathrm{Fe}, \mathrm{Rh}, \mathrm{Ni}, \mathrm{Ru}, \mathrm{Pt}, \mathrm{Co}$, and $\mathrm{Li}$ ) by Pseudomonas aeruginosa SM1." Journal of Nanoparticle Research 14(4): 831. 
Sternberg, C. and T. Tolker-Nielsen (2006). "Growing and analyzing biofilms in flow cells." Current protocols in microbiology Chapter 1: Unit 1B 2.

Stewart, P. S. and M. J. Franklin (2008). "Physiological heterogeneity in biofilms." Nat Rev Micro 6(3): 199-210.

Stoodley, P., Z. Lewandowski, J. D. Boyle and H. M. Lappin-Scott (1998). "Oscillation characteristics of biofilm streamers in turbulent flowing water as related to drag and pressure drop." Biotechnology and Bioengineering 57(5): 536-544.

\section{Stubblefield, B. A., K. E. Howery, B. N. Islam, A. J. Santiago, W. E. Cardenas} and E. S. Gilbert (2010). "Constructing multispecies biofilms with defined compositions by sequential deposition of bacteria." Applied Microbiology and Biotechnology 86(6): 1941-1946.

Sunkar, S. and C. V. Nachiyar (2012). "Biogenesis of antibacterial silver nanoparticles using the endophytic bacterium Bacillus cereus isolated from Garcinia xanthochymus." Asian Pacific Journal of Tropical Biomedicine 2(12): 953-959.

Suresh, A. K., D. A. Pelletier, W. Wang, M. L. Broich, J. W. Moon, B. Gu, D. P. Allison, D. C. Joy, T. J. Phelps and M. J. Doktycz (2011). "Biofabrication of discrete spherical gold nanoparticles using the metal-reducing bacterium Shewanella oneidensis." Acta Biomaterialia 7(5): 2148-2152.

Suresh, A. K., D. A. Pelletier, W. Wang, J.-W. Moon, B. Gu, N. P. Mortensen, D. P. Allison, D. C. Joy, T. J. Phelps and M. J. Doktycz (2010). "Silver Nanocrystallites: Biofabrication using Shewanella oneidensis, and an Evaluation of Their Comparative Toxicity on Gram-negative and Gram-positive Bacteria." Environmental Science \& Technology 44(13): 5210-5215. 
Suri, R. P. S., T. S. Singh and S. Abburi (2010). "Influence of Alkalinity and Salinity on the Sonochemical Degradation of Estrogen Hormones in Aqueous Solution." Environmental Science \& Technology 44(4): 1373-1379.

Teixeira, M., I. Moura, A. V. Xavier, J. J. Moura, J. LeGall, D. V. DerVartanian, H. D. Peck and B. H. Huynh (1989). "Redox intermediates of Desulfovibrio gigas [NiFe] hydrogenase generated under hydrogen. Mössbauer and EPR characterization of the metal centers." Journal of Biological Chemistry 264(28): 16435-16450.

Templeton, A. S., T. P. Trainor, S. J. Traina, A. M. Spormann and G. E. Brown (2001). "Pb(II) distributions at biofilm-metal oxide interfaces." Proceedings of the National Academy of Sciences 98(21): 11897-11902.

Theunissen, S., L. De Smet, A. Dansercoer, B. Motte, T. Coenye, J. J. Van Beeumen, B. Devreese, S. N. Savvides and B. Vergauwen (2010). "The 285 kDa Bap/RTX hybrid cell surface protein (SO4317) of Shewanella oneidensis MR-1 is a key mediator of biofilm formation." Research in microbiology 161(2): 144-152.

Thormann, K. M., S. Duttler, R. M. Saville, M. Hyodo, S. Shukla, Y. Hayakawa and A. M. Spormann (2006). "Control of Formation and Cellular Detachment from Shewanella oneidensis MR-1 Biofilms by Cyclic di-GMP." Journal of Bacteriology 188(7): 2681-2691.

Thorpe, K. L., R. I. Cummings, T. H. Hutchinson, M. Scholze, G. Brighty, J. P. Sumpter and C. R. Tyler (2003). "Relative Potencies and Combination Effects of Steroidal Estrogens in Fish." Environmental Science \& Technology 37(6): 11421149. 
Thorpe, K. L., G. Maack, R. Benstead and C. R. Tyler (2009). "Estrogenic Wastewater Treatment Works Effluents Reduce Egg Production in Fish." Environmental Science \& Technology 43(8): 2976-2982.

Torrie, G. M. and J. P. Valleau (1974). "Monte Carlo free energy estimates using Non-Boltzmann sampling application to the sub-critical Lennard-Jones fluid." $\underline{\mathrm{J}}$ Chem. Phys. Lett 28.

Torrie, G. M. and J. P. Valleau (1977). "Nonphysical sampling distributions in Monte carlo free-energy estimation- Umbrella sampling." J. Comput. Phys. 23: 187-199.

Tsoligkas, A., M. Winn, J. Bowen, T. Overton, M. Simmons and R. Goss (2011). "Engineering Biofilms for Biocatalysis." ChemBioChem 12: 1391-1395.

Valladares Linares, R., V. Yangali-Quintanilla, Z. Li and G. Amy (2011). "Rejection of micropollutants by clean and fouled forward osmosis membrane." Water Research 45(20): 6737-6744.

Vardanyan, Z. and A. Trchounian (2010). "The Effects of Copper (II) lons on Enterococcus hirae Cell Growth and the Proton-Translocating FoF1 ATPase Activity." Cell Biochemistry and Biophysics 57(1): 19-26.

Von Canstein, H., J. Ogawa, S. Shimizu and J. R. Lloyd (2008). "Secretion of flavins by Shewanella species and their role in extracellular electron transfer." Applied and environmental microbiology 74(3): 615-623.

Wang, H., N. Law, G. Pearson, B. E. van Dongen, R. M. Jarvis, R. Goodacre and J. R. Lloyd (2010). "Impact of Silver(I) on the Metabolism of Shewanella oneidensis." Journal of Bacteriology 192(4): 1143-1150. 
Wang, L., N. Wang, L. Zhu, H. Yu and H. Tang (2008). "Photocatalytic reduction of $\mathrm{Cr}(\mathrm{VI})$ over different $\mathrm{TiO} 2$ photocatalysts and the effects of dissolved organic species." Journal of Hazardous Materials 152(1): 93-99.

Wang, R., L. Shi, C. Y. Tang, S. Chou, C. Qiu and A. G. Fane (2010). "Characterization of novel forward osmosis hollow fiber membranes." Journal of Membrane Science 355(1-2): 158-167.

Wang, X., J. F. Preston and T. Romeo (2004). "The pgaABCD locus of Escherichia coli promotes the synthesis of a polysaccharide adhesin required for biofilm formation." Journal of bacteriology 186(9): 2724-2734.

Watnick, P. I., C. M. Lauriano, K. E. Klose, L. Croal and R. Kolter (2001). "The absence of a flagellum leads to altered colony morphology, biofilm development and virulence in Vibrio cholerae O139." Molecular microbiology 39(2): 223-235.

Wilkinson, D. A., S. J. Chacko, C. Vénien-Bryan, G. H. Wadhams and J. P. Armitage (2011). "Regulation of Flagellum Number by FliA and FlgM and Role in Biofilm Formation by Rhodobacter sphaeroides." Journal of Bacteriology 193(15): 4010-4014.

Wimpenny, J., W. Manz and U. Szewzyk (2000). "Heterogeneity in biofilms." FEMS Microbiology Reviews 24(5): 661-671.

Windt, W. D., P. Aelterman and W. Verstraete (2005). "Bioreductive deposition of palladium (0) nanoparticles on Shewanella oneidensis with catalytic activity towards reductive dechlorination of polychlorinated biphenyls." Environmental Microbiology 7(3): 314-325. 
Winn, M., J. Foulkes, S. Perni, M. Simomons, T. Overton and R. Goss (2012).

"Biofilms and their engineered counterparts: A new generation of immobilised biocatalysts." Catalysis Science \& Technology 2: 1544-1547.

Wolfe, A. J. and K. L. Visick (2008). "Get the Message Out: Cyclic-Di-GMP Regulates Multiple Levels of Flagellum-Based Motility." Journal of Bacteriology 190(2): 463-475.

Woodley, J. M. (2006). "Microbial biocatalytic processes and their development." Advances in Applied Microbiology, Vol 60 60: 1-15.

Wu, G., R. Swaidan, D. Li and N. Li (2008). "Enhanced methanol electro-oxidation activity of PtRu catalysts supported on heteroatom-doped carbon." Electrochimica Acta 53(26): 7622-7629.

Wuertz, S., P. Bishop and P. Wilderer, Eds. (2003). Biofilms in Wastewater Treatment: An Interdisciplinary Approach. London, IWA Publishing.

Wuertz, S., P. Pfleiderer, K. Kriebitzsch, R. Späth, T. Griebe, D. Coello-Oviedo, P. A. Wilderer and H.-C. Flemming (1998). "Extracellular redox activity in activated sludge." Water Science and Technology 37(4-5): 379-384.

Wuertz, S., R. Spaeth, A. Hinderberger, T. Griebe, H. Flemming and P. Wilderer (2001). "A new method for extraction of extracellular polymeric substances frombiofilms and activated sludge suitable for direct quantification ofsorbed metals." Water Science \& Technology 43(6): 25-31. 
Xu, N., A. C. Johnson, M. D. Jürgens, N. R. Llewellyn, N. P. Hankins and R. C. Darton (2009). "Estrogen Concentration Affects its Biodegradation Rate in Activated Sludge." Environmental Toxicology and Chemistry 28(11): 2263-2270.

Yan, L., Y. S. Li and C. B. Xiang (2005). "Preparation of poly(vinylidene fluoride)(pvdf) ultrafiltration membrane modified by nano-sized alumina (Al2O3) and its antifouling research." Polymer 46(18): 7701-7706.

Yang, L., S. Jiang, Y. Zhao, L. Zhu, S. Chen, X. Wang, Q. Wu, J. Ma, Y. Ma and Z. Hu (2011). "Boron-Doped Carbon Nanotubes as Metal-Free Electrocatalysts for the Oxygen Reduction Reaction." Angewandte Chemie 123(31): 7270-7273.

Yates, M. D., R. D. Cusick, I. Ivanov and B. E. Logan (2014). "Exoelectrogenic biofilm as a template for sustainable formation of a catalytic mesoporous structure." Biotechnology and Bioengineering (11): 2349-2354.

Yates, M. D., R. D. Cusick and B. E. Logan (2013). "Extracellular Palladium Nanoparticle Production using Geobacter sulfurreducens." ACS Sustainable Chemistry \& Engineering.

Yates, M. D. and B. E. Logan (2014). "Biotemplated Palladium Catalysts Can Be Stabilized on Different Support Materials." ChemElectroChem 1(11): 1867-1873.

Yong, P., N. A. Rowson, J. P. G. Farr, I. R. Harris and L. E. Macaskie (2002). "Bioreduction and biocrystallization of palladium by Desulfovibrio desulfuricans NCIMB 8307." Biotechnology and Bioengineering 80(4): 369-379. 
Yoon, Y., P. Westerhoff, S. A. Snyder and M. Esparza (2003). "HPLC-

fluorescence detection and adsorption of bisphenol A, 17ß-estradiol, and 17a-ethynyl estradiol on powdered activated carbon." Water Research 37(14): 3530-3537.

Zhang, H., Q. Li, Y. Lu, D. Sun, X. Lin, X. Deng, N. He and S. Zheng (2005). "Biosorption and bioreduction of diamine silver complex by Corynebacterium." Journal of Chemical Technology \& Biotechnology 80(3): 285-290.

Zhang, Y., C. K. Ng, Y. Cohen and B. Cao (2014). "Cell Growth and Protein Expression of Shewanella oneidensis in Biofilms and Hydrogel-entrapped Cultures." Molecular BioSystems.

Zheng, H., J. Kim, M. Liew, John K. Yan, O. Herrera, Jin W. Bok, Neil L. Kelleher, Nancy P. Keller and Y. Wang (2015). "Redox Metabolites Signal Polymicrobial Biofilm Development via the NapA Oxidative Stress Cascade in Aspergillus." Current Biology 25(1): 29-37.

Zhou, Y., K. Neyerlin, T. S. Olson, S. Pylypenko, J. Bult, H. N. Dinh, T. Gennett, Z. Shao and R. O'Hayre (2010). "Enhancement of Pt and Pt-alloy fuel cell catalyst activity and durability via nitrogen-modified carbon supports." Energy \& Environmental Science 3(10): 1437-1446.

Zhu, H., J. Yin, X. Wang, H. Wang and X. Yang (2013). "Microorganism-Derived Heteroatom-Doped Carbon Materials for Oxygen Reduction and Supercapacitors." Advanced Functional Materials 23(10): 1305-1312.

Zimmermann, K. (1991). "ORAL: All Purpose Molecular Mechanics Simulator and Energy Minimizer." J. Comput. Chem 12: 310-319. 
